Universidade Federal de Uberlândia

\title{
ENSINO EM RE-VISTA
}

\section{Dossiê}

\section{O conhecimento social na perspectiva piagetiana}

Publicação quadrimestral do Programa de

Pós-graduação em Educação

Faculdade de Educação

Universidade Federal de Uberlândia 


\title{
UJj UNIVERSIDADE FEDERAL DE UBERLÂNDIA
}

Reitor: Valder Steffen Júnior

Vice-reitor: Orlando César Mantese

\section{EDITORA DA UNIVERSIDADE FEDERAL DE UBERLÂNDIA \\ Diretor: Guilherme Fromm}

\author{
Edufu - Editora da Universidade Federal de Uberlândia \\ Av. João Naves de Ávila, 2121 - Campus Santa Mônica - Bloco S, Térreo \\ Cep: 38400-902 - Uberlândia - MG \\ Tel.: (34) 3239 - 4514 \\ Website: www.edufu.ufu.br
}

FACULDADE DE EDUCAÇÃO

Diretor: Rafael Duarte Oliveira Venancio

\section{PROGRAMA DE PÓS-GRADUAÇÃO EM EDUCAÇÃO}

Coordenadora: Elenita Pinheiro de Queiroz Silva

\section{ENSINO EM RE-VISTA}

Editor responsável: Fabiana Fiorezi de Marco

\section{DIVULGAÇÃO/COMERCIALIZAÇÃO}

Universidade Federal de Uberlândia (UFU)

Faculdade de Educação

Av. João Naves de Ávila, 2121 - Campus Santa Mônica, Bloco 1G, Sala 117 E-mail: ensinoemrevista@gmail.com

$$
\text { Caixa Postal } 593
$$

38400902 - Uberlândia/MG - Brasil

Tel: (034) 32394163

Telefax: (034) 32394391 


\section{INDEXAÇÃO}

SEER (Sistema Eletrônico de Editoração de Revistas - Instituto Brasileiro de Informação e Tecnologia). Clase (Base de datos bibliográfica de revistas de ciencias sociales y humanidades - Universidad Nacional Autónoma de México). Latindex (Sistema Regional de Información en Línea para Revistas Científicas de América Latina, el Caribe, Espanha e Portugal). BBE (Bibliografia Brasileira de Educação - INEP). Icap (Indexação Compartilhada de Artigos de Periódicos - Base Pergamum). Doaj (Directory of Open Access Journals. Portal periódicos Capes. EBSCO - Host Connection. Rede Brasileira de Serviços de Preservação Digital - Cariniana.

\section{EDITOR RESPONSÁVEL}

Fabiana Fiorezi de Marco, Universidade Federal de Uberlândia, UFU Brasil

\section{EDITOR GERENTE}

Guilherme Saramago de Oliveira, Universidade Federal de Uberlândia, UFU - Brasil

Roberto Valdés Puentes, Universidade Federal de Uberlândia, UFU - Brasil

\section{CONSELHO EDITORIAL INTERNACIONAL}

Maria Cecília Gramajo, Facultad de Ciencias Exactas, Universidad Nacional de Salta - UNSa - Argentina

María Angélica San Martín Espinoza, Departamento de Educación, Facultad de Ciencias Sociales/Universidad de Chile - UC - Chile

Pedro Guilherme Rocha dos Reis, Instituto de Educação, Universidade de Lisboa - Portugal

Carmen Rosa Mañas Viejo, Facultad Educacion, Universidad de Alicante UA - Espanha

José Zilberstein Toruncha, Universidad Tangamanga - México

Angela Maria Franco Martins Coelho da Paiva Balça, Universidade de Évora - Portugal

Martine Marzloff, Institut Français de l'Éducation, IFE - França

Alberto Matías González, Universidad de Sancti Spíritus "José Martí Pérez" - Cuba

Jose Emílio Palomero Pescador, Universidad de Zaragoza - Espanha

Liudmila Guseva, Nosov Magnitogorsk State Technical University - Rússia

Gloria Fariñas León, Universidade da Havana - Cuba 


\section{CONSELHO EDITORIAL NACIONAL}

Ana Maria Esteves Bortolanza, Universidade de Uberaba, UNIUBE - Brasil Cyntia Graziella Guizelim Simões Girotto, Universidade Estadual Paulista, Unesp - Brasil

Andréa Maturano Longarezi, Universidade Federal de Uberlândia, UFU Brasil

Arlete Aparecida Bertoldo Miranda, Universidade Federal de Uberlândia, UFU - Brasil

Elaine Sampaio Araújo, Universidade de São Paulo, USP -Brasil

Elisete Medianeira Tomazetti, Universidade Federal de Santa Maria, UFSM

- Brasil

Iara Vieira Guimarães, Universidade Federal de Uberlândia, UFU - Brasil

Leandro Belinaso Guimarães, Universidade Federal de Santa Catarina, UFSC - Brasil

Marcos Daniel Longhini, Universidade Federal de Uberlândia, UFU - Brasil Maria Irene Miranda, Universidade Federal de Uberlândia, UFU - Brasil

Margarita De Cássia Viana Rodrigues, Universidade Federal Rural do Rio de Janeiro, UFRRJ - Brasil

Maria Júlia Canazza Dall`Acqua, Universidade Estadual Paulista, Unesp Brasil

Sílvio Donizetti De Oliveira Gallo, Universidade Estadual de Campinas, Unicamp - Brasil

Pareceristas ad hoc: Eliane Giachetto Saravali - UNESP, campus de Marília-SP, Luciana Maria Caetano - IP/USP, Sônia Bessa - Universidade Estadual de Goiás, Orly Zucatto Mantovani de Assis - FE/UNICAMP, Jussara Cristina Barboza Tortella - PUCCAMP, Shiderlene Vieira de Almeida - UTFPR, Gilsenir Maria Prevelato de Almeida Dátilo - UNESP, campus de Marília, Maria de Lourdes Mattos Barreto - Universidade Federal de Viçosa.

Organização do Dossiê 0 conhecimento social na perspectiva piagetiana Ensino em Re-Vista v.25 n.1: Eliane Giachetto Saravali e Amanda de Mattos Pereira Mano

Editoração: Edufu

Revisão: Os autores

Diagramação: Eduardo M. Warpechowski

Capa: Eduardo M. Warpechowski 
ENSINO EM RE-VISTA. Uberlândia, V. 25, N. 01, JAN./ABR. 2018. Universidade Federal de Uberlândia. Faculdade De Educação/EDUFU.

Quadrimestral.

ISSN 1983-1730

"Todos os artigos desta revista são de inteira responsabilidade de seus autores, não cabendo qualquer responsabilidade legal sobre seu conteúdo à EDUFU ou à Ensino em Re-Vista."

"Ao enviar o material para publicação, os proponentes abrem mão de pretensões financeiras decorrentes da comercialização de exemplares, concordam com as diretrizes editoriais da revista ENSINO EM RE-VISTA e assumem que seu texto foi devidamente revisado." 


\title{
SUMÁRIO/ SUMARY
}

\author{
Carta ao leitor
}

\section{DOSSIÊ: O conhecimento social na perspectiva piagetiana}

\author{
Apresentação \\ Eliane Giachetto Saravali e Amanda de Mattos Pereira Mano
}

\section{Artigos}

La construcción del conocimiento sobre la sociedade

The construction of knowledge about society

Juan Delval

Pesquisas sobre a construção do conhecimento social no contexto brasileiro: estado da arte 2005-2017

Construction of social knowledge e researchs in the Brazilian context: state of art 20052017

Eliane Giachetto Saravali, Taislene Guimarães, Rafaela Carolina da Silva

Comprender la economía: Educación económica y financiera en la infancia desde una perspectiva constructivista

Understanding economics: economic and financial education in child hood from a constructivist perspective

Marianela Denegri Coria, Jocelyne Sepúlveda Aravena, Francisca Silva Layer

Conhecimento social: o caso do pagamento mínimo da fatura do cartão de crédito

Social Knowledge: the case of the Minimum Credit Card Bill Payment

Iarê Sandra Cooper, Tania Stoltz

O conceito de trabalho na perspectiva de crianças e adolescentes: uma análise a partir da teoria Piagetiana

The concept of work in the perspective of children and adolescents: an analysis based on the Piagetian theory

Maria de Lourdes Mattos Barreto, Gisele Maria Costa Souza, Márcia Onísia da Silva

Noções de Espaço e Lugar na perspectiva de alunos do $6^{\circ}$ Ano do Ensino Fundamental II: relações de interdependência entre conhecimento social e cognitivo

Social notions about space and place in the meanings of students $6^{\text {th }}$ basic school: 
interdependence relationship between social and cognitive knowledge

Francismara Neves de Oliveira, Guilherme Aparecido Godoi

O Conceito de Violência e a Relação com os Estágios da Inteligência em Crianças e Adolescentes de Diferentes Contextos

The Concept of Violence and Relationship with the Stages of Intelligence in Children and Adolescents of Different Contexts

Tamires Alves Monteiro, Maria Thereza Costa Coelho de Souza

Identidade profissional docente: concepções de futuros professores

Teacher professional identity: conceptions of future teachers

Eliane Paganini da Silva, Amanda de Mattos Pereira Mano

\section{Entrevista}

Orly Zucatto Mantovani de Assis. Universidade Estadual de Campinas.

\section{Varia}

A formação escolar e o componente curricular: a Educação Física em tempos de capitalismo mundial integrado

A formation school and curriculum component: Physical Education in times of capitalism wordl integrated

\section{Rogério Rodrigues}

Da teoria a prática, diferentes formas de metodologias nas aulas de Cálculo Numérico

From theory to practice: problematization and differentiated methodologies in Numerical Calculus

Carmem Lucia Graboski Gama

Mateus das Neves Gomes

Liceia Alves Pires

Curiosidades e desafios matemáticos nas aritméticas da série Concórdia

Curiosities and mathematical challenges in the arithmetic of the Concordia series

Malcus Cassiano Kuhn

Arno Bayer 


\section{CARTA AO LEITOR}

Nesta primeira edição de 2018, o periódico ENSINO EM RE-VISTA tem a grata satisfação de publicar um novo dossiê, com a temática "O conhecimento social na perspectiva piagetiana". Trata-se de um tema que possui ampla comunidade acadêmica que vem se debruçando, há algum tempo, em torno dele. O que é apresentado nesse número é um recorte de trabalhos desenvolvidos por pesquisadores nacionais e internacionais, que trabalham com o tema. Eles perpassam pela construção do conhecimento social, educação econômica e financeira na infância, por práticas pedagógicas desenvolvidas com estudantes da Educação Básica e formação inicial de professores. Agradecemos às pesquisadoras Eliane Giachetto Saravali e Amanda de Mattos Pereira Mano pela organização e coordenação deste dossiê. Além dos artigos que o compõem, a revista conta com mais três importantes artigos na seção Varia. Os textos apresentam alto nível de produção acadêmica, porque abordam diversos aspectos da problemática do ensino de Educação Física e de Matemática e, certamente, serão de interesse para os leitores deste periódico. Queremos agradecer a confiança dos autores, cujas contribuições são publicadas neste novo número, bem como convidar os demais colegas da área a submeter seus textos para avaliação, com o intuito de promover debates significativos na área da Educação. A versão eletrônica da revista pode ser acessada pelo site http://www.seer.ufu.br/index.php/emrevista.

Equipe editorial

Universidade Federal de Uberlândia

Março de 2018. 


\section{Apresentação}

\section{Eliane Giachetto Saravali}

\section{Amanda de Mattos Pereira Mano}

A palavra dossiê nos remete a algo, de maneira concreta, que une e reúne informações importantes acerca de um determinado assunto, acontecimento ou pessoa. Não pode haver dossiê sobre aquilo que não permite um alinhavo ou a respeito daquilo que não tenha se tornado importante a ponto de ser consultado, conforme a necessidade apareça.

Um dossiê temático numa revista científica, como Ensino Em Re-Vista, sempre chama a nossa atenção. Direciona nosso olhar para a temática abordada, para aqueles que estão pesquisando e escrevendo sobre o assunto; faz com que reflitamos sobre o contexto em que se produziu a pertinência da organização do dossiê, bem como sobre as transformações e implicações, de diversas ordens, que podem existir ou, ainda, que aquele material pode produzir.

A teoria de Piaget é um dos maiores presentes que a Educação recebeu no século XX, apesar deste não ser, de forma alguma, o intento do seu mentor. São inegáveis as contribuições que a compreensão do desenvolvimento humano e de seus processos cognitivos, afetivos e sociais oferecem a um professor, por exemplo. São opções pautadas no respeito às condições e potencialidades dos alunos que se abrem a uma escola, quando estudamos a obra piagetiana.

Assim como em sua obra Piaget não se voltou à Educação como mote principal, suas pesquisas também não elegeram o conhecimento social de forma privilegiada. Tal fato não deve soar como uma crítica, dada a amplitude do que sua teoria consegue alcançar e desafiar até os dias atuais. 
Tal é a força desse alcance que o conhecimento social pode ser explorado por seus seguidores.

Muito nos honra, deste modo, organizar o presente dossiê. Reunir pesquisas que abordem o tema nos parece uma oportunidade de leitura e divulgação de dados recentes e interessantes. Mais do que isso, nos mostra a atualidade da pesquisa nessa área, assim como da teoria piagetiana.

A compreensão dos processos envolvidos na construção do conhecimento social tem grande importância se queremos entender as ideias de diferentes gerações, suas concepções e generalizações recorrentes a respeito dos assuntos cotidianos, históricos e interpessoais. Tem grande importância, sobretudo no contexto do século XXI, em que vemos um acesso facilitado a grande quantidade de informação, mas que nem sempre acompanha a construção de conhecimento.

Os temas abordados nos vários artigos do nosso dossiê são atuais e trazem diferentes concepções de crianças e adultos para aspectos essenciais da nossa sociedade, entre eles a economia, o trabalho, a violência e a docência.

Temos, ainda, a honra de contar com duas participações muito especiais no dossiê - o professor e pesquisador Juan Delval, referência dos trabalhos brasileiros e um dos maiores expoentes no assunto - escreveu o texto de abertura e a professora Orly Zucatto Mantovani de Assis que, gentilmente, nos concedeu uma entrevista sobre as práticas pedagógicas envolvendo a construção do conhecimento social.

A leitura e consulta desse material permitirá ainda mais o avanço do conhecimento na área, evidenciando a relevância da continuidade das investigações, assim como a atualidade e magnitude incomparáveis da teoria piagetiana.

A todos, excelente leitura! 


\title{
La construcción del conocimiento sobre la sociedad
}

\begin{abstract}
Juan Delval ${ }^{1}$

\section{RESUMO}

El niño tiene que construir modelos o representaciones de la realidad social en la que vive para tratar de dar un sentido al mundo que le rodea y además esas representaciones sirven de marco para su acción. La mayor parte de ellas no son simples copias de las de los adultos, sino que constituyen una construcción personal y difieren cualitativamente de las de los mayores. El estudio del desarrollo del conocimiento sobre la sociedad en el niño atrae cada vez más atención por parte de los investigadores. La posición constructivista pone el acento sobre la actividad del sujeto, y la existencia de creencias infantiles diferentes de las de los adultos y del contexto social, y la universalidad de algunas de estas creencias, nos obligan a no olvidar la labor personal de construcción que tiene que realizar el sujeto.
\end{abstract}

PALAVRAS-CHAVE: Comprensión infantil de la sociedad. Constructivismo. Representaciones Sociales.

\section{The construction of knowledge about society}

\begin{abstract}
The child has to build models or representations of the social reality in which he lives in order to try to give a sense to the world around him and also these representations serve as a framework for his action. Most of them are not simple copies of the adults, but constitute a personal construction and differ qualitatively from those of the elderly. Study of the knowledge development about society in children attracts more and more attention from researchers. Constructivist position emphasizes the
\end{abstract}

1Doctor en Filosofía. Ha sido catedrático de Psicología evolutiva y de la educación en la Universidad Autónoma de Madrid y en la universidad Nacional de Educación a Distancia de Madrid, España. Actualmente aposentado. Email:juan.delval41.gmail.com 
subject activity, and the existence of infant beliefs different from those of adults and the social context, and the universality of some of these beliefs, force us not to forget the personal construction work that subject has to do.

KEYWORDS: Children's understanding of society. Constructivism.Social Representations.

$$
* * *
$$

\section{El estudio de las representaciones del mundo}

Una de las principales capacidades que poseen los seres humanos es la de construir representaciones complejas de la realidad que les rodea. El conocimiento del ambiente es una forma esencial de adaptación al medio. La posición constructivista formulada por Piaget establece que no podemos conocer la realidad tal y como es sino que construimos modelos de ella, la representamos en nuestra mente, lo que nos permite anticipar lo que va a suceder y actuar de acuerdo con esas representaciones.

La construcción de representaciones precisas de la realidad, incluyendo en ella a uno mismo y a los otros, es, sin duda, el mayor logro de la especie humana, su arma más poderosa para controlar la naturaleza. El hombre reconstruye en su mente la realidad, descubre las relaciones entre las cosas, los hechos, traza modelos del funcionamiento de las fuerzas de la naturaleza, de las relaciones físicas entre los objetos, del papel de los otros y de él mismo. Los hombres no se limitan a actuar para satisfacer sus necesidades biológicas, que son irrenunciables e inaplazables, sino que con su mente elabora esos modelos en los que está representado el mundo, lo cual da un sentido más amplio a su actividad y la dota de una eficacia mucho mayor que si se limitara a la pura acción.

Hombres y mujeres construyen representaciones de toda la realidad que le rodea, del funcionamiento de las fuerzas de la naturaleza, de los otros seres vivos y de ellos mismo. Entre esas representaciones están las de la 
propia vida social, que incluyen cómo nos relacionamos con los demás, cuál debe ser nuestro comportamiento hacia ellos y qué es lo que esperamos que los demás hagan en las distintas situaciones sociales. El hombre tiene que elaborar entonces modelos del funcionamiento social, de las instituciones en cuyo marco se desarrolla la vida social. Es una labor que tiene que hacer cada individuo, con la ayuda de los otros, basándose en el conocimiento acumulado por las generaciones que le han antecedido, pero que no puede recibir ya hecho. Es, por tanto una labor psicológica, que se realiza en un ámbito social.

A lo largo de su desarrollo los individuos llegan a tener ideas bastante precisas sobre cómo funciona el mundo social, sobre las relaciones con los otros y sobre cómo están organizadas las instituciones sociales dentro de las que se desenvuelven. Para actuar en la sociedad las personas necesitan adquirir ideas acerca de cómo se produce el proceso de compra`venta y cómo está organizada la sociedad desde el punto de vista económico, para qué sirve el dinero y cuál es su valor; y también entienden la organización política, las relaciones de poder, las formas de gobierno, el funcionamiento de la administración, el trabajo, las profesiones. Pero su conocimiento no se limita a esto, entienden las diferencias de clases sociales, de razas, de países, la función de instituciones como la escuela, la familia, la nación, la religión, los conflictos entre grupos, que dan lugar a las guerras. Y además entienden las relaciones con los otros, las normas que regulan esas relaciones, la conducta que se debe seguir y la que se debe evitar. En definitiva, se forman 'representaciones' o 'modelos' sobre cómo está organizada y cómo funciona la sociedad, pero también de lo que se debe hacer en distintas situaciones.

Cuando los seres humanos nacen no disponen de esas ideas, que si tienen los adultos, por lo que hay que suponer que las van formando o adquiriendo de alguna manera a lo largo de su periodo de desarrollo, y durante el resto de su vida. Lo que tenemos que examinar es cómo se forman, cómo se 'construyen', las ideas sobre el mundo social, sobre las 
instituciones y sobre las normas que las regulan. Ese es un problema que compete estudiar a la psicología, aunque hay que tener datos de las disciplinas que tienen por objeto estudiar esos distintos aspectos del conocimiento social, como la sociología, antropología, economía, ciencia política. Pero estudiar cómo se forman esas ideas no es un mero entretenimiento o una curiosidad, pues las representaciones del mundo social determinan lo que los sujetos hacen y pueden hacer, cómo actúan. Y para entender las concepciones de los adultos es esencial conocer su proceso de formación. Estamos convencidos, por tanto, de que estudiar la génesis de los conceptos sociales tiene una enorme utilidad para entender las ideas adultas sobre la sociedad y que es un requisito indispensable para desarrollar una epistemología genética de las ciencias sociales. En consecuencia podemos decir que el interés del estudio de la formación del conocimiento social es múltiple y puede considerarse desde el punto de vista epistemológico, desde el psicológico o desde el educativo. Para la educación resulta esencial, pues lo que se pretende en la escuela es que los sujetos formen representaciones adecuadas del mundo en que viven por lo que el profesor tiene que partir necesariamente de las ideas que tienen los sujetos si quiere realizar su tarea de un modo satisfactorio.

Las representaciones no tienen sólo una función explicativa, sino que tratan de satisfacer otras necesidades del sujeto, necesidades que no son sólo de tipo cognitivo, sino que contienen aspectos ideológicos, motivacionales o afectivos. La función explicativa se produce para poder alcanzar los fines de la acción, para poder actuar, por lo que las representaciones están indisolublemente ligadas a los fines que se plantea el sujeto, aunque también los determinan, es decir los sujetos persiguen fines en función de las representaciones que tienen, al mismo tiempo que establecen las representaciones para alcanzar sus fines. Se establece así una relación circular.

Uno de los problemas del estudio de las representaciones es que no puede llegarse a ellas directamente, sino sólo de una forma indirecta, 
infiriendo a partir de lo que hacen o de lo que dicen los sujetos. Podemos considerar las representaciones como el conjunto de propiedades que los individuos atribuyen a una parcela de la realidad, lo que incluye las propiedades de los elementos, las relaciones entre ellos, las explicaciones de por qué acontecen, las relaciones causales, y otras muchas cosas. Además hay que tener en cuenta que las representaciones se establecen para actuar.

\section{El mundo social}

Si todavía nos queda mucho por conocer acerca de cómo son las representaciones de los fenómenos físicos, matemáticos, biológicos o químicos, sabemos todavía menos sobre el mundo social. En ese terreno las cosas son mucho más complicadas. Mientras todos pensamos que nuestra representación de la realidad natural es más o menos adecuada, y que nos aproximamos lentamente hacia una verdad que está ahí, independiente de nosotros, en cambio, en el caso del conocimiento de la sociedad es más fácil darse cuenta de que ese conocimiento está orientado por nuestros prejuicios, por nuestros intereses, por nuestros sesgos particulares, por nuestro propio punto de vista, en una palabra, por nuestra posición en el mundo social, como ya había mostrado Marx. El ser rico o ser pobre, poderoso o insignificante, pertenecer a un país o a otro, profesar una religión concreta o no practicar ninguna, ser hombre o mujer, joven o viejo, etc., determina de una manera muy profunda cómo vemos la sociedad y los fenómenos que se producen en ella. Ni tan siquiera las ciencias sociales están al margen de esos sesgos y ésta es una de las causas de la existencia de puntos de vista a veces contrapuestos entre los propios científicos sociales.

Esto añade una dificultad suplementaria a la comprensión del conocimiento sobre la sociedad, respecto al de los fenómenos físicos, pero al mismo tiempo hace especialmente interesante estudiar su génesis. No se trata sólo de un problema de conocimientos escolares, sino que lo importante es ver cómo un individuo se hace adulto dentro de una sociedad determinada 
y va adquiriendo la ideología de esa sociedad; y también cómo va entendiendo las instituciones sociales, las reglas de funcionamiento social, etc., etc.

Cuando preguntamos a los niños sobre problemas de tipo social, aunque sea incidentalmente en conversaciones informales, nos damos cuenta de la dificultad que tienen para entender cosas que a los adultos nos resultan obvias. Nuevamente, como en el caso del conocimiento acerca de la naturaleza, las respuestas de los niños no son simples curiosidades sino, como nos enseñó Piaget, la expresión profunda de su pensamiento. Pero estudiar estas cuestiones es más difícil que estudiar las nociones de la ciencia natural, entre otras cosas porque no tenemos una guía tan firme y segura que nos sirva de punto de referencia. Los conceptos de las ciencias sociales no sólo son muy complejos y a menudo están mal definidos, sino que ni siquiera existe un acuerdo sobre muchos de ellos. No todo el mundo coincide en qué es una nación, qué es la plusvalía, qué debemos considerar terrorismo, qué es un sistema democrático o una dictadura, qué es una clase social, por poner sólo unos pocos ejemplos. En todo caso, no son conceptos de precisión comparable a los de masa, cantidad de movimiento o conjunto, sobre los que caben pocas divergencias.Esta dificultad explica que hasta hace menos de cincuenta años se habían realizado pocas investigaciones sobre este tema - ver una breve revisión histórica en Delval (1989) y una revisión por temas en Furnham y Stacey (1991) y una visión de conjunto de distintos problemas en Barrett y Buchanan-Barrow (2005).

\section{La formación del conocimiento social}

Las instituciones sociales tienen una característica particular y es que en ellas los individuos desempeñan funciones (tendero, jefe, comprador, asalariado, alumno, ciudadano, etc.) y no actúan como un simple sujeto psicológico. Además las instituciones sociales, que son producto de reglas constitutivas (SEARLE, 1995), lo que hacen es dotar de nuevo significado a 
fenómenos que ya existen, y además son fruto del acuerdo social (el dinero vale porque todos admitimos que vale) (DELVAL, 2000).

Cuando se habla de estos temas es frecuente que se produzca una confusión entre el origen del conocimiento y su contenido. Tenemos que manifestar de forma inequívoca que, en nuestra opinión, todo conocimiento tiene un origen social, que el conocimiento sólo es posible viviendo en sociedad y que compartimos con los otros el conocimiento, tanto el que tiene como objeto el mundo inanimado, como el que se ocupa de los seres vivos en general o de los seres humanos en particular. Por tanto tiene que quedar claro que todo conocimiento es social en su origen. Pero el conocimiento puede versar sobre la realidad inanimada, sobre los seres vivos o sobre los humanos y sus relaciones. Es decir que aunque sea social en su origen los contenidos sobre los que trata se pueden referir a cualquier parcela de la realidad.

Pero el hecho de que el conocimiento sea social, de que otros lo posean e intenten transmitírnoslo, de que sea compartido, no quiere decir que se adquiera por copia o transmisión verbal de lo que los otros saben. El sujeto que adquiere un conocimiento no se limita a adquirir lo que otro sabe, sino que lo tiene que reconstruir. De otro modo no se podría explicar que las concepciones de la sociedad de sujetos de distintas edades difieran mucho entre ellas y difieran de las de los adultos, y en cambio se parezcan entre sujetos de parecida edad que viven en diferentes países o culturas.

Sin embargo, algunas explicaciones acerca de cómo se forma el conocimiento sobre la sociedad sostienen que se trata de un proceso de socialización, que el conocimiento está en la sociedad y es implantado en el individuo por la presión social. Eso es cierto, pero desde el punto de vista del psicólogo lo que hay que explicar precisamente es cómo se produce esa interiorización del conocimiento.

Por ejemplo la teoría de las representaciones sociales propuesta por Moscovici (1976) ha tratado de ocuparse de un tipo de representaciones que serían compartidas por un grupo social de características determinadas. 
Esas representaciones sociales se adquirirían en la vida social y vendrían hechas del exterior. Como dice Moscovici (1976, p. 66) "el individuo forma parte de un 'coro' colectivo, que constituye la opinión pública, en el que el individuo participa, lo quiera o no". Por tanto el sujeto es un elemento pasivo que se limita a cantar en ese coro la partitura que recibe socialmente.

De forma parecida, la psicología histórico-cultural, inspirada en las ideas de Vygotski, pone también el acento en la adquisición por el individuo de conocimientos que están en la sociedad. Pero de este modo no podemos explicar la originalidad que tienen las concepciones sobre la sociedad que defienden los niños (DELVAL, 2002).

La concepción de la formación de las representaciones que defendemos es mucho más amplia que la de Moscovici o la de la psicología históricocultural y el individuo tiene un papel muy activo en su elaboración, que va mucho más allá de formar parte de un coro o de interiorizar lo que piensan los adultos. Precisamente lo que interesa estudiar son las dificultades que el sujeto encuentra para llegar a las nociones adultas y las etapas por las que pasa.

\section{Los campos de la representación del mundo social}

Después de estas observaciones sobre cómo se va formando el conocimiento social, vamos a tratar de describir qué temas, aspectos o campos pueden incluirse bajo ese rótulo. La representación del mundo social es algo enormemente amplio y con límites difusos, en donde se pueden distinguir aspectos centrales y aspectos periféricos. Posiblemente los dos problemas centrales de la representación del mundo social son la comprensión del orden político y la comprensión del orden económico, que constituyen una especie de columna vertebral en torno a la que se organizan otras cuestiones. Pero además de los problemas que podemos considerar genuinamente sociales hay muchos otros que no lo son estrictamente, pero que tienen una vertiente social clara como la vejez o la muerte. Vamos a 
enumerar distintos aspectos que forman parte de esa representación del mundo social, que no la agotan, pero que dan una idea de la amplitud de la problemática.

Respecto al funcionamiento económico de la sociedad es importante averiguar cómo se entiende la producción y el intercambio de las mercancías, y ligado a ello, cuál es el papel del dinero. Esto a su vez está en conexión con la distribución social de la riqueza y la existencia de clases sociales y aquí aparecen entonces los problemas de la comprensión de las diferencias sociales, de la estratificación y la movilidad social.

Respecto a la comprensión del orden político, temas centrales son el papel de los partidos políticos, el funcionamiento del sistema democrático y de otros sistemas políticos, de las instituciones, la representación parlamentaria, el cambio político, la alternancia en el poder, etc. Un aspecto más profundo del problema, es el de la comprensión de las nociones de autoridad y poder y su extensión desde el punto de vista social. Otro aspecto de gran importancia es la comprensión de las leyes, su origen, su función, su evolución, el papel del derecho en la sociedad y las relaciones entre derecho y moral.

Además de estos dos temas centrales, hay otros muchos aspectos relativos a instituciones o simplemente a fenómenos ligados a la práctica social. Entre estos hay que destacar las ideas referentes a la propia nación, la aparición de un apego hacia el propio país y la comprensión del país como una unidad multidimensional, política, económica, cultural, lingüística, religiosa, geográfica, etc. Muy estrechamente relacionado con esto están las ideas y actitudes hacia otros países, y la aparición de sentimientos negativos como el racismo y la xenofobia.

La concepción de la familia y de su papel dentro de la sociedad, las relaciones de parentesco, las funciones paterna y materna y, en relación con ello, el problema de la adopción de papeles sexuales o de género, constituyen otro de los aspectos importantes de la comprensión de la sociedad. La adopción de papeles sexuales ha sido estudiada tradicionalmente desde la 
perspectiva de la socialización mientras que se han descuidado los aspectos cognitivos del problema, es decir, cómo perciben los sujetos su papel y el de los individuos que pertenecen a otro sexo.

Ligada a la existencia de clases sociales, que tiene un fundamento económico, aparece la cuestión de la adopción de papeles sociales, la comprensión de las profesiones y todo lo relativo a la división del trabajo, lo cual se conecta con los progresos del niño en la diferenciación entre los individuos y su papel social.

Los niños pasan una gran cantidad del tiempo en la escuela y construyen ideas sobre cuál es la función de ésta y qué es lo que hacen en ella. El problema de la transmisión del saber, de la generación de conocimientos desde el punto de vista social y de la difusión de esos conocimientos, así como el papel de la ciencia como forma de poder, es otro de los aspectos de nuestro tema, pero que ha sido muy escasamente estudiado.

El nacimiento y la muerte además de fenómenos biológicos son fenómenos sociales, los jóvenes, los adultos y los viejos tienen un papel en la sociedad, y cada sociedad les otorga un lugar. La visión de las etapas de la vida, desde la infancia hasta la vejez, en relación con la organización social, constituye otra parte del campo que nos ocupa.

La guerra y la paz, así como las relaciones entre las naciones en todos los terrenos, forman un aspecto más de este campo que debe ser estudiado. Los niños se interesan enormemente por la guerra como forma de dominación, pero tienen de ella un conocimiento irreal y esquemático. El paso de esa concepción a las ideas complejas de los adolescentes, que incluyen aspectos políticos, económicos y sociales en la conceptualización de la guerra, es un tema que vale la pena estudiar.

La religión constituye también un fenómeno social y las ideas que el niño tiene en el terreno religioso no coinciden con las de los adultos. Es importante por ello saber cuáles son esas ideas de los niños, cómo conciben a Dios, o aspectos más mundanos, como son su pertenencia a una comunidad 
religiosa, en una palabra, cómo es la religión del niño.

Por último, un problema central, que aparece ligado a todos los anteriores, es la comprensión del cambio social, cómo evolucionan las sociedades a lo largo de la historia. Este tema está en relación con el del tiempo histórico, algo que resulta incomprensible para el niño durante largos años. Los niños tienden a ver la sociedad de forma estática y el tiempo sólo aparece tardíamente como un elemento relacionado con los fenómenos sociales. Una compresión completa de la sociedad exige entender la evolución histórica de las sociedades.

Cada uno de los distintos campos requiere el empleo de los instrumentos intelectuales que el niño forma a través de su acción sobre el mundo y uno de los problemas de interés en este estudio es ver cómo interactúan los medios intelectuales del sujeto con los conceptos sociales que forma y si esa interacción es del mismo tipo que la que se produce respecto a los conceptos físicos o matemáticos.

\section{De que están hechos los modelos sociales}

Las representaciones sobre el mundo social tienen algunas características peculiares que las diferencian de otras representaciones, debido al carácter propio del conocimiento social. Es especialmente importante el papel que las normas y los valores desempeñan en la vida social. Las normas sociales regulan la vida social pero, a diferencia de las reglas de la naturaleza, pueden respetarse o no respetarse (DELVAL; ENESCO, 1994).

Puesto que el hombre es un ser social que sólo puede desarrollarse dentro de una sociedad y en contacto estrecho con los otros, los adultos tratan de que los niños se conviertan en miembros completos de esa sociedad inculcándoles las normas, valores, actitudes y formas de comportamiento que caracterizan a los miembros de esa sociedad, en un proceso que globalmente se suele llamar socialización, y que no presupone 
necesariamente cómo se produce, si mediante la presión de los otros o a través de la actividad constructiva del propio sujeto.

Una de las primeras cosas que los sujetos adquieren son las normas o reglas sobre lo que debe hacerse y sobre lo que no debe hacerse. Los adultos se cuidan mucho de que la conducta de los niños siga esas normas y ponen un gran empeño en ello, pues esto es lo que va a garantizar que en el futuro su conducta pueda considerarse social, y que el sujeto pueda interaccionar con los otros. Por ello desde muy pronto se les anima o se les reprime para que se comporten de acuerdo con lo que se considera adecuado. Esas normas están estrechamente ligadas a valores sociales que indican lo que es deseable y lo que no lo es desde el punto de vista de los otros. Esos elementos prescriben lo que debe hacerse y se refieren a cómo deben ser las acciones, no a cómo son. Normas y valores son constituyentes esenciales del conocimiento y de la conducta social.

Pero el niño recibe además informaciones sobre muchos hechos sociales, sobre aspectos concretos de la realidad social, y también las obtiene él mismo actuando dentro del mundo social, registrando sus regularidades y reflexionando sobre él.

Junto con todo lo anterior, y apoyándose en ello, va elaborando explicaciones sobre cómo y por qué suceden las cosas de una determinada manera, en definitiva, sobre el funcionamiento de los sistemas sociales.

Normas, valores, informaciones y explicaciones son entonces algunos de los elementos que componen los modelos o representaciones que el niño va elaborando sobre el mundo social, elementos que podemos agrupar en tres tipos: normativo-valorativos, informativos y explicativos. Quizá esta distinción pueda parecer trivial pero no tenerla presente da lugar a muchos equívocos en las investigaciones y sobre todo en lo referente a cómo se produce el conocimiento social. Intentaremos explicar por qué.

Las normas y los valores que prescriben lo que se debe hacer se empiezan a adquirir desde muy pronto y los adultos ponen un particular empeño en que los niños los adquieran ("No pegues a los otros niños", "para 
comprar en la tienda hay que llevar dinero", "tienes que ir a la escuela para aprender", serían ejemplos de ello). Por lo tanto se transmiten explícitamente y se estimula su imitación, de tal manera que su labor mental en los comienzos de la adquisición de las normas es relativamente pasiva ya que los sujetos las reciben en gran medida hechas. En este caso la transmisión directa por parte de los adultos desempeña un papel importante y podría pensarse que el niño se limita a incorporar lo que los adultos le transmiten, pero, de todas formas, el niño sólo es capaz de incorporar aquellas normas que están al alcance de su comprensión.

En muchos casos las informaciones las recibe también directamente de los adultos o de los medios de comunicación y además la escuela dedica una importante parte de su actividad a la transmisión de informaciones, aunque también el niño las busca por sí mismo (ejemplos de estas serían: "Brasilia es la capital de Brasil", "Benito Juárez fue presidente de México", "médico es una profesión prestigiosa", "la bandera colombiana es blanca, azul y roja").

Por el contrario las explicaciones sobre por qué son así las cosas, sobre cómo funcionan los sistemas sociales, y los conceptos en que se apoyan, apenas se enseñan. No se le explica al niño el sistema de la tienda y la distribución de mercancías, ni sus relaciones con el proceso de producción. Ni tampoco se le explica cómo se produce la movilidad social y cuáles son sus determinantes, ni las causas que motivan las guerras. $Y$ cuando se le enseñan esas cosas hace ya mucho tiempo que tiene explicaciones para ellas, explicaciones que ha tenido que construir por si mismo, porque nadie se las ha dado, y que suponen un trabajo de elaboración propio. El niño las construye con los instrumentos intelectuales de que dispone y llega a explicaciones que no coinciden con las de los adultos y que curiosamente son muy semejantes entre niños de distintos medios sociales y de diferentes países, aunque pudiera creerse lo contrario.

Así vemos que el niño aprende muy pronto como una regla que para comprar hay que llevar dinero a la tienda, mucho antes de que sea capaz de explicar para qué sirve ese dinero, qué hace el tendero con él, cómo se fijan 
los precios, y en general cómo tiene lugar la actividad económica. Posteriormente las explicaciones inciden sobre normas y valores y los reorganizan, y cuando se alcanza un grado de comprensión grande, esas explicaciones proporcionan a las normas y valores un sentido nuevo, haciendo posible la reflexión sobre ellos, e incluso dudar de sus fundamentos.

Algo semejante puede decirse de las informaciones. A nuestros niños se les enseña al llegar a la escuela que "Madrid es la capital de España" y todos saben repetirlo sin errores. Pero, como han puesto de manifiesto varias investigaciones (PIAGET; WEIL, 1951), y nosotros mismos hemos estudiado, antes de los siete años no suelen entender que hay más españoles que madrileños, que no todos los españoles son madrileños, pero si sucede lo contrario, y tampoco tienen la más remota idea de lo que quiere decir "ser capital de" ni lo que es una capital, ni un país (DELVAL; DEL BARRIO; ECHEÍTA, 1981; DELVAL, 1989). Así pues, esa información no les sirve de mucho en ese momento, ni pueden integrarla en sus explicaciones de la organización administrativa de un país.

Consideramos que es útil tener presentes las distinciones anteriores porque cuando estudiamos los modelos del mundo social que elaboran los sujetos, si nos interesamos especialmente por su conocimiento de las reglas, valores e informaciones no podemos apreciar plenamente la labor constructiva del sujeto, que en gran medida está reproduciendo lo que se le ha transmitido. Por ello lo que nos dice depende mucho del medio social y de la cultura en la que vive, de las ideas dominantes, aunque también las está asimilando con sus instrumentos intelectuales. En cambio, en las explicaciones sobre el funcionamiento de los sistemas sociales y en los conceptos que forman parte de ellas, las variaciones son menores y encontramos procesos constructivos que son mucho más universales. Es fácilmente comprensible que los contenidos del pensamiento tienen que variar de acuerdo con el entorno, pero la manera de explicar los fenómenos, que está mucho más ligada a las capacidades mentales de los sujetos, es más 
semejante.

\section{Los niveles del conocimiento social}

A lo largo de diversas investigaciones que hemos realizado en los últimos años sobre las representaciones de niños y adolescentes acerca de la sociedad hemos ido comprobando que cuando les pedimos que nos expliquen el funcionamiento de una parcela amplia de la realidad social y examinamos sujetos de distintas edades hasta la adolescencia los tipos de explicaciones que nos ofrecen siguen algunas pautas constantes, como ya apuntábamos al hablar de la movilidad social. Las ideas sobre el origen y la circulación del dinero, sobre el prestigio de las profesiones, sobre los jefes y sus funciones, sobre los derechos de los niños, sobre la función del profesor en la escuela o incluso sobre la idea de dios pueden describirse siguiendo una progresión en tres niveles, que pueden subdividirse y especificarse en algunos casos. (DELVAL, 2001).

En un primer nivel, que se extiende hasta los 10-11 años (téngase en cuenta que las edades son sólo aproximadas) los sujetos basan sus explicaciones en los aspectos más visibles de la situación, los que pueden observarse a través de la percepción y no tienen en cuenta procesos ocultos que deban ser inferidos. Los pobres son reconocidos por su aspecto físico y los ricos tienen su dinero en la cartera o en una caja; se puede pasar de pobre a rico encontrando dinero en la calle. Las mejores profesiones son aquellas en las que se ayuda a los otros. No existen propiamente derechos de los niños porque los adultos se ocupan convenientemente de ellos y hacen todo lo necesario para su bienestar; si los padres u otras personas impiden a los niños hacer algo que les corresponde lo único que puede hacerse es hablar con ellos y tratar de convencerles, o si no aguantarse.

En ese nivel son poco sensibles a la existencia de conflictos, pues tienden a centrarse en un sólo aspecto de la situación en cada momento. Si reconocen la existencia de un conflicto (por ejemplo unos padres que no 
quieren que su hijo vaya a la escuela en contra de los deseos del niño) no ven soluciones posibles, como no sea dar alternativamente la razón a unos o a otro. No se reconoce la existencia de relaciones propiamente sociales, sino que las relaciones son personales, y por ejemplo el maestro ayuda a los niños porque los quiere y quiere que estén bien y aprendan. De esta forma los conflictos sólo se pueden resolver mediante la buena voluntad de las partes.

En un segundo nivel, que se extiende por término medio entre los 10-11 años y los 13-14, los sujetos empiezan a tener en cuenta aspectos no visibles de las situaciones, es decir procesos que deben inferirse a partir de la información de que se dispone. Los procesos incluyen una duración temporal, es decir se desarrollan en un período más o menos largo. Aparece la distinción entre las relaciones personales y las sociales o institucionalizadas: el vendedor no es un amigo que nos proporciona las cosas que necesitamos, sino alguien que desempeña una función social y vive de eso; el maestro se ocupa del aprendizaje de los niños y de ayudarlos porque esa es su función. En la misma línea la asistencia del niño al colegio no es un deseo de los padres sino que está prescrito por una norma social.

Se perciben más claramente los conflictos, aunque lo más frecuente es que no sea posible encontrar todavía soluciones satisfactorias por la dificultad de considerar aceptables distintos puntos de vista. Los sujetos empiezan a evaluar las normas con sus propios criterios e incluso a criticarlas.

En un tercer nivel, que comienza hacia los 13-14 años, los procesos ocultos, y por lo tanto necesariamente inferidos, ocupan un papel central en las explicaciones. Las distintas posibilidades que se presentan en una situación son examinadas sistemáticamente y el sujeto es capaz de coordinar puntos de vista y de reflexionar sobre lo posible. Los cambios sociales son lentos, incluso muy lentos. Los sujetos poseen mucha más información sobre el funcionamiento social, pero sobre todo saben cómo integrarla o tratan de hacerlo. Uno de los rasgos más claros es que los sujetos intentan encontrar una coherencia en las cosas y abordan directamente los conflictos. La 
solución de esas situaciones problemáticas se ve en relación con el establecimiento de cesiones por parte de los actores sociales, de compromisos entre una posición y otra, que permite llegar a acuerdos en los que cada parte cede algo de sus derechos. Las reglas se aplican de una manera mucho más flexible y se pueden establecer también compromisos entre ellas. Los sujetos se vuelven críticos con el orden social existente, emiten juicios sobre lo que está bien y no está bien y proponen soluciones alternativas.

Por supuesto en cada aspecto de la realidad social que consideramos aparecen rasgos específicos y propios de ese dominio, pero existen también muchas semejanzas interdominios y parece que en cada uno de los niveles hay como una concepción global de la sociedad y de las relaciones entre los actores sociales. No podemos asegurar a priori que estos niveles de explicación se den en todos los terrenos y eso sólo podrá decirlo la investigación sobre cada campo, pero por lo que hemos visto nos parece que puede hablarse de visiones del mundo distintas que van construyéndose a lo largo del desarrollo.

\section{Cómo ve el niño la sociedad}

Para terminar querríamos hacer algunas observaciones sobre cómo parece que es la sociedad que el niño concibe, que resulta bastante diferente de la que conciben los adultos. No podemos extendernos ahora sobre las causas a las que esto se debe, pero si nos gustaría señalar algunos rasgos llamativos. Lo que vamos a apuntar puede resultar sorprendente - y lo presentamos con todo tipo de reservas, sobre todo en lo referente a lo que sucede en otros medios sociales - pero creemos que hay datos suficientes para trazar un cuadro como el que vamos a bosquejar.

El niño entiende una realidad social muy distinta de la que vemos los adultos, que nos hemos acostumbrado a concebir el orden social como un terreno de lucha y de competencia de todos contra todos, haciendo nuestro el dictum hobbesiano homo homini lupus. Por el contrario, parece que los niños 
conciben una sociedad mucho más idílica, viéndola como un terreno de cooperación y de ayuda mutua. Posiblemente la posición del niño dentro de la sociedad, como un ser dependiente, que generalmente es ayudado y querido por los adultos, y sin tener que sufrir, por regla general, los ataques de otros, facilita esta idea.

En primer lugar, la sociedad que concibe el niño parece que se ve como un orden completamente racional (igual, por otra parte, que el mundo físico), en el que cada cosa está situada en el sitio que le corresponde y la realidad sirve para satisfacer las necesidades del hombre. La sociedad es un lugar sin conflictos en el que todos cooperan con todos y cada elemento funciona perfectamente. Los conflictos están ausentes y la injusticia no existe, probablemente porque la injusticia se ve como algo irracional e innecesario. En todo caso, si se comprueba su existencia no puede explicarse, ni se encuentran soluciones viables, y tiene que tratarse de un fenómeno claramente excepcional.

Naturalmente los niños están también en contacto con situaciones en las que las cosas no parecen producirse así. Pueden percibir la pobreza, la desigualdad, la enfermedad o el dolor. Todo esto no encaja bien en el esquema anterior y por ello tienden a verlo como situaciones anómalas y excepcionales, que sólo son alteraciones poco frecuentes de la norma general. Hay individuos que no cumplen con sus obligaciones porque son malos, es decir, por razones personales intrínsecas. Esto se relaciona con otras características del pensamiento social infantil que mencionaremos a continuación.

Los individuos, por su parte, se esfuerzan por comportarse lo mejor posible, ayudando a los demás y movidos siempre por intereses altruistas. $\mathrm{Al}$ mismo tiempo, son personas que conocen muy bien lo que tienen que hacer y que saben cómo se hacen las cosas. Los adultos tienen siempre el saber necesario, y el conocimiento ocupa un lugar muy importante en la valoración del niño. Los políticos, los administradores, los técnicos son personas que saben y que hacen su tarea bien. Los políticos, los que desempeñan 
funciones sociales prominentes, son personas que saben mucho y que han llegado a esos puestos tras largos años de estudio. En conjunto, la noción de saber ocupa un lugar privilegiado en la comprensión infantil de la realidad social. Saber y autoridad se identifican, y las personas que detentan el poder son las que tienen autoridad; la autoridad se relaciona con el conocimiento: los que más mandan son los que más saben.

En segundo lugar, los niños entienden el orden social como si estuviera regido por preferencias personales y no son capaces de ver actuaciones impersonales o de carácter propiamente social institucionalizado. Éste es un aspecto que ha sido señalado por Furth (1980).

En tercer lugar la visión que el niño tiene de la sociedad es como una imagen en blanco y negro, con pocos matices. Las personas buenas son muy buenas y las malas muy malas, los ricos son muy ricos y los pobres muy pobres. Las posiciones intermedias son más difíciles de entender y los niños no gustan mucho de las sutilezas. Ésta es la imagen que presentan los cuentos infantiles que por ello mismo les resultan tan atractivos.

En cuarto lugar, la sociedad del niño es una sociedad de la abundancia en la que la escasez no tiene lugar. Las cosas son abundantes y siempre podemos encontrar lo que necesitamos. En la tienda hay tantos vasos como queramos y si los bolígrafos se agotan, pronto habrá más. El dinero lo podemos obtener en el banco (o incluso a través del cambio en la tienda) y cuando se nos acaba vamos por más. Los pobres son muchas veces los que no saben ir al banco por dinero. Esa abundancia es naturalmente relativa a la situación del propio niño, pero en un orden racional que está hecho para favorecer el bienestar de los humanos las cosas que se necesitan se pueden obtener. El dinero, los alimentos o bienes necesarios para la vida están disponibles cuando se necesitan. Como al mismo tiempo, las cosas están regidas por unos propios pocos principios es necesario pagar por todo y un ejemplo de ello es la creencia en que el trabajo se compra (DELVAL, 1994).

En quinto lugar, al concebir un mundo regido por unos pocos principios simples y de aplicación general, el niño no entiende los conflictos sociales 
como motivados por la presencia de intereses contrapuestos. Los intereses de cada uno deben coincidir y deben coincidir también con el interés general. Por ello no pueden existir los conflictos y si éstos se producen sólo pueden deberse o a la ignorancia o a la maldad. En el caso de los derechos si alguien viola un derecho será debido a que no se ha dado cuenta de lo que está haciendo y la manera de corregir la situación es hacérselo ver. Por eso la figura de un mediador es importante porque permite que se hable con esas personas y que se den cuenta de su error, su función es la de convencerlos.

Por las mismas razones el compromiso es algo que está ausente de las concepciones infantiles. La idea de compromiso en el terreno del desarrollo social, y en concreto político, que ha sido señalada por Furth y McConville (1981) supone la aceptación de que existen diferentes maneras de concebir la realidad o de actuar que son todas razonables o pueden sostenerse por lo que, cuando existen intereses contrapuestos, debe intentar llegarse a un acuerdo en el que los defensores de las diferentes posiciones ceden una parte de sus pretensiones para lograr la posibilidad de llegar a un acuerdo. Por ello la idea de compromiso no resulta precisa en las explicaciones infantiles y es un descubrimiento de la adolescencia tardía. Esto puede dar lugar a entender la figura de un mediador muy distinto del que se concedía anteriormente. El nuevo mediador no tiene como misión convencer sino lograr una cesión de parte de los derechos entre los implicados en el conflicto.

En sexto lugar, el niño concibe difícilmente que el orden social pueda alterarse. Es como es y lo seguirá siendo, como consecuencia de que es el mejor. Esto lo manifiestan los niños en sus respuestas sobre múltiples problemas sociales. Si no hubiera maestros no se podría aprender. Si no hubiera tiendas no podríamos comprar y nos moriríamos. Si no hubiera dinero no podríamos obtener lo necesario para la vida. Si no hubiera jefes sería el desorden total y lo mismo pasaría con la ausencia de leyes. Si cambiaran esas condiciones el orden social se alteraría profundamente o se destruiría totalmente (FURTH, 1980). No se pueden imaginar reajustes en 
el sistema ni formas alternativas de funcionamiento.

Resulta sorprendente ese mundo del niño tan racional y tan ordenado en el que, sin embargo, unos elementos no pueden relacionarse con otros. Pero todo este mundo de bondad y de racionalidad se empieza a desmoronar en el momento de la adolescencia, cuando la realidad se comienza a entender de manera mucho más exacta y, al mismo tiempo, el individuo empieza a comprobar su impotencia para cambiar el mundo irracional que empieza a descubrir y que es tan contrario a todo lo que le han enseñado como niño durante los largos años pasados en la escuela. La realidad social entra en contradicción con todos los valores que se han recibido y con todas las enseñanzas morales que se le han transmitido. El origen de muchos problemas sociales actuales, y también de otras épocas, se encuentra posiblemente en ese choque, en ese conflicto, en esa desilusión, en esa frustración que se produce en la adolescencia y que puede tener consecuencias de muy largo alcance.

\section{Referências}

BARRETT, M.; BUCHANAN-BARROW, E. Children's understanding of society. Hove: Psychology Press, 2005.

DELVAL, J. La representación infantil del mundo social. In: ENESCO, I.; TURIEL, E.; LINAZA, J. (Eds). El mundo social en la mente infantil. Madrid: Alianza, 1989.

. Stages in the child's construction of social knowledge. In: CARRETERO, M.; VOSS, J.F. (Eds.) Cognitive and instructional processes in history and the social sciences. Hillsdale: LEA, 1994.

. Sobre la naturaleza de los fenómenos sociales. In: KORTA,K.; GARCÍA MURGA, F. (Comps.) Palabras. Víctor Sánchez de Zavala in memoriam. Bilbao: Servicio Editorial de la UPV-EHU, 2000. p. 95-122.

- Descubrir el pensamiento de los niños: introducción a la práctica del método clinico. Barcelona: Paidós, 2001.

.; DEL BARRIO, C.; ECHEITA, G. El conocimiento de los niños de su propio país. Cuadernos de Pedagogía, n. 75, p. 33- 36, 1981.

.ENESCO, I. Moral, desarrollo y educación. Madrid: Anaya-Alauda, 1994. 
FURNHAM, A.; STACEY, B. Young people's understanding of society. Londres: Routledge, 1991.

FURTH, H. G. The world of grown-ups.Children's conceptions of society. Nueva York: Elsevier North Holland, 1980.

.; McCONVILLE, K. Adolescent understanding of compromise in political and social arenas. Merrill-Palmer Quarterly, n. 27, p. 413-427, 1981.

MOSCOVICI, S. La psychanalyse, son image et son public. París: P.U.F., 1976.

PIAGET, J. ; WEIL, A. M. Le development, chez l'enfant, de l'idée de patrie et des relations avec l'étranger. Bulletin International des Sciences Sociales, n. 3, p. 605$621,1951$.

SEARLE, J. R. The construction of social reality.Nueva York: Free Press, 1995. 


\title{
Pesquisas sobre a construção do conhecimento social no contexto brasileiro: estado da arte 2005- 2017
}

\author{
Eliane Giachetto Saravali ${ }^{1}$ \\ Taislene Guimarães ${ }^{2}$ \\ Rafaela Carolina da Silva ${ }^{3}$
}

\begin{abstract}
RESUMO
O texto oferece uma ampla revisão das pesquisas realizadas no contexto brasileiro, referentes à construção do conhecimento social na perspectiva piagetiana. As bases de dados consultadas foram Scielo, Portal de Periódicos e Banco de Teses da CAPES e Bibliotecas Digitais das instituições referenciadas neste último, mediante a utilização dos seguintes termos, em busca avançada: conhecimento social, Jean Piaget, epistemologia genética, crenças, noções sociais, Juan Delval e interação social. Foram encontradas 74 referências, entre 2005 e 2017, analisadas sob os seguintes aspectos: veículo de publicação, autores mais produtivos, autores mais citados, instituições de origem das pesquisas, faixa etária dos participantes, delineamentos metodológicos utilizados e as temáticas abordadas nos estudos. Conclui-se, entre outros, a respeito da relevância desses trabalhos e da atualidade da obra piagetiana, referencial teórico que sustenta esse tipo de compreensão sobre a apropriação do mundo social.
\end{abstract}

PALAVRAS-CHAVE: Conhecimento Social. Epistemologia Genética. Estado da Arte.

Construction of social knowledge e researchs in the Brazilian context: state of art 2005-2017

\footnotetext{
${ }^{1}$ Doutora em Educação. Docente do Departamento de Psicologia da Educação e do Programa de Pós-Graduação em Educação da Universidade Estadual Paulista - UNESP, campus de Marília, SP, Brasil. E-mail: eliane.saravali@marilia.unesp.br

${ }^{2}$ Doutora em Educação. Universidade Estadual Paulista - UNESP, campus de Marília, SP, Brasil. E-mail: taislene_ped@yahoo.com.br

${ }^{3}$ Doutoranda em Ciência da Informação. Universidade Estadual Paulista - UNESP, campus de Marília, SP, Brasil. Email: rafaelacarolinasilva@gmail.com
} 


\begin{abstract}
The paper offers a broad review of the research carried out in the Brazilian context, concerning the construction of social knowledge in a Piagetian perspective. The databases consulted were Scielo, Portal de Periódicos eBanco de Teses CAPES and the digital libraries of the institutions referenced, using the following terms, in advanced search: social knowledge, Jean Piaget, genetic epistemology, creed, social notions, Juan Delval, and social interaction. There were 74 references between 2005 and 2017, analyzed by the follow steps: vehicle of publication, more productive authors, more cited authors, origin of theresearch institutions, age range of the participants, methodological delineations,as well as the topics addressed in the studies. It concludes, among others, on the relevance of the works and the actuality of the Piagetian work, theoretical reference which supports this type of understanding about the appropriation of the social world.
\end{abstract}

KEYWORDS: Social Knowledge. Genetic Epistemology. State of Art.

$$
* * *
$$

\title{
Introdução
}

No presente texto, objetivamos sistematizar aspectos de um conjunto de pesquisas desenvolvidas no contexto brasileiro a respeito da construção do conhecimento social, sob a perspectiva piagetiana. Elegemos os últimos 12 anos (2005-2017) como período de análise, tendo em vista que as pesquisas referentes a esta temática começaram a ser publicadas no Brasil a partir de 1996 (GODOY, 1996; TORTELLA, 1996) e, não sendo possível uma análise detalhada de todo período nos limites de um artigo, optamos, neste momento, por dedicarmo-nos a sua segunda metade.

Primeiramente, julgamos oportuno apresentar uma questão essencial: delimitar o que significa "construção do conhecimento social na perspectiva piagetiana”. Na obra do mestre suíço, (Jean Piaget 1896-1980), podemos observar que o social pode se referir a dois aspectos diferentes de nossas vidas, tratados separadamente aqui apenas para fins didáticos, uma vez que 
para compreender o desenvolvimento é necessário ter em mente a construção e evolução de um sujeito epistêmico e de um sujeito psicológico, constantemente. Tais aspectos referem-se à interação social, fator do desenvolvimento, e ao social como objeto de conhecimento, caracterizado diferentemente dos objetos físicos ou matemáticos.

Assim, a interação, necessária à construção do conhecimento, jamais se referiu somente aos limites de um indivíduo e de um objeto físico, inanimado. É na e da interação social que vemos os indivíduos se libertarem de um pensamento egocêntrico, centrado na própria perspectiva; sem ela, dificilmente poderíamos falar em convivência e desenvolvimento moral, por exemplo.

Tal interação, que envolve a coordenação de diferentes perspectivas, possui também o componente da transmissão, daquilo que é proveniente dos antepassados, que se transfere por diferentes meios - o ensino, a televisão, os jornais etc. O conhecimento construído a partir dessa informação é, a nosso ver, parte importante do amplo processo de socialização, porém, insuficiente para a elaboração de ideias menos aparentes e estereotipadas sobre o mundo social.

Assim sendo, numa perspectiva piagetiana, precisamos compreender que essas construções socialmente compartilhadas não devem desconsiderar o papel de quem conhece. Isto é, a transmissão não exclui a assimilação que o sujeito faz, o sentido que ele é capaz de atribuir a esse novo objeto de conhecimento: "toda assimilação é uma reestruturação ou uma reinvenção" (PIAGET, 1998, p.48).

O conhecimento social refere-se ao conhecimento da sociedade e seu funcionamento, ao sistema de valores e crenças, bem como à compreensão dos diferentes papéis sociais das pessoas e nossas interações com elas (ENESCO, DELVAL, LINAZA, 1989). Trata-se do:

[...] conjunto de propriedades que os indivíduos atribuem a uma parcela da realidade, o que inclui as propriedades dos elementos, 
as relações entre eles, as explicações do porquê acontecem, as relações causais e muitas outras coisas. (DELVAL, 2013a, p. 16, tradução nossa).

Pensar, portanto, no conhecimento social, significa considerar, pormenorizadamente, como o sujeito se apropria daquilo que é socialmente construído e compartilhado em seu meio cultural, familiar, escolar. Debruçar-se sobre esses assuntos é ação investigativa mais recente, datada, no contexto internacional, da década de 70 do século passado e, no Brasil, da década de 90, como pontuado anteriormente.

Nos estudos de Delval (Delval, 2013b; Delval, Vila, 2008; Delval, Del Barrio, 1992; Delval, 1989; Denegri, Delval, 2002 a e b), podemos conhecer os processos percorridos para a construção desse tipo de conhecimento, assim como observar as noções elaboradas a respeito de diferentes conteúdos sociais. Tais estudos não devem ser analisados sob uma ótica anedótica ou apenas pela beleza em se dar voz a crianças e adolescentes. A importância desses estudos reside em poder acompanhar como um indivíduo se apropria do mundo social, de tal sorte que a qualidade e os limites dessa apropriação influenciarão as suas ações e sua relação com o mundo.

Estamos convencidos, portanto, que estudar a gênese dos conceitos sociais tem uma grande utilidade para entender as ideias adultas sobre a sociedade, e que é um requisito indispensável para desenvolver uma epistemologia genética das ciências sociais. (DELVAL, 2007, p. 50, tradução nossa).

Considerando o exposto, o presente artigo pretende contribuir àqueles que se dedicam ou pretendem se debruçar sobre a construção do conhecimento social, por meio da apresentação de pesquisas desenvolvidas no contexto nacional e da sistematização desta produção ainda pouco divulgada e que, certamente, nos traz não apenas significativas contribuições para os contextos psicológicos e pedagógicos do 
desenvolvimento infantil, mas também para a compreensão do pensamento adulto de nossa sociedade.

Nessa perspectiva, buscamos identificar, descrever e analisar os autores que formam a elite da produtividade deste campo no que se refere à produção e conteúdo e índices de citação. Para tanto, utilizamos a Lei do Elitismo de Price, advinda da bibliometria, que permite, por meio da análise da literatura produzida sobre um assunto, a identificação e a descrição dessa elite (ALVARADO, 2009).

Buscamos, como apontam Lakatos e Marconi (2003), percorrer os seguintes passos: a apreciação crítica do material; a decomposição dos elementos essenciais; a classificação do que foi encontrado e a análise final. Portanto, a análise permitiu destacar os pesquisadores que, no momento da realização desta pesquisa, mais produziram e foram mais citados na área de estudo (PRICE, 1963). Assim, procuramos os trabalhos que foram desenvolvidos numa perspectiva piagetiana e os que tratam de conteúdos sociais sob esse enfoque. Dessa forma, objetivamos concentrar os estudos que abordam os conteúdos sobre o funcionamento da sociedade em distintos aspectos e aqueles referentes às relações institucionalizadas, com seus respectivos papéis sociais (DELVAL, 2007). Ainda, para o autor, dentro deste recorte, há campos mais explorados, entre ele estão: o funcionamento econômico, a ordem política, as leis, a família, os papéis sexuais, as classes sociais, as profissões; essas são algumas temáticas recorrentes,também, em nosso contexto, conforme poderemos ver a seguir.

\section{Metodologia}

As pesquisas sobre a construção do conhecimento social, no Brasil, tiveram seu início em 1996 (GODOY, 1996; TORTELLA, 1996). Como a quantidade de pesquisas realizadas desde então é bastante grande para os limites de um artigo, optamos por apresentar os dados referentes ao período de 2005-2017, localizados entre março e agosto de 2017. 
As bases de dados consultadas foram: Scielo, Portal de Periódicos e Banco de Teses da CAPES, Bibliotecas Digitais das instituições referenciadas no Banco de Teses da CAPES e das instituições que possuem grupos consolidados dentro da temática, conforme indicado por Saravali, Mano, Guimarães (2015). Ainda, foram consultados os Anais de alguns dos principais eventos da área de Educação, a saber: Encontro Nacional de Didática e Práticas de Ensino (ENDIPE); Reuniões Anuais da Associação Nacional de Pós-Graduação e Pesquisa em Educação (ANPED); Encontros Nacionais de Professores do Programa de Educação Infantil e Ensino Fundamental (PROEPRE) e da área de Psicologia, como o Colóquio Internacional de Epistemologia e Psicologia Genéticas, entre outros.

Os termos utilizados para as buscas foram: conhecimento social, Jean Piaget, epistemologia genética, crenças, noções sociais, Juan Delval, interação social; sempre utilizando a ferramenta de busca avançada. Outra forma de busca se deu pela análise das referências bibliográficas de cada material encontrado, objetivando localizar quem era citado e/ou se havia outros estudos que não tínhamos encontrado nas referidas bases de dados.

A análise contemplou os resumos, o campo teórico, os objetivos, a metodologia, enfatizando-se a leitura dos resultados e as referências bibliográficas.

Apresentaremos, portanto, o resultado destas buscas com foco em seis principais aspectos: veículo de publicação, autores mais produtivos, autores mais citados, instituições de origem das pesquisas, faixa etária dos participantes, delineamentos metodológicos utilizados e as temáticas abordadas nos estudos. Acreditamos que a observação destes aspectos será fundamental para a compreensão e alcance do nosso objetivo.

\section{Resultados}

Dentre o material pesquisado, foram encontradas 74 referências ou produções. A distribuição do material encontrado, conforme o tipo de 
material (artigo, tese etc.) escolhido para divulgação da pesquisa pode ser observada na Tabela 1 , a seguir:

Tabela 1: Tipos de materiais das produções encontradas

\begin{tabular}{c|c}
\hline ANAIS & 28 \\
ARTIGOS & 20 \\
DISSERTAÇÕES & 17 \\
TCCs & 5 \\
TESES & 3 \\
CAPÍTULOS & 1 \\
\hline
\end{tabular}

Fonte: Elaborada pelas autoras.

Observamos que os artigos científicos não predominam dentre os veículos mais escolhidos para a divulgação das pesquisas realizadas, superados pelos Anais de evento. Essa é uma característica marcante na área de Educação que costuma, também, ter sua produção mais distribuída em livros e capítulos de livros, embora isso não tenha sido observado no nosso levantamento. Ao somarmos os materiais que estavam no formato teses, dissertações e Tccs temos 33\% de pesquisas que não foram divulgadas, ou seja, permaneceram em seus formatos originais. Isso pode explicar a razão pela qual, muitas vezes, vemos temáticas parecidas em pesquisas diferentes que não estabelecem um diálogo entre seus dados. Tal acontecimento enfatiza a importância do estado da arte como início de qualquer processo de pesquisa, permitindo, ao pesquisador, partir daquilo que já se conhece ou se produziu na área. Soma-se a isso o fato de que não há um rigor na utilização das palavras-chave, o que certamente pode dificultar o acesso à pesquisa realizada.

Para a análise da produtividade dos autores, utilizamos a Lei do Elitismo de Price, destacando-se 16 autores mais produtivos dentre o total de autores levantados, assim como 16 autores mais citados entre os autores mais produtivos.

O princípio de Price (1963, p. 46) é de que

Ao se contar a produção total daqueles que produzem $\mathrm{n}$ artigos, 
parece que o grande número de pequenos produtores contribuem tanto quanto o total do pequeno número dos grandes produtores; num simples caso esquemático, se pode mostrar uma simetria no ponto correspondente à raiz quadrada do número total de pessoas, ou as contribuições dos grandes produtores. [...] De fato, neste caso ideal, um quarto dos artigos terão sido escritos pelas duas pessoas mais produtivas, e outro quarto por aqueles que publicaram somente um ou dois itens (PRICE, 1963, p. 46).

Nesse contexto, da tabela geral de produtividade, separou-se os autores que mais publicaram no período, seja como autor principal ou como coautor. Excluiu-se os que publicaram apenas uma vez, considerando-se que, para a construção de um sociograma de Price, consistente e não carregado de muitas informações, são relevantes aqueles autores que tiveram mais de uma publicação. Isso decorre do objetivo da pesquisa, que buscou destacar o maior número de publicações e citações da área. Dessa maneira, foram considerados aqueles que tiveram, no mínimo, 2 publicações no período, restando16 autores, como mostra a Tabela 2, a seguir.

Tabela 2: Autores mais produtivos

\begin{tabular}{c|c}
\hline AUTOR & QUANTIDADE DE PUBLICAÇÕES \\
\hline SARAVALI, E. G. & 41 \\
GUIMARÃES, T. & 17 \\
MANO, A. de M. P. & 9 \\
MONTEIRO, T. A. & 9 \\
GUIMARÃES, K. P. & 5 \\
MELCHIORI, A. P. & 5 \\
OTHMAN, Z. A. S. & 5 \\
SILVA, C. F. da & 5 \\
STOLTZ, T. & 5 \\
ALMEIDA, E. Á. F. de & 4 \\
PIECZARKA, T. & 3 \\
COOPER, I. S. & 2 \\
COSTA, R. R. S. & 2 \\
PIRES, L. B. & 2 \\
ROCHA, M. & 2 \\
SOUZA, E. F. P. de & 2 \\
\hline
\end{tabular}

Fonte: Elaborada pelas autoras. 
Separou-se, então, os autores que foram mais citados, conforme apresentado na Tabela 3:

Tabela 3: Autores mais citados.

\begin{tabular}{c|c}
\hline AUTOR & QUANTIDADE DE CITAÇÕES \\
\hline PIAJET, J. & 284 \\
DELVAL, J. & 257 \\
DENEGRI, M. & 95 \\
ENESCO, I. & 81 \\
STOLTZ, T. & 79 \\
SARAVALI, E. G. & 72 \\
OTHMAN, Z. A. S. & 43 \\
AMAR, J. & 42 \\
GUIMARÃES, T. & 41 \\
CANTELL, V. C. B. & 40 \\
INHELDER, B. & 33 \\
NAVARRO, A. & 33 \\
PIECZARKA, T. & 30 \\
TORTELLA, J. C. B. & 30 \\
ARAÚJO, R. M. B. de & 24 \\
BAPTISTELLA, E. C. F. & 22 \\
\hline
\end{tabular}

Fonte: Elaborada pelas autoras.

O critério de escolha dos autores foi que eles tivessem pelo menos 2 citações ou mais de uma publicação, levando em conta que, para a Lei do Elitismo de Price, o total de apenas uma produtividade por autor é desconsiderável. Na tabela 3 , os 4 primeiros autores não são brasileiros, assim como AMAR,J.; INHELDER, B. e NAVARRO, A.

A partir desses dados, foi possível construir um sociograma para melhor ilustrar as relações existentes entre os autores mais produtivos e os autores mais citados por eles. Sendo assim, na Figura 1, os círculos vermelhos são os autores mais produtivos e os quadrados azuis são os mais citados. A linha que sai do ponto vermelho e chega até o azul mostra que o autor vermelho citou o azul. As linhas mais grossas mostram os autores que tiveram maior número de citações. Os autores duplicados, vermelhos e azuis, são produtivos e também citados. 
Figura 1: Relações entre os autores mais produtivos e os autores mais citados.

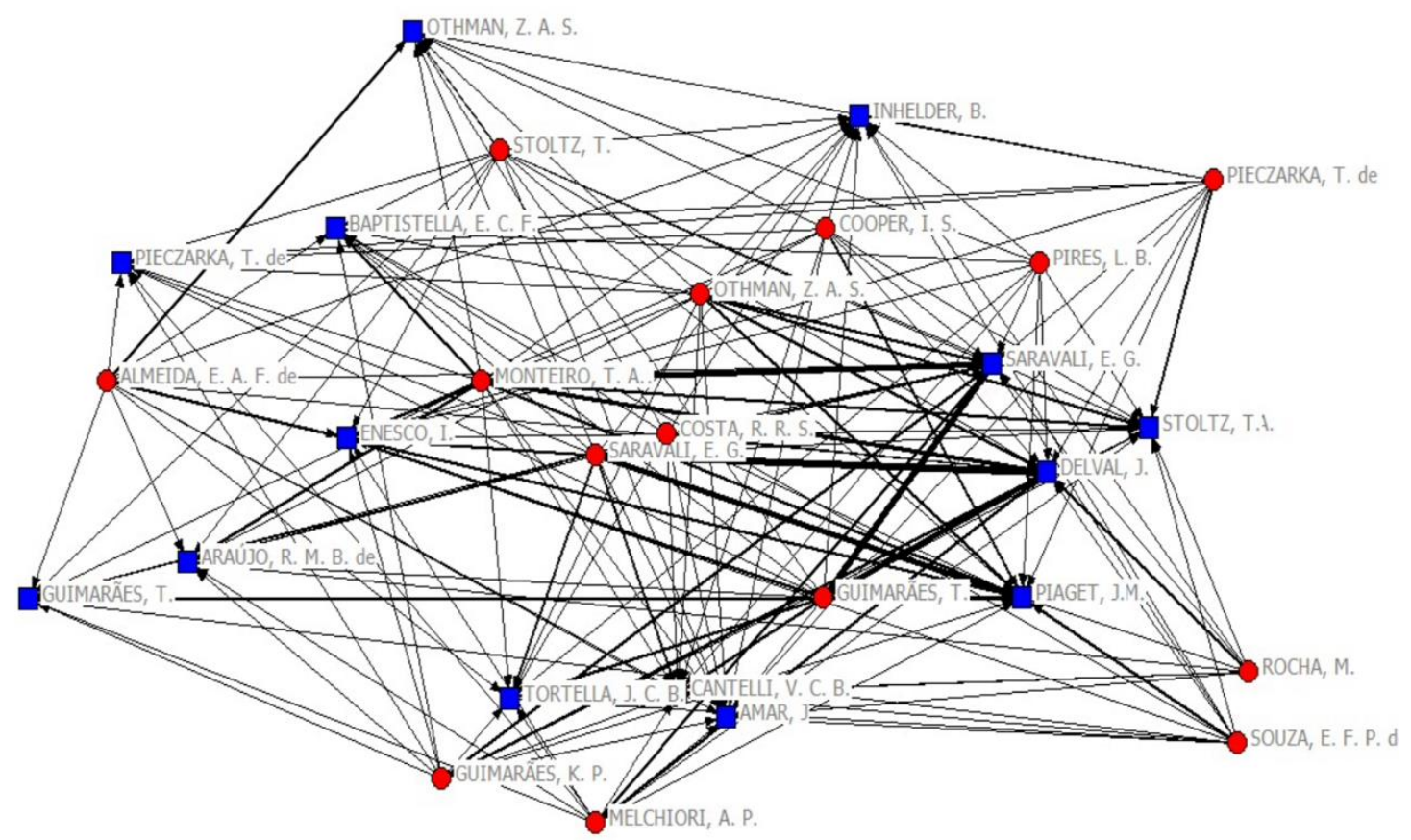

Fonte: Elaborado pelas autoras.

É possível observar que há uma forte relação entre as auto-citações: a título de exemplificação, Saravali, E. G. se cita 36 vezes. Delval, J. é um dos autores mais citadossendo, por exemplo, citado122 vezes nas publicações de Saravali, E. G. e 93 vezes por Guimarães, T.; juntamente com Piaget, J., citado 82 e 75 vezes, respectivamente, pelas mesmas autoras. Esses dois maiores valores representam $50 \%$ do total de citações.

Os dados apresentados indicam que Juan Delval é a grande referência dos trabalhos brasileiros, influenciando a maioria absoluta das pesquisas, superado somente por Piaget que compõe a fundamentação teórica das investigações. Esta influência se dá, sobretudo, pela delimitação do campo, realizada pelo espanhol, que permite ao interessado no assunto compreender as peculiaridades da adoção do conhecimento social numa abordagem piagetiana. Soma-se a isso o fato de que algumas das pesquisas brasileiras são réplicas dos trabalhos desenvolvidos no exterior, apoiando-se, sobretudo, 
nos instrumentos (entrevistas clínicas) já utilizados no contexto internacional.

As similaridades encontradas na evolução das respostas, nestes diferentes estudos e em seus contextos, nos confirmam aspectos teóricos importantes, enunciados na obra piagetiana, bem como nos alerta a respeito da relevância da continuidade das investigações na área.

A questão da auto-citação pode estar relacionada a ausência de levantamento bibliográfico de estudos na área o que gera uma visão menos abrangente do que já se estudou/publicou; algo dificultado, também, pela pouca publicação das pesquisas em bases de dados mais acessadas, ou, ainda, em veículos indexados nessas bases, tais como artigos científicos. Isso gera certa endogenia por parte dos autores que acabam referenciando somente seus próprios trabalhos e/ou os trabalhos do grupo de pesquisa do qual fazem parte.

Outro aspecto a se considerar, a respeito da auto-citação, indicaque as pesquisas sobre a construção do conhecimento social são relativamente recentes, com muitas temáticas pouco desenvolvidas o que acaba por limitar as opções de referenciamento para um autor. De qualquer forma, é sempre importante considerar que ao citar seu próprio trabalho o autor confirma uma tese que vem explorando em outros estudos.

O Gráfico 1 ilustra a dispersão, ou seja, a associação e a correlação entre os autores mais produtivos e os mais citados, das citações ocorridas dentre todos os autores analisados. 
Gráfico 1: Citações entre os autores mais produtivos.

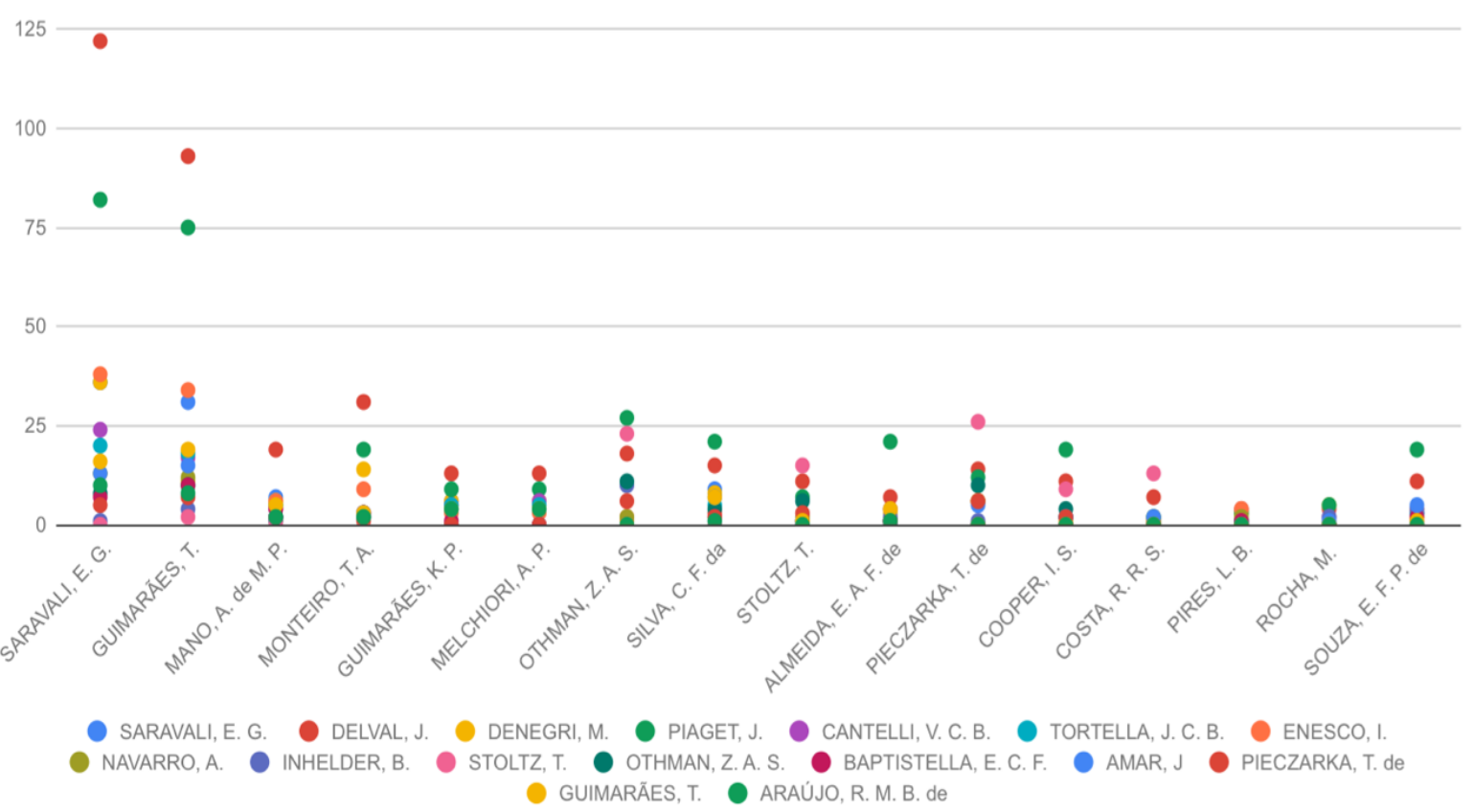

Fonte: Elaborado pelas autoras.

A linha horizontal do gráfico mostra os 16 autores mais produtivos na área e a linha vertical mostra o quanto foram citados em suas próprias produções ou nas produções de outros autores. Isso nos permite visualizar a Lei do Elitismo de Price, ou seja, o quanto os autores mais produtivos estão sendo citados e, assim, perceber qual o impacto dos mesmos para a elaboração de novas produções acadêmicas na área do estudo em questão.

A título de exemplificação, Saravali, E. G. cita ela mesma, Delval, J., Denegri, M., Piaget, J., Cantelli, V. C. V., Tortella, J. C. B., Enesco, I., Navarro, A., Inhelder, B., Othman, Z. A. S., Baptistella, E. C. F., Amar, J., Pieczarka, T. de, Guimarães T. e Araújo, R. M. B. de. Na mesma linha de pensamento, Rocha, M.cita Delval, J., Denegri, M., Piaget, J., Cantelli, V. C. B., Inhelder, B. e Amar, J.

Nessa perspectiva, podemos perceber que Delval, J. e Piaget, J. se destacam dentre os autores mais citados, enquanto que Saravali, E. G. e Guimarães, T. são salientadas como autoras mais produtivas dentre os autores mais produtivos. 
Analisamos, também, a origem desses trabalhos, considerando a Universidade em que a publicação aparece, quando se trata de teses, dissertações e TCCs; bem como o professor orientador mencionado. No caso de artigos, anais e capítulos foi considerada a autoria do trabalho e a vinculação à Universidade ou a um grupo de pesquisa, no momento da publicação. Para essa análise, optou-se por referenciar os orientadores e os grupos de pesquisa, na intenção de facilitar ao leitor o acesso aos locais em que a temática do conhecimento social é um objeto de pesquisa mais consolidado.

Deste modo, temos 47 trabalhos vinculados à UNESP -Universidade Estadual Paulista “Júlio de Mesquita Filho", campus de Marília-SP onde se concentram os estudos com delineamentos interventivos; 9 vinculados à UFPR - Universidade Federal do Paraná, com trabalhos mais específicos sobre o mundo econômico; 6 pertencentes ao Laboratório de Psicologia Genética da UNICAMP, com temáticas variadas; 6 produzidos na Universidade Federal de Viçosa - MG, nos quais predominam as temáticas relacionadas à escola e 2 no Centro Universitário Moura Lacerda. Outras 4 produções foram vinculadas às seguintes instituições, com um produto cada: UNESP -Universidade Estadual Paulista "Júlio de Mesquita Filho", campus de Araraquara-SP; USP - Universidade de São Paulo; UFPE - Universidade Federal da Pernambuco e Instituto Taquaritinguense de Ensino Superior.

O gráfico 2, a seguir, ilustra esses dados.

Gráfico 2: Instituições de origem das pesquisas

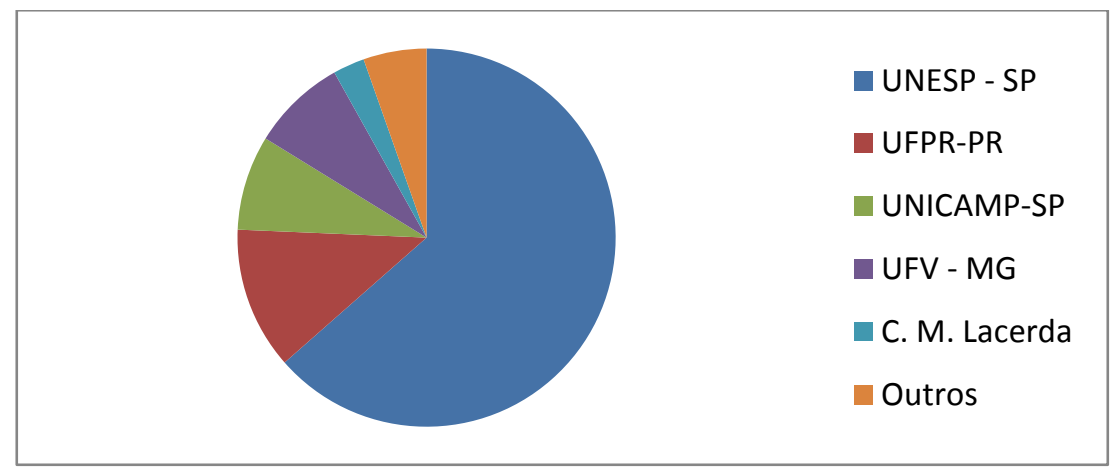

Fonte: Elaborado pelas autoras. 
$\mathrm{Na}$ Tabela 4, a seguir, encontra-se a referência aos orientadores e grupos de pesquisa, cadastrados no diretório de grupos do $\mathrm{CNPq}$, aos quais esses trabalhos estão vinculados.

Tabela 4: Grupos de pesquisas e orientadores.

\begin{tabular}{|c|c|c|}
\hline INSTITUIÇÕES & $\begin{array}{c}\text { PESQUISADOR } \\
\text { (ORIENTOU OU } \\
\text { CONDUZIU A } \\
\text { PESQUISA) }\end{array}$ & $\begin{array}{c}\text { GRUPO DE PESQUISA } \\
\text { CNPQ }\end{array}$ \\
\hline UNESP & Eliane Giachetto Saravali & $\begin{array}{l}\text { GEADEC - Grupo de } \\
\text { Estudos e Pesquisas em } \\
\text { Aprendizagem e } \\
\text { Desenvolvimento na } \\
\text { Perspectiva Construtivista }\end{array}$ \\
\hline UFPR & Tania Stoltz & $\begin{array}{l}\text { Cognição, Aprendizagem e } \\
\text { Desenvolvimento Humano }\end{array}$ \\
\hline UNICAMP & $\begin{array}{l}\text { Orly Zucatto Mantovani } \\
\text { de Assis }\end{array}$ & $\begin{array}{l}\text { LPG - Laboratório de } \\
\text { Psicologia Genética }\end{array}$ \\
\hline UFV & $\begin{array}{l}\text { Maria de Lourdes Mattos } \\
\text { Barreto }\end{array}$ & $\begin{array}{l}\text { Contextos da infância, } \\
\text { adolescência e juventude e } \\
\text { suas inter-relações na } \\
\text { família e na sociedade }\end{array}$ \\
\hline C.M.LACERDA & $\begin{array}{l}\text { Carmen Campoy } \\
\text { Scriptori }\end{array}$ & $\begin{array}{l}\text { Pesquisadora vinculada ao } \\
\text { LPG e ao GEADEC }\end{array}$ \\
\hline
\end{tabular}

Fonte: Elaborada pelas autoras.

Em todos esses estudos, observam-se, ainda, algumas questões importantes. A idade dos participantes destas investigações se concentra na faixa etária entre 6 e 14 anos o que, segundo o referencial teórico piagetiano, abarcaria os estádios pré-operatório, operatório concreto e operatório formal. Somente o estudo de Cooper (2011) foi realizado com sujeitos mais velhos, 20 e 40 anos. 
Essa concentração está diretamente relacionada ao delineamento de pesquisa mais adotado - o estudo evolutivo transversal - em que se investiga uma noção ao longo do desenvolvimento, por meio de recortes etários. Esse tipo de delineamento, presente em mais da metade das produções é, também, muito encontrado nos trabalhos internacionais.

Todavia, algo curioso nos dados brasileiros é uma diferença na evolução dos níveis de construção do conhecimento social, indicados por Delval (2002). Enquanto as pesquisas internacionais apontam para o alcance de noções mais elaboradas, classificadas como de nível III, por volta dos 14 anos, no Brasil, há um relativo atraso e mesmo em pesquisas com participantes de 16 anos não se observa a presença do nível III. Isso significa que, mesmo em idades mais avançadas, há ainda a predominância de ideias mais simplistas e rudimentares em diferentes conteúdos do mundo social (COSTA, 2009; PIECZARKA, 2009; COOPER, 2011; SARAVALI et al, 2013).

Alguns trabalhos mais recentes abordam esse atraso, objetivando explicá-lo mediante a análise do desenvolvimento cognitivo e a construção do raciocínio operatório e formal. Nestes estudos, (MANO; SARAVALI, 2014; SOUZA; SARAVALI, 2016), são apresentadas relações entre as construções sociais e as lógico-matemáticas, de tal forma que noções sociais mais elaboradas necessitam estar acompanhadas de um desenvolvimento cognitivo formal; portanto, considerando a faixa etária predominante, percebe-se um atraso no desenvolvimento que possui consequências nefastas para além dos problemas relacionados à construção do conhecimento social. De qualquer forma, para o conhecimento social, em específico, elevar a faixa etária para a realização de novas investigações é um procedimento importante e que pode nos explicar melhor a maneira como esse atraso permanece ou se dissipa.

Os delineamentos evolutivos transversais, como dissemos, são os predominantes e tem a vantagem de nos mostrar como uma noção pode se apresentar em momentos diferentes do desenvolvimento. Alguns destes estudos investigam a influência do nível sócio-econômico na construção da 
noção social em questão (PIRES; ASSIS, 2005), outros analisam a construção do conhecimento social para papéis sociais diferentes (OTHMAN, 2006), ou, ainda, em ambientes sociais diferenciados (MONTEIRO, 2013). Para o campo pedagógico, conhecer essa evolução, bem como os fatores que a influenciam ou não, pode ajudar os mestres na seleção de atividades mais condizentes com as possibilidades reais de seus alunos, respeitando-se os processos cognitivos que os mesmos percorrem.

Nesta mesma linha de trabalhos de cunho diagnóstico, temos os estudos de caso, (26\% das pesquisas encontradas), que promovem uma análise a partir de um número menor de participantes com concentração numa determinada faixa etária. Entre eles, destacamos a pesquisa de Saravali e Guimarães (2010).

Nesse sentido, é interessante notar o número pequeno de delineamentos interventivos, sobretudo aqueles voltados a auxiliar/problematizar a evolução das noções encontradas. Nos trabalhos encontrados nessa linha (SARAVALI, 2005; ARAÚJO, 2007; GUIMARÃES, 2012; ALMEIDA; SARAVALI, 2015; GUIMARÃES, 2017), percebemos como é possível promover a construção desse tipo de conhecimento, mediante a organização de intervenções pedagógicas voltadas aos processos de equilibração e que promovem um avanço na construção de diferentes noções. A realização de mais investigações com esse caráter nos parece uma necessidade importante da área de Educação.

Ainda no que se refere aos aspectos metodológicos dessas pesquisas, destacamos que o instrumento mais utilizado, em maioria absoluta, é a entrevista clínica, também denominada por entrevista semi-estruturada, motivadas (SILVA, 2009; ROCHA, 2009; ALMEIDA, 2015) ou não (GRANJA, 2012) por apresentação de figuras/fotos e pautadas no método clínico-crítico piagetiano (PIAGET, 1967; 1979). Os pesquisadores procuram, assim, aproximar-se das interpretações dos participantes por meio de uma entrevista especialmente desenvolvida para a avaliação de crenças 
desencadeadas e/ou espontâneas, interessantes aos olhos do pesquisador piagetiano.

A entrevista clínica é seguida, em menor escala, pela apresentação e análise de histórias com (RAVAGNANI, 2006) ou sem material de apoio (SOARES, 2012); realização e interpretação de desenhos (SARAVALI, 2005; GARCIA; SARAVALI, 2014); apresentação e interpretação de filmes (MONTEIRO, 2013). Com esse tipo de instrumentação, os pesquisadores evitam a abordagem direta sobre temas mais complexos, sobretudo junto a sujeitos menores.

Delval (2007) nos explica que o conhecimento social possui diferentes campos, doravante denominado por nós de temas. Cada tema explora diferentes questões sociais, com características específicas, mais ou menos complexas.

Os distintos campos da representação do mundo social possuem características diferentes e graus de dificuldade desiguais. Em alguns casos, trata-se simplesmente de compreender regulamentos simples sobre certos usos sociais. Em outros, é necessário entender sistemas simples, muitos dos quais podem ser compreendidos de uma forma concreta. Isso acontece, por exemplo, com muitas vertentes da ideia de país. Por outro lado, há casos em que se trata de entender um sistema muito amplo que, por sua vez, possui subsistemas que interagem com ele, como é o caso da organização econômica ou da organização política da sociedade, que se mostra muito complexa de se entender, e sua compreensão parece exigir instrumentos do tipo formal. (DELVAL, 2007, p. 59, tradução nossa).

Em relação aos temas pesquisados nas investigações brasileiras, temos um predomínio dos trabalhos voltados à construção do pensamento econômico. Entre eles, destacamos: a noção de lucro (PIRES; ASSIS, 2005; COSTA, 2009); a noção de mobilidade social (PIECZARKA, 2009; ARAÚJO; GOMES, 2010); e o consumo (ROCHA et al., 2012). Essa temática esteve presente em $30 \%$ das produções analisadas. 
Em seguida, temos 20\%dos estudos voltados a aspectos que envolvem as instituições escolares, como o papel do professor (GUIMARÃES; SARAVALI, 2010), as situações de aprendizagem e não aprendizagem (SARAVALI et al., 2013; GARCIA; SARAVALI, 2014) e a própria noção de escola (SARAVALI; GUIMARÃES, 2010; COSTA, 2012).

Encontramos 4trabalhos, (11\%), a respeito de questões ambientais (FERREIRA, 2008; MELLO, 2008, GUIMARÃES, 2012 e 2017) e 2,6\%, sobre violência (MONTEIRO; SARAVALI, 2011; MONTEIRO, 2013). Outros temas também apareceram de forma isolada em nosso levantamento, ou seja, com uma referência no período, em destaque: trabalho (SILVA, 2009), festas escolares (OLIVEIRA, 2010), etnia (ALMEIDA, 2015), origem da Terra e da vida (MANO; SARAVALI, 2012), direitos das crianças (SILVA, 2017).

A revisão mais cuidadosa do estado do conhecimento, antes do início de uma investigação, pode auxiliar o pesquisador a optar por temas ainda pouco explorados no Brasil. Há, ainda, a possibilidade de se investigar temas originais, específicos da nossa realidade, mediante a criação de instrumentos metodológicos novos, sem apoio nos estudos internacionais. Observamos que a repetição de algumas temáticas em estudos diferentes nem sempre nos trazem dados inéditos ou desconhecidos.

\section{Considerações}

Nosso objetivo, no presente artigo, consistiu em oferecer àqueles que estudam e/ou pesquisam a respeito do conhecimento social, numa perspectiva piagetiana, um panorama detalhado do que se investigou em nosso país entre os anos de 2005 e 2017. Pretendemos, também, oferecer ao leitor, uma análise e a sistematização desses estudos, de modo a facilitar o acesso às produções, e a seus conteúdos, e auxiliar o pesquisador em análises mais aprofundadas no que tange a alguns aspectos, a saber: veículo de publicação, autores mais produtivos, autores mais citados, instituições de 
origem das pesquisas, faixa etária dos participantes, delineamentos metodológicos utilizados e as temáticas abordadas.

Após essa extensa análise, ressaltamos alguns aspectos:

1) Os pesquisadores da área citam pouco os estudos brasileiros quando estes se encontram fora de seus próprios grupos de pesquisa. Tal fato, além de favorecer uma valorização dos trabalhos internacionais, em detrimento dos nacionais, permite a realização de pesquisas semelhantes que acabam não inovando em seus dados;

2) Há grupos constituídos no país que devem ser considerados como referências para os novos estudos da área;

3) Para a Educação, os delineamentos interventivos, ainda bastante escassos, podem ser bastante interessantes a pesquisadores, estudiosos e professores, com reais possibilidades de contribuição para a melhoria da educação básica;

4) Há necessidade em se aumentar a faixa etária dos estudos realizados com nossos participantes a fim de se verificar a construção e evolução das noções sociais em nosso contexto;

5) Há temáticas mais exploradas e outras ainda inéditas a serem pesquisadas no Brasil.

Acreditamos que todos esses trabalhos e os dados apresentados apontam para a atualidade dos estudos sobre a temática. Nesse sentido, é importante ressaltar que nosso levantamento ocorreu até o mês de agosto de 2017 e que, dada a atualidade, novos trabalhos podem ter sido realizados após esse período, ou lançados nas bases de dados que investigamos após o mês de agosto. Portanto, sugerimos que o pesquisador interessado nessa atualização rigorosa proceda a novo levantamento do ano de 2017. Sobre isso, cumpre destacar que, no momento da finalização do presente artigo, tivemos conhecimento de três novas produções: Peralta; Oliveira (2017); Freire (2017); Peralta (2017). 
Longe de esgotarmos o assunto, a sequência destes trabalhos e o aprofundamento de estudos na área contribuirão para a compreensão a respeito da construção do conhecimento social, nas áreas pedagógica, psicológica e epistemológica.

Destaque-se, ainda, a atualidade e a importância da obra piagetiana, que oferece o suporte teórico para as interpretações específicas sobre a apropriação do mundo social, evidenciadas nos estudos apresentados aqui.

\section{Referências}

ALMEIDA, E. A. Intervenção pedagógica e construção de noções étnicas por meio da pesquisa escolar: um estudo piagetiano. 2015. 280f.Dissertação (Mestrado em Educação) -Universidade Estadual Paulista, Marília, 2015.

ALMEIDA, E. A. F.; SARAVALI, E. G.Construção de concepções étnicos-raciais africanas em sala de aula. In: REUNIÃO NACIONAL DA ANPED, 37., 2015, Florianópolis. Anais... Florianópolis: ANPED, 2015.

ALVARADO, R. U. Elitismo na literatura sobre a produtividade dos autores. Ciência da Informação, Brasília, v. 38, n. 2, p. 69-79, maio/ago. 2009. Disponível em: < http://revista.ibict.br/ciinf/article/view/1246/1424>. Acesso em: 14 dez. 2017.

ARAÚJO, R. M. B. O desenvolvimento do pensamento econômico em crianças: avaliação e intervenção em classes de $3^{\mathrm{a}}$ e $4^{\mathrm{a}}$ série do Ensino Fundamental. 2007. Tese (Doutorado em Educação) - Faculdade de Educação, Universidade de Campinas, Campinas, 2007.

ARAÚJO, A. S.; GOMES, L. R. A noção de mobilidade social em adolescentes. Educar em Revista, Curitiba, v.26, n.38, set./dez., 2010, p. 193- 204. Disponível em: $<\mathrm{http}: / /$ revistas.ufpr.br/educar/article/view/12360>. Acesso em: 10 jul. 2017.

COOPER, I. S. Cartão de crédito: salvação ou perdição? Representações de adultos jovens sobre instituições financeiras e utilização de cartão de crédito. 2012. 268f. Dissertação (Mestrado em Educação) - Setor de Educação, Universidade Federal do Paraná, Curitiba, 2011.

COSTA, B. de A.Com a voz as crianças: um estudo sobre as representações de escola na educação infantil. 2012. Dissertação (Mestrado em Economia Doméstica) - Faculdade de Economia, Universidade Federal de Viçosa, Viçosa, 2012.

COSTA, R. R. S. O mundo econômico em questão: como crianças e adolescentes escolarizados entendem o lucro? 2009. 303 f. Dissertação (Mestrado em Educação) Universidade Federal do Paraná, Curitiba, 2009. 
DELVAL, J. Aspectos de la construcción del conocimiento sobre la sociedad. Educar em revista. Curitiba: Editora da UFPR, n. 30, p.45-64, 2007.

. El aprendizaje y la enseñanza de las ciencias experimentales y sociales. México: Siglo XXI Editores, 2013a.

. Descubrir el pensamiento de los niños. México: Siglo XXI Editores, 2013b.

.Introdução à prática do método clínico: descobrindo o pensamento das crianças. Tradução Fátima Murad. Porto Alegre: Artmed, 2002.

.La representación infantil del mundo social. In: TURIEL, E., ENESCO, I. y LINAZA, J. (comps.). El mundo social en la mente del niño. Madrid: Alianza, 1989.

.DEL BARRIO, C. Las ideas de los niños acerca de la guerra y la paz.MARTÍN, F.; BURILLO, F. (coord.).La guerra: realidad y alternativas. Madrid: Editorial Complutense, 1992. p.165-175.

. .; VILA, I. Los niños y Dios: ideas infantiles sobre la divinidad, los orígenes y la muerte. México: Siglo Venitiuno Editores, 2008.

; DELVAL, J. Concepciones evolutivas acerca de la fabricación del dinero. Los niveles de comprensión. Investigación en la Escuela, v. 1, n. 48, p.39-54. 2002a.

.; C__ Concepciones evolutivas acerca de la fabricación del dinero. Los tipos de respuestas. Investigación en la Escuela, v. 1, n. 48, p.55-70. 2002b.

ENESCO; I., DELVAL, J.; LINAZA, J. Conocimiento social y no social. In: TURIEL, E., ENESCO, I.; LINAZA, J. El mundo social em la mente infantil. Madrid: Alianza Editorial, 1989.

FERREIRA, L. M. Concepção de crianças de 4 a 6 anos sobre o consumo de água: uma abordagem baseada no método clínico. 2008. 136 f. Dissertação (Mestrado em Economia doméstica) - Faculdade de Economia, Universidade Federal de Viçosa, Viçosa, 2008.

FREIRE, J. F. de C. Direito de expressão, protesto e greve: noções sociais construídas por alunos de diferentes níveis de escolaridade e os processos de generalização. 2017. 124 f. Dissertação (Mestrado em Educação) - Universidade Estadual de Londrina, Londrina, 2017.

GARCIA, M. A.; SARAVALI, E. G. Aprender e não aprender por quem não aprende: um estudo evolutivo psicogenético. Linha Mestra, Campinas, n. 24, jan./jul. 2014, p. 1114-1119.

Disponível

em: $<$ https://repositorio.unesp.br/bitstream/handle/11449/115372/ISSN19809026-201424-1114-1119.pdf; sequence=1>. Acesso em: 09 fev. 2017.

GRANJA, M. C. L. O mundo econômico da criança: uma investigação psicológica sobre o dinheiro. 2012. Dissertação (Mestrado em Psicologia Cognitiva) Universidade Federal de Pernambuco, Recife, 2012. 
GODOY, E. A. de. A representação étnica por crianças pré-escolares: um estudo de caso a luz da teoria piagetiana. 1996. Dissertação (Mestrado em Educação) Faculdade de Educação, Universidade de Campinas, Campinas, 1996.

GUIMARÃES, T. A sala de aula sob o olhar piagetiano: intervenção pedagógica e construção do conhecimento social. 2017. Tese (Doutorado em Educação) Faculdade de Filosofia e Ciências, Universidade Estadual Paulista, Marília, 2017.

Intervenção pedagógica e noções sobre o meio ambiente: a construção do conhecimento social à luz da epistemologia genética. 2012. Dissertação (Mestrado em Educação) - Faculdade de Filosofia e Ciências, Universidade Estadual Paulista, Marília, 2012.

.; SARAVALI, E. G. O papel da escola e do professor numa situação de não aprendizagem: o que dizem as crianças. Educar em Revista (Impresso), p. 141-158, 2011.

LAKATOS, E. M.; MARCONI, M. de A. Fundamentos de metodologia científica. 5. ed. São Paulo: Atlas, 2003.

MANO, A. M. P. Ideias de estudantes sobre a origem da Terra e da vida e suas relações com o desenvolvimento cognitivo: um estudo psicogenético. $2013.171 \mathrm{f}$. Dissertação (Mestrado em Educação) - Faculdade de Ciências e Filosofia, Universidade Estadual Paulista, Marília, 2013.

.; GUIMARÃES, T.; SARAVALI, E. G. Estado da arte (2009-2013) de teses e dissertações sobre o conhecimento social no âmbito brasileiro. In: COLÓQUIO INTERNACIONAL DE EPISTEMOLOGIA E PSICOLOGIA GENÉTICAS, 3., 2013, João Pessoa. Anais...João Pessoa: Universidade Federal da Paraíba, 2013.

.; _ _ A construção da noção de origem da vida na terra sob o enfoque psicogenético. In: ENCONTRO NACIONAL DE DIDÁTICA E PRÁTICAS DE ENSINO, 16., 2012, Campinas. Anais...Campinas: Junqueira \& Marin Editores, 2012.

; __ G. As relações entre a construção da abstração reflexionante e o conhecimento social: um estudo psicogenético. Revista de Educação Pública, Cuiabá, v. 23, p. 759-779, 2014.

MELLO, J. de A. S. Conhecendo as idéias das crianças sobre produção e destinação do lixo doméstico e escolar.2008. 126f. Dissertação (Mestrado em Educação) Faculdade de Educação, Centro Universitário Moura Lacerda, Ribeirão Preto, $2008 . \quad$ Disponível em: $<$ http://mestrado.mouralacerda.edu.br/arquivos/dissertacoes/dissertacao_51.pdf $>$. Acesso em 7 mai. 2013.

MONTEIRO, T. A. A construção da noção de violência em crianças e adolescentes inseridos em diferentes contextos. 2013. Dissertação (Mestrado em Psicologia) Instituto de Psicologia, Universidade de São Paulo, São Paulo. 2013. 
.; SARAVALI, E. G. Psicogênese da noção de violência: um estudo evolutivo a partir da perspectiva piagetiana. Educação: Revista do Centro de Educação da UFSM, v. 36, n. 12, maio/ago., 2011, p. 279-296. Disponível em: $<$ https://periodicos.ufsm.br/reveducacao/article/view/2361>. Acesso em: 18 jan. 2018.

OLIVEIRA, R. M. Sentidos e significações das festas escolares: implicações para a construção do conhecimento social e da noção de cidadania. 2010. 99 f. Dissertação (Mestrado em Educação)- Centro Universitário Moura Lacerda, Ribeirão Preto, 2010.

OTHMAN, Z. A. Compreensão da noção de lucro em crianças e adolescentes vendedores e não vendedores de rua de Curitiba. 2006. 179f. Dissertação (Mestrado em Educação) - Setor de Educação, Universidade Federal do Paraná, Curitiba, 2006.

PERALTA, T. P. A relação entre escola e trabalho: noções sociais e processos de generalização na perspectiva de crianças e adolescentes. 98 f. Dissertação (Mestrado em Educação). Universidade Estadual de Londrina, Londrina, 2017.

PERALTA, T.; OLIVEIRA, F.N. A relação entre escola e trabalho: a realidade social na perspectiva de crianças. Educação em Questão, UFRN, Natal, v. 55, n. 45, p. 200-226, jul./set. 2017.

PIAGET, J. Psicologia e pedagogia. Rio de Janeiro: Forense universitária, 1998.

. A representação do mundo na criança. Rio de Janeiro: Record, 1979.

. O raciocínio na criança. Rio de Janeiro: Record, 1967.

PIECZARKA, T. Concepções de desigualdade social e mobilidade socioeconômica de adolescentes de escola pública de Curitiba. 2009. 255f. Dissertação (Mestrado em Educação) - Universidade Federal do Paraná, Curitiba, 2009.

PIRES, L.; ASSIS, O. Z. M. As representações das crianças sobre a noção de lucro: a construção do conhecimento social numa perspectiva construtivista. In: Encontro Nacional de Professores do Proepre, 22., 2005, Campinas. Anais... Campinas: UNICAMP/FE/LPG, 2005. p. 471.

PRICE, J. D. de S. Litle science, big science. New York: Columbia University Press, 1963.

RAVAGNANI, M. C. A. N. Autoridade autoritarismo e autonomia docente: representações de professores e alunos. 2006. 257f. Tese (Doutorado em Educação) Universidade Estadual Paulista, Araraquara, 2009.

ROCHA, M. Estudo da representação sobre os recursos monetários e a sua relação com o consumo por crianças e adolescentes, em uma perspectiva piagetiana,2009. 267f. Dissertação (Mestrado em Economia Doméstica) - Universidade Federal de Viçosa. 2009. 
et al. As representações de crianças e adolescentes sobre a inter-relação entre os recursos monetários e o consumo numa perspectiva. Revista Brasileira de Economia Doméstica, Viçosa,v.23, n. 2, 2012, p. 142-162. Disponível em: $<$ http://www.seer.ufv.br/seer/oikos/index.php/httpwwwseerufvbrseeroikos/article/vi ew/118/129>. Acesso em: 10 set. 2017.

SARAVALI, E. G. Trabalhando os direitos das crianças numa sala de educação infantil. In: REUNIÃO ANUAL DA ANPED, 28., 2005, Caxambú. Anais... Caxambú: ANPED, 2005. p.1-25.

; GUIMARÃES,T. Ambientes educativos e conhecimento social: um estudo sobre as representações de escola. Educação em revista, Belo Horizonte, v.26, n.1, 2010

.; ___ GUIMARÃES, K. P.; MELCHIORI, A. P. Crenças envolvendo o não aprender: um estudo evolutivo sobre a construção do conhecimento social. Educação em Revista, Belo Horizonte, v. 29, n.3, p. 143-176, 2013. Disponível em:<http://educa.fcc.org.br/pdf/edur/v29n03/v29n03a07.pdf $>$. Acesso em: 25 jun. 2014.

.; MANO, A. de M.; GUIMARÃES, T. As relações entre a construção do conhecimento social e lógico-matemático: o que dizem as pesquisas brasileiras. In: ENCONTRO NACIONAL DE DIDÁTICA E PRÁTICA DE ENSINO, 17., 2015, Fortaleza. Anais... Fortaleza: EdUCE, 2015.

SOARES, O. M. A. A representação de crianças e adolescentes sobre a inclusão escolar. 2012. 171f. Dissertação (Mestrado em Economia Doméstica) Universidade Federal de Viçosa. 2012.

SOUZA, E.; SARAVALI, E.G. As relações entre o raciocínio lógico-matemático e a construção do conhecimento social: um estudo evolutivo. Cadernos de Educação, Pelotas, n.53, p.101-122, 2016.

SILVA, M. O. da. Representações de crianças e adolescentes sobre trabalho numa perspectiva piagetiana. 2009. 283f. Dissertação (Mestrado em Economia Doméstica) - Universidade Federal de Viçosa, Viçosa, 2009.

SILVA, C. F. da. A construção da noção de direito em alunos do $3^{\circ}$ ano do Ensino Fundamental. uma pesquisa-ação na perspectiva piagetiana. 2017.Dissertação (Mestrado em Educação) - Faculdade de Filosofia e Ciências, Universidade Estadual Paulista, Marília, 2017.

TORTELLA, J.C.B. Amizade no contexto escolar. 1996. Dissertação (Mestrado em Educação) - Faculdade de Educação, Universidade de Campinas, Campinas, 1996. 


\title{
Comprender la economía: Educación económica y financiera en la infancia desde una perspectiva constructivista
}

\author{
Marianela Denegri Coria ${ }^{1}$ \\ Jocelyne Sepúlveda Aravena ${ }^{2}$ \\ Francisca Silva Layera ${ }^{3}$
}

\begin{abstract}
RESUMO
La globalización y los cambios estructurales a nivel económico, social y político han modificado las dinámicas relacionales en la sociedad y han otorgado un papel protagónico al consumo (BAUMANN, 2007), situación transversal a todas las edades. Un segmento especialmente relevante son los niños, quienes enfrentan las demandas del medio social y vivencian la construcción de su identidad en un entorno de alta mercantilización. En este artículo se aborda la descripción y análisis de los niveles de compresión económica desde la infancia y los actores y procesos que configuran la socialización económica, definida como un proceso de aprendizaje de pautas de interacción con el mundo económico (DENEGRI et al., 2004). A partir de un enfoque constructivista piagetiano, se propone un modelo de educación económica y financiera que se articula con los requerimientos de la formación ciudadana. Se concluye con reflexiones en torno a la importancia de la educación económica y financiera para el desarrollo de una ciudadanía crítica y económicamente empoderada desde la infancia.
\end{abstract}

PALAVRAS-CHAVE: Educación económica y financiera, socialización económica, niñez y juventud, ciudadanía.

\footnotetext{
${ }^{1}$ Doctora en Psicología. Centro de Excelencia en Psicología Económica y del Consumo, Universidad de La Frontera, Temuco, Chile.E-mail: marianela.denegri@ufrontera.cl

${ }^{2}$ Magíster en Psicología. Centro de Excelencia en Psicología Económica y del Consumo, Universidad de La Frontera, Temuco, Chile.E-mail: jocelyne.sepulveda@ufrontera.cl

${ }^{3}$ Licenciada en Psicología. Centro de Excelencia en Psicología Económica y del Consumo, Universidad de La Frontera, Temuco, Chile.E-mail: francisca.silva@ufrontera.cl
} 
Understanding economics: economic and financial education in child hood from a constructivist perspective

\begin{abstract}
Globalization and structural changes at the economic, social and political level shave modified the relational dynamics in society and have given a leading role to consumption (BAUMANN, 2007), a situation that transcends all ages. A particular lyre levant segmentist he children, who faces the demands of the social environment and experiences the construction identity in an environment of high com modification. This article deals witht he description and analysis of levels of economic compression from child hood and the actors and processes that shapes the economic socialization, defined as a process of learning patterns of interaction with the economic world (DENEGRI et al., 2004). Based on a Piagetian constructivist approach, a model of economic and financial education is proposed that articulate es with there quire ments of citizen education. It concludes with reflection son the importance of economic and financial education for the development of a critically and economically empowered citizen ship from childhood.
\end{abstract}

KEYWORDS: Economic and financial education, economic socialization, childhood and youth, citizenship.

$$
* * *
$$

\title{
Introdução
}

En Chile, la progresiva globalización y el cambio estructural em función del conocimiento y del intercambio de información, cambió para siempre las dinámicas de relaciones al interior de la sociedad, dando le un poder inusitado a ciertas prácticas, dentro de las cuales destaca de manera particular, el consumo y su valoración (BAUMANN, 2007; DENEGRI; MARTÍNEZ, 2004), no sólo como un medio de satisfacción de aquellas necesidades esenciales o básicas, sino como un referente de definición identitaria tanto a nivel individual como colectivo y una variable que influye fuertemente en La percepción de bien estar subjetivo de la población. 
A su vez se han producido profundos cambios en los valores de la sociedad, la que ha cambiado desde una concepción de austeridad altamente valorada, hacia la búsqueda del hedonismo y la satisfacción inmediata de los deseos, flexibilizando el concepto y actitud hacia La deuda, lo que ha permitido mayor desarrollo económico (mayor consumo), pero al mismo tiempo ha aumentado El riesgo de las operaciones financieras especialmente en las poblaciones más vulnerables como es el caso de los jóvenes, especialmente de los adolescentes, por el impacto que ello puede tener em su futura seguridad financiera (NORVILITIS; SAZBLICKI; WILSON, 2003; NORVILITIS; SANTA MARÍA，2002; LYONS, 2004;AMAR et al., 2003; DENEGRI; MARTÍNEZ; ETCHEBARNE, 2007; LUSARDI; TRUFANO, 2009).

Sin embargo, las modernas sociedades globalizadas no necesariamente entregan a sus ciudadanos las herramientas para comprender La complejidad de los cambios a los que están cotidianamente expuestos. Uno de estos vacíos se vincula a las formas de incorporar el conocimiento económico necesario para comprenderlos profundos cambios que ha sufrido la humanidad como producto de los procesos globalizadores (KHAN; NARU, 2006; LUSARDI; TRUFANO, 2009; LUSARDI; MITCHELL, 2013; BRAUNSTEIN, 2008; LUSARDI; MITCHELL, 2007; LUSARDI; TRUFANO, 2009; ORGANISATION FOR ECONOMIC COOPERATION AND DEVELOPMENT [OECD]，2005a， 2005b，2008，2009,PNUD， 2009, DENEGRI; MARTÍNEZ, 2004; SALEMI, 2005; SANTOMERO, 2003).

En este escenario, resulta crucial apoyar a niños y adolescentes para que comprendan las cuestiones financieras y desarrollen competencias, actitudes y valores que les protejan frente a la presión constante para un consumo poco reflexivo. Esta generación, según lo establecen los análisis de la OECD (2012) deberá soportar muchos más riesgos financieros en la edad adulta que sus padres, especialmente aquellos vinculados a las estrategias de logro de ahorro en un entorno laboral cada vez más inestable, la 
planificación para la jubilación y la necesidad de cubrir sus necesidades personales y familiares de cuidado de la salud.

\section{La comprensión de la economía en la niñez y adolescencia}

A modo de contexto, cerca de 2,5 billones de personas, o un tercio de La población mundial, se espera que sean menores de 18 años para el año 2020 (ZMUDA, 2011). Estos antecedentes permiten comenzar a dimensionar La estrecha vinculación entre economía y niñez/adolescencia.

La mayor parte de las primeras investigaciones que se preguntaron ¿cómo los niños y niñas llegan a comprender el mundo económico? se centraron en la comprensión de los conceptos económicos en la infancia y adolescencia a partir de la perspectiva piagetana del desarrollo cognitivo y comprobaron que en la niñez se construyen activamente explicaciones acerca del mundo económico y que estas explicaciones están a la base de sus conductas de consumo (BERTI; BOMBI, 1988; BERTI; GRIVET, 1990; JAHODA, 1983; FURTH, 1980). Ello nos permitió comprender que las ideas que expresan los niños acerca del mundo social son cualitativamente diferentes de las de los adultos y que el cambio cognitivo, evidenciado en el desarrollo hacia una mayor coherencia y organización interna, expresa un proceso de construcción que no puede ser atribuido solo a la influencia de los conocimientos transmitidos por los adultos, sino a un esfuerzo activo del niño por seleccionar, organizar y hacer coherentes las experiencias e informaciones sociales de acuerdo a las posibilidades de su aparato cognitivo. Esto implica que la comprensión de la economía puede ser interpretada como un proceso de diferenciación y articulación en el cual el niño construye reglas cada vez más precisas y complejas (FURTH, 1980; JAHODA, 1983, 1984; BERTI; BOMBI, 1988; BERTI; GRIVET, 1990).

A partir de un enfoque psicogenético, nuestro equipo de investigación también ha realizado una serie de trabajos sobre comprensión de la economía en la infancia y adolescencia en España, Chile, Colombia y Brasil 
(AMAR; ABELLO; DENEGRI, 2001; ARAUJO, 2009; DENEGRI, 1995a; 1995b; 1997; DENEGRI et al., 1998; DENEGRI et al., 2000). Los resultados obtenidos mostraron la existencia de una secuencia evolutiva caracterizada por un patrón de cambio conceptual en una construcción progresiva en una secuencia evolutiva, en la cual el razonamiento en torno a la economía se complejiza a medida que los sujetos avanzan en edad, por lo que los cambios en las representaciones o explicaciones que los individuos manejan para explicarse la economía, responden a etapas de un proceso constructivo y progresivo mediado por factores como la edad, el contacto con el dinero y las oportunidades de socialización económica (DENEGRI, 1995b, AMAR et al., 2002; Ello nos permitió postular la presencia de un modelo de Psicogénesis del pensamiento económico que se expresa en tres niveles de desarrollo: Nivel I Pensamiento extraeconómico y económico primitivo (correspondientes a los niños de 6 a 9 años), Nivel II Pensamiento económico subordinado (que corresponde a los niños mayores de 10 años, adolescentes e incluso algunos adultos) y Nivel III Pensamiento económico Independiente o inferencial (correspondientes a adolescentes mayores y adultos).

Al someter este modelo a validación empírica, se observan diferencias significativas en la distribución de los sujetos por edad para cada uno de los niveles, apreciándose que los niños de 6 a 10 años tienden a ubicarse mayoritariamente en un nivel de pensamiento económico primitivo, mientras que los sujetos entre 11 a 14 años se ubican en el nivel de pensamiento económico subordinado. Ello corresponde a lo esperable de acuerdo a su manejo de informaciones económicas y a las herramientas cognitivas que disponen. Sin embargo, llama la atención el alto porcentaje de adolescentes entre 15 a 18 años que permanece en un nivel de pensamiento económico subordinado y el escaso porcentaje que alcanza el nivel de pensamiento económico inferencial, que sería el esperable teóricamente para su edad.

Aparecen además diferencias significativas entre niveles socioeconómicos, donde los adolescentes de nivel socioeconómico bajo tienden 
a permanecer mayoritariamente en el nivel de pensamiento económico subordinado en comparación con los individuos del nivel socioeconómico alto que alcanzan el nivel inferencial y, por lo tanto, logran una comprensión más eficiente del sistema económico y del origen y circulación del dinero. Algo similar sucede asociado al lugar de residencia, apreciándose que los adolescentes que proceden de ciudades multifinancieras desarrollan una comprensión más completa y articulada del funcionamiento económico (AMAR; ABELLO; DENEGRI, 2001; ARAUJO, 2009; DENEGRI, 1995a; 1995b; 1997; GEMPP et al., 2006; DENEGRI et al., 1998; DENEGRI et al., 2000; DENEGRI; MARTÍNEZ; ETCHEBARNE, 2007).

Los niños y jóvenes se socializan económica y financieramente no solo en las redes educativas formales sino también de lãs interacciones com los agentes de socialización como amigos, familia y medios de comunicación (HILGERT, HOGARTH y BEVERLY, 2003), siendo los puntos que abordaremos a continuación.

\section{La socialización económica en la infancia: actores y procesos}

La socialización económica es definida como un proceso de aprendizaje de pautas de interacción con el mundo económico mediante La construcción activa por parte del niño, de conocimientos, destrezas, estrategias, patrones de comportamiento y actitudes acerca del uso del dinero y su valor en La sociedad. En este proceso intervienen varios agentes de socialización, siendo la familia el primero de ellos y probablemente uno de los más importantes (DENEGRI, PALAVECINOS, GEMPP, y CAPRILE, 2005).

Los niños y jóvenes se socializan económica y financieramente en las interacciones con los agentes de socialización como La escuela, amigos, familia y medios de comunicación (HILGERT, HOGARTH y BEVERLY, 2003). La familia, especialmente los padres, constituyen una fuente primaria en la valoración del dinero y el ahorro las tendencias actitudinales hacia el endeudamiento y la comprensión de cómo funciona el mundo 
económico y financiero (CLARKE, HEATON, ISRAELSEN y EGGETT, 2005; (NORVILITIS et al., 2006; LYONS, SCHERPF y ROBERTS, 2006).

En la siguiente figura (Figura 1), podemos observar cómo interactúan los distintos actores en el proceso de socialización económica y cómo ello redunda en su nivel de alfabetización económica (AE) lo que habilita o no al individuo para tomar decisiones.

Figura 1: Modelo de Socialización Económica

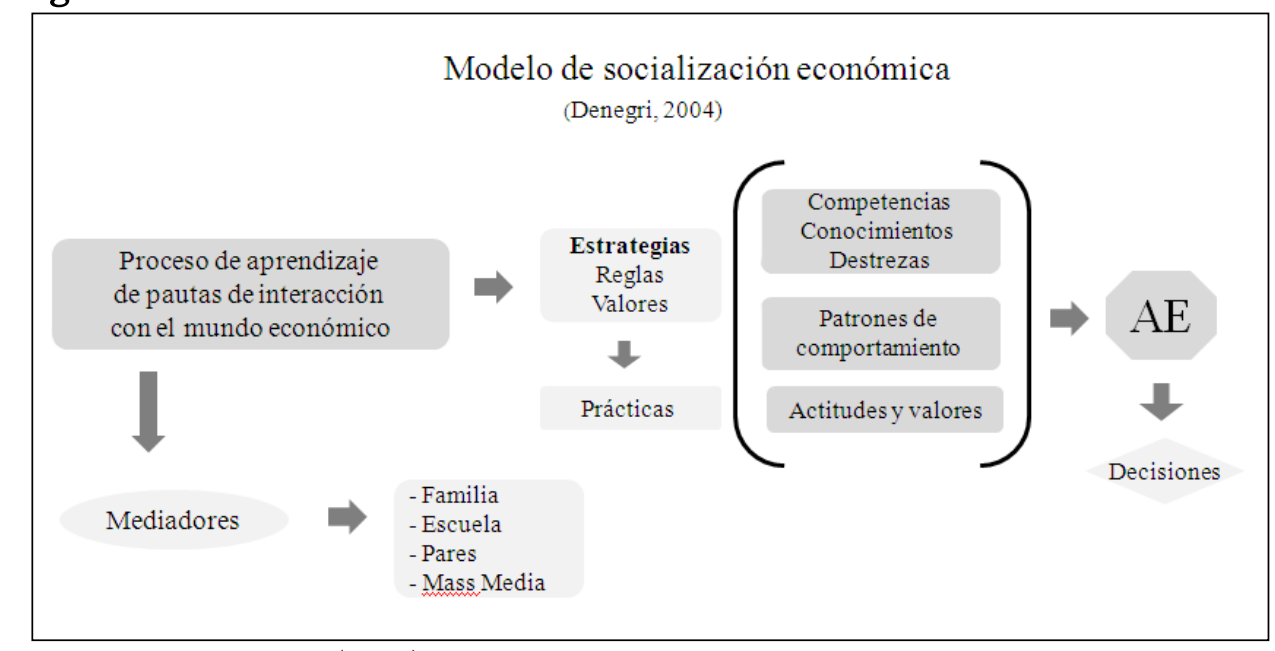

Fuente: Denegri et al. (2005).

En nuestro equipo de trabajo hemos investigado las estrategias y prácticas de socialización económica utilizadas por familias urbanas de diversos niveles socioeconómicos En concordancia con los hallazgos disponibles en la literatura previa (DENEGRI et al, 2005; MORI; LEWIS, 2001), los resultados encontrados indican que la socialización económica comienza tempranamente durante la niñez. Antes de llegar a comprender la complejidad del mundo de la economía los niños han observado, y probablemente imitado, una gran cantidad de estereotipos acerca del consumo, por lo que a un nivel simple han tenido experiencia directa con una amplia variedad de actividades económicas; tal experiencia aumenta durante los años escolares. Sin embargo, también se aprecia que niños y jóvenes adquieren la mayoría de las informaciones y conductas como consumidores de modo informal, ya sea copiando experiencias de sus padres, 
de sus pares y/o por influencia de medios de comunicación de masas, no teniendo acceso a una formación intencionada que les prepare para interactuar con una sociedad de consumo cada vez más agresiva y compleja. Ello es evidente al observar la discordancia entre el discurso de los padres y el de los niños especialmente en cuanto a las prácticas y valores que los adultos dicen fomentar en sus hijos.

Al mismo tiempo, se observa que los padres utilizan como estrategia principal de socialización la "conversación” especialmente valórica y muy cercana a lo que Piaget llamaba "lecciones morales" (PIAGET, 1971; DENEGRI, 2005), donde se repiten varios de los discursos valóricos que los mismos padres internalizaron de sus familias de origen. Si bien la transmisión valórica es un importante elemento de socialización, en el caso de la socialización económica es insuficiente si no va acompañada del desarrollo de competencias para un consumo reflexivo. En el caso de las familias del estudio (DENEGRI et al, 2005), se apreció como los padres dicen "enseñar a comprar" y "ahorrar", sin ser percibida esta enseñanza como tal; por el contrario, a espaldas de los padres los niños comienzan a desarrollar tempranas conductas de endeudamiento informal que pueden marcar futuros estilos de consumo (DENEGRI et al., 2005; DENEGRI; GEMPP; MARTÍNEZ, 2005; DENEGRI et al., 2008). Llama La atención que si bien en el discurso de los padres se reconoce La importancia de educar en el uso del dinero a sus hijos; esto no parece reflejarse coherente mente en las prácticas cotidianas de socialización económica que ellos llevan a cabo. Pese a que los padres dicen valorar un estilo de vida austero, con sus hijos se comportan más bien como consumidores impulsivos, donde la reflexión y los límites a las peticiones de consumo de los niños parecen ser bastante difusas. Por otro lado, si bien valoran la importancia de aprender a administrar el dinero, no fomentan la autonomía ni La responsabilidad efectiva de dicha administración en sus hijos.

En síntesis, los resultados de este conjunto de investigaciones señalan la presencia de estilos diferenciales de socialización económica relacionados 
con el nivel socioeconómico de la familia. En el nivel socioeconómico alto existe un patrón característico de atesoramiento y gasto racional donde las prácticas de socialización económica son más sistemáticas y organizadas. Por su parte, en el nivel socioeconómico medio se observa un patrón consumista a través del escaso ahorro y el gasto no planificado, donde el discurso y las prácticas concretas de socialización generadas por los padres son contradictorias. Por último, en el nivel socioeconómico bajo existe un patrón caracterizado por la supervivencia presentista, los niños consideran destinar gran parte de sus recursos monetarios en necesidades de sus familias, viéndose al dinero más como un instrumento de ayuda familiar por sobre las necesidades personales, sumado a la sensación de incontrolabilidad de la economía individual (LLANOS et al., 2008).

En la misma línea de socialización económica, otras investigaciones han señalado como un factor relevante a la influencia de los pares, siendo esto particularmente fuerte en la adolescencia. Al respecto, se propone que los adolescentes aprenden los aspectos racionales de consumo de sus padres y los aspectos sociales y afectivos relacionados con el materialismo de sus pares (MOORE, 2003), fundamentalmente por la necesidad de pertenencia e identificación, propia del proceso de construcción de identidad adolescente. En esta perspectiva, se interpreta la presión ejercida por los pares como la razón por la que los adolescentes valoran los bienes materiales y las marcas populares moldeando actitudes, valores, normas y aspiraciones de consumo (BATRA et al, 2001) y afectando la elección de productos y marcas (WOOTEN; REED, 2004) e influyendo en el desarrollo, por modelaje, de competencias financieras y económicas (KRETSCHMER; PIKE, 2009, MASCHE， 2010;NEYMOTIN， 2010; OYSERMAN; DESTIN， 2010; FRIEDLINE; ELLIOT; NAM, 2013). Esto sucede en un contexto evolutivo donde los jóvenes están madurando sus destrezas de autocontrol y, por lo tanto, son más susceptibles al poder del mercado (COLLINS; STEINBERG, 2006). 
Sin embargo, no son solo la familia y los pares quienes juegan un rol de mediador en los procesos de socialización y alfabetización económica en la infancia, también es debe relevarse la mediación simbólica ejercida por los medios de comunicación masiva, inicialmente la televisión y más recientemente Internet. Ello constituye una influencia que compite con la familia dada la gran cantidad de tiempo que le dedican los niños cotidianamente (BUKSTEIN, 2007). Durante este tiempo son bombardeados por persuasiones publicitarias de las que no siempre tienen conciencia y fidelizados tempranamente hacia objetos de consumo tanto presentes como futuros. Ello se amplifica si consideramos las características del pensamiento infantil y preadolescente, donde la transición entre la lógica concreta y abstracta, entre lo mágico y lo real, influye profundamente en las condiciones de construcción de identidad (DENEGRI; MARTÍNEZ, 2004), lo cual es aprovechado por las industrias del marketing y los anuncios publicitarios para inducir la identificación del yo con los productos que se consumen (CNTV, 2004; OZGEN, 2003; PAGE; RIDGWAY, 2001). En suma, los medios presentan una doble influencia en la conducta económica infantil; por una parte, constituyen una forma permanente de penetración y persuasión, por ende, de estimuladores de patrones de consumo, y por otra pueden tener un importante rol en el desarrollo de propuestas educativas más motivantes y cercanas a la cultura de los niños (DEL VALLE, 2000; 2003). Sin embargo, lo anterior implica también el requerimiento de desarrollar actividades que permitan "una lectura crítica" de los medios y la preparación de profesores.

\section{Los desafíos de La educación económica y financiera en la formación ciudadana de niños y adolescentes: Una mirada constructivista}

La educación económica y financiera debe estar presente desde muy temprano en la vida de niños y niñas, incorporando la reflexión sistemática sobre problemas económicos reales de la vida cotidiana para ayudarlos a 
diferenciar aquellos aspectos que se consideran claves para comprender el mundo social. Uno de ellos es la comprensión de la diferencia entre concebir a la vida como una secuencia de eventos que suceden fuera de nosotros y donde no tenemos posibilidad de control versus la conceptualización de los fenómenos sociales como resultado de elecciones realizadas por individuos y colectivos. El segundo aspecto clave implica la toma de conciencia que en cada decisión hay implicados costos y beneficios y que ellos deben ser evaluados antes de actuar. Ambos aspectos implican el desarrollo de La capacidad de relacionar procesos, evaluar cursos de acción y reflexionar sobre consecuencias, todo lo cual forma parte importante de las capacidades cognitivas, de comportamiento y actitudinal es necesarias para la instalación de una lógica ciudadana en contraposición con una postura pasiva frente a la realidad social (DENEGRI; MARTÍNEZ, 2004).

Para comprender la complejidad de los procesos que intervienen em el comportamiento económico, es necesario considerar que este no tiene lugar en el vacío o separado de otros aspectos del comportamiento humano, sino que involucra a la persona en su totalidad, con su historia, características personales, sociales y culturales y al contexto general en que ocurre el comportamiento. Por lo tanto, las propuestas de educación financiera deben necesariamente complementarse con la educación ciudadana y con el logro de alfabetización política. Así, los estudios coinciden en la necesidad de un abordaje constructivista que la enlace con problemas de la vida cotidiana que requieran de organización personal y colectiva para ser enfrentados, y especialmente con el aprendizaje de conceptos, el desarrollo de procesos de razonamiento y pensamiento económico y la estimulación de actitudes prosociales que incorporen la alfabetización económica y financiera como parte de las bases de la educación para la ciudadanía (SANTOMERO, 2003; SUITER et al., 2005; LUSARDI; MITCHELL, 2007; LUSARDI; MITCHELL, 2013; THALER; SUNSTEIN, 2008; VAN ROOIJ; LUSARDI; ALESSIE, 2007). 
Por ello, Murphy y Yetmar (2010) señalan que la educación financiera debe estar orientada al cambio de comportamiento y enfatizan la importancia de la toma de decisiones en contextos reales y el enfrentamiento a conflictos cognitivos, ello para que los estudiantes puedan poner efectivamente a prueba sus conocimientos financieros. Otro aspecto clave, es la diferenciación entre los públicos o segmentos hacia los cuales irán dirigidas las estrategias de educación financiera, y allí cobra relevancia considerar que la comprensión del mundo financiero tiene sus particularidades a lo largo del ciclo vital y que ello es especialmente relevante en el caso de los niños y jóvenes, siendo muy importante La consideración del nivel de desarrollo cognitivo y social de los niños y sus propias concepciones en torno al mundo del dinero, la economía y el consumo.

En términos más específicos, la alfabetización financiera es la habilidad de hacer juicios informados y tomar decisiones eficaces para la administración actual y futura del dinero. Incluye la habilidad de comprender las diferentes opciones financieras, planear para el futuro, gastar sabiamente, y saber manejar los retos asociados con las situaciones cotidianas de la vida como la posible pérdida del empleo, el ahorro para el retiro o pagar la educación de los hijos (COHEN; CANDACE, 2011). La alfabetización económica y su complemento financiero se cristalizan conductualmente en el concepto de capacidad financiera, definida como la habilidad y oportunidad de usar el conocimiento y las habilidades implicados en la alfabetización económica y financiera, combinando conocimiento, habilidades y actitudes, con la oportunidad de aplicarlas satisfactoriamente para resolver problemas de la vida cotidiana (COHEN; CANDACE, 2011; LUSARDI; MITCHELL, 2013).

En este contexto, hemos construido una definición de lo que vamos a entender como educación económica, la que se concibe como una acción educativa intencionada cuyo objetivo es aportar a los participantes, las nociones económicas básicas y las estrategias para tomar decisiones 
adecuadas que les permitan situarse ante la sociedad de consumo como personas conscientes, críticas, responsables y solidarias conscientes de sus deberes y responsabilidades como ciudadanos y por lo tanto capacitados para ejercer plenamente su ciudadanía económica.

Estas ideas quedan reflejadas en el modelo de Educación Económica y Financiera (Figura 2) que nuestro equipo ha desarrollado en los últimos años y que se ha validado empíricamente en varias investigaciones.

FIGURA 2: Modelo de Educación Económica y Financiera

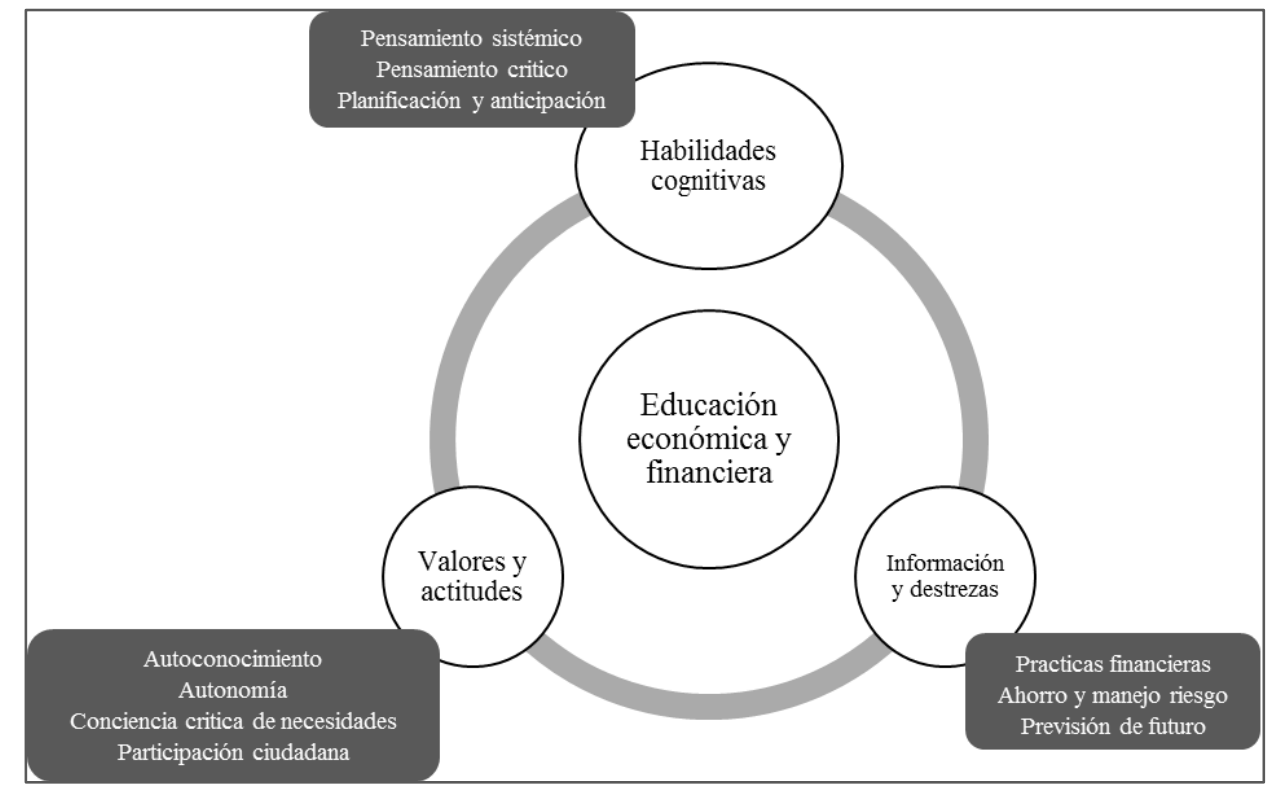

Fuente: Denegri et al., (2014).

Desde una perspectiva constructivista, el modelo articula tres componentes esenciales: 1) Habilidades cognitivas de base; 2) Información y destrezas y 3) Valores y actitudes que son de carácter transversal y cumplen la función tanto de articular los distintos contenidos como aumentar la probabilidad de transferirlos al comportamiento.

Las habilidades cognitivas incluyen el pensamiento sistémico o complejo, pensamiento crítico y capacidad de planificación y anticipación. El pensamiento sistémico se traduce en la habilidad cognitiva de establecer relaciones y complementos y percibir la realidad como un todo. Esta habilidad resulta crucial para comprender los procesos económicos y su 
impacto global. La otra habilidad cognitiva fundamental es el pensamiento crítico, entendido como la capacidad de realizar juicios documentados, discriminar la calidad de la información, exponer correcta y ordenadamente y pensar de manera autónoma, es decir, realizar juicios y tomar decisiones luego del análisis, evaluación y contraste de argumentos, afirmaciones, puntos de vista y evidencias. Habilidad vital para la ciudadanía económica y para el consumo inteligente y sustentable. Finalmente, se incluye la capacidad de planificación y anticipación definida como el proceso mental que permite seleccionar las acciones necesarias para alcanzar una meta, decidir sobre el orden apropiado, asignar a cada tarea recursos necesarios y el establecer el plan de acción adecuado, aspecto vital para la planificación financiera.

El componente de información y destrezas de comportamiento, está constituido por el conjunto de conocimientos y procedimientos de acción que permiten al individuo desarrollar prácticas financieras de uso y administración del dinero eficientes en la vida cotidiana, desarrollar estrategias de ahorro y de manejo del riesgo financiero y planear su futuro financiero previendo el riesgo financiero y desarrollando un plan. En este último punto se incluyen las estrategias de aseguramiento y planeación de ahorros previsionales para un futuro retiro de la vida laboral.

Finalmente, el componente de valores y actitudes es esencial para el desarrollo de una postura crítica ante los impactos del modelo económico en la conducta personal y social y proporciona herramientas para discernir y evaluar el impacto que el comportamiento económico y financiero tiene en la calidad de vida y en el desarrollo personal. Se incluyen aquí el autoconocimiento que permite comprender las motivaciones y emociones a la base de la toma de decisiones económicas, la autonomía que posibilita tomar distancia de las presiones del mercado y publicidad, la conciencia crítica de necesidades que permite diferenciarlas de los deseos y la valoración del ejercicio responsable de la ciudadanía económica. Los componentes interactúan entre si y deben ser abordados en forma transversal e integrada 
para el logro del propósito de una educación financiera crítica y orientada a la formación ciudadana.

Así, este modelo también hace eco de los componentes que el propio Piaget (1986) incorpora como parte de su noción de sociedad y de construcción colectiva de operaciones donde el propio entorno social es concebido como un sistema de actividades cuyas interacciones elementales consisten en acciones que se modifican las unas a las otras de acuerdo con ciertas leyes de organización o de equilibrio y que incorporan acciones técnicas de fabricación y de utilización, acciones económicas de producción y distribución, acciones morales y jurídicas de colaboración o constreñimiento y opresión y acciones intelectuales de comunicación, de búsqueda de información y de crítica mutua.

En cuanto al momento idóneo para incorporar la educación financiera en la infancia, las investigaciones señalan que a partir de los 10 u 11 años están presentes tanto las competencias cognitivas como la autonomía relativa, el interés progresivo en el mundo social $\mathrm{y}$ una mayor susceptibilidad a la influencia del grupo de pares y los medios de comunicación (DENEGRI, 1995b; PIAGET, 1964), este segmento resulta especialmente interesante para focalizar estrategias de educación económica y financiera. El impacto que puede tener una intervención en este grupo etáreo es estratégico dado que por sus características agrupan en si tres tipos de mercado: un mercado presente por la cantidad de recursos que manejan y su autonomía para tomar decisiones de consumo, un mercado futuro dado que en estas edades se establecen actitudes y patrones de consumo que pueden persistir en la edad juvenil y adulta y un mercado de influencia por el impacto que tienen en las decisiones de consumo familiar. Por lo tanto, el logro de perfiles de consumo responsable, eficiente e informado puede impactar no sólo a nivel personal sino también familiar y social.

En cuanto a contenidos, la mayoría de los modelos de educación económica y financiera, coinciden en que es fundamental incorporar la 
relación entre al menos tres variables que interactúan en el comportamiento económico, ellas son: (1) las elecciones económicas, (2) los conceptos económicos y (3) las metas del comportamiento (SCHUG, 1982; 1996; SCHUG; HAGEDORN, 2005). Ello es coincidente, como plantea DONGOMONTOYA (2008) con el sentido del aprendizaje desde la óptica piagetana que implica colocar a los niños y adolescentes en la condición de verdaderos sujetos activos del aprendizaje y por esto en situaciones donde la investigación y el descubrimiento posibiliten una verdadera creación de conocimiento.

La importancia de la experiencia y la actividad en la construcción de conceptos económicos y financieros queda en evidencia en aquellas investigaciones que han mostrado que los niños y los adolescentes que participan activamente en el manejo autónomo de dinero, que deben establecer un presupuesto y que han tenido experiencias de ahorro bancario o de otros productos financieros tienen mayor probabilidad de ahorrar e invertir y ser más cuidosos en sus finanzas personales cuando adultos (JOHNSON; SHERRADEN, 2007; KOTLIKOFF; BERNHEIM, 2001; NATIONAL ENDOWMENT FOR FINANCIAL EDUCATION [NEFE], 2004).

\section{Conclusiones}

La evidencia empírica demuestra que las personas que han estado expuestos tempranamente a procesos de educación financiera desarrollan comportamientos más proclives hacia el ahorro, la planificación de recursos y la previsión de futuro (BERNHEIM; GARRETT; MAKI, 2001; COLE; SAMPSON; ZIA, 2010; LUSARDI, 2009). En esta misma línea, se ha encontrado que mayores niveles de alfabetización financiera se relacionan no solo a la creación de activos, sino también con más capacidades de gestión de la deuda, donde los individuos optan por hipotecas menos costosas, evitando los altos intereses y cargos adicionales (GERARDI; GOETTE; 
MEIER, 2010; LUSARDI; TRUFANO, 2009a; MOORE, 2003). Esta evidencia sugiere una relación causal directa entre educación financiera y cambios en el comportamiento, es decir, un impacto directo en la competencia financiera. Por otra parte, otros estudios señalan una correlación positiva entre el indicador de capital humano evaluado por la prueba PISA y el nivel de alfabetización económica de la población (JAPELLI, 2009), lo que la sitúa como una variable que interviene en el nivel global de desarrollo de un país.

Todas las experiencias internacionales parecen indicar que la educación económica y financiera beneficia a los individuos en todas las etapas de la vida. A los niños les hace comprender el valor del dinero y del ahorro; a los jóvenes les prepara para la vida independiente y a los adultos les ayuda a planificar decisiones básicas como la compra de una vivienda, el mantenimiento de una familia, la financiación de los estudios de sus hijos o a preparar la jubilación.

En términos de beneficios globales, en el plano individual la educación económica y financiera, contribuye a mejorar las condiciones de vida de la población al proporcionar las herramientas necesarias para la toma de decisiones relativas a la planeación para el futuro y a la administración de los recursos, así como información pertinente y clara que da lugar a un mayor y mejor uso de los productos y servicios financieros. Así, los usuarios con mayores niveles de educación financiera tienden a ahorrar más, lo que normalmente se traduce en mayores niveles de inversión y crecimiento de la economía en su conjunto.

A su vez, una ciudadanía educada financieramente contribuye a mejorar el desempeño de las instituciones generando un intercambio de información de mayor calidad entre las instituciones financieras y sus clientes, apoyando la construcción y/o restablecimiento de las confianzas en el sistema financiero, aumentando la competitividad e innovación y mayores mecanismos de autorregulación del propio mercado ante la necesidad de rendir cuentas de su acción frente a una ciudadanía informada y activa. 
Resulta crucial apoyar a los niños y adolescentes para que comprendan las cuestiones financieras y desarrollen competencias, actitudes y valores que les protejan frente a la presión constante del mercado hacia un consumo poco reflexivo y al respecto, la mayoría de los autores coinciden en la importancia que tiene la alfabetización económica y financiera temprana, dado que es en la infancia y adolescencia donde se instalan la mayoría de las actitudes y valores que sustentarán gran parte del comportamiento económico adulto.

Bajo estos principios, surge la interrogante de “¿Qué se debe enseñar en la escuela?, para lo cual la evidencia de la literatura y nuestra propia experiencia en proyectos de aula en educación económica y financiera se orientan a la importancia de habilidades para planificar y gestionar las finanzas personales, la comprensión de los mecanismos de ahorro, endeudamiento e impuestos, la anticipación de riesgos y evaluación de recompensas y aspectos más específicos de los derechos del consumidor y la instalación de actitudes y valores proclives a un uso racional de los recursos y la valoración del ahorro y consumo inteligente (DENEGRI et al., 2014).

Si bien es importante el papel de agente socializador y educador de la familia en el ámbito económico, no es posible ignorar que los propios padres también carecen en muchos casos de una adecuada alfabetización económica y ello se traduce en la transmisión intergeneracional de pautas de consumo y uso del dinero poco reflexivas o ineficientes.

Por ello, se debe intencionar la inclusión curricular temprana de la educación económica y financiera desde la educación básica mediante aproximaciones didácticas que potencien la reflexión, el pensamiento crítico y el trabajo cooperativo para el desarrollo de actitudes y destrezas que permitan a niños y niñas el control y especialmente el autocontrol de sus procesos de consumo. Es evidente que en esta aproximación, el aporte del enfoque constructivista y su conocimiento de las formas sobre cómo se construye el conocimiento tanto en el aula como fuera de ella y las variables que intervienen en este proceso, resulta indispensable para el diseño de 
programas educativos que efectivamente respondan a las necesidades y características de los estudiantes y aporten efectivamente a su formación como ciudadanos críticos y propositivos (PIAGET, 1972).

En conclusión, introducir los temas económicos en el currículo escolar y con ello lograr que nuestros niños y jóvenes sean alfabetizados económicamente, presenta una serie de ventajas específicas. En primer lugar, el desarrollo de las destrezas en el uso y administración del dinero puede ayudar a niños y jóvenes a prepararse de manera real para los problemas de toma de decisiones económicas que deberán enfrentar en la vida adulta, y, por ello, ayuda a la transición entre la vida escolar y laboral. Por otra parte, la alfabetización económica requiere del desarrollo de estrategias de planificación, toma de decisiones y resolución de problemas, las cuales constituyen destrezas transferibles a otros ámbitos de conocimiento y, por tanto, estimulan el desarrollo de capacidades generales de razonamiento.

Finalmente, confrontar a los alumnos con el reconocimiento de su entorno económico y social, de los problemas presentes en él y ayudarlos a construir su juicio crítico en torno a su propia actuación frente al mundo del consumo, estimula el desarrollo de un pensamiento social que constituye la base de la educación para la ciudadanía.

La diferencia entre el ciudadano y el consumidor está dada fundamentalmente porque el primero es capaz de evaluar críticamente el entorno social y asumir el rol que le corresponde como controlador de las decisiones de aquellos a quienes encomendó su representación mediante el voto. Ello involucra el concepto de "accountability" tan necesario para asegurar la gobernabilidad en los sistemas democráticos.

\section{Referências}

AMAR, J.; ABELLO, R.; DENEGRI, M. El desarrollo de conceptos económicos en niños y adolescentes colombianos y su interacción con los sectores educativo y calidad de vida. Informe Final Proyecto COLCIENCIAS, n. 12, 2001. 
Uninorte, 2002.

et al. Desarrollo del pensamiento económico en niños de la región caribe colombiana.Revista latinoamericana de psicologia, Colômbia, v. 35, n. 1, p. 7-18, 2003.

ARAUJO, R. Alfabetização Econômica: compromisso social na educação das crianças. São Bernardo do Campo: Editora Universidade Metodista de São Paulo, 2009.

BATRA, R.; HOMER, P.; KAHLE, L. Values, susceptibility to normative influence, and attribute importance weights: a nomological analysis. Journal of Consumer Psychology, v. 11, n. 2, p. 115-128, 2001.

BAUMANN, Z. Vida de consumo. Buenos Aires: Fondo de Cultura Económica, 2007.

BERNHEIM, D.; GARRETT, D.;MAKI, D. Education and saving: The long-term effects of high school financial curriculum mandates. Journal of Public Economics, n. 85, p. $435-565,2001$.

BERTI, A. E.; BOMBI, A. S. The child's construction of economics. Cambridge: Cambridge University Press, 1988.

; GRIVET, A. The development of economic reasoning in children from 8 to 13 years old: Price Mechanism. Contributi di Psicologia, n. 3, p. 37-47, 1990.

BRAUnSTEIN, S. Director Division of Consumer and Community Affairs, Before the Committee on Financial Services, U.S. House of Representatives. Consultado en:

http://www.federalreserve.gov/newsevents/testimony/ braunstein20080415a.htm, 2008.

BUKSTEIN, M. Relación entre alfabetización económica, prácticas del uso del dinero y hábitos de consumo televisivo en preadolescentes (tweens) de Temuco. Tesis (Magíster en Psicología) - Universidad de La Frontera, Temuco, Chile, 2007.

CLARKE, M. C.; HEATON, M. B.; ISRAELSEN, C. L.; EGGETT, D.L. The acquisition of family financial roles and responsibilities. Family and Consumer Sciences Research Journal, v. 33, p. 321-340, 2005.

COHEN, M.; CANDACE, N. Financial Literacy: a step for clients towards financial inclusion. Microcredit Summit Campaign. Microfinance Opportunities, 2011.

COLE, S.; SAMPSON, T.; ZIA, B. Prices or Knowledge? What Drives Demand for Financial Services in Emerging Markets? HBS Working Papers - forthcoming in The Journal of Finance v. 9, n. 11, 2010. 
COLLINS, W. A.; STEINBERG, L. Adolescent development in interpersonal context. In: W. DAMON, R.; LERNER, W. (Eds.). Social, emotional, and personality development. Handbook of Child Psychology.New York: Wiley, 2006.P. 1003-1067.

CONSEJO NACIONAL DE TELEVISIÓN [CNTV] y MCCANN - ERICSSON. Informe 8/13: Los tweens Chilenos. Maval. Santiago, 2003.

CONSEJO NACIONAL DE TELEVISIÓN [CNTV]. Zoom Tweens. Estudios Cualitativos. Santiago de Chile. CNTV, 2004.

DEL VALLE, C. La producción de comunicación (medial) en contextos educativos interculturales. Revista Educación y Humanidades, v. 9, p. 27-37, 2000.

La comunicación mediática. Problemas epistemológicos y pragmáticos en la cobertura y tratamiento de contenidos de interés social. Tercer Milenio - Revista de Comunicación y Periodismo, v. 8, p. 18-20, 2003.

DENEGRI, M. El desarrollo de las ideas acerca de la emisión monetaria en niños y adolescentes: estudio exploratorio. Revista del Instituto de Ciencias de la Educación, n. 9, enero-abril, p. 47-62,1995a.

El desarrollo de las ideas acerca del origen y circulación del dinero: un estudio evolutivo con niños y adolescentes. Ediciones Universidad Autónoma de Madrid. España, 1995b.

Psicogénesis de las ideas en torno a la relación Estado-economía. In: GUZMÁN,L. (Ed.) Exploraciones en Psicología Política. Universidad Diego Portales: Santiago, 1997.

Proyectos de aula interdisciplinarios y reprofesionalización de profesores: un modelo de capacitación. Estudios Pedagógicos, v. 31, n. 1, p. 35-50, 2005.

et al. Desarrollo del pensamiento económico en la infancia y adolescencia. Boletín de Investigación Educacional, v. 13, p. 291-308, 1998.

et al. Informe Final Proyecto Fondecyt, n. 1970364.Fondo Nacional de Ciencia y Tecnología. Santiago, Chile, 2000.

et al. Socialização econômica em famílias chilenas de classe média: educando cidadãos ou consumidores? Psicologia\&Sociedade, Belo Horizonte, v. 17, n. 2, p. 8898, 2005.

et al. Prácticas de ahorro y uso del dinero en pre adolescentes (tweens) chilenos.Revista UNIVERSUM, v. 23, n. 1, p. 24-38, 2008.

et al. Educación Económica y Financiera para la formación inicial de profesores. In: SEPÚLVEDA, J. (Ed.). Herramientas conceptuales y didácticas. Chile: Ediciones Universidad de La Frontera, 2014. 
.; GEMPP, R.; MARTÍNEZ, G. Estrategias de Socialización Económica en Familias de Clase Alta y Media- Alta y su impacto en las prácticas de uso del dinero de los hijos. Boletín de Investigación Educacional, v. 20, n. 2, p. 41 -60, 2005.

;MARTÍNEZ, G. ¿Ciudadanos o consumidores? Aportes constructivista a la educación para el consumo. PAIDEIA - Revista de Educación, Ribeirão Preto, v. 37, p. 101-116, 2004.

.; ___ _ETCHEBARNE, S. La comprensión del funcionamiento bancario en adolescentes chilenos: un estudio de psicología económica. Interdisciplinaria, v. 24, n. 2, p. 137-160, 2007.

DONGO-MONTOYA, A. La teoría del aprendizaje de Piaget y sus consecuencias para la praxis educativa. Revista IIPSI, v. 11, n. 1, p. 167- 181, 2008.

FRIEDLINE, T.; ELLIOTT, W. Connections with banking institutions and diverse asset portfolios in young adulthood: children as potential future investors. Children and Youth Services Review, v. 35, n. 6, p. 994-1006, 2013.

FURTH, H.G. The world of grown - ups. Children 's conceptions of society. Nueva York: Elsevier North Holland, 1980.

GEMPP, R. et al. Medición de la alfabetización económica en niños: una aplicación del modelo de crédito parcial.Revista Psykhe, v. 15, n. 1, p. 13-28, 2006.

GERARDI, K.; GOETTE L.; MEIER, S. Financial literacy and subprime mortgage delinquency: evidence from a survey matched to administrative data. Working Paper - Federal Reserve Bank of Atlanta, April, 2010.Disponívelem:https://www.frbatlanta.org//media/documents/research/publications/wp/2010/wp1010.pdf

HILGERT, M. A.; HOGARTH, J. M.; BEVERLY, S. G. Household Financial Management: The Connection between Knowledge and Behavior. Federal Reserve Bulletin, v. 89, n. 7, p. 309-322, 2003.

JAHODA, G. European lag in the development of an economic concept: a study in Zimbabwe. British Journal of Developmental Psychology, n. 1, p. 113-120, 1983.

JAHODA, G. The development of thinking about socio-economic systems. In: TAJFEL, H. (Ed.). The social dimension. Vol. I, Cambridge: Cambridge University Press, 1984.

JAPELLI, T. Economic Literacy: an International comparison. Centre for studies in economics and finance, University of Salerno, n. 238, 2009.

JOHNSON, M; SHERRADEN, M. From Financial Literacy to Financial capability Among Youth. The Journal of Sociology \& Social Welfare, v. 34, n. 3, 2007.

KHAN, S.; NARU, A. Modernizing economic education in the global economy with reference to Pakistan. Journal of Asian Economics, v. 17, n. 5, p. 904-922, 2006. 
KRETSCHMER, T; PIKE, A. Links between nonshared friendship experiences and adolescent siblings' differences in aspirations. Journal of Adolescence, v. 33, n. 1, p. 101-10, 2009.

KOTLIKOFF, L. J.; BERNHEIM, B.D. Household financial planning and financial literacy. In: KOTLIKOFF, L. J. (Ed.) Essays on saving, bequests, altruism, and lifecycle planning. Cambridge, MA: MIT Press, 2001. p. 427-478.

LUSARDI, A. U.S. Household savings behavior: the role of financial literacy, information and financial education programs .In: FOOTE, C.; GOETTE, L.; MEIER, L. (Eds.). Policymaking Insights from Behavioral Economics. Boston: Federal Reserve Bank of Boston, 2009. p.109-149.

.; MITCHELL, O. Baby boomer retirement security: the roles of planning, financial literacy, and housing wealth. Journal of Monetary Economics, v. 54, n. 1, p. 205-224, 2007.

.; The economic importance of financial literacy. Theory and evidence: National Bureau of Economic Research, 2013.

.; TRUFANO, P. Debt literacy, financial experiences, and over indebtedness. NBER Working Paper, n. 14808, 2009.

LYONS, A.A profile of financially at-risk college students. The Journal of Consumer Affairs, v. 38, p. 56-80, 2004.

SCHERPF, E.; ROBERTS, H. Financial Education and Communication between Parents and Children. Journal of Consumer Education, v. 23, p. 64-76, 2006.

LLANOS, M. et al. Aprendiendo a comprender el mundo económico. Ediciones Uninorte. Colombia, 2008.

MASHE, J.G. Explanation of normative declines in parents' knowledge about their adolescent children. Journal of Adolescence, v. 33, n. 2, p. 271-284, 2010.

MORI, E.; LEWIS, A. Money in the contemporary family.Nestle Family Monitor, v. 20, n. 3, p. $21,2001$.

MOORE, D. Survey of financial literacy in Washington State: knowledge, behavior, attitudes, and experiences. Washington State University: Social and Economic Sciences Research Center, 2003.

MURPHY, D.; YETMAR, S. Personal financial planning attitudes: A preliminary study of graduate students. Management Research Review, v. 33, n. 8, p. 811-817, 2010 .

NATIONAL ENDOWMENT FOR FINANCIAL EDUCATION (NEFE). What is the NEFE high school financial planning program? 2004. Disponível em: http://www.nefe.org/ 
hsfppportal/includes/main/home.asp?portal=4\&page=4000\#evaluation2, 2004.Acesso em: 03 de Abril de 2006.

NEYMOTIN, F. Linking self-esteem with the tendency to engage in financial planning. Journal of Economic Psychology, v. 31, n. 6, p. 996-1007, 2010.

NORVILITIS, J.; SANTA MARÍA, P. Credit card debt on college campuses: causes, consequences, and solutions. College Student Journal, v. 36, p. 356-364, 2002.

; et al. Personality Factors, Money Attitudes, Financial Knowledge, and Credit-Card Debt in College Students. Journal of Applied Social Psychology, v. 36, p. 1395-1413, 2006.

.; SAZBLICKI, J.; WILSON, S. Factors Influencing Levels of Credit-Card Debt in College Students. Journal of Applied Social Psychology, v. 33, n.5, p. 935947, 2003.

ORGANISATION FOR ECONOMIC CO-OPERATION AND DEVELOPMENT [OECD] Improving financial literacy: analysis of issues and policies. OECD Publishing, 2005a.

. Recommendation on Principles and Good Practices for Financial Education and Awareness. OECD Publishing, Directorate for Financial and Enterprise Affairs, 2005b.

Improving Financial Education and Awareness on Insurance and Private Pensions. OECD Publishing, 2008.

. Financial literacy and consumer protection: overlooked aspects of the crisis. 2009. Disponível em: http://www.financialeducation.org/dataoecd/32/3/43138294.pdf

.Closing the Gender Gap: Act now. OECD Publishing, 2012.

PISA 2012 Results - Students and Money: Financial Literacy Skills for the 21st Century. V. IV. PISA: OECD Publishing, 2014.

OYSERMAN, D.; DESTIN, M. Identity-based motivation: Implications for intervention. The Counseling PSychologist,v. 38, p. 1001-1043, 2010.

OZGEN, O. An analysis of child consumers in Turkey. International Journal of Consumer Studies, v. 27, p. 366-380, 2003.

PAGE, C.; RIDGWAY, N. The impact consumer environments on consumption patterns on children from disparate socioeconomic backgrounds. Journal of Consumer Marketing, v. 18, p. 21-40, 2001.

PIAGET, J. El criterio moral en el niño. Barcelona: Fontanella, 1971. 
Desarrollo y aprendizaje.In: Piaget rediscovered: a report of the Conference on cognitive studies and curriculum development. Ithaca: Cornell Univ. Press, 1964. p. 7-20.

.Fondements scientifiques pour l'éducation de demain.Perspectives: revue trimestrielle de l'éducation, París, v. 2, n. 1, p. 13-30, 1972.

. Estudios Sociológicos. Editorial: Planeta Agostini, Barcelona, 1986.

PROGRAMA DE LAS NACIONES UNIDAS PARA EL DESARROLLO [PNUD]. Desarrollo humano en Chile: la manera de hacer las cosas. Chile: PNUD, 2009.

SALEMI, M. K. Teaching economic literacy: Why, what and how. International Review of Economics Education, v. 4, p. 46-57, 2005.

SANTOMERO, A. Knowledge is power: the importance of economic education. Business Review, v. 5, n. 1, 2003.

SCHUG, M. Economic education across the curriculum. Bloomington: Phi Delta Kappa Educational Foundation, 1982.

SCHUG, M.; HAGEDORN, E. The money savvy pig tm goes to the big city: testing the effectiveness of an economics curriculum four young children. The Social Studies, v. 96, n. 2, p. 68-71, 2005.

SUITER, M. et al. The math factory. In: GRENIER, M. P. (Ed), Mathematics \& economics: connections for life, grades 3-5. New York: National Council on Economic Education, 2005.p. 57-68.

THALER, R.; SUNSTEIN, C. Nudge: improving decisions about health, wealth, and happiness. New Haven: Yale University Press, 2008.

WOOTEN, D.; REED, A. Playing it safe: susceptibility to normative influence and protective self-presentation. Journal of consumer research, v. 31, n. 3, p. 551-556, 2004.

VAN ROOIJ, M.; LUSARDI.A; ALESSIE, R. Financial literacy and stock market participation. Documento de Trabajo. Ann Arbor, MI: University of Michigan Retirement Research Center, 2007. Disponível em: http://www.mrrc.isr.umich.edu/publications/papers/pdf/wp162.pdf

ZMUDA, N. Coca Cola launches global music effort to connect with teens advertisingage. Disponível em: http://adage.com/article/global-news/coca-colalaunches-global-music-effort-connect-teens/149204/ 


\title{
Conhecimento social: o caso do pagamento mínimo da fatura do cartão de crédito
}

\author{
Iarê Sandra Cooper ${ }^{1}$ \\ Tania Stoltz ${ }^{2}$
}

\section{RESUMO}

Trata-se de extrato de pesquisa de mestrado relacionada à construção do conhecimento social. Objetiva-se analisar as representações de adultos jovens, usuários de cartão de crédito, quanto à forma de pagamento das faturas, mais precisamente, em relação à possibilidade de pagamento mínimo do valor da fatura. Participaram do estudo vinte adultos jovens usuários de cartão de crédito. Os dados foram coletados por meio de entrevistas individuais cujo roteiro foi elaborado a partir do método clínico de Piaget. A análise dos dados originou dez categorias descritivas do pensamento dos participantes. Neste, enfatiza-se as representações dos participantes sobre as formas de pagamento das faturas. A análise dos dados demonstra que os participantes apresentam conhecimento elementar em relação a esses aspectos e aos demais relacionados ao uso do cartão de crédito. Ressalta-se a importância da compreensão dos processos envolvidos na utilização de cartão crédito, uma vez que o seu mau uso pode resultar em sobre-endividamento, comprometendo a qualidade de vida dos sujeitos.

PALAVRAS-CHAVE: Piaget. Adultos jovens. Cartão de crédito.

Social Knowledge: the case of the Minimum Credit Card Bill Payment

\section{ABSTRACT}

It is a next ract from master's degree research that a imed to identify there

\footnotetext{
${ }^{1}$ Doutora em Educação. Universidade Federal do Paraná. Curitiba, Paraná, Brasil.E-mail:iarecooper@yahoo.com.br

${ }^{2}$ Doutora em Educação. Universidade Federal do Paraná. Curitiba, Paraná, Brasil. E-mail:tania.stoltz795@gmail.
} 
presentations of young adults, credit card users, regarding the payment of method the invoices, more precisely, in relation to the possibility of minium payment of the in voice value. Twenty young adult credit card users participated in the study. The data were collected through individual interviews whose script was drawn from the clinical method of Piaget. Analysis of the data originated tende scriptive categories of participants' thinking. In this, the participants' representation so the pay ment methods of in voices are emphasized. The analysis of the data shows that the participants present elementary know led gere garding these aspect sand the others related to the use of the credit card. It is important to understand the processes involved in the use of credit cards, since their misuse can lead to over-indebtedness, compromising the subjects' quality of life.

KEYWORDS: Piaget. Young adults. Credit card.

\section{Introdução}

Este artigo visa a analisar as representações de adultos jovens, usuários de cartão de crédito, quanto à forma de pagamento das faturas, mais precisamente, em relação à possibilidade de pagamento mínimo ou parcial do valor da fatura. Para tanto, a análise se deu a partir dos dados obtidos em estudo de mestrado ${ }^{3}$ de perspectiva construtivista de base piagetiana, inserido no campo dos estudos sobre o conhecimento social e que buscou identificar as representações de adultos jovens de Curitiba referentes aos processos de obtenção de lucro das instituições financeiras a partir da utilização do cartão de crédito.

\footnotetext{
${ }^{3}$ Trata-se de extrato de pesquisa de mestrado intitulada "Cartão de crédito: salvação ou perdição. As representações de adultos jovens sobre a obtenção de lucro das instituições financeiras” (COOPER, 2012), realizada junto ao Programa de Pós-Graduação em Educação da Universidade Federal do Paraná, sob a orientação da Profa. Dra. Tania Stoltz.
} 
Quando se fala em desenvolvimento cognitivo pode-se afirmar que, atualmente, estamos relativamente bem informados sobre os processos de desenvolvimento funcional e estrutural desde o bebê até a adolescência. Entretanto, ainda é pouco o que se sabe sobre o período que separa a adolescência da fase adulta (DANIS; SOLAR, 2001). Se por um lado, os estudos com crianças e adolescentes contribuem para a compreensão do desenvolvimento dos adultos, por outro lado, as pesquisas com jovens adultos 4 podem contribuir para avaliar o que já se sabe sobre os estádios anteriores de desenvolvimento.

Apesar de não ter tido como foco o estudo do desenvolvimento cognitivo de sujeitos adultos, os estudos de Piaget contribuem para a compreensão do desenvolvimento cognitivo destes, uma vez que descrevem o processo de desenvolvimento das estruturas do conhecimento, principalmente no que se refere às estruturas formais do pensamento.

De acordo com a teoria piagetiana (PIAGET, 1978/1924; 1979/1926; 1977/1932; 1987/1936; 1975/1946; 1958/1947; 1964), o início do desenvolvimento do pensamento formal começa por volta dos 12 anos e recebe essa designação porque, nesse estádio, os pensamentos do sujeito desprendemse do concreto e "avançam mais e mais em direção a raciocínios formais e abstratos" (KESSELRING, 2008, p. 140). A principal característica desse estádio de desenvolvimento é a inversão de sentido entre o real e o possível. O pensamento formal é essencialmente hipotético-dedutivo, sendo que,

a dedução não mais se refere diretamente a realidades concebidas, mas a enunciados hipotéticos, isto é, a proposições que se referem a hipóteses ou apresentam dados apenas como simples dados,

\footnotetext{
${ }^{4}$ Adulto jovem: fase do desenvolvimento humano que corresponde ao período entre 20 e 40 anos de segundo Papalia, Olds e Feldman, 2006.
} 
independentemente de seu caráter real: a dedução consiste então, em ligar essas suposições, e delas deduzir suas consequências necessárias, mesmo quando sua verdade experimental não ultrapassa o possível. (INHELDER, PIAGET, 1976/1955, p. 198).

Operar formalmente requer a descentração do pensamento. Liberto do concreto, agora o sujeito é capaz de fazer inferências a respeito de fatos e objetos ausentes e em relação ao futuro. É o momento da elaboração de teorias e das grandes ideias, da cientificidade do pensamento. Segundo Piaget e Inhelder (2009/1968), o pensamento formal amplia os aspectos da realidade, antes limitados e concretos, em função da possibilidade ilimitada de combinações possíveis, reforçando os poderes da inteligência dedutiva. Sendo que,

as operações formais representam, exclusivamente, a estrutura do equilíbrio final, para o qual tendem as operações concretas, ao se refletirem em sistemas mais gerais combinando entre si proposições que as exprimem. (PIAGET, 1958/1947, p. 193).

Em Piaget (1964), o pensamento formal é tido como a conclusão do desenvolvimento cognitivo em nível estrutural e a abertura ilimitada em termos de possibilidades, sem limites para o aprimoramento e a construção de novos conhecimentos. Segundo Kesselring (2008), Piaget reconhece, mais tarde, a possibilidade de desenvolvimento de outras estruturas, para além das operatório-formais. Contudo, os sujeitos alcançam o nível de pensamento operatório formal em diferentes áreas do conhecimento, de acordo com suas atitudes e especializações profissionais. A maneira como essas estruturas serão usadas não será necessariamente a mesma em todos os casos (Piaget, 1972). 
Um sujeito poderá apresentar um pensamento mais elaborado em áreas específicas do conhecimento e um pensamento elementar em outras.

Compreender as questões que envolvem o crédito e o lucro requer grande potencial de abstração, não sendo possível sem a generalização, característica do pensamento formal. A ampliação desse potencial de generalização resulta da qualidade de interação entre o sujeito e o objeto de conhecimento.

A maneira como se entende a realidade econômica e os conceitos referentes ao uso do dinheiro e do crédito é de grande interesse para os estudos envolvendo noções sociais, pois servem de modelo para a compreensão de toda a realidade social (DELVAL; PADILLA, 1999b). Dentre os campos do conhecimento social, são ao menos duas as razões para que o conhecimento econômico seja o de maior destaque dentre os estudos do desenvolvimento psicológico. Primeiro, por constituir-se um dos principais eixos da organização social, sendo o campo com o qual todos entram em contato desde muito cedo e, segundo, pelas possibilidades de estudos, principalmente experimentais que esse campo viabiliza. Apesar da dificuldade em abordar todas as noções econômicas, há elementos objetiváveis, de fácil comprovação empírica, como as questões de compra e venda e a noção de lucro, que podem ser estudados de maneira bem direta (DELVAL, 2007; DELVAL; PADILLA, 1999b).

Os estudos sobre a noção de lucro podem ser organizados a partir de três grandes enfoques. O primeiro e mais antigo enfoque, baseado em estudos evolutivos, observa a construção de estruturas cada vez mais complexas, que vão do desenvolvimento da criança ao adolescente, e que seriam determinantes para a compreensão do lucro. O enfoque adotado na maioria dos estudos é de fundamentação piagetiana e discute a existência ou não de um desenvolvimento estrutural que abrangeria tanto o conhecimento social como o conhecimento físico (STRAUSS; SCHUESSLER, 1951; STRAUSS, 1952, 1954; 
FURTH, 1980; JAHODA, 1981，1984; DELVAL，2007; DELVAL; PADILLA, 1999b). Embora sejam evocados os conceitos piagetianos de equilibração e de conflito cognitivo na construção de conceitos econômicos, os pesquisadores dividem-se entre os que relacionam a construção de conceitos econômicos ao aparecimento das operações e os que não postulam a possibilidade de analogia entre o desenvolvimento do conhecimento físico e o desenvolvimento do conhecimento social. No entanto, há concordância de que há certo atraso no desenvolvimento do conhecimento social em relação ao conhecimento físico em ambas as abordagens.

Outra abordagem concentra-se nas possibilidades da educação para a aquisição de conceitos econômicos, discutindo se o conteúdo de economia em currículos, bem como questões metodológicas relacionadas ao ensino de noções de economia, possibilitam o aprendizado de noções econômicas por meio de intervenções educativas (BERTI, 1993; BERTI; BOMBI, 1998; BERTI; BOMBI; BENI, 1986; DANIS; SOLAR, 2001). No entanto, esses estudos não explicitam claramente os processos que determinam a mudança conceitual. Esses estudos seguem basicamente as relações entre desenvolvimento e aprendizagem propostas na obra de Inhelder, Sinclair e Bovet (1975). Há ainda, estudos que enfatizam o conflito sociocognitivo no desenvolvimento de conceitos econômicos. De modo geral, esses estudos consideram que o pensamento hipotético-dedutivo é necessário para o entendimento do mundo econômico, enfatizando que os conceitos econômicos requerem mais informações do meio social e cultural que os conhecimentos físicos.

A terceira linha de estudos concentra-se na compreensão de conceitos econômicos ao término da adolescência e na idade adulta. Esses estudos justificam-se pelas mudanças conceituais no adulto a partir de sua interação com o mundo socioeconômico. Os estudos sob essa abordagem respondem à 
questão epistemológica relacionada ao conhecimento geral versus o conhecimento de domínio, investigando se o problema do conhecimento econômico é um problema de quantidade de informações trabalhadas ou de reestruturação conceitual. Esses estudos indicam mudanças significativas no pensamento econômico de estudantes universitários em relação ao nível de instrução econômica de seus cursos. Observa-se que quanto maior o nível de instrução, maior a proporção de pensamento econômico inferencial. Por essa razão e considerando o impacto do nível de instrução econômica, defendem a incorporação, no currículo universitário, da alfabetização econômica para auxiliar na transição da vida universitária para o mundo do trabalho, para o desenvolvimento de juízo crítico em torno da própria atuação no mundo de consumo e, mais do que isto, para o desenvolvimento do pensamento social, fundamental para a verdadeira cidadania (AMAR et al., 2001; AMAR et al., 2006).

Consequentemente entende-se, como um dos papéis da educação, promover o conhecimento acerca do mundo social, principalmente do mundo econômico, não apenas para que o sujeito compreenda como a sociedade se organiza, mas também de que maneira suas ações se refletem nessa sociedade, possibilitando, assim, transformações sociais.

Estando o acesso ao crédito cada vez mais amplo, é imprescindível que os sujeitos estejam aptos a usufruir criticamente destes benefícios e isso só será possível a partir da reflexão e compreensão dos fatores que influenciam esses sistemas de financiamento. Então, para que se atue de forma crítica e consciente, é preciso que se pense em uma educação para jovens e adultos que contribua para a compreensão dos processos econômicos, sobretudo em relação às questões que envolvem a compreensão dos processos de obtenção de lucro e 
aos processos envolvidos no uso de cartão de crédito ofertado, possibilitando, dentre outras coisas, a utilização adequada desse meio de crédito.

\section{Procedimentos Metodológicos}

A pesquisa foi realizada junto a adultos jovens, moradores da cidade de Curitiba, usuários de cartão de crédito provenientes de contas bancárias ou de estabelecimentos comerciais.

A idade dos participantes foi determinada a partir da definição de adulto jovem de Papalia, Olds e Feldman (2006) que corresponde ao indivíduo com idade entre vinte e quarenta anos. Neste estudo foram selecionados 10 participantes com vinte e 10 com quarenta anos de idade, caracterizando o início e o fim dessa fase do desenvolvimento, totalizando 20 participantes, sendo 5 mulheres e 5 homens com vinte anos de idade e 5 mulheres e 5 homens com quarenta anos de idade. Os participantes foram selecionados a partir dos contatos pessoais da autora e por intermédio de indicações. Estando o sujeito dentro do perfil da amostra da pesquisa e concordando em participar do estudo, a coleta de dados foi agendada e realizada em local de melhor conveniência para o participante.

Para a realização da coleta de dados deste estudo fez-se uso do método clínico de Piaget (1926) por se tratar de um método cuja "essência é a intervenção sistemática do pesquisador em função do que o sujeito vai fazendo ou dizendo. [...] O pesquisador, mediante suas ações e suas perguntas, procura compreender melhor a maneira como o sujeito representa a situação e organiza sua ação" (DELVAL, 2002, p.12). Este método foi criado por Piaget e apresentado na obra $A$ representação do mundo na criança (1926), que aborda a 
forma como o pesquisador pode desenvolver a entrevista e os variados tipos de respostas que podem ser alcançados com a utilização do método clínico.

O método clínico permite acompanhar o curso do pensamento dos sujeitos ao longo de uma dada situação, fazendo sempre novas perguntas para esclarecer respostas anteriores. A entrevista é constituída por perguntas básicas que devem ser respondidas por todos os participantes e por perguntas que são acrescentadas conforme as respostas dadas pelos sujeitos, estando sempre orientadas pelo objetivo da pesquisa que está sendo realizada (DELVAL, 2002). Por ser um método flexível, o entrevistador conduz a entrevista buscando sempre elucidar a maneira como o sujeito chega às suas concepções, visando a tornar claras e conscientes as explicações destes.

Para alcançar os objetivos desse estudo foi elaborado, como instrumento de coleta de dados, um roteiro de entrevista que, após a análise de um especialista, foi testado a partir de um estudo piloto, o que permitiu a reformulação e reconsiderações de algumas perguntas visando ao aprimoramento desse instrumento.

As entrevistas foram realizadas individualmente e gravadas, com a autorização dos participantes, para possibilitar a transcrição literal das respostas. Os protocolos com as transcrições das entrevistas foram analisados, inicialmente, de forma individual e, para a análise do conjunto de dados, as respostas dos participantes foram dispostas em planilhas descritivas, possibilitando a análise do conjunto de respostas dadas por todos os participantes da pesquisa, originado 10 categorias descritivas do pensamento dos participantes em relação aos processos de utilização de cartão de crédito. 


\section{Resultados}

A partir das planilhas descritivas e de acordo com a apresentação e regularidade nas respostas, foram instituídas dez categorias representativas do pensamento dos sujeitos em relação ao uso do cartão de crédito e em relação às suas concepções sobre as formas de obtenção de lucro das instituições financeiras, a saber:

1) Quantidade de cartões de crédito;

2) Formas de obtenção de cartão de crédito;

3) Formas de pagamento com cartão;

4) Controle de gastos com cartão;

5) Formas de pagamento das faturas;

6) Vantagens e desvantagens das financeiras conforme forma de pagamento das faturas;

7) Limite de crédito;

8) Prejuízos e benefícios na utilização de cartão de crédito;

9) Recomendações para a utilização de cartão de crédito e;

10) Representações referentes aos processos de obtenção de lucro das instituições financeiras.

Aqui será dada ênfase às categorias 5 - Formas de pagamento das faturas, e 6 - Vantagens e desvantagens das financeiras conforme forma de pagamento das faturas. Mas, antes de apresentar os resultados dessas categorias, segue breve exposição das demais.

Em relação à quantidade e forma de obtenção dos cartões de crédito, os dados demonstram que, dos 39 cartões totalizados pelos participantes da pesquisa, são os homens que detêm o maior número de cartões, somando 22 . 
Em relação à idade, os participantes com quarenta anos de idade, somando homens e mulheres, totalizam 24 cartões de crédito. Dos 39 cartões acumulados pelos 20 participantes, 27 foram obtidos a partir da oferta de bancos, na abertura de conta corrente ou em lojas, supermercados e demais estabelecimentos comerciais. Apenas 12 cartões foram solicitados pelos participantes junto às financeiras.

Quanto à forma de pagamento na aquisição de bens e serviços utilizando cartão, apenas um homem, com vinte anos de idade, afirma que utiliza apenas a função débito do cartão, visando evitar o endividamento. O pagamento de despesas utilizando as funções débito e crédito do cartão é usual para 3 homens com vinte anos de idade e 4 com quarenta anos. São as mulheres, 4 com vinte anos de idade e 4 com quarenta anos, que afirmam utilizar exclusivamente a função crédito do cartão.

A categoria forma de pagamento com cartão originou uma subcategoria que analisa a relação forma de pagamento e preço a ser faturado. As respostas dos participantes da pesquisa demonstram que a maioria não relaciona a forma de pagamento ao valor final dos produtos ou serviços que estejam adquirindo, afirmando que o preço é sempre o mesmo, independentemente se pago em dinheiro, no débito, no crédito rotativo ou parcelado do cartão.

A categoria controle de gastos com o cartão de crédito permite avaliar se e como os participantes realizam o controle das despesas faturadas no cartão. Os resultados demonstram que apenas 2 homens com vinte anos e 2 homens e 1 mulher com quarenta anos de idade declaram não controlar seus gastos com cartão de crédito. No entanto, a investigação permitiu observar que, o que os participantes definem como controle, na realidade, trata-se apenas de simples conferências dos valores cobrados em fatura.

A categoria limite de crédito apresenta a forma como os participantes 
utilizam o limite e as suas concepções sobre as vantagens e desvantagens na utilização do limite. Dentre os participantes com vinte anos de idade, 3 mulheres e 3 homens afirmam que não costumam utilizar todo o limite ofertado pelas financeiras de cartão de crédito. $\mathrm{O}$ mesmo ocorre com 5 mulheres e 4 homens com quarenta anos de idade. No entanto, dos 5 homens com quarenta anos de idade, 4 afirmam que só há vantagens na utilização do limite e 1 afirma que há vantagens e desvantagens no limite de crédito. Dentre os participantes com vinte anos de idade, 4 mulheres e 3 homens afirmam que só há desvantagens na utilização do limite, 1 mulher vê apenas vantagens e 2 homens afirmam que há tanto vantagens quanto desvantagens na utilização do limite.

Quanto aos possíveis prejuízos ou benefícios para os usuários de cartão de crédito, dos participantes com vinte anos de idade, 2 mulheres e 2 homens acreditam haver apenas benefícios, 2 mulheres acreditam que há prejuízo e 1 mulher e 3 homens acreditam que fica tudo na mesma, nem prejuízos nem benefícios. Para os participantes com quarenta anos de idade, 3 mulheres e 5 homens veem apenas benefícios na utilização do cartão de crédito e 2 mulheres acreditam que fica tudo na mesma.

Em relação aos possíveis prejuízos ou benefícios para as financeiras de cartão de crédito, dos participantes com vinte anos de idade, 3 mulheres e 5 homens afirmam que as financeiras obtêm apenas benefícios e, para 2 mulheres, as financeiras não têm nem benefícios nem prejuízos quando os clientes utilizam cartão de crédito. Para os participantes com quarenta anos de idade, 4 mulheres e 5 homens afirmam que as financeiras só têm benefícios e 1 mulher acredita que fica tudo na mesma, ou seja, as financeiras não obtêm nem benefícios nem prejuízos com a utilização do cartão de crédito.

Sobre as recomendações para a utilização do cartão de crédito, 1 mulher e 
2 homens com vinte anos de idade e 2 homens e 2 mulheres com quarenta anos afirmam que indicariam a aquisição e o uso do cartão para amigos e 3 mulheres com vinte anos afirmam que não indicariam. Para 1 mulher e 3 homens com vinte anos e 3 mulheres e 3 homens com quarenta anos de idade, a indicação para aquisição e utilização do cartão de crédito dependerá do perfil do usuário. De acordo com esses participantes, o perfil ideal do usuário de cartão de crédito seria o de uma pessoa controlada, que compra apenas o que necessita e não contrai dívidas maiores que sua receita mensal.

Quanto à categoria que corresponde às representações referentes aos processos de obtenção de lucro das instituições financeiras, os dados revelam que, de modo geral, os participantes não compreendem os processos envolvidos nas transações com cartões de crédito e nem nas relações com as demais transações realizadas pelas financeiras.

Retornando o tema a ser tratado aqui - as representações dos participantes em relação ao pagamento do valor mínimo da fatura -os dados que originaram a categoria referente à forma de pagamento das faturas revelam que 5 mulheres e 4 homens com vinte anos de idade e 4 mulheres e 4 homens com quarenta anos de idade afirmam pagar as faturas em dia e no valor integral. Os demais participantes, 1 homem com vinte anos e 1 homem e 1 mulher com quarenta anos de idade, afirmam pagar apenas o valor mínimo ou parcial da fatura.

Um exemplo interessante, em relação à forma de pagamento das faturas, é o caso do participante Célio, assistente de produção que afirma possuir ao menos oito cartões de crédito provenientes de contas bancárias, dos quais utiliza dois nas compras pessoais e os outros cede para que seus parentes, que não dispõem de outro meio de crédito, possam adquirir bens e serviços. Quando questionado sob a forma como efetua o pagamento das faturas de seu cartão, 
Célio se refere aos dois que ele utiliza como seus e aos demais como "deles", dando a ideia de que os demais não estão sob sua responsabilidade, conforme extrato de entrevista que segue.

E como você efetua o pagamento da fatura na maioria das vezes? $E u$ tenho pagado, pelo menos, é... O que é meu, eu pago, o que vem ali eu pago à vista. É, com 30 dias, né? Quando é do pessoal, eu pago o mínimo deles. É, o mínimo do cartão, mas é dividido entre eles, né? Como que vocês fazem? Digamos: tem três pessoas usando o mesmo cartão, daí um paga 80, outro paga 150, outro paga 40... É assim que eu pago. Daí dá o mínimo ali. Daí cada um paga o mínimo. Daí cada um dá um pouco e paga o mínimo. E o restante da fatura? Vai ficando, né? Vai ficando. E quem paga...? Eles mesmo vão pagando. E tem alguma taxa, juro...? Não. Não. Se tiver eles me pagam. Se a empresa cobrar alguma coisa a mais eles pagam. Entendeu?

Extrato de protocolo de entrevista com participante Célio, 40 anos. (COOPER, 2012, p. 202).

Os riscos de sobre-endividamento, quando do pagamento de apenas o valor mínimo da fatura também são descritos pelos participantes. Ressalta-se que, no caso dos participantes com vinte anos de idade, os relatos, na maioria das vezes, correspondem às experiências de terceiros e não às experiências pessoais, como na afirmação da bartender Ângela: "Porque eu já ouvi falar que, se você paga só aquele mínimo, ele vem acrescentado depois" (COOPER, 2012, p. 122).

Como já expresso anteriormente, foram também investigadas as representações dos participantes sobre as vantagens e desvantagens das financeiras, conforme a forma como os usuários de cartões de crédito efetuam o 
pagamento das faturas. Segundo os dados correspondentes a esta categoria, 4 mulheres e 5 homens com vinte anos de idade e 5 mulheres e 4 homens com quarenta anos acreditam que as financeiras obtêm vantagens quando os usuários pagam parcialmente ou com atraso as suas faturas. Uma mulher com vinte anos e um homem com quarenta anos afirmam que, nesses casos, não há nem prejuízos nem benefícios para as financeiras.

Para o caso do pagamento integral e no vencimento, 3 mulheres e 1 homem com vinte anos e 2 mulheres e 4 homens com quarenta anos de idade acreditam que as financeiras obtêm vantagens. Interessante ressaltar o relato da participante Bruna, com quarenta anos de idade, que afirma que as financeiras têm prejuízo quando as faturas são pagas integralmente e na data de vencimento: "Eu acho que ela sai perdendo porque ela prefere que eu pague a taxa mínima, que eu entre no rotativo... É... Eu acho que eles preferem que eu... Que a pessoa atrase. Eu acho que eles perdem." (COOPER, 2012, p. 127). $\mathrm{E}$, para os demais participantes, as financeiras não obtém benefícios nem prejuízos quando as faturas são pagas em dia e integralmente.

\section{Discussão}

Os resultados da pesquisa, obtidos a partir de uma pequena amostra selecionada, demonstram que são os homens que tendem a possuir o maior número de cartões de crédito, o que pode ser justificado pela possível existência de um modelo patriarcal, onde o homem assume o papel de provedor do sustento da família que, em muitos casos, está limitado às despesas da casa, mas também ao sustento de sua esposa e filhos, abrangendo, em alguns casos, os irmãos, cunhados e demais parentes e agregados. Os dados demonstram ainda que a maioria dos cartões é obtida de modo quase que compulsório, uma 
vez que foram poucos os participantes que relataram ter solicitado cartão de crédito às financeiras ou aos estabelecimentos comerciais.

Dentre o grupo masculino que possui a maior quantidade de cartões, são os participantes do grupo com quarenta anos de idade os detentores da maioria dos cartões. Este fato pode resultar do aumento das responsabilidades financeiras pessoais, familiares e profissionais que, muitas vezes, implica a abertura de novas contas bancárias e a adesão a cartões de financiamento de instituições comerciais particulares (lojas de departamentos, supermercados, lojas de materiais de construção). A adesão aos cartões de lojas e demais instituições pode justificar a solicitação "espontânea" destes cartões pelo grupo participante feminino, sendo elas, na maioria dos casos, as responsáveis pelas compras domésticas.

De acordo com os resultados da pesquisa, é mais vantajoso comprar parcelado, principalmente produtos com alto valor de custo, já que os lojistas informam que o valor parcelado é o mesmo que o valor à vista, sem cobranças de juros. Assim, os clientes são induzidos ao uso do crédito rotativo ao entenderem que não há vantagens em pagar à vista. Mesmo ao reconhecerem os riscos da utilização indevida do cartão, os participantes declaram considerar apenas as vantagens em seu uso. Afirmam, por exemplo, que o limite, além de ser uma forma de controlar seus gastos, é uma excelente forma de adquirir bens ou serviços pelos quais não poderiam pagar de outra forma.

Importante ressaltar que, ainda que fazendo uso cotidianamente de cartão, alguns participantes revelam não compreender as diferenças entre as formas de pagamento com o cartão e, tampouco, utilizam-se de meios eficientes de controle dos gastos pessoais com o cartão de crédito.

Quanto à compreensão dos processos envolvidos no uso de cartão de crédito, o estudo demonstra que os participantes, adultos jovens, desconhecem 
os processos que envolvem a utilização do cartão ficando, desse modo, suscetíveis aos riscos e às armadilhas desse modelo de crédito. Dentre elas, destaque para a possibilidade de não pagar o valor total da fatura, entendida como uma possibilidade de prorrogar o vencimento de suas dívidas, não considerando que essa atitude poderá resultar em processo de sobreendividamento ${ }^{5}$, muitas vezes conhecido como "bola de neve".

Apesar de a maioria dos participantes afirmar que pagam as faturas em dia e no valor integral, suas respostas demonstram considerar o pagamento do valor mínimo ou de parte do valor total da fatura como uma alternativa viável em caso de impossibilidade de quitação. Os participantes veem o pagamento do valor mínimo como um jeito de pagar valores menores de juros na fatura subsequente. Há ainda os que afirmam não haver cobrança de juros ao se pagar o valor mínimo na data de vencimento da fatura, sendo os juros cobrados somente em caso de atraso no pagamento. Outros entendem o pagamento do valor mínimo da fatura como uma oportunidade, proporcionada pelas financeiras, para que seus clientes mantenham em dia o pagamento das faturas, oportunizando a manutenção de seus nomes "limpos", uma vez que, assim, não serão inseridos no Serviço de Proteção ao Crédito - SPC.

Ao afirmar que o pagamento do valor mínimo da fatura impede que seu nome entre nos cadastros de devedores como SERASA e SPC, os sujeitos parecem não perceber que, ao pagar apenas o valor mínimo ou parcial, além das financeiras garantirem o recebimento, adiantado, dos juros cobrados pelo

\footnotetext{
${ }^{5}$ Sobre-endividamento corresponde à situação em que o sujeito não consegue cumprir com seus compromissos financeiros, correndo o risco de comprometer a subsistência familiar. De acordo com Zarrenner (2007), o papel do sujeito no sobre-endividamento pode ser ativo ou passivo, sendo que, no primeiro caso, o sujeito contribui ativamente ao colocar-se em situação de impossibilidade de pagamento, adquirindo dívidas superiores à sua receita mensal e, no segundo caso, o sujeito encontra-se sobre-endividado por conta de circunstâncias que fogem de seu controle como desemprego, despesas extras com saúde, dentre outras.
} 
refinanciamento ${ }^{6}$, não há o bloqueio do crédito do usuário. O sujeito, mesmo não conseguindo quitar as despesas que já acumulou, continua com o crédito liberado, podendo efetuar novas aquisições, o que pode ocasionar o sobreendividamento, comprometendo o orçamento pessoal ou familiar e, consequentemente, sua qualidade de vida.

Mesmo quando verbalizam que o pagamento parcial da fatura pode resultar em processo de sobre-endividamento, ou "bola de neve", as respostas dos participantes demonstram que eles veem na possibilidade de pagar apenas uma parte do valor da fatura, uma oportunidade que as financeiras "oferecem" para que seus clientes mantenham seu crédito. Essas afirmações demonstram que o pensamento desses sujeitos apresenta características do estágio operatório concreto e até do pré-operatório (INHELDER; PIAGET, 1976/1955; PIAGET, 1978/1924, 1979/1926; 1977/1932; 1987/1936; 1975/1946; 1958/1947; 1964), uma vez que apresentam ideias quase que infantilizadas em relação às financeiras, acreditando que a possibilidade de pagamento mínimo das faturas seja apenas mais uma vantagem oferecida pelas financeiras aos seus clientes, com único intuito de ajudar.

\section{Conclusão}

A análise geral dos dados e das referidas categorias, permite concluir que os adultos jovens, participantes do estudo, apresentam uma compreensão muito elementar em relação aos processos de obtenção de lucro das instituições financeiras e sobre os processos que envolvem a utilização do cartão de crédito.

A possibilidade de pagamento de valor mínimo ou parcial da fatura,

\footnotetext{
${ }^{6}$ Ao efetuar uma compra parcelada com o cartão de crédito o indivíduo está recorrendo a um financiamento. Caso não consiga pagar alguma das faturas, pagando apenas uma parte do valor, o restante da fatura será refinanciado, cobrado posteriormente em próxima fatura, acrescido de juros, muitas vezes abusivos.
} 
evidencia que os partícipes da pesquisa não compreendem que, pagando o valor mínimo, o crédito continua disponível para compras com o cartão, o que pode resultar em sobre-endividamento, pois, com a manutenção do crédito, poderão efetivar novas compras e, uma vez que na fatura do mês subsequente serão cobrados os valores pendentes do mês anterior, além dos juros sobre o remanescente e as novas compras efetuadas.

Os participantes parecem não perceber que, mesmo parecendo ser um grande alívio não precisar pagar o valor total de uma fatura, ao estar desprovido financeiramente, o uso abusivo desta "vantagem" trata-se, na verdade, de um grande embuste, uma vez que pode resultar em descontrole de gastos, sobre-endividamento e, consequentemente, no comprometimento da receita mensal pessoal e ou familiar, prejudicando sua qualidade de vida.

A ideia que os sujeitos têm das financeiras como parceiras que provêm os recursos para a aquisição de bens e serviços é semelhante às representações dos adolescentes estudados por Jahoda $(1981,1984)$ que viam o banco como uma instituição amiga e sem fins lucrativos. Os participantes demonstram entender que o crédito ofertado pelas financeiras por meio de cartão e, principalmente, a possibilidade de não quitação do valor total da fatura, realizando apenas o pagamento de valor mínimo ou parcial, trata-se de uma fonte quase mágica de realizações de seus desejos, vendo as financeiras como provedoras de suas necessidades. Esse pensamento assemelha-se aos achados nos estudos com crianças e adolescentes que demonstram vislumbrar o mundo social isento de conflitos e em que as desigualdades sociais são entendidas e aceitas como um processo social natural (ARAÚJO, 2010; CASTORINA, 2005; CASTORINA; LENZI, 2000; DELVAL, 2007; DELVAL; PADILLA, 1999b; FURNHAM, 1990; FURNHAM; CLEARE; 1988; FURTH, 1980; GANUZA, 
1999; LAUER-LEITEet al., 2010; PARRAT-DAYAN, 2007; STOLTZ; PARRATDAYAN, 2007; STOLTZ et al., 2014).

A não compreensão desses fatores, apresentada pelos adultos jovens participantes da pesquisa que, em tese, encontram-se no estádio formal do desenvolvimento, pode ser explicada ao entender que, de acordo com a teoria piagetiana, as operações formais podem estar presentes em situações que envolvam as especialidades do sujeito, ou seja, em que ele qualitativamente interaja mais. Ressalta-se que o estádio formal implica o fechamento do desenvolvimento cognitivo em nível estrutural. No entanto, as possibilidades para o refinamento e a elaboração de novos conhecimentos a partir das operações formais são ilimitadas. Deve-se considerar que cada indivíduo poderá alcançar esse estádio de desenvolvimento em áreas distintas, conforme suas aptidões e especializações. Entendendo que a forma como essas estruturas serão empregadas pelos sujeitos não será necessariamente a mesma em todos os casos (PIAGET, 1972).

Estudar o desenvolvimento cognitivo dos adultos é de suma importância para fundamentar a elaboração de propostas pedagógicas para jovens e adultos que vislumbrem a construção das noções socioeconômicas, como a noção de lucro, por exemplo (STOLTZet al., 2014; OTHMAN; STOLTZ, 2017). Desse modo, destaca-se a importância do desenvolvimento de práticas pedagógicas voltadas à educação econômico-financeira de jovens e adultos que oportunize a compreensão dos processos envolvidos no uso de cartão de crédito, uma vez que este é tido como o meio de crédito mais relacionado às situações de sobreendividamento pessoal (VELUDO-DE-OLIVEIRA; IKEDA; SANTOS, 2004; DONADIO; CAMPANARIO; RANGEL, 2012).

Importante ressaltar que o acesso à informação não implica, necessariamente, em conhecimento ou em transformação da ação. Portanto, a 
prática pedagógica deve oportunizar que o sujeito reflita sobre as próprias ações, compreendendo, além dos fatores externos, os fatores internos envolvidos na sua relação como cartão de crédito (PIAGET, 1977, 1978), resultando na aquisição de bens e serviços, com ou sem o uso de cartão de crédito, de forma consciente.

É importante esclarecer que esse trabalho não tem a intenção de avaliar a utilização do cartão de crédito, mas sim, as representações que os sujeitos têm em relação ao uso do cartão e a obtenção de lucro por parte das financeiras. Nesse sentido, considera-se que o cartão de crédito pode ser um excelente instrumento para a aquisição de bens e serviços, desde que os usuários sejam capazes de avaliar de forma crítica e consciente suas necessidades e os riscos e benefícios que podem estar implícitos no uso do cartão.

\section{Referências}

AMAR, J.; ABELLO, R.; DENEGRI, M.; LLANOS, M. La comprensión del funcionamiento bancario en la adolescencia ¿Crónica de un sobreendeudamiento anunciado? Psicologia desde el Caribe, Universidad del Norte, Barranquilla, Colombia, n.8, Jul-Dic, p. 94-109, 2001.

AMAR, J.; ABELLO, R.; DENEGRI, M.; LLANOS, M. Análisis de las representaciones acerca de la economía en jóvenes universitarios del Caribe colombiano. Investigación y desarrollo, v. 1, n. 14, p. 152-173, 2006.

ARAÚJO, R. M. B. O pensamento econômico das crianças: para iniciar o debate. Revista Tecer, Belo Horizonte, v. 3, n. 5, nov., 2010. Disponível em: $<$ https://www.google.com.br/search?client=safari\&rls=en\&q=Revista + Tecer++Belo+Horizonte+\%E2\%80\%93+vol.+3,+no+5,+novembro+2010\&ie=UTF-8\&oe=UTF8\&gfe_rd=cr\&ei=tfQLV9mGK_Kp8we2joKYBA>. Acessoem: 28 deMarço de 2016.

BERTI, A. Fifth graders' ideas on bank functions and interest before and after a lesson on banking. European Journal of Psychology of Education, v. 8, p. 183-193, 1993.

BERTI, A.; BOMBI, A. S. The child's construction of economics. Tradução inglesa de G. Duveen. Cambridge: Cambrigde University Press, 1998. 
.; BOMBI, A. S.; DE BENI, R. Acquiring economic notions: profit. International. Journal of Behavioral Development, v. 9, p. 15-29, 1986.

CASTORINA, J. Construcción conceptual y representaciones sociales: el conocimiento de la sociedad. Buenos Aires: Editorial Miño y Dávila, 2005.

CASTORINA, J.; LENZI, A. M. (orgs.) La formación de los conocimientos sociales en los niños: Investigaciones psicológicas y perspectivas educativas. Barcelona. Editorial Gedisa, 2000.

COOPER, I. S. Cartão de crédito: salvação ou perdição? As representações de adultos jovens sobre instituições financeiras e utilização de cartão de crédito. 268f. Dissertação (Mestrado em Educação) - Universidade Federal do Paraná, UFPR, Curitiba, 2012.

DANIS, C.; SOLAR, C. Aprendizagem e desenvolvimento dos adultos. Tradução de Joana Chaves. Lisboa: Instituto Piaget. 2001.

DELVAL, J. Introdução à prática do Método clínico: descobrindo o pensamento das crianças. Tradução de Fátima Murad. Porto Alegre: Artmed, 2002.

. Aspectos de la construcción del conocimiento sobre la sociedad. Revista IIPSI, Madrid, v. 10, n. 1, p. 9-48, 2007.

DELVAL, J.; PADILLA, M. El desarrollo del conocimiento sobre la sociedad. In.: LÓPEZ, F.; ETXEBARRÍA, I.; FUENTES, M. J.; ORTIZ, M. J. (Coord.). Desarrollo afectivo y social. Madrid: Pirámide, 1999b.

DONADIO,R.; CAMPANARIO, M. A.; RANGEL, A. S. O papel da alfabetização financeira e do cartão de crédito no endividamento dos consumidores brasileiros. REMark - Revista Brasileira de Marketing, São Paulo, v. 11, n. 1, p. 75-93, jan./abril, 2012. Disponível em: <http://www.revistabrasileiramarketing.org/ojs2.2.4/index.php/remark/article/view/2281/pdf_70>. Acesso em: 29 de Março de 2016.

FURNHAM, A. Parental attitudes towards pocket money/allowances for children. Journal of Economic Psychology, v. 22,p. 397-329, 1990.

FURNHAM, A.; CLEARE, A. School children's conceptions of economics: Prices, wages, investments, and strikes. Journal of Economic Psychology, v.9, p. 467-479, 1988.

FURTH, H. G. The world of grown-ups: Children's conceptions of society. New York: Elsevier, 1980. 
GANUZA, F. B. La construcción de nociones sociales. Revista Psicodidáctica, Universidaddel País Vasco Vitoria-Gazteis, España, n. 9, 1999. Disponível em:<http://www.redalyc.org/articulo.oa?id=17500903>. Acesso em: 6 de Abril de 2016.

INHELDER, B.; PIAGET, J. Da lógica da criança à lógica do adolescente: ensaio sobre a construção das estruturas operatórias formais. Tradução de Dante Moreira Leite. São Paulo: Pioneira, 1976. (Ed. original. 1955).

INHELDER, B.; BOVET, M.; SINCLAIR, H. Aprendizagem e estruturas do conhecimento. São Paulo: Saraiva, 1974/1977.

JAHODA, G. The development of thinking about economic institutions: the bank. Cahiers de Psychologie, v. 1, p. 55-73, 1981.

The development of think ingabout socio-economic systems. In: TAJFEL, H. (ed.) The social dimension. Cambridge: Cambridge University Press, v. 1, 1984.p. 6988

KESSELRING, T. Jean Piaget. Educs: Caxias do Sul, 2008.

LAUER-LEITE, I. D.; MAGALHÃES, C. M. C.; LORDELO, E. R.;LELIS, I. L. Socialização econômica: conhecendo o mundo econômico das crianças. Estudos de Psicologia, v. 2, n. 15, Mai.-Ago., 2010. Disponível em: www.scielo.br/epsic. Acesso em: 28 de Março de 2016.

OTHMAN, Z.A.S.; STOLTZ, T. Compra uma bala aí, tio? A noção de lucro como eixo central para a compreensão do mundo econômico-social. Curitiba: Appris, 2017.

PAPALIA, D. E.; OLDS, S. W.; FELDMAN, R. D. Desenvolvimento Humano. Porto Alegre: Artmed, 2006.

PARRAT-DAYAN, S. A discussão como ferramenta para o processo de socialização e para a construção do pensamento. Educação em Revista, Belo Horizonte, v. 45. p. 1323, 2007. Disponível em: <http://www.scielo.br/pdf/edur/n45/a02n45.pdf>. Acesso em 17 de Novembro de 2015.

PIAGET, J. Psicologia da Inteligência. Rio de Janeiro: Fundo de Cultura, 1958. (Ed. orig. 1947).

. Development and learning Journal of Research in Science Teaching, New York, v. 2, n. 3, p. 176-186, 1964.

. Intellectual Evolution from Adolescence to Adul thood. Human Development, Genève, Univ. de Genève, n.15, p. 1-12, 1972. 
- A formação do símbolo na criança - Imitação, jogo e sonho, imagem e representação. 2 ed. Tradução de Álvaro Cabral e Cristiano M. Oiticica. Rio de Janeiro: Zahar Editores, 1975. (Ed. orig. 1946).

. O julgamento moral na criança. Tradução de Elzon Lenardon. São Paulo: Mestre Jou, 1977a. (Ed. orig. 1932).

- A Tomada de consciência. Tradução de Edson Braga de Souza. São Paulo: Melhoramentos, Ed. USP, 1977.

- Fazer e compreender. Tradução de Christina Larroudé de Paula Leite. São Paulo: Melhoramentos, Ed. USP, 1978.

- O raciocínio na criança. 2 ed. Tradução de Valerie Rumjanek Chaves. Rio de Janeiro: Record,1978. (Ed. orig. 1924).

A representação do mundo na criança. Tradução de Rubens Fiúza. Rio de Janeiro. Ed. Record. 1979 (Ed. orig. 1926).

. O nascimento da inteligência na criança. 4 ed. Tradução de Álvaro Cabral. Rio de Janeiro: LTC Editora, 1987. (Ed. orig. 1936).

PIAGET, J.; INHELDER, B. A psicologia da criança. Tradução de Octavio Mendes Cajado. Rio de Janeiro: DIFEL, 2009. (Ed. Orig. 1968).

STRAUSS, A. L. The development and transformation of monetary meanings in the child. American Sociological Review,v. 17, p. 275-286, 1952.

. The development of conceptions of rules in children. Child Development, v. 25, n. 3, p. 193-208, 1954.

STRAUSS, A.L.; SCHUESSLER, K. Socialization, logical reasoning, and concept development in the child. American Sociological Review, v. 16, p. 514-523, 1951.

STOLTZ, T.; COSTA, R. R. S.; PIECZARKA T.; OTHMAN, Z. A. S., COOPER, I.; D’AROZ, M. S. Revista Eletrônica Científica Inovação e Tecnologia, v. 1, n. 9, p. 01-15, 2014.

STOLTZ, T.; PARRAT-DAYAN, S. Educação e incluso social: uma leitura possível a partir de Piaget. In: GUERIOS, E; STOLTZ, S. (Org.). Educação, Inclusão e Exclusão Social: contribuições para o debate. Curitiba: Aos Quatro Ventos, v. 1, 2007.p. 95-104. 
VELUDO-DE-OLIVEIRA T. M.; IKEDA, A. A.; SANTOS, R. C. Compra compulsiva e a influência do cartão de crédito. Mercadologia. v. 44, n. 3, Jul-Set, 2004. Disponível em: <http://www.scielo.br/pdf/rae/v44n3/v44n3a07.pdf>. Acesso em: 31 de Maio de 2013.

ZERRENER, S. A. Estudo sobre as razões para o endividamento da população de baixa renda. Dissertação (Mestrado em Ciências Administrativas), Universidade Estadual de São Paulo - USP, São Paulo, 2007.

Recebido em 02 de outubro de 2017. Aprovado em 25 de novembro de 2017. 


\title{
O conceito de trabalho na perspectiva de crianças e adolescentes: uma análise a partir da teoria piagetiana
}

\author{
Maria de Lourdes Mattos Barreto ${ }^{1}$ \\ Gisele Maria Costa Souza ${ }^{2}$ \\ Márcia Onísia da Silva ${ }^{3}$
}

\begin{abstract}
RESUMO
A evolução do conhecimento social, utilizando o método clínico piagetiano, tem sido estudada com o objetivo de verificar como as crianças e adolescentes representam o mundo à sua volta. Partindo da indagação: "quais as representações de crianças e adolescentes sobre trabalho?" objetivou-se, nesse estudo, buscar a gênese do conceito de trabalho, analisando essas representações ao longo do desenvolvimento de crianças e adolescentes. Por meio das entrevistas clínicas realizadas com 60 sujeitos, obteve-se 4 níveis de conhecimento, identificando desde as ideias de que o trabalho é comprado, indo para uma noção de que é necessário à sobrevivência humana até as relações sociais de trabalho e de formação necessária para exercício profissional. Demonstrou-se que este tipo de conhecimento é construído e coerente com a estrutura cognitiva, influenciados pelo meio social, mas não determinadas por ele.
\end{abstract}

PALAVRAS-CHAVE: Crianças e Adolescentes. Trabalho-conceito. Representações. Método Clínico Piagetiano.

The concept of work in the perspective of children and adolescents: an analysis based on the Piagetian theory

\footnotetext{
${ }^{1}$ Doutora em Educação. Universidade Federal de Viçosa, Viçosa, MG, Brasil. E-mail: mmattos@ufv.br.

${ }^{2}$ Doutora em Motricidade Infantil. Universidade Federal Rural do Rio de Janeiro, Seropédica, RJ, Brasil. E-mail: gisele.souza@hotmail.com.

${ }_{3}^{3}$ Mestre em Economia Doméstica. Universidade Federal de Viçosa, Viçosa, MG, Brasil. E-mail: monisia@ufv.br.
} 


\begin{abstract}
The evolution of social knowledge, using the Piagetian clinical method, has been studied in order to verify how children and adolescents represent the world around them. Starting from the question: "what representations of children and adolescents about work?", The purpose of this study was to search for the genesis of the concept of work, analyzing these representations throughout the development of children and adolescents. Through clinical interviews with 60 subjects, 4 levels of knowledge were obtained, identifying from the ideas that the work is bought, going to a notion that it is necessary to human survival to social relations of work and that requires appropriate training for professional practice. It has been shown that this type of knowledge is constructed and consistent with the cognitive structure, influenced by the social environment, but not determined by it.
\end{abstract}

KEYWORDS: Children And Adolescents. Work-Concept. Representations. Clinic Piaget Method.

\title{
Introdução
}

O conhecimento social é uma das formas de conhecimento consideradas por Piaget e deriva das trocas com os outros indivíduos por meio das interações e transmissões sociais que o sujeito estabelece no decorrer de sua vida. Esse tipo de conhecimento evolui de forma mais simples na infância para formas mais elaboradas, quando o indivíduo atinge a adolescência. Nossa proposta foi verificar como se dá a construção do conhecimento sobre a categoria trabalho por crianças e adolescentes, considerando que são seres ativos na construção de seu próprio conhecimento e que este é construído na interação com o meio físico e social, não copiando os dados da realidade, mas os transformando ativamente.

Ao eleger as crianças e adolescentes como fonte de estudo para a compreensão da sociedade e da família, é necessário situar qual a concepção de criança e de adolescente norteia a investigação, pois a visão de criança e 
adolescente varia de acordo com a sociedade e em diferentes períodos históricos. Historicamente, essa visão passa por mudanças marcantes no decorrer do tempo, e pesquisa como a de Ariès (1986) indica como essa visão foi sendo construída em diferentes momentos na história da humanidade. Ariès realizou estudos sobre a história da infância por meio de muitas fontes, utilizando a iconografia religiosa e leiga, os registros de batismo e os diários de família, entre outros.

Educadores como Rousseau (1712-1778), Pestalozzi (1746-1827) e Froebel (1782-1852) introduziram novas concepções sobre a criança, afirmando que ela tem natureza peculiar, boa, sensível e merece atenção diferenciada do adulto. Atualmente, a criança é considerada um ser ativo na construção do próprio conhecimento e, conforme Piaget (1967), o desenvolvimento se dá por estágios que têm uma sequência e uma ordem lógica.

Salles (2005) apontou que, atualmente, a criança e o adolescente são concebidos como sujeitos com modos específicos de se comportar, agir e sentir. Essa visão indica que devem ser compreendidos a partir da relação estabelecida entre eles e os adultos. Uma influência mútua se institui de acordo com as condições objetivas da cultura na qual se insere, a partir de condições históricas, políticas e culturais diferentes.

É importante ouvir a criança e, nesse sentido, Cruz (2008) reiterou que a fala da criança e do adolescente pode subsidiar ações a seu favor e contribuir para mudanças que as beneficiem, em razão dos elementos que seu ponto de vista traz, fortalecendo pessoas e entidades preocupadas com seus interesses e que desenvolvem ações voltadas para a construção de melhores condições da vivência da infância. Por isso, é necessário que a criança e o adolescente saibam o que vai ser feito e participem, de forma consciente e voluntária, do estudo. Criança não trabalha! Porque pesquisar suas representações sobre uma temática tão distante de sua realidade?

A criança enquanto sujeito histórico-cultural se constitui em uma sociedade e na sua cultura. Procuramos compreender a constituição desse 
sujeito, via de regra, estudando suas manifestações visíveis: cotidiano, saúde física, crescimento/desenvolvimento, nutrição, habitação, oportunidades de lazer, acesso a bens e serviços específicos, dentre outros. Essas análises, embasadas em teorias psicológicas, educacionais, sociológicas, biológicas e econômicas visam oferecer sempre um panorama de como as crianças estão e como podem ficar a partir de políticas públicas e da instituição de direitos, atribuindo às famílias e ao Estado, a responsabilidade por seu bem estar.

No entanto, deve-se acrescentar a elas, o "falar" da criança. O que ELA nos tem a dizer? Como se sente diante do mundo que a cerca? O que ela gostaria que fosse criado/melhorado nesse seu mundo? Por essas questões, é que o trabalho enquanto categoria de análise deve ser incluído nas pesquisas com crianças. Diante do papel que ocupa na vida das pessoas, a importância social que assume, a criança (que não trabalha) está diretamente ligada nesse universo, por meio das interações que estabelece com seus pares, especialmente, com seu grupo familiar.

Esse trabalho é um recorte da dissertação de mestrado, intitulada "Representações de Crianças e Adolescentes sobre trabalho numa perspectiva Piagetiana" e parte das seguintes questão: quais as representações de crianças e adolescentes, na faixa etária de 4 a 14 anos, sobre trabalho? Diante dessa indagação, realizou-se uma pequisa qualitativa, do tipo ex-post facto, constituída pelo objetivo de analisar por meio de um estudo evolutivo as representações de crianças e adolescentes sobre a categoria trabalho, buscando a conceituação presente nessas representações.

\section{A ideia de trabalho em diferentes momentos da história humana}

O termo trabalho pode assumir vários significados e receber conotações e sentidos diversos de acordo com a cultura. Carmo (2005) afirmou que sua origem no latim tripalium denota instrumento formado por três estacas, cuja função era a de manter presos bois e cavalos difíceis de ferrar. Sua 
tradução no latim vulgar significa "pena ou servidão do homem à natureza". $\mathrm{Na}$ língua alemã arbeit e no latim laborar, o sentido é de algo penoso. A definição apresentada pelo autor é de que o trabalho é toda atividade humana realizada pelo homem civilizado que transforma a natureza com sua inteligência (CARMO, 2005).

Migeotte (2005), revisitando a Antiguidade Grega, afirmou que as primeiras reflexões sobre o trabalho surgiram nas obras homéricas e, posteriormente, em Hesíodo, por volta do ano 700 a.C., além de outras obras poéticas do período arcaico. O ponto culminante dessas reflexões ocorre no período clássico, nos século V e IV, nos textos de Xenofontes e Platão, inspirados nas obras de Sócrates, especialmente em seu livro Política. A maneira de ver o trabalho pelos gregos estava ligada à concepção que tinham da economia como um vasto conjunto de produção, de trocas e de consumo.

Predominou, conforme Carmo (2005), na Idade Média o regime de servidão, entendido como um meio-termo entre o trabalho-escravo e o trabalho livre. Vigorava também, nesse período, uma visão contrastante entre o catolicismo - para o qual o trabalho era considerado penitência para o pecado e ensejo para obter redenção divina, e o protestantismo - para o qual o trabalho era considerado meio de obter riqueza, mas também de servir a Deus, à medida que mantinha à distância o ócio e a luxúria.

Ramalho (2004) considerou que as transformações no mundo do trabalho afetam as sociedades, principalmente as industriais, de forma intensa. A produtividade tão valorizada atualmente é enfatizada na busca pela competitividade e qualidade, as quais são marcadas pelas inovações tecnológicas e novas formas de gestão das forças de trabalho. Para Morin et al. (2007), a partir de meados dos anos de 1950 vários pesquisadores buscaram compreender o significado do trabalho para as pessoas, utilizando diferentes metodologias. As pesquisas apontaram para uma conceituação de trabalho em que este é considerado essencial na vida das pessoas, uma vez que garante a sobrevivência. 
Estudo de Morin (2002) apontou para as seguintes características do trabalho, as quais possibilitam que tenha sentido: o trabalho deve ser feito de maneira eficiente, levando a um resultado útil; precisa ser satisfatório, possibilitando a obtenção de prazer e satisfação na realização das tarefas, permitindo ao trabalhador a resolução de problemas, uso do talento e potencial, com autonomia; precisa ter aceitação moral, denotando responsabilidade social; constituir-se como fonte de experiências de relações humanas aceitáveis; deve garantir segurança, por meio do vínculo empregatício; e a condição de receber um salário que permita a sobrevivência.

Dessa forma, nas considerações de Carmo (2005), o trabalho ocupa lugares e momentos diversos na vida humana, o que já demonstra a importância dele para a nossa sociedade. Para esse autor, pode-se considerar trabalho a atividade das plantas, dos animais, das máquinas, dos atletas, do pintor, do aluno, da bailarina etc., como se tudo na vida se resumisse ao trabalho, indiferente das diversas facetas que ele assume em nossa sociedade. Com o surgimento do capitalismo, grandes mudanças se colocaram na frente do pensamento medieval, passando a imperar o produtivismo.

Pesquisar essa categoria enquanto campo do conhecimento social é de importância vital para compreender a sociedade e os desdobramentos que mudanças no universo do trabalho acarretam na vida das pessoas e como afetam a infância. Faz-se necessário esse estudo delimitando a teoria que orienta a análise e, em razão disso, optou-se pela Teoria de Piaget para que tal busca fosse a efeito.

\section{O conhecimento social na teoria de Piaget}

As interações sociais são de fundamental importância para o desenvolvimento do indivíduo, e Chakur (2002) mencionou que a inteligência em sua forma lógica depende do desenvolvimento orgânico do 
indivíduo e da estimulação ambiental. No campo do conhecimento social, é de extrema importância o meio em que a criança se insere, pois as interações e transmissões sociais podem estar carregadas de preconceitos e são formas diretas de transmissão de valores e regras. Para Piaget (1973), a sociedade é formada por um sistema de atividades em que as ações do sujeito e o meio se modificam mutuamente. O conhecimento social origina-se na cultura e difere de uma cultura para outra, sendo construído pela criança enquanto interage com outras crianças e com adultos e não pode ser extraído das ações sobre os objetos, como acontece com o conhecimento físico e não depende só do sujeito.

Conforme La Taille (1992), a maneira de ser social de adolescentes e de crianças é diferente, pois as crianças não são capazes ainda de participar de relações sociais que expressem equilíbrio de trocas intelectuais. É necessário, então, que o sujeito possua estrutura lógica para que ocorra a assimilação do conhecimento, seja ele conhecimento físico, lógicomatemático ou social.

Wadsworth (1987) afirmou que, para Piaget, as transmissões sociais são fatores do desenvolvimento, não respondendo por si só pelo desenvolvimento da criança como querem crer algumas correntes. A experiência social é um processo ativo do mesmo modo que a experiência física, sendo necessário examiná-la, pois é instrumental no processo de desenvolvimento. As crianças aprendem muitas coisas através de outras pessoas, de suas ações com estas e das interações estabelecidas.

Piaget (1973) distinguiu diferenciações nas relações sociais da criança desde seu nascimento até a formação da personalidade, a última fase do desenvolvimento social. A afetividade da criança sensoriomotora deriva de um estado de não diferenciação do eu e todos os elementos físicos e humanos que o cercam. Com o aparecimento da representação, no período préoperatório, o objeto afetivo poderá ser evocado mesmo em sua ausência física, e esse fato acarreta a formação de novos afetos, como a simpatia ou antipatia duradouras que são dirigidas ao outro. A partir do estágio 
operatório, as trocas intelectuais começam a ir em direção ao equilíbrio, alcançando, nesse nível, o que Piaget denominou personalidade.

No estágio operatório concreto, a criança já é mais sociável e menos egocêntrica, utilizando de forma mais eficaz, a linguagem, podendo descentrar e considerar diferentes pontos de vista, mas ainda aplicando soluções apenas a problemas concretos. No estágio operatório formal, o sujeito já é capaz de lidar com classes de problemas diferentes, raciocinando sobre os hipotéticos e abstratos de forma eficiente. Significa que o indivíduo se submete voluntariamente às normas de reciprocidade e de universalidade. A personalidade constitui o produto mais refinado da socialização e é a capacidade de inserir seu ponto de vista entre os outros. (PIAGET, 1973).

Trabalho se compra, trabalho se faz, trabalho é para ganhar dinheiro - a evolução das representações das crianças e dos adolescentes: apresentação da metodologia e dos resultados

Para atender nossos objetivos, fundamentamos a pesquisa no Método Clínico Piagetiano, realizando as entrevistas clínicas com as crianças e adolescentes, levantando e sistematizando as categorias presentes em suas respostas. A pesquisa possui abordagem descritivo-comparativa, pois partimos da teoria piagetiana, que pressupõe que o conhecimento é construído e evolui de forma mais simples para uma mais elaborada e é uma construção ativa do sujeito, através de um processo contínuo de assimilação e equilibração (PIAGET, 1967; 1964; 1968).

A população foi composta por crianças e adolescentes matriculados em uma escola da rede particular de Viçosa, MG. A população atendida nessa escola caracterizava-se por crianças de classe média e classe média alta, oriundas de famílias residentes na cidade de Viçosa. A amostra do estudo foi constituída de 10 crianças de cada grupo etário, compreendendo a média de idade de $4 ; 6 ; 7 ; 10 ; 11$; e 14 anos, totalizando 60 sujeitos. A definição de 
criança e de adolescente adotada nesta proposta baseou-se no Estatuto da Criança e do Adolescente - ECA (1990), que considera criança a pessoa até 12 anos de idade incompletos, e adolescente aquela entre 12 e 18 anos de idade (ECA, 1990).

Sendo um estudo transversal, que se caracteriza pela análise de diferentes grupos de sujeitos de idades distintas, a definição das faixas etárias se deu em função da necessidade de cobrir, teoricamente, três estágios de desenvolvimento - pré-operatório, operatório concreto e operatório formal, o que permitiu obter dados evolutivos, examinando-se um número apropriado de sujeitos. Para a seleção da amostra, utilizamos a técnica da amostragem intencional, que segundo Marconi e Lakatos (1999), é um tipo de amostragem não probabilística, na qual se escolhem intencionalmente os sujeitos que farão parte do estudo. Utilizou-se como referência para análise das respostas, o quadro proposto por Delval (2002).

Iniciamos a descrição dos resultados mostrando como, em cada nível de desenvolvimento, crianças e adolescentes representaram a categoria "trabalho". O conceito de trabalho parte da identificação do que é trabalho para crianças e adolescentes, buscando as noções subjacentes às ideias principais acerca do tema. Na Tabela 1 são apresentados os percentuais de crianças e adolescentes encontrados em cada nível, sendo:

\section{A - Conceito: $O$ que é trabalho - constituição e evolução}

B - As estratégias de entrada no mercado de trabalho (Como se consegue um trabalho)

Tabela 1: Percentuais de crianças e adolescentes em cada nível, segundo a categoria conceito de trabalho

\begin{tabular}{|c|c|c|c|c|c|c|c|c|c|c|c|c|c|c|c|c|c|c|c|c|}
\hline \multicolumn{21}{|c|}{ CONCEITO DE TRABALHO } \\
\hline $\begin{array}{l}\text { Faixa } \\
\text { etária }\end{array}$ & \multicolumn{4}{|c|}{ O que é trabalho } & \multicolumn{4}{|c|}{$\begin{array}{c}\text { Como se consegue } \\
\text { Trabalho }\end{array}$} & \multicolumn{4}{|c|}{$\begin{array}{c}\text { Extensão } \\
\begin{array}{c}\text { (quem são as pessoas que } \\
\text { trabalham) }\end{array}\end{array}$} & \multicolumn{4}{|c|}{$\begin{array}{c}\text { Mudança } \\
\text { (como se entra ou sai do } \\
\text { trabalho) }\end{array}$} & \multicolumn{4}{|c|}{ Média (\%) } \\
\hline & PI & $\mathbf{I}$ & II & III & PI & $\mathbf{I}$ & II & $\begin{array}{c}\text { II } \\
\text { I }\end{array}$ & PI & $\mathbf{I}$ & II & III & PI & $\mathbf{I}$ & II & III & PI & $\mathbf{I}$ & II & III \\
\hline 4 & 100 & - & - & - & 100 & - & - & - & 100 & - & - & - & 100 & - & - & - & 100 & - & - & - \\
\hline 6 & 60 & 40 & - & - & 60 & 40 & - & - & 80 & 20 & - & - & 80 & 20 & - & - & 70 & 30 & - & - \\
\hline
\end{tabular}




\begin{tabular}{|c|c|c|c|c|c|c|c|c|c|c|c|c|c|c|c|c|c|c|c|c|}
\hline 7 & 10 & 90 & - & - & 10 & 90 & - & - & 40 & 60 & - & - & 20 & 80 & - & - & 20 & 80 & - & - \\
\hline 10 & - & 20 & 80 & - & - & 20 & 80 & - & - & 10 & 90 & - & - & 10 & 90 & - & - & 15 & 85 & - \\
\hline 11 & - & - & 70 & 30 & - & - & 70 & 30 & - & - & 80 & 20 & - & 50 & 50 & - & - & $\begin{array}{c}12, \\
5\end{array}$ & 67,5 & 20 \\
\hline 14 & - & - & 40 & 60 & - & - & 40 & 60 & - & - & 70 & 30 & - & - & 70 & 30 & - & - & 55 & 45 \\
\hline
\end{tabular}

Fonte: Dados da pesquisa.

Legenda: PI - Nível Pré-I; I - Nível I; II - Nível II; III - Nível III

\section{A - Constituição e evolução do conceito de trabalho}

Como pode ser observado na tabela 1, para a subcategoria "o que é trabalho", encontramos no nível Pré-I 100\% das crianças de 4 anos, $60 \%$ das crianças de 6 anos e 10\% das crianças de 7 anos de idade. O nível Pré-I caracteriza-se pela ausência de conceitos elaborados e de uma visão prática e ligada ao real. O mundo concreto está presente de forma decisiva na visão de crianças na faixa etária de quatro a sete anos de idade. Para estas crianças, o trabalho é algo que os adultos e, especialmente, seus pais fazem com a finalidade de ganhar dinheiro. Quando solicitadas a dizer o que é trabalho as crianças deste nível apresentam ideias pouco elaboradas, muito voltadas às ações que as pessoas executam.

No nível Pré-I encontramos $30 \%$ de respostas fabuladas e nãoimportistas. Há ausência de sistemas interpretativos e, devido a isto, a criança não entende bem o que é trabalho, conceituando-o em função das atividades que seus pais fazem. Os conceitos são pré-conceitos, ligados ao real e ao concreto. Crianças no nível Pré-I sabem que o trabalho é algo que as pessoas fazem para ganhar dinheiro, fazendo uma relação direta entre estas duas variáveis. O finalismo está presente nas respostas das crianças analisadas e, em consequência disso, o trabalho não é conceituado em relação ao "o que é", mas "para que serve". Essas características podem ser constatadas nas falas das crianças dos extratos a seguir.

- O que você acha que é trabalhar? É dá aula pros alunos... fazer curso... - Isso é trabalhar? (balança a cabeça em sinal positivo). Porque você acha que as pessoas trabalham? Pra ganhar dinheiro.

- Por que você acha que as pessoas precisam de dinheiro? Pra 
comprar coisas... mas pelo menos os de rua, não... né? Os de rua é pobre. (Criança 1, 4;4 anos, nível Pré-I).

- Ah! Vender cerveja... vender café... - Quem vende cerveja, vende café está trabalhando? - Tá! . - Porque você acha que as pessoas trabalham? Elas ganham dinheiro. - Porque você acha que as pessoas precisam de dinheiro? Pra...comprar coisas...vender cerveja...pra ganhar dinheiro. (Criança 6, de 6;5 anos, nível Pré-I).

Fazer coisa pra ganhá dinheiro. - Porque você acha que as pessoas trabalham? Pra ganhar dinheiro. - Por que você acha que as pessoas precisam de dinheiro? Pra pagar conta... comprá coisas... (Criança 10, de 7,7 anos, nível Pré-I).

Percebe-se, nesta faixa etária, uma dificuldade em conceituar o trabalho, mas as crianças já o relacionam com a necessidade de ganhar dinheiro. Já aparece neste início de construção do conhecimento a ideia do trabalho como uma atividade dos adultos e uma percepção da divisão de classes presentes na sociedade, onde alguns têm acesso ao trabalho, outros não.

Este resultado mostra a mobilidade presente em cada nível. Conforme Delval (2002), para as crianças menores o trabalho é algo misterioso do qual tinham ouvido falar, que seus pais faziam, mas não sabiam exatamente o que é e quais as razões para receberem, em troca, dinheiro. Esses dados foram encontrados também em nossa pesquisa confirmando essa característica, embora em nossa pesquisa as crianças demonstraram relacionar a finalidade do trabalho com a obtenção do dinheiro e este, por sua vez, serve para compra de bens de consumo.

No nível I as crianças relacionam o trabalho ao ganho de dinheiro e esta agora se mostra como uma finalidade específica, aparecendo já na definição que apresentam ao termo. Como pode ser visto na tabela 1 , encontramos $40 \%$ de crianças de seis anos, $90 \%$ das crianças de sete anos e 
20\% das crianças de dez anos no nível I, não sendo encontradas crianças de outras faixas etárias neste nível. As frases das crianças do nível I são mais completas do que as das crianças do nível Pré-I. O vocabulário é mais definido e há mais coerência em suas respostas. Entretanto, encontramos respostas finalistas, assim como as apresentadas pelas crianças do nível anterior. As crianças de sete anos apresentam uma forte tendência de exemplificar suas respostas, como pode ser visto nos extratos a seguir.

- O que você acha que é trabalhar? - É...tipo....a gente...sair de casa pra ganhar dinheiro. - Porque você acha que as pessoas trabalham? Pra ganhar dinheiro. - Por que você acha que as pessoas precisam de dinheiro? Porque... muitas coisas importantes... tipo... tem muitas coisas que a gente precisa de comprar. (Criança 4, de 6;9 anos, Nível I).

- Trabalhar? É tipo assim...minha mãe... ela trabalha, ela dá aula de Inglês na universidade...aqui à noite...de manhã e de tarde, isso é...ela trabalha. Meu pai...ele é dono de uma farmácia e ganhava muito, aí ele vendeu uma farmácia e só tá com a manipulação...ele trabalhava ne outro lugar e na manipulação...ele também trabalha. Ele vende é... as pessoas vão lá, pedem pra fazer o remédio que elas precisam, meu pai manda fazer...e pede pro moço entregar na casa delas ou pede pra elas buscar lá. Tem vários tipos de trabalho- Porque você acha que as pessoas trabalham? Pra ganhar dinheiro, se tiver filho pra sustentar, se tiver que comprar comida, cobertor...e pra pagar a casa...aluguel...água...luz...tipo...os bichos, eles matam outros bichos pra comer...tipo o leão...- Você acha que isso é o trabalho deles? Não. Pra sustentar eles...tipo assim...se eles não caçasse nenhum, ele ia morrer de fome. (Criança 2, de 7;5 anos, nível I).

Por volta dos seis/sete anos as crianças iniciam uma transição para o estágio operatório concreto caracterizado pelo pensamento concreto, baseado nas percepções da realidade, mas com modificações importantes no 
desenvolvimento mental, em que surgem novas formas de organização, atingindo um equilíbrio mais estável. A queda acentuada do egocentrismo permite a coordenação de pontos de vista diferentes. Entretanto, há indícios de que a construção do conhecimento social é relativamente mais vagarosa do que as transformações cognitivas alcançadas até agora e, conforme Delval (2002), as explicações para este fato não estão ainda muito claras. Pode-se considerar que o mundo social é mais complexo do que o mundo físico, pois os problemas para este último são facilmente materializáveis por meio de situações com materiais concretos como varetas, pêndulos, sombras e o mesmo não ocorre com os fenômenos sociais.

Aproximadamente aos sete anos as crianças iniciam uma transição para o pensamento operatório concreto, o que significa o desenvolvimento da habilidade de aplicar o pensamento lógico a problemas concretos. O quadro de referências conceitual parece mais estável e regular, aplicando-se sistematicamente ao mundo de objetos que rodeia a criança. Com o declínio do egocentrismo e o pensamento tornando-se lógico, a realidade começa a ser estruturada pela razão e não mais pela assimilação egocêntrica. Entretanto, embora o pensamento seja lógico, ele é restrito ao mundo concreto.

Um número significativo das crianças de sete anos (70\%) afirmou que há necessidade de se ter dinheiro para "comprar" o trabalho. É nesta faixa etária que este tipo de resposta é mais recorrente e é uma das características mais marcantes das respostas. Delval (2002) afirma que este tipo de resposta se deve ao fato de a criança, em busca de explicações, generalizar a partir de situações que não conferem com as que têm diante de si. Há falta de compreensão das limitações externas, como a escassez de trabalho ou de bens.

Já no nível II, uma característica que diferencia as crianças das de nível anterior é o surgimento da ideia de um processo de qualificação por meio de estudos e de cursos para obtenção de trabalho. O trabalho se converte na principal forma de mudança, mas os trabalhos se diferenciam de 
acordo com sua qualidade. Os extratos a seguir exemplificam as falas das crianças.

- O que você acha que é trabalhar? Trabalhar é primeiro você faz um curso pra poder ter um emprego, e depois você consegue um trabalho em algum lugar e trabalha pra ganhar algum lucro.Porque você acha que as pessoas trabalham? Pra poder ganhar dinheiro pra comprar coisas que precisam. ( Criança 2, de 10;5 anos, nível II).

- Eu acho que é...é...fazer alguma coisa que as outras pessoas necessitam. - Porque você acha que as pessoas trabalham? Pra ajudar a sociedade. - Você acha que elas recebem alguma coisa pelo trabalho delas? Recebem o salário. - Porque você acha que as pessoas precisam de dinheiro? Pra comprar o que precisam pra viver. (Criança 8, de 11;5 anos, nível II).

Percebe-se, nesta fala, uma noção de relações sociais que se estabelecem entre as pessoas. Além da remuneração, o trabalho é uma forma de produzir algo para o outro.

- O que eu acho que é trabalhar? Trabalhar...é fazer alguma coisa que a gente ganha dinheiro, né? Pra sustentar a família, pra...algumas vezes comprar alguma coisa que precisa, né? Eu acho que é isso. - Porque você acha que as pessoas trabalham? Pra conseguir dinheiro, né? Algumas vezes porque uma pessoa precisa ter uma profissão, né? Precisa trabalhar pra conseguir dinheiro pra ajudar a família quando ela ta precisando, mas o trabalho é muito essencial pras pessoas! (Criança 10, de 11;10 anos, nível II).

- Ah...é quando cê faz alguma coisa e recebe por isso.- Porque você acha que as pessoas trabalham? Pra se sustentar, pra ganhar dinheiro, pra ocupar o tempo...acho que é por isso. - $\mathrm{O}$ que é se sustentar? Sustentar..é...tipo...ganhar o dinheiro por esforço dele, 
pra poder pagar conta, comprar coisas pra família ou mesmo...pra ele mesmo.- Por que você acha que as pessoas precisam de dinheiro? - Porque hoje em dia tudo é dinheiro. (Adolescente 2, de 13;7 anos, nível II).

Nesta fala, aparece outra característica do trabalho, além da finalidade de remuneração: a ocupação do tempo. Outra questão que chama a atenção é o valor que o sujeito já atribui ao dinheiro. As conceituações das crianças a partir de 11 anos apresentam uma articulação mais organizada que a de crianças das faixas etárias anteriores. O trabalho assume importância vital para as pessoas, como demonstram as fala a seguir.

- O que você acha que é trabalhar? - Sei lá (sorri)...um meio de ganhar dinheiro. - Porque você acha que as pessoas trabalham? Pra conseguir dinheiro pra sustentar a família. - O que você acha que é "sustentar a família"? - Arrumar comida pra casa...arrumar é...sei lá...(sorrisos)...televisão...essas coisas básicas, construir uma casa também. (Adolescente 6, de 13;4 anos, nível II).

No nível II, conforme a fala das crianças e adolescentes, o trabalho é um meio para se sustentar, ter mais qualidade de vida e manter não só as necessidades materiais, mas amplia-se sua função para garantias de segurança e manutenção de futuro. As crianças já têm mais informações sobre o funcionamento do mundo, por meio da escolarização e da maior inserção social, o que permite ampliar suas respostas. A média de crianças e adolescentes no nível II, considerando o somatório das subcategorias, foi de 85\% das crianças de 10 anos; 67,5\% das crianças de 6 anos e 55\% dos adolescentes, o que mostra a mobilidade presente neste nível.

O nível III caracteriza-se pelo pensamento formal propriamente dito, constituindo-se na capacidade de pensar sobre aspectos não visíveis da realidade. De acordo com Piaget e Inhelder (1966/1989), a característica mais geral do pensamento formal é a de que ele opera sobre as próprias proposições, ou seja, pelo seu alto grau de descentração e de reversibilidade, 
o pensamento reflete sobre o processo intrínseco do próprio pensar. As respostas são mais elaboradas e mais articuladas que nos níveis anteriores. No Nível III, o sujeito começa a raciocinar não somente sobre o real, mas também sobre o possível e o real passa, assim, a ser somente um componente do possível. O sujeito começa a usar a lógica das proposições para raciocinar sobre o possível o que se caracteriza por basear-se em uma lógica estritamente verbal e numa combinatória. Os extratos a seguir exemplificam as falas das crianças e dos adolescentes do nível III.

- O que você acha que é trabalhar? Trabalhar!? Ah! É...(longo tempo). - Pode falar o que você achar, do jeito que você sabe. É...Depois que cê se forma, ce vai seguir alguma coisa e essa coisa que você seguir, vai trabalhar nela. Ai, nisso ce pode ou trabalhar e ser um funcionário e receber salário ou ser... ser um...tipo...um dentista e receber dos clientes. E nisso vai ganhar uma vida... pra você ter uma casa...comida, ter uma vida boa. - Porque você acha que as pessoas trabalham? - Eu acho que é...pra pessoa sobreviver. O que você acha que é sobreviver? Ah, ter um lugar onde morar, num precisar dormir debaixo da ponte...ter o que comer...é...ter..ter saúde, se precisar ir no médico, se precisar a família pode...pode...levar..tem as...as vantagens ...porque pode ir lá...se precisar de ir no hospital, a família pode levar.. O que as pessoas recebem em troca do trabalho delas? Dinheiro. (Criança 6, de 11;3 anos, nível III).

- Trabalhar? Meio complexa essa pergunta, mas...se...seria cota diária...cê trabalha oito horas, é...normalmente, cinco ou seis dias por semana, a troco de um salário. - Porque você acha que as pessoas trabalham? Pelo dinheiro...pra não ficarem a toa...porque gostam... - Por que você acha que as pessoas precisam de dinheiro? Ah...alimentação...lazer, né? Ah...escola...pros filhos...sei lá! Tudo envolve dinheiro! (Adolescente 10, de 14;2 anos, nível III). 
De acordo com as falas dos adolescentes, percebe-se que eles já apresentam um início de conceituações e apontam outras possibilidades que não se baseiam unicamente em suas percepções da realidade, mas pensam sobre as alternativas a serem buscadas para entrada do indivíduo no mercado de trabalho. A conceituação de trabalho é bem mais elaborada e sistemática do que nas faixas etárias anteriores. Permanece a ideia de "ganhar dinheiro" e este ainda é fundamental como pagamento pelo trabalho, porém ele é consequência do mesmo.

O trabalho é concebido, pelas crianças e adolescentes, como meio para se sustentar, ter mais qualidade de vida e manter não só as necessidades materiais, mas amplia-se sua função para garantias de segurança e manutenção de futuro. O trabalho também começa a ser visto como forma de ocupação do tempo e de realização pessoal, pois pode auxiliar as pessoas a serem felizes. Autores como Delval (2002), Enesco e Purificacion (1995) afirmam que no nível III começa-se a se entender a criação de trabalho por mudanças no sistema social, as influências externas tornam-se visíveis, iniciando-se o entendimento que existem restrições devidas ao sistema social.

\section{B - Compreensão das estratégias de entrada no mercado de trabalho}

Dois tipos de resposta foram encontrados no nível Pré-I: aquelas que não sabem como se consegue um trabalho e as que acreditam que, para conseguir trabalho é preciso somente procurar. Os extratos a seguir exemplificam respostas obtidas na entrevista com as crianças. Encontramos 100\% das crianças de 4 anos, 60\% das crianças de 6 anos e 10\% das crianças de 7 anos no nível Pré-I.

- Como você acha uma pessoa consegue um trabalho? Ela vai pro trabalho. O que ela precisa fazer? Ela procura e vai...(Criança 9, de 4;7 anos, nível Pré-I). 
- Eu acho que a pessoa chama elas e... pra trabalhar, onde ele fica e... ela fica trabalhando lá. (Criança 1, de 6;5 anos, nível Pré-I).

- Não sei! (Criança 10, de 7,7 anos, nível Pré-I).

As crianças afirmam que é só procurar um trabalho e começar a trabalhar. As restrições sociais, a dificuldade de entrar no mercado de trabalho, a necessidade de se qualificar ou de estudar ainda não estão presentes. Este tipo de reposta se deve à ausência de sistemas interpretativos. Os dados da realidade se restringem aos aspectos visíveis, com os quais elas têm contato pois ainda não são capazes de inferências.

No nível I as respostas das crianças compreendem os processos de estudar, pagar pelo trabalho, sair de casa, procurar na rua, como algumas das alternativas para se conseguir um trabalho. Apesar de apresentarem mais possibilidades nas formas de se conseguir um trabalho, a ideia de comprá-lo é mais forte do que nas idades anteriores. O estudo aparece como processo e surge uma hierarquia de ações que vai desde entrar na escola, procurar o trabalho, comprá-lo e mostrar ao empregador o que aprendeu na escola. Ainda não há noção da escassez de trabalho nem das influências externas, confirmando os dados encontrados por Delval (1994, 2002).

O esforço individual é fundamental para obtenção do trabalho. Comprar o trabalho como se compra qualquer mercadoria é uma resposta freqüente no nível I, permanecendo até os 7 anos de idade, não sendo encontradas repostas desse tipo em crianças de 10 anos. Delval (2002) também encontrou este tipo de resposta com crianças até 7 anos.

- Como você acha que uma pessoa consegue um trabalho? Precisa pedir pra outra pessoa... pra prefeitura... precisa... é... é... de dinheiro... - Ela precisa ter dinheiro para conseguir trabalho? (balança a cabeça em sinal positivo). - Por quê? Porque sim. (Criança 1, de 4; 4 anos, nível I). 
- Ela ganha dinheiro e ai procura um trabalho. (Criança 10, de 6;11 anos, nível I).

- Trabalhando. - O que ela precisa fazer para conseguir o trabalho? Pagar. - Pagar o quê? O trabalho. (Criança 9, de 7;6 anos, nível I).

No nível II, conforme Delval (2002), as crianças começam a compreender os processos temporais que constam de várias etapas. Desta forma, as crianças afirmam que há um processo a ser seguido para obtenção de trabalho começando pelo estudo e, em seguida, a procura por trabalho. Caso não se passe por esse processo a pessoa conseguirá um trabalho "ruim" e terá mais dificuldades de entrar no mercado de trabalho. A compreensão desse processo leva as crianças a perceberem as dificuldades de uma pessoa que não estudou para conseguir um trabalho e apontar que, para determinados locais, as exigências de formação são maiores, como é o caso de entrada numa universidade para lecionar. As crianças diferenciam os tipos de trabalhos, apresentando agora "trabalhos bons", que são mais bem pagos, trabalha-se menos e com menor esforço e "trabalhos ruins", que são executados com mais esforço e pelos quais se recebe remuneração menor. Os trabalhos considerados ruins não dependem de estudo e a pessoa cuja formação é baixa deve procurar nos locais em que são oferecidos, como é o caso das empregadas domésticas, pedreiros e trabalhadores de lojas. Estes dados foram também encontrados nas pesquisas de Delval (2002).

As relações sociais se tornam mais amplas, as crianças e os adolescentes, como afirma Delval (2002), começam a estabelecer relações sociais não mais entendidas somente como relações entre os indivíduos, mas entre papéis sociais, como a relação entre comprador e vendedor ou entre chefe e empregado, isto é, relações entre tipos de funções e não entre pessoas. Nos extratos das falas das crianças estas características podem ser vistas. 
- Como uma pessoa consegue um trabalho? Se esforçando? Pra maioria dos empregos hoje em dia, a gente tem que ter estudos, ter diploma...senão....pra conseguir mais fácil. - Se não tiver diploma... Consegue também, mas é mais difícil e aqueles...trabalhos que pagam mal. (Criança 1, de 10;2 anos, nível II).

- Ela precisa estudar, aprender e ter uma universidade, o diploma.

- E se não tiver diploma, não tiver estudado? Olha, o certo é estudar e ter diploma, mas, por exemplo, para trabalhar em loja, às vezes, só precisa ter experiência, saber o serviço... (Criança 4, de 10;11 anos, nível II).

Pode-se perceber que as crianças no nível II acreditam que, além da formação, é necessário esforço para obter trabalho, mas esse esforço, diferente da ideia encontrada no nível anterior, deve estar voltado para um objetivo: trabalhar para ter condições de se sustentar. As possibilidades de conceituação são aumentadas devido às influências sociais, ao desenvolvimento da capacidade de abstração e às estruturas de pensamento que, neste nível, permitem ao adolescente pensar sobre um mundo possível, hipotético, não mais baseado apenas na percepção da realidade.

Para os adolescentes do nível III, além das opções apresentadas no nível II como estudar, querer, se formar etc. há a vontade, compreendida como desejo individual e consiste em tomar consciência das dificuldades que existem para alcançar um estado ou meta e a ação do sujeito deverá ser dirigida à superação dos obstáculos, dos quais ele tem consciência. Este tipo de resposta é também apontado por Delval (2002). Nos extratos a seguir, exemplificamos essas características.

- Como você acha que uma pessoa consegue um trabalho? O que ela precisa fazer? Primeiro, ela precisa estudar. Precisa ter vontade de trabalhar.. e procurar um emprego e ver se aparece. Mas, se não estudar, uma pessoa pode conseguir um trabalho? Consegue... mas não vai ser um emprego tão bom assim... vai 
receber só um salário mínimo, vai ser complicado pra ela sobreviver. - O que seria um"emprego bom"? Emprego bom... é... tipo... ah... eu não sei dizer o que é um emprego bom... é um emprego que dê pra você viver normal, sabe? Não tem que passar dificuldade. O emprego de pedreiro é um emprego que cê não tem que estudar, mas tem que saber as coisas pra construir. (Adolescente 2, de 13;7 anos, nível III).

- Como ela consegue? Normalmente, ela vai atrás. - Como? Ah...assiste o jornal...meu pai quando ele emprega as pessoas, ele coloca anúncios, aí as pessoas interessadas vão atrás. - Além disso, elas precisam fazer mais alguma coisa? Normalmente, o currículo, né. - O que é currículo? É...a...seria uma ficha de experiência...que relata...tipo...o que cê já fez, que graduação você tem...sua capacitação...tudo tá no currículo. - O que é "graduação"? Até onde ce foi na escola. - Quem não estuda, não chega a ter uma graduação, consegue trabalho? Conseguir...consegue, mas não te garanto que seja um trabalho bom. - O que seria um "trabalho bom"? Que ganha bom salário. - Então, se não estudou, ela conseguiria um trabalho... De faxineiro de rua...de gari. - Que ganha menos? Ganha menos. (Adolescente 10, de 14;2 anos, nível III).

Os adolescentes acreditam que há um caminho a ser percorrido para obtenção de trabalho, obedecendo a uma hierarquia dos fatos, ou seja, a pessoa estuda, faz seu currículo, procura emprego e enfrenta a concorrência para obter trabalho. Os estudos não são mais a única forma de se preparar para o trabalho, mas a pessoa que não estudou pode tentar trabalhar no que denominaram de "trabalhos ruins", pelos quais a remuneração é menor, o tempo de trabalho é maior e há dispêndio maior de energia física. Porém, independente de ser um emprego "bom" ou "ruim" deve-se saber executar as tarefas inerentes a cada profissão. A capacidade individual deve ser comprovada para que se entre no mercado de trabalho. Ressaltamos que as 
crianças e adolescentes deste estudo estão inseridos em um contexto social que difere de outros locais. Viçosa é uma cidade universitária e as crianças entram em contato, desde muito cedo, com termos como "universidade", "graduação", "capacitação", "currículo", termos estes já utilizados pelas crianças, como foi mostrado nos extratos apresentados.

Neste estudo, pode-se perceber uma evolução do conceito de trabalho nas representações de crianças e adolescentes, uma vez que os mesmos apresentam respostas denotando níveis diferenciados de compreensão. Isto se deve, segundo Piaget $(1964,1973)$ a um processo contínuo de assimilação e acomodação do sujeito ao mundo social e deste ao sujeito. As transmissões sociais assumem importância impar nesta construção, pois nota-se que as crianças sempre retomam suas experiências pessoais para exemplificar suas respostas. Como pôde ser visto, fica evidente a mobilidade de crianças e adolescentes de uma mesma faixa etária em níveis diferentes de representação.

\section{Conclusão}

A partir da pesquisa com crianças e adolescentes de 4 a 14 anos de idade, obtivemos dados relevantes sobre a construção do conhecimento social, demonstrando que este tipo de conhecimento se dá por níveis, que são coerentes e influenciados pelo meio social em que a criança está inserida, onde a transmissão e as interações sociais são fatores importantes na formação de conceitos pela criança. Percebe-se, em todos os níveis, diferenças individuais, que nos levam a reforçar a ideia de Piaget de que os conhecimentos, mesmo aqueles que a criança adquire por meio das trocas com as pessoas, são transformados pela criança de forma ativa, não se configurando em meras cópias da realidade.

Diante destas considerações, percebe-se a dificuldade que as crianças enfrentam para ultrapassar as ideias concretas e o pensamento ligado ao real para chegar ao pensamento formal. Os fatores apontados por Piaget 
(maturação e hereditariedade; interações e transmissões sociais, exercício e experiência e a equilibração além da afetividade que está presente em cada um desses fatores) explicam porque o desenvolvimento e o meio social influenciam na representação que crianças e adolescentes tem sobre o mundo social e, especificamente, sobre o trabalho. Entretanto, essa assimilação é ativa e sofre transformações, sendo produto original do pensamento da criança.

Nesta pesquisa, os objetivos foram buscar a gênese do conceito de trabalho, identificando e analisando quais são as representações de crianças e adolescentes sobre trabalho. Procuramos ainda examinar as ideias subjacentes às suas representações, de acordo com os níveis de desenvolvimento estudados, levantando-se as tendências gerais presentes em suas respostas. Fundamentamos nossa investigação na teoria piagetiana, cujo pressuposto básico é de que o conhecimento é construído a partir da interação do sujeito com o objeto, evoluindo de um nível mais simples para um nível mais complexo.

A análise dos resultados permitiu confirmar tal hipótese, pois como pôde ser verificado neste estudo, as ideias dos sujeitos sobre o trabalho vão mudando no decorrer de seu processo de desenvolvimento, indo de ideias realistas e ligadas ao real, até uma forma de pensamento em que já é capaz de lançar hipóteses e inferir dados, não mais a partir de uma realidade concreta, mas pensando sobre possibilidades.

Os resultados encontrados neste trabalho sugerem que há uma tendência evolutiva nas representações de crianças e adolescentes sobre a conceituação de trabalho. O trabalho é percebido pelas crianças, mesmo as mais jovens, como algo que as pessoas fazem para sobreviver, por meio do pagamento recebido em troca de suas tarefas laborativas. Como visto, as crianças de 4, 6 e 7 anos não apresentaram conceituações, estando presente em suas respostas o finalismo, característico deste estágio. O dinheiro é a única finalidade do trabalho, entretanto há um inicio da idéia de que as pessoas podem ganhar amigos, conhecimento, etc. No estágio pré-operatório, 
que vai aproximadamente, de dois a seis anos de idade, as crianças possuem pensamento concreto e não conseguem pensar sobre situações abstratas, tomando as ações das pessoas para "dizer" o que é trabalho. Por volta dos seis anos, aparecem as ações que as pessoas fazem como forma de definir o que é trabalho. Chama a atenção a ideia de que o trabalho é "comprador" pelo trabalhador. O trabalho continua sendo um meio para ganhar dinheiro. Permanece ainda o finalismo encontrado em crianças de 4 anos.

Por volta dos sete anos, as crianças iniciam uma transição para o estágio operatório concreto caracterizado pelo pensamento concreto, baseado nas percepções da realidade, mas com modificações importantes no desenvolvimento mental, em que surgem novas formas de organização, atingindo um equilíbrio mais estável. A queda acentuada do egocentrismo permite a coordenação de pontos de vista diferentes. Entretanto, há indícios que a construção do conhecimento social é relativamente mais vagarosa que as transformações cognitivas alcançadas até agora e conforme Delval (2002) as explicações para este fato não estão ainda muito claras. Pode-se considerar que o mundo social é mais complexo que o mundo físico, pois os problemas para este último são facilmente materializáveis por meio de situações com materiais concretos como varetas, pêndulos, sombras e o mesmo não ocorre com os fenômenos sociais.

Aproximadamente, aos 10 anos, as respostas já diferem em grau de complexidade em relação às crianças de 7 anos embora pertençam, teoricamente, ao mesmo estágio de desenvolvimento cognitivo. O uso do termo sustentar, relacionado ao conceito de trabalho, é recorrente e apareceu apenas em uma criança de 7 anos, sendo considerado, portanto, uma novidade no grupo de crianças de 10 anos. Essa constatação nos permite inferir que ha uma tendência diferenciação conceitual dentro do mesmo grupo. Aproximadamente aos 11 anos, as crianças iniciam uma transição para o estágio operatório formal, no entanto, suas conceituações se parecem com as apresentadas pelas crianças de 10 anos. Não encontramos diferenças significativas dentro deste grupo. Há um início de diferenciação 
entre tempo de trabalho e tempo de lazer. As relações passam a ser entendidas como relações sociais e não como relações entre os indivíduos confirmando os resultados encontrados por Sierra e Enesco (1995) e Delval (2002).

No estágio operatório formal, as características do pensamento mudam. Os adolescentes já são capazes de pensar em termos de conceituações, seu pensamento é descentrado e eles possuem a capacidade de pensar de forma abstrata sobre problemas hipotéticos e situações abstratas, formulando suas hipóteses. Os termos sustentar, sobreviver podem ter o mesmo sentido de "ter qualidade de vida". Os estudos aparecem de forma hierárquica na conceituação priorizando-se na escala estudo, formatura, procura pelo trabalho e são esses os passos que devem ser seguidos pelo sujeito. O trabalho é visto como meio para alcançar fins.

Ressaltamos a importância de pesquisas sobre o conhecimento social, uma vez que traduzem o pensamento/representações da criança em seu processo evolutivo e podem se constituir como termômetros para políticas públicas de atendimento à infancia, repercurtindo também em políticas e práticas educacionais. A fala da criança (que tem muito a nos dizer) deve ser valorizada, pois desenvolve-se imersa em uma cultura, trazendo à tona, elementos que muitas vezes, passam despercebidos para os adultos que a educam.

\section{Referências}

ARIÈS, P. História social da criança e da família. 2. ed. Rio de Janeiro: Guanabara, 1986.

CARMO, P. S. A ideologia do trabalho. 15. ed. São Paulo: Moderna, 2005.

CRUZ, S. H. V. A criança fala: a escuta de crianças em pesquisas. São Paulo: Cortez, 2008.

CHAKUR, C. R. S. L. O social e o lógico-matemático na mente infantil: cognição, valores e representações ideológicas. São Paulo: Arte e Ciência. 2002. 
DELVAL, R. Algumas reflexiones sobre los derechos de los niños. Infância y sociedad, Madrid, n. 27/28, p. 14-41, 1994.

Introdução à prática do método clínico: descobrindo o pensamento das crianças. Porto Alegre: Artmed, 2002.

ENESCO, I.; NAVARRO, I. La comprensión de la organización social en niños y adolescentes. Madrid: CIDE. 1995.

LA TAILLE, I . Desenvolvimento do juízo moral e afetividade na teoria de Jean Piaget. In: Piaget, Vygotsky e Wallon: teorias psicogenéticas em discussão. São Paulo: Summus, 1992.

LEI n. 8.069, de 13 de julho de 1990. "Dispõe sobre o Estatuto da Criança e do Adolescente e dá outras providências". Diário Oficial da União, Brasília: DF, 16 de julho de 1990 .

MARCONI, M. A.; LAKATOS, E. M. Técnicas de pesquisa. 4. ed. São Paulo: Atlas, 1999.

MIGEOTTE, L. Os filósofos gregos e o trabalho na antiguidade. In: MERCURE, D.; SPURK, J. (orgs). O trabalho na história do pensamento ocidental. Petrópolis: Vozes, 2005.

MORIN, E. Os sentidos do trabalho. In: WOOD, T. (Ed.). Gestão empresarial: o fator humano. São Paulo: Atlas, 2002. p. 13-34.

TONELLI, M. J.; PLIOPAS, A. O trabalho e seus sentidos. Psicologia e Sociedade, Belo Horizonte, n. 19 (Especial), p. 47-56, 2007.

PIAGET, J. A Epistemologia Genética. Petrópolis: Vozes, 1971. (ed. orig. 1970).

Estudos sociológicos. Rio de Janeiro: Forense, 1973.

. Da lógica da criança à lógica do adolescente. São Paulo: Pioneira, 1976.

Biologia e conhecimento. 2. ed. Petrópolis: Vozes, 1996. (ed. orig. 1967).

A linguagem e o pensamento da criança. 7. ed. São Paulo: Martins Fontes, 1999. (ed. orig. 1966).

. A representação do mundo na criança. São Paulo: Idéias e letras, 2005. (ed. orig. 1926).

. Seis estudos de psicologia. 24. ed. Rio de Janeiro: Forense Universitária, 2007. (ed. orig. 1964).

INHELDER, B. A psicologia da criança. 2. ed. Rio de Janeiro: Difel, 2006. (ed. orig. 1968). 
SALAMITO, J. M. Trabalho e trabalhadores na obra de Santo Agostinho. In: MERCURE, D.; SPURK, J. (orgs). O trabalho na história do pensamento ocidental. Taborda. Petrópolis: Vozes, 2005.

SALLES, L. M. F. Infância e adolescência na sociedade contemporânea: alguns apontamentos. Estudos de psicologia, Campinas, v. 22, n. 1., jan./mar., 2005.

RAMALHO, J. R; SANTANA, M. A. Sociologia do trabalho no mundo contemporâneo. Rio de Janeiro: Jorge Zahar, 2004.

WADSWORTH, B. Piaget para o professor da pré-escola e o $1^{\circ}$ grau. São Paulo: Pioneira, 1987.

Recebido em 04 de dezembro de 2017. Aprovado em 05 de fevereiro de 2018. 


\title{
Noções de Espaço e Lugar na perspectiva de alunos do $6^{\circ}$ Ano do Ensino Fundamental II: relações de interdependência entre conhecimento social e cognitivo
}

\author{
Francismara Neves de Oliveira ${ }^{1}$ \\ Guilherme Aparecido Godoi ${ }^{2}$
}

\begin{abstract}
RESUMO
Trata-se de estudo exploratório-descritivo de abordagem qualitativa baseado na Epistemologia Genética. Integra as pesquisas sobre conhecimento social, compreendendo o espaço vivido para além da materialidade, o que requer operações mentais avançadas. Objetivou relacionar desenvolvimento cognitivo e noções de espaço e lugar nas significações de 8 alunos do $6^{\circ}$ ano do Ensino Fundamental II, de escola estadual paranaense. Os participantes foram submetidos à provas cognitivas e entrevista clínica. Os resultados indicaram que as noções de espaço e lugar requerem construção inferencial. Dos 8 participantes, 6 classificaram-se no nível I, 1 nível II e 1 nível III de conhecimento social, correspondentes aos níveis de abstração. A maioria apresentou nível mais elementar de conhecimento social (N1=6 alunos, N2=1 e N3=1). Conclui-se que a construção cognitiva mais elaborada (abstração reflexiva), melhora a compreensão da realidade social de espaço e lugar e favorece a atuação do sujeito na produção de espaços criativos e solidários.
\end{abstract}

PALAVRAS-CHAVE: Epistemologia Genética. Representação do espaço. Conhecimento Social. Noções de Espaço e Lugar.

\footnotetext{
${ }^{1}$ Pós-Doutorado em Psicologia da Educação- IPUSP-USP, Doutorado em Educação - UNICAMP, Mestrado em Educação - UNICAMP, Pedagogia-UEL. E-mail: francis.uel@gmail.com.

2 Mestre em Educação - UEM, Bacharelado e Licenciatura em Geografia - UNICAMP. E-mail: guilhermeapgodoi@gmail.com.
} 
Social notions about space and place in the meanings of students $6^{\text {th }}$ basic school: interdependence relationship between social and cognitive knowledge

\begin{abstract}
This is an exploratory, descriptive study, with a qualitative approach based on Genetic Epistemology. Integrates researches about social knowledge, comprising the lived space beyond of materiality, wich requires advanced cognitive operations. Had as objective to link cognitive development and social notions of space and place in the meanings of 8 students of 6th series of basic educacional, of public school in Paraná. The participants were submitted to the cognitive tests and clinical interview. The results indicated that social notions require inferential constructions. Six participants were under in level I, 1 participant in level II and 1 participant in level III of social knowledge, in levels of abstraction corresponding. The most part of the participants was concentrated at elementary level of social knowledge ( $\mathrm{N} 1=6$ alunos, $\mathrm{N} 2=1$ e N3=1). The conclusion is that cognitive construction more refined, corresponding reflexive abstractions, improvement social understanding and influence to produce creative and supportive places.
\end{abstract}

KEYWORDS: Genetic Epistemology. Representation of space. Social knowledge. Notions of Space and Place.

$* * *$

\title{
Introdução
}

O aporte teórico-metodológico da Epistemologia Genética tomado para análise neste artigo, adota como ponto de partida que o conhecimento se diferencia em três tipos: o físico, o lógico-matemático e o social. Apesar de distintos, há uma interdependência entre os três tipos de conhecimento. Assim, não é concebível um conhecimento puramente físico ou social. A inteligência lógica assume caráter fundamental nesta construção, pois é a coordenação de relações lógicas que possibilita pensar o objeto. 
Concebemos que todo conhecimento tem sua origem nas interações sociais. Como afirma Delval, 2007, p.56: “[...] Tenemos que manifestar de forma inequívoca que, en nuestra opinión, todo conocimiento tiene un origen social, que el conocimiento sólo es posible viviendo en sociedad y que compartimos con los otros el conocimiento [...]”.

Nessa linha de compreensão, os conceitos são sociais e cognitivos simultaneamente, pois produzidos socialmente precisam ser significados internamente pelo sujeito que os conhece. A discussão que apresentamos no presente artigo, se insere nessa compreensão de integração entre os três tipos de conhecimento, mas busca analisar em especial, a relação entre conhecimento lógico-matemático e social no que concerne à representação cognitiva do espaço e a noção geográfica de espaço e lugar.

O conceito de "país” estudado por Piaget (1967), é um exemplo da coordenação entre os tipos de conhecimento na construção de um conceito. Ao explorar as significações que as crianças possuíam sobre a ideia de "país", Piaget estava interessado em desvendar a lógica envolvida na construção do conceito. Notou que as crianças apresentavam ideias bem particulares sobre o tema distinguindo três estágios de respostas: país como unidade simples indiferenciando cidades, cantões e país, depois cidades e cantões compreendidas como pertencentes ao país e por fim ligação correta entre os três elementos.

A noção de "país" constitui-se pela evolução da elaboração da noção de conjunto, isto é, a relação entre a parte e o todo e as indissociabilidades que a constituem. Cada estágio compreende um melhor equilíbrio das estruturas do pensamento por meio das quais se avança pouco a pouco, até estabelecer a relação correta entre a parte e o todo, compreendendo-os em relação de codependência.

Portanto, não se trata de uma transmissão passiva da realidade, ou incorporação da informação externa, pois segundo Piaget (1978, p. 224) "para que uma transmissão seja possível entre o adulto e a criança ou entre o meio social e a criança educada, é necessário haver assimilação pela 
criança do que lhe procuram inculcar do exterior". As transmissões sociais, são condição necessária, mas insuficientes para o desenvolvimento cognitivo, intelectual e social dos sujeitos. Além da interação social, a ação sobre o objeto é um fator fundamental e corresponde a uma construção singular e constante do sujeito.

As pesquisas no campo do conhecimento social tiveram início na década de 1970 internacionalmente, com destaque para os trabalhos desenvolvidos pelo espanhol Juan Delval, que foi responsável pelo intercâmbio e introdução do tema no Brasil, influenciando os primeiros estudos brasileiros relacionados ao conhecimento social durante a década de 90 (GUIMARÃES; SARAVALI, 2009).

Delval (2007) identificou que os conceitos e ideias que as crianças apresentam sobre as diversas temáticas sociais não se limitam à reprodução fiel da realidade. Pelo contrário, suas significações apresentam aspectos singulares revelando o processo construtivo de novos conhecimentos. As transmissões sociais não se impõem, tampouco são absorvidas tal como são pelo sujeito. Os dados transmitidos socialmente se integram às estruturas mentais do sujeito, o qual os interpreta e reorganiza com base nos processos de assimilação e acomodação, configurando um processo dialético entre o individual e o social.

Conforme Delval e Padilla (1997) e Denegri (1998) isto explicaria as diferentes concepções existentes entre sujeitos de diferentes idades, na mesma cultura e em culturas distintas, bem como as semelhanças de respostas dos sujeitos de mesmo momento de desenvolvimento, em diferentes contextos sociais. Também explicaria a diferença de pensamento pela diferença de qualidade da estrutura mental.

A partir das crenças que as crianças elaboram acerca da realidade social, Delval (2002) estabeleceu três níveis (estágios) de evolução. No nível I o sujeito se baseia nos aspectos visíveis para estabelecer suas representações sociais e desconsidera os processos ocultos. As imagens são 
estereotipadas, não há coordenação de perspectivas diferentes e não reconhecem as relações sociais (as relações são vistas como pessoais).

No Nível II o sujeito começa a considerar os processos ocultos (inferências) e ainda têm dificuldade em coordenar diferentes pontos de vista, mas começa a estabelecer relações de ordem social, distanciando-se das puramente pessoais. No nível III o sujeito passa a considerar os processos ocultos, reconhece os diferentes pontos de vista, possibilidades e alternativas, se torna mais crítico e passa a estabelecer relações de ordem social. A sucessão dos três níveis compreende o processo de descentração do pensamento do sujeito, afastando-se dos aspectos puramente visíveis em direção à proposições mais abstratas.

Alguns pesquisadores tem procurado compreender os processos percorridos pelos sujeitos na elaboração do saber social, evidenciando que o conhecimento é produzido na interação social, por meio de significações atribuídas pelo próprio sujeito. No âmbito internacional, destacam-se as pesquisas de Delval (1989, 1992, 1993, 1997, 2002, 2007, 2013); Delval e del Barrio (1992); Delval e Echeita (1991); Delval e Padilla (1997); Delval e Vila (2008); Denegri (1998); Denegri, Toro e López (2007); Enesco et al. (1995); Navarro e Enesco (1993, 1998); Navarro e Peñaranda (1998); e Rodríguez, Kohen e delval (2008).

Apesar da inexistência de estudos específicos sobre a temática do lugar e espaço geográfico, tema que nos interessa diretamente neste artigo, destacamos a seguir algumas pesquisas nacionais e internacionais que consideramos pertinentes à nossa investigação, pois elas ilustram o modo de pensar questões abstratas e o sistema inferencial necessário à leitura do mundo e do espaço.

$\mathrm{Na}$ modalidade de estudo evolutivo, dos quais participaram crianças e adolescentes de distintas idades, é destacada a relação solidária entre os domínios cognitivo e social na construção de elaborações da realidade social. No âmbito internacional, citamos Delval e del Barrio (1992); Enesco et al. (1995); Navarro e Peñaranda (1998); e Rodríguez, Kohen e Delval (2008). 
No contexto nacional destacamos pesquisas que nos permitem compreender como se dá a construção de inferências, tais como: Barroso (2000); Cantelli (2000); Freire (2017); Guimarães (2012); Mano (2013); Monteiro (2013); Peralta, (2017); Pieczarka (2009); Saravali e Guimarães (2010) e Saravali et al. (2012, 2013, 2014).

Em suma, as pesquisas sobre o conhecimento social confirmam que toda construção é gradual e protagonizada pelo sujeito, assim como evidenciam o caráter fundamental da inteligência lógico-matemática e das estruturas do pensamento formal na elaboração do conhecimento social em níveis mais elevados. Mostram que a elaboração do saber envolve uma relação de interdependência, produzida pelas interações entre o sujeito e o meio físico e social, configurando um contexto dinâmico e indissociável (PIAGET, 1978). Essa relação entre as dimensões cognitiva e social nos interessou verificar na noção de espaço e lugar.

\section{Conhecimento Social: espaço e lugar}

O processo de construção da noção de espaço se dá por elaborações cada vez mais complexas do mundo físico e social. O sujeito primeiramente constrói relações menos complexas do espaço topológico, formado pelas noções de vizinhança, separação, ordem, envolvimento e continuidade. São noções elementares, pois é a partir delas que se compreende o espaço projetivo e euclidiano.

O espaço projetivo por sua vez, envolve o relacionamento da perspectiva espacial, compreendendo não apenas o ponto de vista do sujeito, mas sim os diferentes pontos de vista possíveis. Este relacionamento pressupõe as noções de acima-abaixo, frente-atrás e as noções de direitaesquerda. Por fim, o espaço euclidiano envolve a construção de um sistema de coordenadas espaciais que requer a noção métrica de distância e proporção. 
O espaço projetivo e euclidiano são construções correlatas e solidárias, pois à medida que um alcança patamares mais elevados de elaboração, o outro acompanha esse processo construtivo (PIAGET; INHELDER, 1993). O espaço cognitivamente elaborado permite a representação do espaço Geográfico. É na leitura do espaço geográfico que o espaço cognitivo se estrutura.

Alguns estudos nacionais corroboram a ideia de que a noção espacial é construção gradativa e depende de conflitos cognitivos advindos do meio social, mas coordenados internamente, que atuam para desequilibrar o sistema cognitivo e obrigá-lo a descentrar e construir novas relações espaçorepresentativas. Indicam que o conceito de espaço envolve experiência física, relações lógico-matemáticas e conhecimento convencionado socialmente. Citamos: Bom Jardim (2003); Costella (2008); Justo (2014); Miranda (2001); Paganelli (1982); Pires (2016); Silva (2013) e Solka (2017).

Correspondente à noção ampliada do espaço representativo, o espaço geográfico é definido por Santos (2008, p. 46) como "o conjunto indissociável de sistemas de objetos, naturais ou fabricados, e de sistemas de ações, deliberados ou não. A cada época, novos objetos e novas ações vêm juntar-se às outras, modificando o todo, tanto formal quanto substancialmente". O Homem e o espaço se relacionam de uma forma dialética: de um lado o espaço fornece condições para o desenvolvimento das sociedades, e de outro as sociedades por meio de seu trabalho e simbolismo produzem e reproduzem constantemente o espaço. Sendo assim toda prática social também é espacial, o espaço é um conjunto de formas que contém frações da sociedade em movimento (SANTOS, 1988). É na compreensão dessa relação socioespacial que o indivíduo adquire consciência para intervir e transformar a sua realidade (CAVALCANTI, 1998).

Nesse contexto de análise situamos a noção de lugar, reconhecendo que o conceito é considerado controverso e polissêmico. Conforme Holzer (1999, p. 67), a noção de lugar - restrita ao âmbito locacional - é característica do positivismo da Geografia predominante no século XX. Naquele contexto, os 
conceitos mais referenciados no período da Geografia Clássica foram o de paisagem e território, justapondo os aspectos físicos aos sociais (LENCIONI, 2005; QUEIROZ, 2014).

Interessante observar que o movimento da ciência e o da construção de relações cognitivas e sociais por parte dos sujeitos é análogo. Assim, tanto na ciência quanto na construção individual do pensamento científico, é possível inferir um processo gradativo e evolutivo de ressignificação, coordenado por relações indissociáveis, parte e todo em movimento dialético.

Superada essa fragmentação, a partir da década de 1970, surgiram duas novas correntes: a Geografia Crítica embasada no materialismo histórico e dialético e Geografia Humanística que tem por base filosófica a fenomenologia e o existencialismo. Apesar de apresentarem posturas metodológicas, filosóficas e epistemológicas diferentes, tinham um ponto em comum: a compreensão do mundo a partir das relações entre a sociedade e o espaço, convergindo esforços para a configuração de uma Geografia de caráter social (GOMES, 2000; LENCIONI, 2005).

Os Geógrafos humanistas em especial, encontraram neste conceito a possibilidade de compreender o mundo, o diálogo entre o homem e seu meio, marcado pela experiência, percepção e subjetividades (HOLZER, 1999; TUAN, 1983). A noção de lugar, nesta compreensão se integra à noção de espaço, enfatizando as experiências que o sujeito estabelece com o mundo ao seu redor e a consciência construída a partir dessas significações. Assim, o lugar não pode ser compreendido sem ser experienciado e só adquire significado através das intenções e ações humanas em relação a ele.

Por adotarmos essa compreensão do conceito de lugar é que o justificamos como conhecimento social. Não se refere apenas a objetos e atributos das localizações espaciais (conhecimento físico), mas requer experiências diversificadas e continuamente ressignificadas (conhecimento lógico-matemático) no envolvimento dos sujeitos com o mundo e a realidade na qual está inserido (conhecimento social). 
Compreender o lugar como o espaço vivido, é de suma importância para o desenvolvimento da vida em sociedade. Porém, o conhecimento sobre os objetos sociais é de difícil elaboração (DELVAL, 2002), e portanto, necessita além do acesso às informações no contexto social, da ação ativa (reflexiva) do sujeito sobre os objetos de conhecimento, o que o vincula, pelo significado que atribui às experiências vividas. Ou seja, nesse processo, o sujeito constrói-se a si mesmo ao mesmo tempo que elabora uma noção social de lugar.

\section{Aspectos Metodológicos}

O Método Clínico-Crítico embasou a entrevista clínica semiestruturada e as duas provas operatórias aplicadas: o experimento das Três Montanhas (ou "O Relacionamento das Perspectivas") e o Mapa da Aldeia.

A prova das três montanhas investiga as relações projetivas, principalmente a noção de perspectiva. O material consiste em uma maquete de três montanhas sobre um plano de $50 \mathrm{~cm}$ por $50 \mathrm{~cm}$. O tamanho das montanhas varia de $6 \mathrm{~cm}$ a $20 \mathrm{~cm}$ e cada montanha apresenta características particulares. Além da maquete (Figura 1) compõe o material um boneco de $3 \mathrm{~cm}$ de altura e 10 cartões cada um representando uma fotografia que foi tirada em 8 posições diferentes da maquete.

FIGURA 1: Relacionamento das Perspectivas

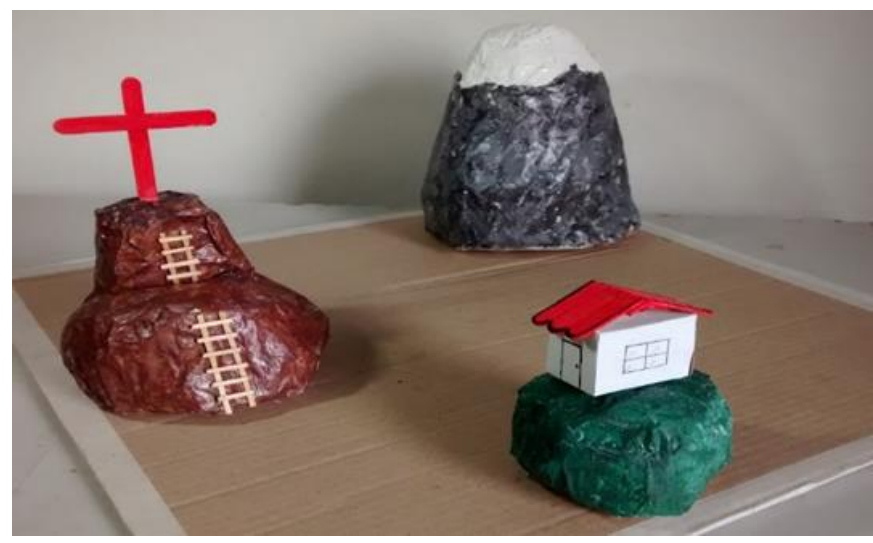

Fonte: Elaboração própria. 
A prova da Aldeia investiga as relações euclidianas de proporção, distância e sistema de coordenadas/ângulos na vertical e horizontal (PIAGET; INHELDER, 1993). O material é formado por uma maquete em um plano de $50 \mathrm{~cm}$ por $50 \mathrm{~cm}$. Os objetos variam entre 7,5 cm e $20 \mathrm{~cm}$. Algumas adaptações foram realizadas mantendo-se a apresentação de um conjunto de elementos que figurariam um território (Figura 2).

FIGURA 2: Prova da Aldeia adaptada

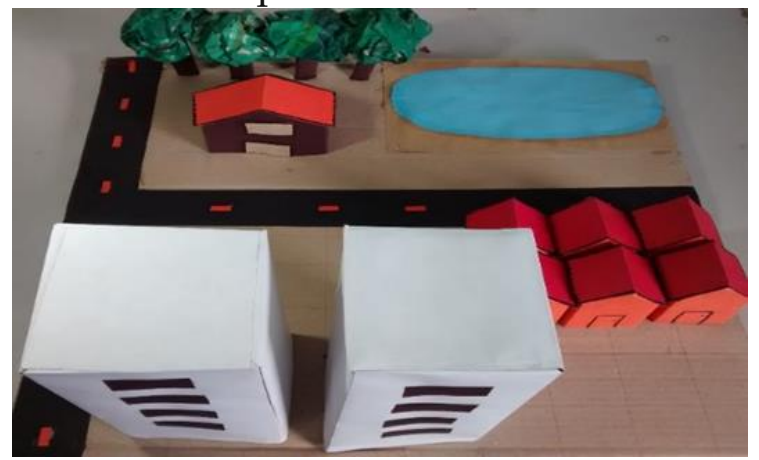

Fonte: Elaboração própria

A entrevista clínica foi utilizada para conhecer as ideias que os alunos possuem sobre o conceito de "lugar" e "espaço geográfico". Perguntou-se: sobre o espaço geográfico e noção de lugar. Para suscitar conflito, questões apoiadas em uma fotografia da favela de Paraisópolis-SP (Figura 3) foram utilizadas e enfatizaram contraste entre os lugares, relações sócio-políticas, razões para mudanças que ocorrem nos espaços e pertencimento ao lugar.

FIGURA 3: Favela de Paraisópolis (SP).

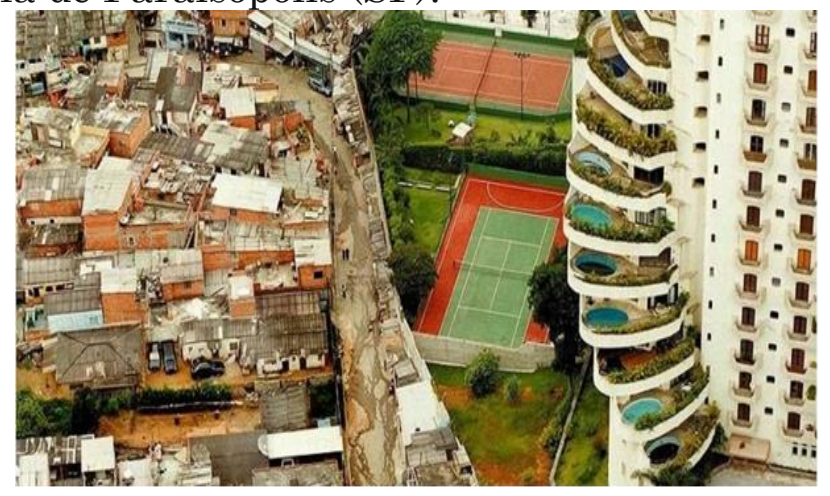

Fonte: Tuca Vieira, 2012 . 
O cenário da pesquisa foi uma escola estadual, central, da cidade de Londrina- PR que recebe alunos de vários bairros da cidade. Participaram desta pesquisa 8 alunos do $6^{\circ}$ ano do Ensino Fundamental II. A escolha dos participantes foi aleatória, realizada por meio de um sorteio. Foram sorteados 6 meninos e 2 meninas com idades entre 10 e 14 anos, sendo que no grupo havia um participante $\left(14\right.$ anos) reprovado por duas vezes $\left(5^{\circ}\right.$ e o $6^{\circ}$ ano) e um participante (12 anos de idade) reprovado uma vez ( $4^{\circ}$ ano) e os demais participantes sem reprovação em sua trajetória escolar.

A pesquisa seguiu os procedimentos éticos e foi aprovada com parecer consubstanciado do comitê de ética em pesquisa envolvendo seres humanos (CEP/UEL/HU) $\mathrm{n}^{\circ}$ 1.962.044.

\section{Resultados e Discussão}

Retoma-se o objetivo que norteou a pesquisa o qual consistiu em investigar a relação existente entre o desenvolvimento cognitivo e a compreensão da realidade socioespacial. Nossa hipótese baseava-se no pressuposto de que o avanço no conhecimento lógico-matemático favorece a elaboração da realidade social, justamente pela necessária abstração reflexiva para a leitura dos fatos ocultos, mas que compõem o fenômeno social.

As demandas solicitadas cognitivamente dos participantes foram: na prova das Montanhas relacionar as perspectivas e construir um sistema de conjunto capaz de relacionar as diferentes perspectivas entre si e estabelecer relações entre a perspectiva própria e a dos outros observadores (PIAGET; INHELDER, 1993). O terceiro nível implica na relatividade completa das perspectivas. Na referida prova os autores não investigaram a perspectiva vertical.

No experimento Mapa da Aldeia, por outro lado que investigava as noções métricas euclidianas, são identificados 4 níveis, sendo o último 
(subestádio IV) o nível das operações abstratas. Conforme Piaget e Inhelder (1993), o Mapa da Aldeia envolve a síntese de todas as relações do espaço representativo, apontando tanto a lógica abstrata para as noções euclidianas, como também para as projetivas.

$\mathrm{O}$ relacionamento abstrato da perspectiva envolve a visão vertical e a sua bidimensionalidade, isto é, para a perspectiva aérea a altura dos elementos é desprezada, levando-se em conta apenas sua largura e profundidade. Ponderamos essa questão porque parece haver uma limitação do instrumento das Três Montanhas, por não alcançar o relacionamento da perspectiva vertical, que, poderia compor o estádio IV deste instrumento, requerendo abstrações. Porém, considerando que a prova do Mapa da Aldeia é sintetizadora dessas relações, que ao atingir o nível elevado na prova mais complexa (Aldeia), o nível máximo da prova das Montanhas seria superado. Diante disso, apresentamos de modo sintetizado no Quadro 1 a relação entre as noções do espaço representativo e o conhecimento social sobre espaço e lugar para os três instrumentos utilizados na coleta de dados.

Quadro 1 - Correspondência entre níveis de Conhecimento Social e Desenvolvimento Cognitivo

\begin{tabular}{|c|c|c|c|}
\hline Participante & $\begin{array}{c}\text { Prova das } \\
\text { Montanhas }\end{array}$ & Prova da Aldeia & $\begin{array}{c}\text { Conhecimento } \\
\text { Social }\end{array}$ \\
\hline S1 & III A & III A & I \\
\hline S2 & III A & III A & I \\
\hline S3 & III B & III B & I \\
\hline S4 & III B & IV B & III \\
\hline S5 & II B & II B & I \\
\hline S6 & III B & IV A & II \\
\hline S7 & III A & II A & I \\
\hline S8 & II B & II B & I \\
\hline
\end{tabular}

Fonte: Elaboração própria. 
$\mathrm{Na}$ intenção de solidificar os resultados encontrados, apresentamos a seguir excertos de protocolos da entrevista clínica, que exemplificam os respectivos níveis de conhecimento social.

\section{Nível I: Ideias Elementares Sobre o Lugar e o Espaço Geográfico}

Os dados mostram que 6 sujeitos dessa pesquisa apresentaram ideias de nível I sobre o conhecimento social de espaço e lugar (S1, S2, S3, S5, S7 e S8). Estes participantes, no Mapa da Aldeia não alcançaram o nível das abstrações reflexivas (nível IV) quanto às noções do espaço representativo. $\mathrm{Na}$ prova das Montanhas, 4 deles atingiram nível III (S1, S2, S3 e S7) enquanto 2 participantes ficaram no nível II (S5 e S8).

Alguns excertos dos protocolos sobre conhecimento social servem para exemplificar esse nível de pensamento. Quando questionados sobre o que é espaço geográfico definem: "Medir alguma coisa que você não sabe quanto espaço tem" (S8); “O espaço geográfico é o lugar, são as ruas... não sei explicar muito bem... o espaço geográfico é tudo" (S1); "Paisagem natural" (S3); ou ainda "Planeta Terra" (S5).

No nível I, não alcançaram compreensão que considerasse as relações sociais envolvidas na construção do espaço geográfico. As respostas baseiamse apenas nos aspectos mais visíveis e aparentes do espaço vivido: " $E$ onde tem casa, loja, mercado" (S8); "Porque eu estou vendo casas, prédios, algumas árvores" (S2); ou ainda: é “Cada passo que a gente dá [...] onde a gente consegue pisar" (S5); "Porque a gente consegue ir nele, porque eu vou nele, eu consigo entrar nele, eu consigo ver ele” (S3). São respostas autocentradas baseadas em relações pessoais e não sociais.

Sobre a fotografia de Paraisópolis, o participante S8, por exemplo, mencionou que "esse lugar poderia ficar mais arrumado e bonito, já os prédios do condomínio poderiam ficar velhos e com isso cairiam suas paredes". O participante S1 apresentou respostas semelhantes, disse que os lugares mudam porque ficam velhos. Também fez menção às mudanças 
mais aparentes no espaço, dizendo que "as casas da favela poderiam ter seus telhados arrancados" e que "as piscinas do condomínio poderiam transbordar com a água da chuva”.

Quanto à conjuntura social na produção do espaço, não estabelecem relações. Para eles, o tempo seria encarregado das transformações do lugar. Essa ideia desconsidera a bagagem histórica que os lugares possuem em sua constituição material e imaterial. Delval (2002, p. 225) explica que para esses sujeitos "as coisas sempre foram assim [...] não se entende a história nem a mudança social, nem que a vida em sociedade poderia ser de outra forma”.

Mesmo quando os participantes fazem alguma alusão à ação humana, essa se mostra limitada a certos atores sociais. Os participantes S8 e S1, por exemplo, consideraram que apenas as autoridades políticas, os arquitetos e os pedreiros seriam os agentes transformadores do espaço. Não compreendem a dinâmica socioespacial em sua totalidade, assim como excluem a si próprios desse processo.

Segundo Delval (2002) é comum neste nível I os sujeitos apresentarem respostas fantasiosas, em detrimento de relações mais lógicas sobre a realidade vivida. Esse é o caso de S2 que apresenta a seguinte solução para o contraste provocador da fotografia de Paraisópolis: "Os ricos, dando dinheiro para os moradores da favela, eles poderiam reformar suas casas". Para ele a pobreza só seria extinta por doação de dinheiro aos mais pobres. Trata-se de uma solução mágica e reducionista, sem levar em conta as complexidades da conjuntura econômica e social na produção do espaço.

$\mathrm{O}$ participante $\mathrm{S} 1$ apresentou uma reação semelhante, disse que a fotografia se tratava de uma montagem: "Nunca vi um negócio parecido, eu acho que a foto foi montada, porque não tem como uma casa como essa (condomínio) ficar perto de um lugar meio que acabadinho (favela)'.

Em suma, as respostas dos participantes não alcançaram um nível de compreensão sobre a dinâmica socioespacial na configuração dos lugares. Os 
sujeitos enxergam apenas as mudanças mais aparentes e não chegam a relacionar objetivamente a ação do Homem na construção do espaço.

\section{Nível II: Ideias em Transição Sobre o Lugar e o Espaço Geográfico}

Consideramos que houve coerência na relação entre os domínios social e cognitivo porque é possível atingir nível II e III nas perspectivas, porém manter-se no nível I de Conhecimento Social como apresentado anteriormente. Esse dado parece indicar que há uma especificidade do desenvolvimento cognitivo a ser gradativamente conquistada: as abstrações do nível III de conhecimento social.

A relação se manteve no caso de S6, único participante que atingiu nível II de conhecimento social, pois na prova das Montanhas ele atingiu o nível mais elevado enquanto na prova do Mapa da Aldeia atingiu o nível IV A. Ou seja, onde já se manifestam as abstrações, há avanço no conhecimento da realidade social.

Neste segundo nível, as ideias sobre a realidade se apresentam mais coerentes. As noções do mundo social apresentam consideráveis progressos em relação ao primeiro nível. Porém, ainda são ideias que estão em transição, isto é, a meio caminho de uma objetividade completa. O sujeito aos poucos vai se afastando da lógica puramente concreta e visível. Passa a organizar um pensamento abstrato que opera por meio de hipóteses e deduções.

Surge uma visão mais realista e dinâmica, afastada do que é mais evidente. A percepção aos poucos perde espaço para o pensamento lógico abstrato e com isso o sujeito passa a operar por inferências. Por espaço geográfico compreende: "Espaço geográfico é o espaço que cada pessoa... esqueci agora"; "Acho que cria laços alguma coisa assim, não me lembro direito"; "O espaço geográfico acho que é onde a gente faz as coisas”.

Esta resposta mostra um nível de compreensão mais elaborado sobre o espaço, em duas ideias muito interessantes: a primeira diz respeito aos laços 
ou vínculos que criamos com o espaço ao nosso redor, configurando o lugar, isto é, o espaço vivido. A segunda, quando o participante disse "onde a gente faz as coisas", onde se percebe que ele está se inserindo no processo construtivo do espaço, ou seja, considera-se também um ator nas dinâmicas socioespaciais.

Em relação à dinâmica construtiva do espaço, as respostas de S6 vão além do mais evidente, relacionando os aspectos ocultos envolvidos na configuração socioespacial: "Porque antigamente não tinha esses lugares, o Homem que criou", "Porque o homem construiu tudo isso daqui, antigamente era tudo grama e árvore", "Porque às vezes a pessoa tenta melhorar, mas acaba sendo pior"; "Porque retiraram muitas árvores daqui".

Sobre a desigualdade social representada na foto de Paraisópolis, inicia um processo de percepção da coexistência de contrastes, mas com nível crítico limitado, responde: "Porque aqui tem um lugar um pouco mais pobre e aqui um lugar mais ou menos, a realidade é essa, não tem separação"; "Não tem um lugar próprio pra um lugar assim, é tudo junto".

Entretanto, as realidades sociais na foto são discrepantes e exacerbadas e o participante as analisa como um lugar "um pouco mais pobre e outro mais ou menos", mas ainda assim, concebe que estão juntas, sem separação. Ainda em outro momento da entrevista, sobre os protagonistas responsáveis pelas mudanças no lugar, elege a escola e então explica que daqui há 10 anos, a escola "estará melhor, mais bonita". Ao ser questionado "e quem a deixará mais bonita?", responde: “Ah depende, acho que o diretor. O diretor e a pedagoga”.

Em suma, as respostas de $\mathrm{S} 6$ sugerem um pensamento que inicia a construção de abstrações, mas que ainda está incompleto e oscila, por isso não alcança o nível III do conhecimento social. 


\section{Nível III: Ideias Elaboradas Sobre o Lugar e o Espaço Geográfico}

A confirmação desse princípio se dá ao analisarmos o caso de $\mathrm{S} 4$, único participante a atingir o maior nível (III) nas respostas de conhecimento social. Ele atinge o nível III na Prova das Montanhas e o nível IV B na prova do Mapa da Aldeia.

Infere-se portanto, uma forte relação entre as noções do espaço representativo e o conhecimento social de espaço e lugar. A noção de conjunto permeia toda construção do espaço projetivo e euclidiano. É a coordenação das partes entre si e destas com o todo que torna possível o relacionamento da perspectiva e as noções métricas do espaço. Sendo assim, os participantes desta pesquisa que alcançaram o nível IV, possuem a noção de conjunto mais elaborada, um pensamento mais descentrado, no qual os diferentes pontos de vista são analisados um em relação ao outro.

Foram estes avanços que permitiram à S4 (embora IV A o tenha mantido na transição típica do nível II) e S6 construírem uma noção de espaço e lugar mais realista e complexa, pois a compreensão do espaço geográfico pressupõe o cruzamento dos diversos atores sociais culminando na construção material do espaço, assim como o espaço influenciando a vida dos que nele habitam. Uma relação dinâmica e dialética entre as partes e o todo.

$\mathrm{O}$ participante $\mathrm{S} 4$ foi o único que apresentou as ideias críticas sobre a temática pesquisada. Além de compreender a questão sobre o espaço geográfico também traz uma ideia mais elaborada sobre o conceito. Semelhante ao participante anterior, S4 apresentou a noção de vínculo e pertencimento com o espaço vivido. Disse que o espaço geográfico é o "lugar que convivemos", mesmo sem saber explicar precisamente. Diante de contraposição, feita pelo pesquisador, respondeu que aquilo que fica fora de um mapa também faz parte do espaço geográfico.

A ideia de pertencimento também aparece na questão sobre o lugar, $\mathrm{S} 4$ explicou que o lugar é onde "convivemos mais", citando como exemplo o seu 
quarto e o do seu irmão. A relação estabelecida pelo participante foi muito interessante, trazendo aspectos discutidos na corrente Humanística da Geografia. Sua resposta indica a interação que cada um constrói com o espaço, envolvendo a experiência intersubjetiva entre o sujeito, o espaço e seu grupo cultural. É por meio dessa experiência que os significados espaciais são construídos, fazendo com que o espaço em sua constituição mais abstrata se transforme em lugar, isto é, um espaço dotado de significados e sentimentos (TUAN, 1983). Tal aspecto aparece quando o participante diferencia o seu lugar (o seu quarto) e o lugar do seu irmão.

A experiência e o convívio no espaço escolar são os elementos que S4 utilizou na justificativa sobre a escola ser um lugar. Sua experiência neste espaço é tão profunda e significativa que o participante diz amar a escola, o que para Tuan (1983) seria o sentimento de topofilia e para Relph (1980 apud FERREIRA, 2002) uma internidade empática (emocional) com o lugar. As ideias do participante chegaram, inclusive, a se aproximar dos conceitos da Geografia Crítica sobre o espaço geográfico. O último trecho do protocolo mostra a compreensão de que o espaço não é formado apenas pelos objetos fabricados pelo ser humano, mas também de objetos naturais, formados pelas dinâmicas da natureza e da história geológica do planeta Terra. $\mathrm{O}$ participante disse que "a natureza pode criar montanhas e muitas coisas" e completou afirmando "que hoje em dia o que mais domina o mundo são as construções".

O participante alcançou uma compreensão de espaço geográfico bem próxima a de SANTOS (2008, p. 46): "conjunto indissociável de sistemas de objetos, naturais ou fabricados, e de sistemas de ações, deliberadas ou não". O conhecimento social de S4 vai ao encontro dos pressupostos descritos por Delval (2002) para o nível III no qual as respostas são inferidas a partir das informações disponíveis, se afastando dos elementos mais aparentes e concretos.

Em suma, ao verificar os dados apresentados pelos sujeitos dessa pesquisa, pode-se perceber que a elaboração do conhecimento social está 
atrelada ao desenvolvimento cognitivo. Diante disso, os resultados encontrados estão em conformidade com as ideias de Piaget (1973) e Delval (2002), pois indicam a interdependência entre os tipos de conhecimento, assim como evidenciam o caráter fundamental da inteligência lógicomatemática para a elaboração dos demais tipos de conhecimento, inclusive o social.

\section{Conclusão}

No contexto escolar a Geografia tem como demanda fomentar a construção de pensamento crítico que permita ao sujeito enfrentar as contradições socioespaciais, buscando a construção de espaços mais solidários.

A leitura significativa da realidade social pressupõe domínio cognitivo do espaço representativo. São as noções do espaço topológico, projetivo e euclidiano que permitem tanto a construção quanto a interpretação das noções sociais. A teoria piagetiana revela que o conhecimento é um processo em permanente construção, envolvendo a ação do sujeito em interação com seu meio físico e social. Assim também é para a construção das noções espaciais, que são elaboradas tanto no campo perceptivo quanto no representativo.

Diante de tais constatações, o presente estudo objetivou relacionar desenvolvimento cognitivo e noções sociais de espaço e lugar nas significações de 8 participantes, alunos do $6^{\circ}$ ano do Ensino Fundamental II, de uma escola estadual paranaense. A análise dos resultados nos levou a perceber relação entre os instrumentos lógicos e a construção dos saberes geográficos. Os aspectos cognitivos envolvidos na representação do espaço mostraram-se fundamentais para a elaboração do conhecimento social de lugar e espaço geográfico.

Com as provas operatórias e entrevista clínica foi possível conhecer as estruturas próprias da representação espacial bem como as ideias acerca da 
realidade social de lugar para cada participante. Os dados indicaram que cada um se encontra num momento particular de elaboração das noções projetivas e euclidianas, embora sejam todos da mesma série de escolarização. Enquanto alguns participantes apresentaram noções espaciais mais elaboradas na construção e argumentação, outros se encontravam num patamar inferior de elaboração. Diante disso, constatamos que o espaço representativo não é uma simples tradução do espaço percebido, pois o avanço da idade não garante por si só, sua construção.

Esta constatação vai ao encontro dos pressupostos piagetianos de que a representação espacial é uma construção do sujeito em sua interação com o meio e se processa gradualmente, partindo das relações topológicas, para posteriormente alcançar as relações próprias do espaço projetivo e euclidiano. Por mais que o sujeito elabore no campo perceptivo as noções espaciais, para a representação é necessário uma nova construção, que envolve a interação e experiência lógico-matemática sobre o objeto de conhecimento.

Em relação ao conhecimento social de lugar e espaço geográfico, constatamos que os participantes apresentam ideias bem particulares sobre a temática pesquisada. No cruzamento entre os dados do conhecimento cognitivo e social, revelaram-se relações que sugerem uma explicação para a predominância das ideias de nível I sobre a temática do espaço e lugar. Percebemos que somente os participantes que alcançaram o nível IV (formal) nas provas operatórias do Mapa da Aldeia, conseguiram apresentar ideias mais elaboradas sobre o espaço e lugar. O conhecimento social de nível II foi alcançado por S6, que apresentou relações projetivas e euclidianas típicas do subnível IV A. Já o participante S4 compôs o nível III do conhecimento social e nas provas operatórias o subnível IV B. Diante disso, apontamos uma forte relação entre o desenvolvimento cognitivo e a compreensão da realidade social. Envolve o relacionamento das perspectivas 
possíveis, a relação entre as partes e o todo (conjunto) e dinâmica construtiva do espaço geográfico, em sua totalidade material e social.

Portanto, compreender o espaço vivido para além de suas materialidades requer do sujeito operações avançadas do espaço representativo, não sendo suficiente apenas as transmissões sociais. O estudo permite inferir como relevante, práticas pedagógicas que favoreçam operação de relações do espaço representativo, propiciando gradativa elaboração desse tipo de conhecimento a fim de promoverem desenvolvimento cognitivo e social dos alunos.

Essas considerações reforçam a hipótese de que quanto mais complexa for a construção do conhecimento social e cognitivo do indivíduo acerca do espaço, maior será sua ação crítica na produção e significação construtiva do espaço vivido.

\section{Referências}

BARROSO, L. M. S. As idéias das crianças e adolescentes sobre seus direitos: um estudo evolutivo à luz da teoria piagetiana. 2000. 344 f. Dissertação (Mestrado em Educação) - Faculdade de Educação, UNICAMP, Campinas, 2000.

BOM JARDIM, R. P. Alfabetização cartográfica nos primeiros ciclos do ensino fundamental: o caso do SIMAVE. 2003. 101 f. Dissertação (Mestrado em Engenharia de Produção) - Programa de Pós-Graduação em Engenharia de Produção, Universidade Federal de Santa Catarina, Florianópolis, 2002.

CANTELLI, V. C. B. Um estudo psicogenético sobre as representações de escola em crianças e adolescentes. 2000. 243 f. Dissertação (Mestrado em Educação) Faculdade de Educação, UNICAMP, Campinas, 2000.

CAVALCANTI, L. S. Geografia, escola e construção de conhecimentos. Campinas: Papirus, 1998.

COSTELLA, R. Z. O significado da construção do conhecimento geográfico gerado por vivências e por representações espaciais. 2008. $202 \mathrm{f}$. Tese (Doutorado em Geografia) - Instituto de Geociências, UFRGS, Porto Alegre, 2008.

DELVAL, J. La representación infantil del mundo social. In: TURIEL, E.; ENESCO, I.; LINANZA, J. El mundo social en la mente del niño. Madrid: Alianza, 1989 . 
El construtivismo y la aquisición del conocimiento social. Apuntes de Psicologia, Madrid, n. 36, p. 05- 24, 1992. (mimeo).

La construcción del conocimiento social. In: Primer Encuentro Educar. 1993

A fecundidade da epistemologia de Piaget. In: TEBEROSKY, A.; TOLCHINSKY, L. Tradução Beatriz Affonso Neves. Substratum: Temas Fundamentais em Psicologia. Porto Alegre: Artes Médicas, 1997. (Cem anos com Piaget).

Introdução à prática do Método Clínico: descobrindo o pensamento das crianças. Tradução Fátima Murad. Porto Alegre: Artmed, 2002.

. Aspectos de la construcción del conocimiento sobre la sociedad. Educar em revista, Curitiba, n. 30, p. 45-64, 2007.

. El descubrimiento del mundo economico por niños y adolescentes. Madrid: Ediciones Morata, 2013.

.; DEL BARRIO, C. Las ideas de los niños acerca de la guerra y la paz. In: MARTIN, F.; BURILLO, F. (Coord.). La guerra: realidad y alternativas. Madrid: Complutense, p. 165-174, 1992.

.; ECHEÍTA, G. La comprensión en el niño del mecanismo de intercambio económico y el problema de la ganancia. Infancia y Aprendizaje, Madrid, n. 54, p. 71-108, 1991.

.; VILA, I. M. Los niños y Dios: ideas infantiles sobre la divinidad, los orígenes e la muerte. México: Siglo xxi, 2008.

.; PADILLA, M. L. El desarrollo del conocimiento sobre la sociedad. 1997.

DENEGRI, M. A construção do conhecimento social na infância e a representação da pobreza e desigualdade social: desafios para a ação educativa. In: Encontro Nacional de Professores do PROEPRE: A criança e a escola ,15, 1998. Anais... Campinas: UNICAMP/FE/LPG, 1998. p. 43-54.

DENEGRI, M.; TORO, G. M.; LÓPEZ, S. E. La comprensión del funcionamiento bancArio en adolescentes chilenos: un estudio de psicología econômica. Interdisciplinaria, Buenos Aires, v. 2, n. 24, p. 137-159, ago./dez., 2007.

ENESCO, I. et al. La comprensión de la organización social em niños y adolescentes. Madrid: CIDE, 1995.

FERREIRA, L. F. Iluminando o lugar: três abordagens (Relph, Buttimer e Harvey). Boletim Goiano de Geografia, Goiânia, v. 22, n. 1, p. 43- 72, jan./jun., 2002.

FREIRE, J. F. C. Direito de expressão, protesto e greve: noções sociais construídas por alunos de diferentes níveis de escolaridade e os precessos de generalização. 
2017. Dissertação (Mestrado em Educação) - Centro de Educação Cominicação e Artes, Universidade Estadual de Londrina, Londrina, 2017.

GOMES, P. C. C. Geografia e modernidade. 2. ed. Rio de Janeiro: Bertrand Brasil, 2000.

GUIMARÃES, T. Intervenção pedagógica e noções sobre o meio ambiente: a construção do conhecimento social à luz da epistemologia genética. 2012. $221 \mathrm{f}$. Dissertação (Mestrado em Educação) - Faculdade de Filosofia e Ciências, Universidade Estadual Paulista, Marília, 2012.

GUIMARÃES, T.; SARAVALI, E. G. A importância atribuída à escola por crianças inseridas em ambiente sócio-moral construtivista e ambiente tradicional: o desenho como forma de expressão do conhecimento social. Revista Scheme, Marília, v. 3, n. 3, p. 242-277, jan./jun., 2009.

HOLZER, W.. O lugar na geografia Humanista. Revista Território, Rio de Janeiro, ano IV, n. 7, p. 67-78, jul./dez., 1999.

JUSTO, Gláucia Reuwsaat. As relações espaciais e a aproximação entre a Geografia e a Matemática com crianças do $1^{\circ}$ ano do ensino fundamental. 2014. 87 f. Dissertação (Mestrado em Educação) - Faculdade de Educação, USP, São Paulo, 2014

LENCIONI, S. Região e geografia: a noção de região no pensamento geográfico. In: CARLOS, A. F. A. (org.). Novos caminhos da geografia. 5. ed. São Paulo: Contexto, 2005.

MANO, A. M. P. Ideias de estudantes sobre a origem da Terra e da vida e suas relações com o desenvolvimento cognitivo: um estudo psicogenético. 2013. $171 \mathrm{f}$. Dissertação (Mestrado em Educação) - Faculdade de Filosofia e Ciências, Universidade Estadual Paulista, Marília, 2013.

MIRANDA, S. L. A noção de curva de nível no modelo tridimensional. 2001. $136 \mathrm{f}$. Dissertação (Mestrado em Geografia) - Instituto de Geociências e Ciências Exatas, Universidade Estadual Paulista, Rio Claro, 2001.

MONTEIRO, T. A. A construção da noção de violência em crianças e adolescentes inseridos em diferentes contextos. 2013. 162 f. Dissertação (Mestrado em Psicologia) - Instituto de Psicologia, USP, São Paulo, 2013.

NAVARRO, A.; ENESCO, I. Las ideas infantiles sobre la movilidad socioeconômica: un estúdio com niños mexicanos y españoles. Infancia y Aprendizage, Madrid, n. 81, p. 27-44, 1998.

NAVARRO, A.; ENESCO, I. Por qué hay guerras? La representación de los conflitos sociales en los niños. Signos: Teoria y práctica de la educación, Madrid, n. 10, p. 54- $61,1993$. 
NAVARRO, A.; PEÑARANDA, A. Que és um rico? Y un pobre?: un estudio evolutivo com niños mexicanos y españoles. Infancia y Aprendizage, Madrid, n. 13, v.1, p. 67-80, jan. 1998.

PAGANELLI, Tomoko Iyda. Para construção do espaço geográfico na criança. 1982. Dissertação (Mestrado em Educação) - Instituto de Estudos Avançados em Educação, Fundação Getúlio Vargas, Rio de Janeiro, 1982.

PERALTA, T. P. A relação entre escola e trabalho: noções sociais e precessos de generalização na perspectiva de crianças e adolescentes. 2017. Dissertação (Mestrado em Educação) - Centro de Educação Cominicação e Artes, Universidade Estadual de Londrina, Londrina, 2017.

PIAGET, J. O raciocínio na criança. Tradução Valerie Rumjanek Chaves. Rio de Janeiro, Distribuidora Record, 1967.

Vozes, 1973.

Biologia e Conhecimento. Tradução Francisco M. Guimarães. Petróplois:

A epistemologia genética, sabedoria e ilusões da filosofia, problemas de epistemologia genética. São Paulo: Abril Cultural, 1978. (Os Pensadores).

.; INHELDER, B. A representação do espaço na criança. Porto Alegre: Artes Médicas, 1993.

PIECZARKA, T. Concepções de desigualdade social e mobilidade socioeconômica de adolescentes de escola pública de Curitiba. 2009. 255 f. Dissertação (Mestrado em Educação) - Universidade Federal do Paraná, Curitiba, 2009.

PIRES, V. R. O significado da leitura do espaço por intermédio de proposta de letramento cartográfico nos anos iniciais. 2016. 145 f. Dissertação (Mestrado em Geografia) - Centro de Ciências Naturais e Exatas, Universidade Federal de Santa Maria, Santa Maria, 2016.

QUEIROZ, T. A. N. Espaço geográfico, território usado e lugar: ensaio sobre o pensamento de Milton Santos. Revista Para Onde!?, Porto Alegre, v. 9, n. 1, p. 154161, ago./dez., 2014.

RODRÍGUEZ, M.; KOHEN, R.; DELVAL, J. El desarrollo sostenible en la mente del niño y el adolescente: el puente entre lá naturaleza y la economia. Meio Ambiente y Comportamiento humano, Tenerif, v. 9, p. 197-221, 2008.

SANTOS, M. Metamorfose do espaço habitado. São Paulo: Hucitec, 1988.

Técnica, Espaço e Tempo: globalização e meio técnico-científicoinformacional. 5. ed. São Paulo: EDUSP, 2008.

et al. Desenhos sobre aprendizagem e não aprendizagem: a construção do conhecimento social sob o enfoque piagetiano. ETD - Educação temática digital, Campinas, v.14, n. 2, p.140-163, jul./dez. 2012. 
. et al. Crenças envolvendo o não aprender: um estudo evolutivo sobre a construção do conhecimento. Educação em Revista, v. 29, n. 3, p. 143-176, set. 2013.

. et al. Como resolver uma situação de não aprendizagem: um estudo psicogenético sobre a construção do conhecimento social. Educação em Perspectiva, Viçosa, v. 5, n. 1, p. 92-116, jan./jun. 2014.

; GUIMARÃES, T. Ambientes educativos e conhecimento social: um estudo sobre as representações de escola. Belo Horizonte, Educação em Revista, v. 26, n. 1, p. 157-184, abr. 2010.

SILVA, P. R. F. A. Cartografando a construção do conhecimento cartográfico no ensino de geografia. 2013. Tese (doutorado em Geografia) - UFRGS, Porto Alegre, 2013.

SOLKA, M. H. Alcances e limites do avaliar e aprender a avaliar- as representações espaciais de estudantes de Ensino Médio em Geografia: Ação docente fundamentada na Epistemologia Genética. 2017. 144 f. Dissertação (Mestrado em Geografia) - Instituto de Geociências, UFRGS, Porto Alegre, 2017.

TUAN, Yi-Fu. Espaço e lugar: a perspectiva da experiência. Tradução Lívia de Oliveira. São Paulo: Difel, 1983.

VIEIRA, T. A foto da favela de Paraisópolis, 2012. Disponível em: $<$ http://www.tucavieira.com.br/A-foto-da-favela-de-Paraisopolis>. Acesso em: 06 out. 2017. 


\title{
O conceito de violência e a relação com os estágios da inteligência em crianças e adolescentes de diferentes contextos
}

\author{
Tamires Alves Monteiro 1 \\ Maria Thereza Costa Coelho de Souza ${ }^{2}$
}

\begin{abstract}
RESUMO
$\mathrm{O}$ artigo apresenta parte de um estudo evolutivo a respeito das ideias de crianças e adolescentes sobre violência, inseridos em diferentes contextos; fundamentado na teoria piagetiana e nas pesquisas referentes à construção do conhecimento social. Participaram da pesquisa 40 sujeitos entre 6 e 18 anos de idade. Apresentam-se os dados obtidos a partir do primeiro bloco de análise (definição de violência) a partir do segundo instrumento metodológico utilizado na pesquisa - entrevista clínica. Os resultados indicam que grande parte dos sujeitos da amostra não consegue retratar o fenômeno da violência em sua complexidade. Há uma tendência a associá-la somente à aspectos mais visíveis e concretos das situações ou conflitos retratados, concentrando-se no nível mais elementar de compreensão da realidade social.
\end{abstract}

PALAVRAS-CHAVE: Violência. Crenças. Jean Piaget. Epistemologia Genética.

The Concept of Violence and Relationship with the Stages of Intelligence in Children and Adolescents of Different Contexts

\begin{abstract}
The article presents part of an evolutionary study on the ideas of children and adolescents on violence, inserted at different based on Piagetian theory and research concerning the construction of social knowledge contexts. 40 subjects participated in the study between 6 and
\end{abstract}

\footnotetext{
${ }^{1}$ Mestre em Psicologia Escolar e do Desenvolvimento Humano. Instituto de Psicologia da Universidade de São Paulo, São Paulo, São Paulo, Brasil.E-mail: tamires.monteiro@usp.br

${ }^{2}$ Livre Docente. Instituto de Psicologia da Universidade de São Paulo, São Paulo, São Paulo, Brasil. E-mail: mtdesouza@usp.br
} 
18 years of age. Presents the data obtained from the first block of analysis (definition of violence) according to the second methodological instrument used in the research - clinical interview. The results indicate that most of the subjects fail to portray the phenomenon of violence in all its complexity. There is a tendency to associate it only the most visible and tangible aspects of the depicted situations or conflicts, focusing on the most basic level of understanding of social reality.

KEYWORDS: Violence. Beliefs. Jean Piaget. Genetic Epistemology.

$$
* * *
$$

\section{Introdução}

Neste artigo buscamos apresentar dados parciais de uma pesquisa que objetivou investigar a psicogênese da noção de violência em crianças e adolescentes, inseridos em diferentes contextos. Para tanto, partimos do referencial piagetiano a respeito da construção do conhecimento, das pesquisas que vem sendo desenvolvidas sobre a aquisição do conhecimento social e também de uma breve revisão na literatura a respeito do conceito de violência.

Diversos teóricos (MICHAUD, 1989; CANDAU, 2000; DERBARBIEUX; BLAYA, 2002) ao elegerem esse fenômeno como objeto de estudo enfatizam a complexidade em se atribuir um sentido exato ao termo. Destacando o quanto este fenômeno assume um caráter polissêmico e multifacetado.

Segundo Porto (2010), uma das dificuldades colocadas à reflexão sociológica sobre a violência se refere à sua construção enquanto objeto de estudos, pois a violência se caracteriza por ser um fenômeno empírico antes de ser um conceito teórico. Desta forma, um ponto referencial para a construção da violência enquanto conceito teórico seria a divisão deste fenômeno em diferentes tipos: violência física e violência simbólica. Isso porque a subjetividade que caracteriza os âmbitos moral ou simbólico não elimina o caráter de constrangimento dos atos agressivos aos sujeitos, mesmo na ausência de implicações físicas. Além dessa distinção entre 
violência física e simbólica é preciso considerar os sentidos e formas que a violência adquire em sua concretização.

É comum a palavra violência estar associada à ideia de força e/ou coação, no entanto, é preciso ser cuidadoso ao usar uma como sinônimo da outra. Afinal, nem toda ação que envolve o uso da força pode ser diretamente classificada como violenta. $\mathrm{O}$ que nos leva a seguinte questão: Em que momento o uso da força pode ser definido e visto como uma violência? Para responder a essa questão recorreremos novamente ao autor. Para Michaud (1989) são as normas e valores de uma determinada sociedade que define tal fato, ou seja, são os valores culturais e sociais que definirão quando uma força pode ou não ser compreendida como uma ação violenta. Portanto, tal como as normas e a cultura, a própria definição de violência deve sempre ser entendida como produto de um contexto social e histórico e, nesse sentido, nunca pode ser vista de forma universal e imutável.

A violência é algo que está intrinsicamente presente na nossa sociedade, que aflige e atinge tantos os adultos, como também as crianças e adolescentes, fazendo com que estes construam crenças e sentimentos sobre o fenômeno. Segundo dados da pesquisa de Waiselfisz (2011) 8 em cada 10 brasileiros têm muito medo de morrer assassinado e 7 em cada 10 de sofrer um assalto à mão armada. No que diz respeito às crianças, $42,7 \%$ de brasileiros entre 10 anos ou mais não se sentem seguros na cidade onde moram, 7,3\% das crianças brasileiras nessa faixa etária já foram vítimas de roubo ou furto e 1,6\% já sofreram alguma agressão física.

Nessa mesma pesquisa, o autor destaca que os jovens com idade entre 15 e 24 anos são as principais vítimas da violência. Entre os anos de 2008 a 2011, houve um aumento considerável de mortes dessa faixa etária da população, sendo que uma das principais causas foi o homicídio (39,7\%).

Diante desse contexto, sentimos a necessidade de pesquisar o que as crianças e os jovens pensam sobre este tema tão presente em nossa sociedade, assim o objetivo dessa pesquisa foi investigar quais eram as 
crenças que as crianças e adolescentes, inseridos em diferentes contextos, tinham a respeito da violência, como também analisar se haveria uma possível correspondência entre o conhecimento social e os estágios da inteligência.

\section{A Construção do Conhecimento Social numa Visão Interacionista}

Dentre os estudos psicogenéticos notamos que há alguns anos pesquisadores têm investigado como o sujeito pensa o mundo social. Estes trabalhos têm sido iniciados desde 1926, quando o epistemólogo Jean Piaget (1896 - 1980) se propôs a estudar as concepções infantis sobre o mundo. Em decorrência de suas obras sobre o assunto e as aberturas que elas proporcionaram, a partir da década de setenta do século passado, diversas pesquisas foram publicadas em diferentes países europeus e latinoamericanos.

No Brasil, um importante polo de pesquisa sobre a temática encontrase no Laboratório de Psicologia Genética da Universidade Estadual de Campinas (LPG/FE-UNICAMP), que desde 1994 vem estudando a construção do conhecimento social a partir de diferentes domínios desse conhecimento. É importante ressaltar que a ampliação desse campo de estudo, no Brasil, se deu, em grande parte, pelas contribuições advindas dos estudos de Juan Delval e sua equipe, na Espanha.

Tanto as pesquisas brasileiras, quantos as pesquisas internacionais vêm provando que a construção do mundo social é algo complexo que envolve tanto os aspectos físicos, quanto os cognitivos e sociais. Assim, os sujeitos constroem suas representações sobre o mundo a partir do rol de informações a que têm acesso, interpretando-as, reorganizando-as e reinventando-as a partir de um processo longo e criativo, que nada tem haver com uma simples cópia da realidade. É nesse processo de construção que o estágio de desenvolvimento cognitivo assume uma importância considerável no nível de compreensão do mundo social. 
As pesquisas sobre a temática numa abordagem piagetiana são um tanto recentes e datam do início dos anos 70 do século passado. Antes dessa época, os estudos sobre o conhecimento social, principalmente os primeiros estudos, tinham como foco a transmissão social e a pressão do ambiente como responsáveis pela formação das representações sociais. Para esta visão, as crianças absorviam as ideias vindas dos adultos e das pressões do ambiente sem ter um trabalho de elaboração e reinvenção dessas informações. Este ponto de vista serviu como base para trabalhos posteriores, como, por exemplo, a perspectiva de Durkheim que defendia a ideia de que era a pressão social (ou como dito por ele, a coação social) que determinava as representações sociais.

A partir dos anos 60, Serge Moscovici, apoiado nas ideias de Durkhein, traz a discussão de que as representações sociais são produto do conjunto de proposições, reações, avaliações e conhecimentos compartilhados pelos sujeitos de um determinado grupo social. A ideia principal, defendida por Moscovici, era de que as representações sociais eram um produto da sociedade, por isto, não podiam ser o resultado de uma construção individual.

De maneira geral podemos observar que essas diferentes abordagens se centram mais nos conteúdos do pensamento do indivíduo, buscando estabelecer relações de como essas representações vão permitindo sua socialização no seu meio social.

De acordo com Delval (2007), a construção de representações da realidade permite ao sujeito reconstruir em sua mente o mundo que o rodeia, e, por consequência, atuar e entender o meio em que vive. Diante disso, notamos que essa capacidade permite aos sujeitos não apenas dar sentido aos acontecimentos, mas também antecipar tais acontecimentos e atuar de acordo com essas representações.

O indivíduo ao longo do seu desenvolvimento constrói explicações bastante precisas sobre como funciona o mundo social. Para Delval (2007), as pessoas necessitam adquirir ideias sobre como está organizada a 
sociedade do ponto de vista econômico, político e das relações sociais para poderem atuar sobre ela. No entanto, não se pode chegar a essas ideias diretamente, é necessário construí-las por meio de um processo individual e lento.

Nesse sentido, os trabalhos de Delval (2007, 2002, 1989) mostram que as crianças não assimilam passivamente as informações que recebem do meio que as rodeia, mas realizam um trabalho árduo e gradual na construção do seu conhecimento e do conhecimento social.

Delval (2002) traz à tona a discussão sobre possíveis formas de organizar as diversas ideias que os sujeitos apresentam sobre a realidade. $\mathrm{O}$ autor levanta a hipótese de que as ideias que os sujeitos constroem sobre o mundo social têm um conjunto de traços comuns que se aplicam a diferentes domínios do conhecimento social, tais como as noções sobre direito, economia, escola, família etc. Assim, os sujeitos vão passando por diferentes formas de conceber a realidade. Tais formas seguem uma progressão em diferentes níveis, que podem ser compreendidos como uma maneira de ver e explicar a realidade.

No primeiro nível, as explicações são baseadas nos aspectos mais visíveis da situação, ou seja, em questões observáveis e não em processos ocultos que, muitas vezes, necessitam ser inferidos. Nesse nível as relações são vistas como pessoais e os sujeitos não reconhecem a existência de relações propriamente sociais, há ainda a dificuldade em se considerar a existência de conflitos.

O segundo nível caracteriza-se pelo início de consideração de aspectos não visíveis das situações, isto é, o sujeito começa a levar em conta processos inferidos a partir das informações de que dispõe. Aparece a distinção entre as relações pessoais e as institucionalizadas ou sociais. Os sujeitos desse nível percebem mais claramente os conflitos, "mas não conseguem encontrar soluções satisfatórias pela dificuldade de considerar aceitáveis os diferentes pontos de vista”. (DELVAL, 2002, p. 230).

No terceiro nível, os processos inferenciais ocupam um papel central 
nas explicações. A percepção dos conflitos é mais complexa e diferentes perspectivas e possibilidades são analisadas. A aplicação das regras sociais ocorre de uma maneira muito mais flexível.

A partir das discussões feitas no âmbito dos estudos sobre conhecimento encontra-se uma grande polêmica a respeito das semelhanças e diferenças entre conhecimento social e não social. Os problemas levantados que giram em torno dos níveis gerais de análise desses conhecimentos são: os processos implícitos na construção dos conhecimentos e as características dos objetos a conhecer.

De maneira geral, pode-se observar que alguns autores sustentam a ideia de que o conhecimento social é estruturalmente isomórfico ao conhecimento não social e que não cabe estabelecer uma distinção entre a esfera física e a social. Entre os adeptos dessa ideia estão Flavell (1985/1999), Jahoda (1984 apud Chakur, 2002), dentre outros.

Por outro lado, há estudiosos (FURTH, 1980; DAMON, 1979apud DELVAL, 1989; TURIEL, 1983, 1995) que buscam mostrar as diferenças entre esses conhecimentos, pautando-se na ideia de que essas se encontram na natureza, isto é, as formas de interações entre sujeito e objeto são diferentes. Pois, para o conhecimento social essas relações são permeadas por diversos componentes, tais como: afeto, arbitrariedade, história etc., elementos não existentes no domínio físico.

No âmbito das pesquisas brasileiras podemos destacar os estudos de Baptistella (2001), Borges (2001), Guimarães (2012) e Mano (2013), que tiveram como preocupação buscar uma relação entre os estágios do desenvolvimento cognitivo e os níveis de compreensão do mundo social propostos por Delval (2002). Os resultados dessas pesquisas demonstraram uma correspondência entre os conhecimentos lógico-matemático e social, defendendo a ideia de que, quanto mais elaborada é a estrutura cognitiva do sujeito, melhor será a sua compreensão sobre um determinado conteúdo do conhecimento social.

Segundo Delval (1989) as discussões a respeito das diferenças entre os 
tipos de conhecimento recaem sobre o problema das características do objeto a conhecer (físico ou social), da relação sujeito - objeto de conhecimento, dos processos cognitivos subjacentes e, por fim, nos mecanismos de aquisição do conhecimento.

Para Delval (1989), o conhecimento social e o não social se constroem da mesma forma, o que os diferencia são seus conteúdos, pois todos os conhecimentos têm suas peculiaridades e suas complexidades. No entanto, os processos e mecanismos que utilizamos para construir e conhecer determinado conhecimento são sempre os mesmos.

É importante destacar que embora estejamos partindo desse contexto mais amplo sobre a violência enquanto um conteúdo do conhecimento social, nosso objetivo no trabalho não será aprofundá-la, e sim estabelecer as possíveis relações entre o que a literatura tem a dizer sobre o fenômeno, o que nossos sujeitos pensam sobre ela e a construção dessas ideias a partir da visão de uma teoria do desenvolvimento. Considerando que nosso campo de estudo é a investigação da construção da noção de violência achamos válido trazer discussões sobre a sociogênese do fenômeno para assim analisarmos sua psicogênese.

\section{Método}

\section{Participantes}

Participaram desta pesquisa 40 sujeitos entre 06 e 18 anos de idade, de ambos os sexos, inseridos em diferentes ambientes. Sendo que uma parte desses alunos provenientes de instituições localizadas em bairros de baixo índice de violência e a outra parte oriundos de instituições localizadas em bairros de alto índice de violência.

Com base na obra de Delval (2002), os sujeitos foram divididos da seguinte forma: 10 sujeitos de 06 anos; 10 de 10 anos; 10 de 14 anos e 10 de 18 anos. A escolha dos locais para a coleta de dados foi feita a partir da 
análise de dados estatísticos sobre o índice de criminalidade das regiões da cidade de São Paulo. Tais dados foram consultados por meio de pesquisas estatísticas realizadas pelo site da segurança pública do Estado de São Paulo.

Assim, de acordo com os dados apresentados por este site, entre os meses de janeiro a maio do ano de 2011, a região do Belém, localizada na zona leste da cidade de São Paulo, foi considerada a que possui o menor índice de criminalidade e a região da Sé e Centro a que possui o maior índice.

Para uma melhor visualização da distribuição dos sujeitos por idade e contexto, apresentaremos a figura a seguir.

FIGURA 1: Distribuição dos sujeitos por idade e contexto

\begin{tabular}{|c|c|c|}
\hline Idade & Alto Índice de Violência & $\begin{array}{c}\text { Baixo Índice de } \\
\text { Violência }\end{array}$ \\
\hline 6 & 5 & 5 \\
\hline 10 & 5 & 5 \\
\hline 14 & 5 & 5 \\
\hline 18 & 5 & 5 \\
\hline
\end{tabular}

Fonte: Monteiro, 2013

\section{Instrumentos}

Os participantes foram submetidos, individualmente, a três instrumentos metodológicos diferentes, sendo o primeiro provaspiagetianas para o diagnóstico operatório,que pudessem verificar os estágios de desenvolvimento do pré-operatório até o operatório formal. As provas escolhidas foram: operações de permutações, avaliando à noção de acaso; oscilações do pêndulo, em relação à identidade (PAULI et. al., 1981).A justificativa para a aplicação deste instrumento foi analisar em que estágio de desenvolvimento intelectual os sujeitos eram classificados, bem como 
verificar se um sujeito que constitui uma estrutura operatória possuía uma noção mais elaborada do conhecimento social, mais especificamente, da noção de violência.

Após a aplicação das provas piagetianas os sujeitos foram convidados a participarem de uma entrevista semiestruturada com questões que tiveram como temática a violência. $\mathrm{O}$ objetivo do uso deste instrumento foi analisar como os sujeitos percebem a violência, suas causas e soluções.

Esse instrumento foi elaborado com base em metodologia utilizada em estudo anterior (MONTEIRO, 2010). A entrevista (clinica) foi composta da seguinte forma: 1) Você já ouviu falar de violência? O que acha que é violência? 2 ) Você já viu alguma violência? Se sim, qual e onde? 3) O que você acha da violência? Por que você acha isso? 4) Você acha que existe só uma violência ou tem mais? Se sim, qual e por quê? 5) Você acha que alguma violência é mais grave? Qual? Por quê? 6) Quem você acha que faz a violência? 7) Por que será que a violência existe? 8) Será que tem um jeito de acabar com ela?

O terceiro instrumento foi o curta-metragem "Jonas e Lisa" da coletânea "Direitos do Coração" (COTÈ; SCHORR, 2006). Esta coletânea é composta por uma série de curtas-metragens, em formato de desenho animado, que contam diversas e diferentes histórias que envolvem a violação dos direitos humanos. O curta-metragem escolhido "Jonas e Lisa" tem a duração de dez minutos e apresenta, em formato de desenho animado sem falas, a história de duas crianças e um bebê que vivem em um morro carioca e que passam por diversos tipos de violência, desde a pobreza até o trabalho infantil. O objetivo do uso desse instrumento foi analisar como os sujeitos interpretam esse filme e se conseguiam perceber os vários tipos de violência ali contidos.

É importante ressaltar que optamos por esta sequência de aplicação dos instrumentos metodológicos, seguindo os pressupostos do método-clínico crítico Piagetiano (PIAGET, 1926/1979). Nesse sentido, com o primeiro instrumento buscamos ter uma ideia de qual era a estrutura operatória de 
pensamento do sujeito entrevistado. Já com o segundo instrumento (entrevista clínica), buscamos encontrar as crenças espontâneas a respeito da noção da violência e por fim com o terceiro instrumento (curta-metragem) tivemos como objetivo localizar as crenças desencadeadas nesses sujeitos.

\section{Procedimentos para Coleta de Dados}

Os instrumentos metodológicos foram aplicados pela pesquisadora na escola do aluno, individualmente, e todo o diálogo estabelecido com o experimentador foi gravado em áudio e vídeo, para posteriormente ser transcrito e analisado.

As provas piagetianas foram aplicadas inicialmente para o diagnóstico do pensamento operatório (operações de permutações, oscilações do pêndulo e conservação do volume). Num segundo momento os sujeitos foram convidados a responder questões numa entrevista semiestruturada. Em seguida, apresentamos aos sujeitos um curta-metragem que foi exibido no computador; depois de assistir ao filme os sujeitos foram questionados sobre o que viram, o que os agradou ou não, além de serem perguntados, diretamente, se no vídeo havia algum tipo de violência.

\section{Análise dos Dados}

Após a coleta de dados, as respostas dos participantes foram transcritas na íntegra e analisadas quantitativa e qualitativamente. A análise qualitativa se deu por meio da construção de categorias de respostas. No caso das entrevistas, primeiramente foram criados eixos temáticos que agruparam questões tratando do mesmo aspecto e posteriormente foram estabelecidas as categorias. Já para o curta-metragem, as respostas foram agrupadas somente em categorias.

Essas categorias foram elaboradas a partir das respostas dos sujeitos e eram definidas conforme a frequência e a regularidade com que apareciam, 
indicando, portanto, uma crença desencadeada ou espontânea que os entrevistados tinham sobre a questão. Assim, quando uma crença aparecia algumas vezes, considerávamos como uma categoria de resposta. Posteriormente, as categorias foram interpretadas de acordo com os níveis de compreensão da realidade social, conforme proposto por Delval (2002).

Por fim, os dados foram tabulados e analisados estatisticamente por meio do pacote estatístico "SPSS versão 16.0 for Windows". Assim, para as variáveis contínuas, realizamos o teste de normalidade de KolmogorovSmirnov, sendo que para variáveis com distribuição normal realizamos os testes paramétricos $\mathrm{t}$ de Student e para variáveis sem distribuição normal utilizamos os testes não paramétricos de Kruskal-Wallis.Comparamos os sujeitos quanto à idade em relação à classificação nas provas piagetianas, entrevista clínica, curta-metragem e contexto. Além disso, também comparamos os sujeitos quanto às provas piagetianas e a entrevista clínica.

É importante destacar que adotamos o nível de significância de $5 \%$ $(0,050)$ para a aplicação dos testes estatísticos.

A seguir apresentaremos a análise e os resultados dos dados referentes ao primeiro eixo temático - Definição de violência, da entrevista clínica, objetivo deste artigo.

\section{Resultados e Discussão}

\section{Eixo Temático - Definição de Violência}

Neste eixo buscamos analisar como os sujeitos definiam violência. As perguntas que foram agrupadas nesse eixo são: "Você já ouviu falar de violência? O que acha que é violência?”; “Você já viu alguma violência? Se sim, qual e onde?" e "Você acha que existe só uma violência ou tem mais? Se sim, qual e por quê?".

Categoria 1 - Ações isoladas 
As respostas que correspondem a esta categoria relacionam a violência como agressões físicas, como brigar e bater, ao bullying quando o relacionavam as ações isoladas, tais como: agressões físicas e verbais. Nesta categoria também foram incluídos os atos criminosos, como, por exemplo, roubar, matar, estuprar etc. As respostas desse tipo foram as mais apresentadas, aparecendo nas diversas idades. Conforme pode ser visto no exemplo a seguir:

LIS $(7 ; 4) \mathbf{a}^{3} \mathrm{E}$ o que você acha que é violência? Acho que é agredir as pessoas. Agredir? E como que a gente agride as pessoas? Quando... Assim, você enche o saco da outra pessoa. E ai quando você fica em cima, ela também enche o seu. Como que é "encher o saco"? É quando você... Obriga a fazer uma coisa ai a outra briga com você [...]

Categoria 2 - Ações que envolvem diferentes fatores e questões sociais mais amplas

Nas respostas desta categoria, percebemos que os sujeitos acreditam que a violência está relacionada ao tráfico e uso de drogas lícitas ou ilícitas, pessoas morando na rua, preconceito, violência política, como, por exemplo, a corrupção etc. Conforme ilustra o exemplo a seguir:

GAS (14; 3)bE para você o que é violência? Violência é um tema muito amplo. Mas se você fosse nomear, o que seria a violência? Falta de segurança. Mais coisas? Falta de consciência da própria pessoa que muitas vezes se coloca no meio da própria violência, o lugar onde vive, se ocorrem muitos assassinatos, muitas brigas. [...] Você acha que tem uma violência ou tem mais? Não, tem mais. Você consegue me falar algumas?Bullying, violência doméstica, o

\footnotetext{
${ }^{3} \mathrm{~A}$ identificação dos sujeitos foi apresentada conforme o método clínico-crítico piagetiano. Assim, apresentamos, primeiramente, as iniciais do nome dos participantes, logo em seguida, entre parênteses, há a idade em anos e meses e, por fim, a instituição a qual os sujeitos pertencem. Assim, as letras a e b representam as instituições localizadas em ambientes de baixo índice de violência e as letras c e d as localizadas num local de alto índice.
} 
assédio moral que vem a ser uma violência, o preconceito é uma violência contra a autoestima da pessoa.

Categoria 3 - Tudo que fere o outro (fisicamente e psicologicamente)

Nesta categoria foram agrupadas as resposta em que os sujeitos relacionavam a violência com tudo àquilo que pode ferir, tanto psicológica e/ou fisicamente, uma pessoa. Aqui também foi enquadrado o caso do bullying, quando os sujeitos sabiam explicar corretamente o que era o fenômeno. Vejamos alguns exemplos:

GAB $(17 ; 2) b$ Eu quero que você fale pra mim o que você acha que é violência? Violência na minha opinião? Isso, o que você pensa sobre isso? Acredito que violência não venha a ser todo tipo de agressão, toda violência é uma agressão. Porém violência é um atentado a uma outra pessoa. E que tipo "atentado"? Suponhamos, pichar a parede não é violento, é vandalismo, porém se picham a parede da sua casa você acha que de alguma maneira invadiram seu espaço, e esses que invadiram seu espaço estão sendo violentos e não têm punição. Vou explicar... Formular aqui sua resposta. Toda uma ação direcionada ao outro que não está ciente causa um desconforto.

\section{Categoria 4 - Outros}

Nesta categoria foram enquadradas as respostas pouco frequentes que os sujeitos davam ao falarem o que era violência. Conforme pode ser visto no exemplo a seguir:

REN (6; 7)c O que você imagina que seja violência? Eu imagino que seja mau amor pelos outros. O mau amor pelos outros? Como assim? Assim, se a gente gosta de uma pessoa a gente tem amor por ela, se a gente não gosta, a gente tem malcriação por ela. E o que é a violência em si? Eu acho que é a violência em si é a 
malcriação pelas pessoas. Como que a gente faz malcriação? Que nem assim, a minha mãe fala: "REN vai tomar banho." Ai eu falo: "Eu não quero mãe.” Ai isso chama malcriação.

$\mathrm{Na}$ tabela e na figura a seguir encontram-se os dados referentes à quantidade de sujeitos inseridos em cada categoria de respostas e contexto social.

TABELA 1: Distribuição dos sujeitos nas categorias de respostas do eixo definição de violência

\begin{tabular}{|c|c|c|c|c|c|}
\hline \multirow[t]{2}{*}{ Categorias de Respostas } & \multicolumn{4}{|c|}{ Idade } & \multirow[t]{2}{*}{$\%$} \\
\hline & 06 & 10 & 14 & 18 & \\
\hline Categoria 1 - Ações Isoladas & 10 & 10 & 9 & 1 & $61,2 \%$ \\
\hline $\begin{array}{c}\text { Categoria } 2 \text {-Ações que envolvem } \\
\text { diferentes fatores e questões sociais } \\
\text { mais amplas }\end{array}$ & - & 1 & 2 & 5 & $16,3 \%$ \\
\hline $\begin{array}{c}\text { Categoria } 3 \text { - Tudo que fere o outro, } \\
\text { física e psicologicamente }\end{array}$ & - & - & 3 & 7 & $20,4 \%$ \\
\hline Categoria $4-$ Outros & 1 & - & - & - & $2,1 \%$ \\
\hline TOTAL & 11 & 11 & 14 & 13 & $100 \%$ \\
\hline
\end{tabular}

FIGURA 2: Distribuição dos sujeitos nas categorias de respostas e contexto social do eixo definição de violência

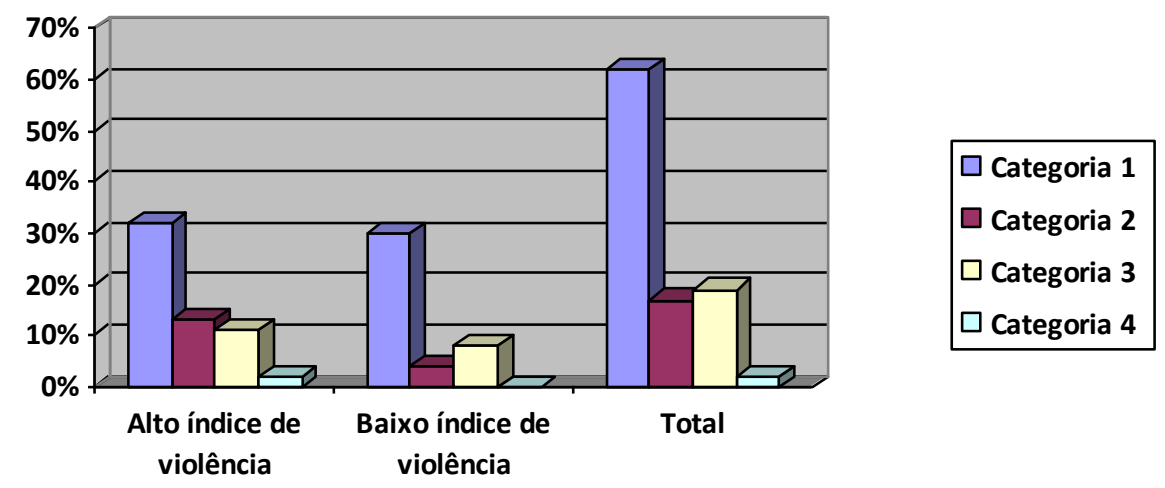

Fonte: Monteiro, 2013.

Ao analisarmos a tabela 1 podemos perceber que as respostas que se enquadram na categoria 1 são as mais mencionada pelos sujeitos de todas as 
idades. A partir desse dado evidenciamos o quanto o fenômeno da violência ainda é pouco compreendido pelas crianças e adolescentes. Estes ficam somente numa análise mais superficial e perceptível sobre a temática, demonstrando a dificuldade que estes têm de compreender o fenômeno da violência e sua complexidade, como aponta os estudos de Michaud (1989), Candau (2000) e Porto (2010).

Conforme pode ser observado na tabela 1 somente os sujeitos mais velhos (14 a 18 anos de idade) foram enquadrados na categoria 3. Estes sujeitos conseguiram ampliar suas ideias a respeito do fenômeno, demonstrando considerar outros aspectos mais abstratos e menos perceptíveis da violência.

Ao observamos a figura 1, vemos que a distribuição dos sujeitos inseridos em diferentes contextos é bem próxima, evidenciando que não há grandes diferenças entre as crenças desses sujeitos em decorrência dos locais que estão inseridos. No entanto, apesar de haver semelhanças entre as respostas destes, notamos que os sujeitos inseridos em instituições localizadas em regiões com alto índice de violência foram que deram mais respostas que poderiam ser enquadradas em diversas categorias.

Tal dado nos faz pensar que a exposição maior a essas situações faz com que o sujeito amplie seu repertório de ideias a respeito do fenômeno, todavia, sabemos que a qualidade dessas ideias não depende unicamente de uma maior exposição a esse fenômeno, mas das experiência significativas que se tem com o objeto, assim como os conteúdos afetivos, sociais e morais que o sujeito constrói em relação a violência.

A fim de enquadrarmos os sujeitos dentro dos níveis de compreensão da realidade social, todo o protocolo da entrevista clínica era lido, interpretado e analisado conforme as características dos níveis segundo Delval (2002), apresentadas no decorrer desse trabalho. Com intuito de oferecermos uma melhor visualização da distribuição dos sujeitos dentro dos níveis de compreensão, apresentaremos a seguir a tabela 2 . 
TABELA 2: Distribuição dos sujeitos por nivéis de compreensão da realidade social na entrevista clínica

\begin{tabular}{cccccc}
\hline $\begin{array}{c}\text { Nível de Compreensão da } \\
\text { Realidade Social }\end{array}$ & 06 & 10 & 14 & 18 & $\%$ \\
\hline Nível I & 10 & 10 & 7 & 1 & $70 \%$ \\
\hline Nível II & - & - & 3 & 6 & $22,5 \%$ \\
\hline Nível III & - & - & - & 3 & $7,5 \%$ \\
\hline Total & 10 & 10 & 10 & 10 & $100 \%$ \\
\hline
\end{tabular}

Fonte: Monteiro, 2013.

Como podemos observar a partir da tabela 2, a maioria dos sujeitos participantes concentram-se no nível mais elementar da compreensão do conhecimento social, mesmo os sujeitos mais velhos, como os de 14 anos de idade. Segundo Delval (2002), os sujeitos pertencentes a este nível possuem explicações simplistas sobre o mundo social. Estas explicações se baseiam nas aparências, naquilo que há mais de concreto e perceptível. Nesse sentido, os sujeitos enquadrados nesse nível acreditam que a violência está relacionada às questões mais concretas, assim a denominam como sendo: bater, roubar, matar, brigar etc.

$\mathrm{Na}$ busca de uma relação entre o conhecimento social e os estágios da inteligência, notamos que as respostas deste primeiro nível revelam a presença de um pensamento egocêntrico. Segundo Piaget (1965/1973), o sujeito nesse estágio vê a realidade a partir do seu ponto de vista porque é regulado pelo egocentrismo. Nesse sentido, estes têm dificuldade em considerar o outro, por isso, não consideram os diversos aspectos da realidade que os cercam, nesse caso, os diversos aspectos que compõem o fenômeno da violência. Portanto, por estarem num momento em que o egocentrismo se faz tão presente, não conseguem explicar a realidade tal como ela é, limitando-se a caracterizá-la e descrevê-la como a veem.

Em relação ao nível II de compreensão da realidade social, os sujeitos pertencentes a este nível começam a ver o mundo social como algo em 
transformação. Todavia, apesar das respostas dos sujeitos serem mais elaboradas, ainda se caracterizam por justificativas elementares, que são manifestadas de forma confusa. As explicações próprias desse nível refletem a grande dificuldade que os sujeitos apresentam para considerar os distintos elementos envolvidos no processo de compreensão do mundo social. Por esse motivo, as explicações são variadas e mais amplas que as do nível anterior, no entanto, suas justificativas ora retornam a argumentos no nível I, ora buscam uma articulação mais coerente, mas sem atingir a elaboração própria do nível III, demonstrando assim um período de transição.

Delval (2002) afirma que as explicações decorrentes desse segundo nível não só são encontradas nas crianças e adolescente, mas podem também ser vistas em alguns adultos, o que pode ser observado no nosso estudo, considerando que grande parte dos adolescentes na faixa de 18 e 19 anos de idade concentram־se nesse nível.

Os sujeitos classificados nesse segundo nível começam a ver a violência com algo mais amplo, envolvendo questões de ordem social e moral, tais como: O uso e o tráfico de drogas, pessoas morando na rua, preconceito etc. Embora apresentam características mais sofisticadas para denominarem o que é violência, como, por exemplo, o preconceito, ao falarem sobre ela, seus argumentos muitas vezes são pobres e um tanto estereotipados.

Ao recorrermos à teoria piagetiana para explicar esse momento, podemos perceber semelhanças com o estágio operatório concreto. Visto que nesse estágio os sujeitos passam pelo processo de descentração, isto é, deixam de lado o egocentrismo e começam a levar em conta os outros pontos de vista. Este fato faz que o sujeito consiga organizar um número cada vez maior de situações, dando a suas explicações uma forma mais objetiva; entretanto, permanecem presos a situações concretas.

As respostas enquadradas no nível III de compreensão demonstram que os sujeitos, em suas explicações, parecem buscar uma relação entre os fatos observados e as informações que recebem, seja pela mídia, seja pela escola, seja no cotidiano de suas vidas, levando em consideração inclusive os 
aspectos mais abstratos.

As explicações enquadradas no nível III, interpretadas a partir da teoria piagetiana, revelam que, com a conquista do pensamento formal, o sujeito tem possibilidade de compreender as noções sociais em toda a sua amplitude, uma vez que eles são capazes de coordenar diferentes pontos de vista e basear suas explicações sobre enunciados verbais, ou seja, de hipóteses.

Os sujeitos pertencentes a este nível relacionam a violência não só a algo físico, mas também a aspectos psicológicos, ou seja, a violência passa a ser vista como aquilo que fere o outro, seja física ou psicologicamente. Além disso, a violência também é relacionada a questões sociais, tais como: pobreza, desigualdade social, preconceito, corrupção, etc; acompanhadas de argumentos mais realistas que abordam a complexidade do tema.

A seguir encontra-se uma tabela com os resultados obtidos por meio do teste estatístico em relação ao estágio cognitivo e os níveis de compreensão da realidade social na entrevista clínica.

TABELA 3: Resultados da aplicação do teste Krusal-Wallis para níveis de compreensão da realidade social na entrevista clínica e estágio de desenvolvimento cognitivo

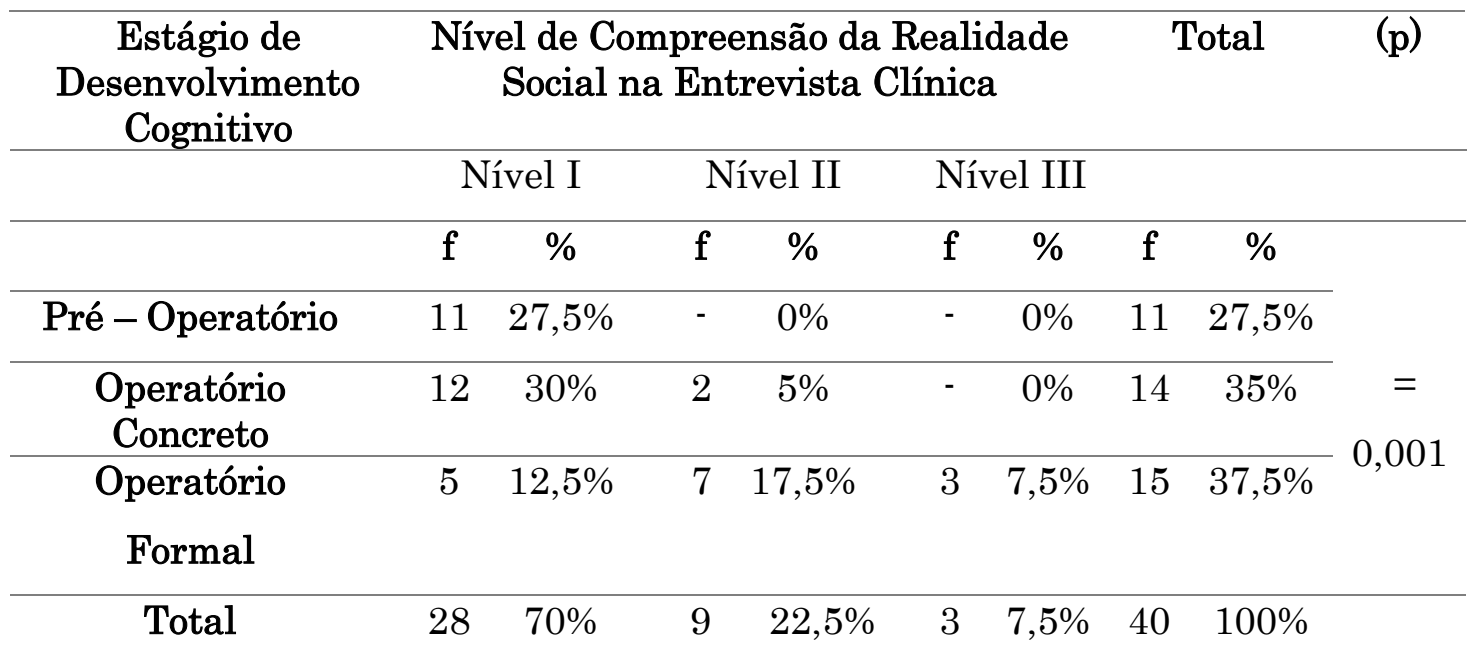

Fonte: Monteiro, 2013.

$\mathrm{Na}$ busca por uma correlação entre o estágio de desenvolvimento 
cognitivo e os níveis de compreensão da realidade social na entrevista clínica foi possível observar, por meio do teste Kruskal-Wallis, uma diferença estatisticamente significativa $\left(x^{2}=18,754 ; p=0,001\right)$. Demonstrando que há uma estreita correspondência entre os níveis de compreensão da realidade social na entrevista clínica e os estágios da inteligência. Assim, podemos dizer que os níveis de compreensão mais elaborados do mundo social são acompanhados por estágios mais avançados do desenvolvimento cognitivo, como demonstram os estudos de Delval (1989), Baptistella (2001), Borges (2001), Guimarães (2012) e Mano (2013).

É importante ressaltar que a passagem de um nível ao outro não ocorre de forma direta e mecânica, mas é fruto de um longo processo de interação com o meio social. Em que implica num processo amplo de desequilíbrios contínuos, de assimilações e acomodações. Para construir essa compreensão, o sujeito precisa realizar e passar pelas as várias etapas da abstração reflexionante e também da tomada de consciência, isto é, conseguir coordenar as ações que realiza sobre os fenômenos da realidade social.

Após a análise dos resultados, notamos que há entre as diversas respostas fornecidas pelos sujeitos uma organização complexa e evolutiva, seguindo um caminho bem semelhante ao estudo de Monteiro (2010) e outras pesquisas que tiveram como intuito investigar as noções sociais.

A respeito da relação entre os níveis de compreensão da realidade social na entrevista e o contexto social, de acordo com os resultados do teste Krusal-Wallis não houve diferença estatística significante $\left(\mathrm{x}^{2}=3,254 ; \mathrm{p}>\right.$ 0,05). Tal dado demonstra que o contexto social no qual os sujeitos participantes pertenciam não influenciava no tipo e na qualidade das respostas que os sujeitos davam ao pensar na violência (tanto estruralmente, quanto em conteúdo).

\section{Considerações Finais}

A partir dos dados apresentados foi possível evidenciar que as 
respostas que os sujeitos dão em relação às questões sobre a violência não se limitam a uma simples reprodução de informações e, muito menos, são cópias da realidade, mas o resultado de um processo criativo e ativo do sujeito. Além disso, percebemos que tais ideias e o processo de construção sobre o tema são, em muitos aspectos, coincidentes com a própria evolução do termo apresentada pela literatura. Nessa evolução, percebe-se as dificuldades e as necessidades de inserção de novos elementos e novos enfoques para a definição e interpretação sobre o fenômeno da violência.

A fim de verificar a existência de uma correspondência entre os níveis de compreensão da realidade social e os estágios do desenvolvimento cognitivo, partimos da hipótese de que compreensões mais elaboradas do mundo social, no caso da nossa pesquisa, a noção de violência, são pautadas em estruturas cognitivas mais sofisticadas. A partir do teste Kruskal-Wallis encontramos uma relação estatisticamente significativa, isto é, nossa hipótese foi comprovada.

Apesar de nossa hipótese ter sido comprovada, um dado nos chamou a atenção: somente $7,5 \%$ dos sujeitos da nossa amostra alcançaram o nível mais elevado da compreensão do mundo social. Grande parte dos nossos sujeitos se concentraram nos níveis mais elementares. Este dado evidencia que tanto as crianças, quanto os adolescentes possuem uma visão muito simplista sobre a violência e, consequentemente, não conseguem perceber e compreender a complexidade do tema. Além disso, notamos que o fenômeno da violência não é visto por esses sujeitos como um material para a reflexão, assim muitos ficam presos à ideias imediatistas e concretas e, muitas vezes, pautadas no senso comum. Adotando o referencial piagetiano podemos dizer que esses sujeitos não conseguem atingir os níveis mais superiores das abstrações e, por consequência, não chegam a uma tomada de consciência sobre o assunto.

Este dado também nos permite inferir que as estruturas cognitivas são uma condição necessária e extremamente importante para a construção e compreensão das noções sociais, no entanto, não são suficientes. As 
experiências significativas com o objeto de conhecimento, os conteúdos afetivos, sociais e morais que o sujeito tem com este objeto de conhecimento também têm uma grande relevância.

Assim, todos os progressos evolutivos em relação a noção de violência não são determinados unicamente pelo acesso a uma maior quantidade de informações que o sujeito recebe conforme avança em seu desenvolvimento, mas deve-se ao fato de como essas informações vão sendo incorporadas pelo sujeito e como ele vai dando significado a elas. Isto é, como o sujeito ao longo da sua interação com este objeto de conhecimento vai assimilando e acomodando essas informações e com isto buscando e realizando abstrações cada vez mais potentes e complexas até chegar numa tomada de consciência sobre essas questões.

Uma das questões que nos preocupa é em relação a compreensão elementar e pobre dos fenômenos do mundo social que nossos adolescentes possuem. Quando comparamos as pesquisas psicogenéticas brasileiras com as internacionais notamos que nossos jovens possuem uma visão muito simplista de alguns contéudos da realidade social (CANTELLI, 2000; PIECZARKA, 2009; MONTEIRO, 2010; MANO, 2013). Dessa forma, acreditamos ser importante que haja outras investigações com diferentes conteúdos do mundo social, para que se confirmem ou não esse fato, além de buscarem explicações para isto. Caso esse dado se confirme é necessário pensarmos: O que pode ser feito para solucionar tal problema? Será que nossas escolas e outras instituições responsavéis pela formação dos sujeitos têm um papel relevante e importante nesse processo? Acreditamos que sim.

Notamos o quanto a escola está preocupada em informar seus alunos sobre um fenômeno que apesar de não ser recente tem ganhado muito destaque ultimamente. No entanto, apesar da boa intenção, a escola acaba fazendo um trabalho sem muito sentido, pois tem como ideia que somente a transmissão daria conta da conscientização de seus alunos para com o fenômeno.

Sabemos que somente esclarecer o tema com os alunos não é suficiente 
para minimizar e/ou erradicar a violência como um todo, mas é preciso que a escola vá além da transmissão, que tenha a preocupação de discutir com seus alunos sobre essas questões, que eles possam, acima de tudo, serem ouvidos e a partir das suas ideias buscarem um trabalho de conscientização.

Defendemos a ideia de que seja necessário um trabalho adequado em relação ao conhecimento social. Os conteúdos deste tipo de conhecimento necessitam de um trabalho semelhante aos dos outros tipos de conhecimentos (físico e lógico-matemático). Sendo assim, a construção das noções sociais não pode ficar restrita somente a transmissão social, é preciso que nossas crianças e adolescentes experimentem e vivenciem atividades que os levem a refletir sobre os fenômenos sociais, que possam agir, debater e trocar experiências sobre isso, isto é, é necessário que haja uma experimentação ativa do sujeito, informações adequadas e reflexões para além da prática para a construção das noções sociais. Em síntese, o processo pode ser entendido como partindo de um saber fazer para uma compreensão cada vez mais elaborada do processo.

Dessa forma, é essencial que o educador conheça como seu aluno se desenvolve e aprende, além de ter conhecimento do quanto é importante ter um ambiente solicitador, cooperativo e livre de pressões e sanções expiatórias, pois só assim ele consiguirá desenvolver atividades e estratégias de ensino que possibilitem uma aprendizagem significativa e de qualidade, como também um espaço cada vez mais democrático e propício para o desenvolvimento integral do sujeito.

\section{Referências}

BAPTISTELLA, E. C. F. A compreensão de um conteúdo de um comercial televisivo na infância. 2001. 225 f. Dissertação (Mestrado em Educação) - Faculdade de Educação, Universidade Estadual de Campinas, Campinas, 2001.

BORGES, R. R.A construção da noção de família em crianças pré-escolares. 2001. 204 f. Dissertação (Mestrado em educação) - Faculdade de Educação, Universidade Estadual de Campinas, Campinas, 2001.

CANDAU, V. M. Direitos humanos, violência e cotidiano escolar. In: CANDAU, V. 
M. (org.). Reiventar a escolar. Petrópolis/RJ: Vozes, p. 137-166, 2000.

CANTELLI, V. C. B. Um estudo psicogenético sobre as representações de escola em crianças e adolescentes. 2000. 243 f. Dissertação (Mestrado em Educação) Faculdade de Educação, Universidade Estadual de Campinas, Campinas, 2000.

CHAKUR, C. R. S. L. O social e o lógico-matemático na mente infantil. cognição, valores e representações ideológicas. São Paulo: Arte \& Ciência, 2002.

COTÉ, Z.; SCHORR, D. Jonas e Lisa. In: Pierre Trudeau (direção). Direitos do Coração. Brasil: Paulinas, 2006. DVD.

DEBARBIEUX, E.; BLAYA, C. Violência nas escolas e politicas públicas. (Relatório de pesquisa). Brasília: UNESCO. Disponível em: http://unesdoc.unesco.org/images/0012/001287/128720por.pdf. Acesso em: 10 jul. 2017.

DELVAL, J. La representación infantil del mundo social In: TURIEL, E.; ENESCO, L.; LINAZA, J. (Comps). El mundo social e la mente del niño. Madrid: Alianza, 1989 .

Introdução à prática do método clínico: descobrindo o pensamento da criança. Tradução de Fátima Murad. Porto Alegre: Artmed, 2002.

Aspectos de la construcción del conocimiento sobre la sociedad. Educar em revista, n. 30, p. 45-64, 2007.

FLAVELL, J. et. al. Desenvolvimento cognitivo. Tradução de Claúdia Dornelles. 3. ed., Porto Alegre: Artmed, [1985], 1999.

GUIMARÃES, T. Intervenção pedagógica e noções sobre o meio ambiente: a construção do conhecimento social à luz da epistemologia genética. 2012. $221 \mathrm{f}$. Dissertação (Mestrado em educação) - Faculdade de Ciências e Filosofia, Universidade Estadual Paulista, Marília, 2012.

MANO, A. M. P. Ideias de estudantes sobre a origem da Terra e da vida e suas relaçôes com o desenvolvimento cognitivo: um estudo psicogenético. 2013. $171 \mathrm{f}$. Dissertação (Mestrado em educação) - Faculdade de Ciências e Filosofia, Universidade Estadual Paulista, Marília, 2013.

MICHAUD, Y. A violência. São Paulo: Ática, 1989.

MONTEIRO, T. Um estudo evolutivo sobre as ideias de crianças e adolescentes a respeito da violência urbana. 2010. $222 \mathrm{f}$. Trabalho de conclusão de curso de Pedagogia (Licenciatura em Pedagogia)- Faculdade de Ciências e Filosofia, Universidade Estadual Paulista, Marília, 2010.

PAULI, L. et. al. Inventários de Jean Piaget. Lisboa: Estampa, 1981.

PIAGET, J. Estudos sociológicos. Tradução de Agnes Cretella. Rio de Janeiro: 
Forense, [1965], 1973.

A representação do mundo na criança. Tradução de R. Fiúza. Rio de Janeiro: Record, [1926], 1979.

PIECZARKA. T. Concepção de desigualdade social e mobilidade socioeconômica de adolescentes de escola pública de Curitiba. 2009. 257 f. Dissertação (Mestrado em educação) - Faculdade de Educação, Universidade Federal do Paraná, Curitiba, 2009.

PORTO, M. S. G. A violência entre o fenômeno e o conceito: possibilidades e limites de definição. IN: PORTO, M. S. G. (org.). Sociologia da violência: do conceito às representações sociais. Brasília: Editora Francis, 2010.

TURIEL, E. The development of social knowledge morality an convention. New York: Cambridge University Press, 1983.

TURIEL, E. Interaction and development social cognition. In: HIGGINS, E. T.; RUBLE, D. N.; HARTUP, W. W. (eds.). Social cognition and social development: a sociocultural perspective. Cambridge: Press, p. 333 -355, 1995.

WAISELFISZ, J. J. O mapa da violência de 2011: os jovens do Brasil. Brasília: UNESCO, Instituto Sangari, Ministério da Justiça, 2011.

Recebido em 27 de setembro de 2017. Aprovado em 04 de dezembro de 2017. 


\title{
Identidade profissional docente: concepções de futuros professores
}

\author{
Eliane Paganini da Silva ${ }^{1}$ \\ Amanda de Mattos Pereira Mano 2
}

\begin{abstract}
RESUMO
A identidade profissional docente pode ser compreendida no âmbito da construção do conhecimento social. Nesse particular, investigou-se a concepção de 65 estudantes do curso de Pedagogia de uma universidade pública, sendo 33 estudantes do primeiro ano e 32 do quarto ano, acerca dessa identidade específica. Os participantes responderam a um questionário aberto, com questões que versavam sobre a identidade docente, as quais foram analisadas qualitativamente, sendo enquadradas nos níveis de compreensão da realidade social.Os resultados mostraram que as respostas dos alunos do primeiro ano concebem que a profissão do professor está ligada ao amor e ao cuidado com as crianças, já os alunos do quarto ano compreendem que outros fatores concorrem para a execução do trabalho docente, tais como a necessidade de uma formação específica e da consideração dos processos de ensino e aprendizagem. Pretendeu-se com essa investigação compreender os processos de construção da identidade profissional nesse grupo específico, bem como promover discussões pertinentes à formação inicial de professores.
\end{abstract}

PALAVRAS-CHAVE: Identidade docente. Conhecimento social. Ensino Superior.

\section{Teacher professional identity: conceptions of future teachers}

\footnotetext{
ABSTRACT

Teacher's professional identity can be understood in the context of social knowledge construction. In this particular, we investigated the

${ }^{1}$ Doutora em Educação. Universidade Estadual do Paraná - Unespar, Apucarana, Paraná, Brasil. E-mail: eliane_ps@hotmail.com.

${ }^{2}$ Doutora em Educação. Universidade Estadual do Paraná - Unespar, União da Vitória, Paraná, Brasil. E-mail: amanda_mattosbio@yahoo.com.br.
} 
conception of 65 Pedagogy course students of a public university, being 33 first year students and 32 of the fourth year, about that specific identity. Participants answered an open questionnaire, with questions that dealt with the subject matter mentioned, which were qualitatively analyzed, being framed in the levels of social reality understanding. The results show that answers of first-year students conceive teacher's profession as linked to love and children care, while the fourth-year students understand that other factors contribute to teaching work execution, such as the need for specific formation and consideration of teaching and learning processes. The aim of this research was to understand construction processes of professional identity in this specific group, as well as to promote discussions relevant to teacher's initial formation.

KEYWORDS: Teacher identity. Social knowledge. Higereducation.

$$
* * *
$$

\section{Introdução}

O termo identidade é de origem latina com significado de igualdade, continuidade. Esse termo polissêmico e o estudo de sua aquisição é discutido em domínios diferentes (sociológico, psicológico, antropológico, dentre outros) e considerando diferentes perspectivas.

Neste estudo, trataremos do conceito de identidade profissional docente e, para isso, o detalharemos por meio da compreensão de que essa identidade profissional específica, em sua constituição, abarca componentes de âmbito individual e coletivo.

No que se refere a dimensão individual, tem-se que a história da vida de um indivíduo é marcada por uma sucessão de mudanças de identidade, que envolvem, necessariamente, a substituição dos traços de identificações anteriores por novos (ROGERS, 1972). Sobre esse aspecto Giddens (2002) afirma que essa identidade pessoal é possível de ser observada nas reações das pessoas umas com as outras e na capacidade que cada indivíduo possui para manter algo particular, que diz respeito somente a ele. 
Nesse sentido, as identidades possuem sua subjetividade e particularidade (algo individual), mas que se constitui por meio das interações estabelecidas em um meio social.

Com relação aos aspectos coletivos, Berger e Luckman (1985) esclarecem que a identidade é um elemento chave da subjetividade e da sociedade, podendo ser reformulado a partir ou em função das relações sociais, sendo essa identidade construída por meio de um processo dialético entre o individual e o social.

Frente a tais conceituações, algumas indagações que perpassam a consolidação dessa identidade profissional específica, são: De que maneira professores em exercício concebem sua identidade profissional? Existem diferenças entre as concepções de professores que atuam nos diferentes anos da Educação Básica? E, ainda, os universitários das licenciaturas, isto é, os possíveis futuros professores, já possuem elementos dessa identidade profissional específica? Os elementos indicados por tais acadêmicos, no momento do ingresso no curso, são os mesmos dos alunos concluintes?

Acerca desses questionamentos os estudos de Paganini-da-Silva (2006; 2015) são investigações que vão ao encontro de algumas dessas questões. No entanto, em relação a identidade profissional de universitários de licenciatura não foi possível encontrar estudos que pudessem trazer elementos para compreensão de seu desenvolvimento.

Diante do exposto, esse artigo pretende explanar a respeito de uma investigação empregada com o objetivo de conhecer a concepção de licenciandos do curso de Pedagogia, de uma Universidade Estadual do Paraná, acerca da identidade docente, sob a ótica da construção do conhecimento social.

\section{A identidade docente e a construção do conhecimento social}

No início da análise sobre o conceito de identidade, a perspectiva da personalidade foi uma das únicas considerações aceitas e, até por volta dos 
anos 1960, o conceito de identidade se restringia ao campo da Psicologia. Apartir dessa década, começa a ser abordada sob o ponto de vista da Sociologia, entendendo que os indivíduos passam a ocupar uma posição enquanto atores das relações sociais.

A identidade individual ou pessoal está sempre sofrendo transformações e influenciando as experiências individuais e sociais. Nesse sentido, Vianna (1999), Pimenta (1997) e Dubar (1997) ressaltam uma relação estreita entre as identidades individuais e coletivas.

A identidade coletiva não é decorrência da individual, mas sem dúvida é marcada por certa dualidade: a identidade para si e a identidade para o outro (DUBAR, 1997) e ambas as identidades são essenciais para definir a identidade profissional do indivíduo.

A esse respeito Pimenta (1997) define que a identidade profissional do professor é construída sob aspectos sociais e internos a cada indivíduo, sendo esses atores e autores da própria história (com saberes, representações anseios, angustias) na constituição do ser professor.

Também influenciam e contribuem para a construção da identidade docente os antecedentes socioeconômicos, o tamanho da cidade natal, as experiências com outros professores, os conselhos de amigos, professores e pais, as identificações com um adulto admirado, as experiências passadas, além de aspectos profissionais específicos, tais como segurança, prestígio, salário e condições de trabalho,

Outro aspecto significativo acerca da identidade profissional dos professores é a imagem social do magistério, construída historicamente no âmbito coletivo, mas também a autoimagem construída no interior da carreira e profissão docente (NÓVOA, 1991). Para Arroyo (2000), as imagens e autoimagens dos professores são diversas e difusas, não existindo uma imagem única.

Para os professores de Educação Infantil, a imagem é difusa e pouco profissional; para as professoras primárias ela se torna mais definida já que existe um predomínio da "competência para o ensino das primeiras letras e 
contas, mas, sobretudo, o carinho, o cuidado, a dedicação e 0 acompanhamento das crianças" (p. 30); aflora entre os professores do segundo ciclo do Ensino Fundamental ( $6^{\circ}$ ao $9^{\circ}$ anos) e de Ensino Médio uma "indefinição profissional e pessoal que tem sua origem na indefinição social” (p. 31).

Paganini-da-Silva (2015) define a identidade profissional docente como um

processo contínuo, subjetivo, que obedece às trajetórias individuais e sociais, que tem como possibilidade a construção/desconstrução/reconstrução, atribuindo sentido ao trabalho e centrado na imagem e autoimagem social que se tem da profissão e também legitimado a partir da relação de pertencimento ao Magistério. (PAGANINI-DA-SILVA, 2015, p. $74)$.

Mas com relação à identidade dos alunos dos cursos de licenciatura e pedagogia o que se pode aferir é que, como ressaltam Pimenta e Libâneo(1999), as características desses cursos no decorrer do século XX possuem u a concepção tecnicista própria dos anos 70 que reduzia a formação do pedagogo à docência. Os autores evidenciam que desde os anos 1920 é possível perceber que os estudos pedagógicos perdem espaço para um entendimento de a Pedagogia ser resumida às contribuições da Psicologia e com o passar do tempo vai adquirindo "conotação de operacionalização metodológica do ensino" (PIMENTA; LIBÂNEO, 1999, p. 246).

Atualmente, a Resolução $\mathrm{N}^{\circ} 2$ de 1 de Julho de 2015, define as Diretrizes Curriculares Nacionais para a formação inicial em nível superior (cursos de licenciatura, cursos de formação pedagógica para graduados e cursos de segunda licenciatura) e para a formação continuada. Esse documento garante, em primeiro lugar, que os Cursos de Pedagogia tenham uma carga horária específica destinada às especialidades próprias da 
Pedagogia e, em segundo lugar, uma base comum que garante a docênciaou o ensinar como sendo o foco da identidade do educador.

Pimenta e Libâneo (1999) fazem algumas críticas a maneira como os cursos de Pedagogia eram estruturados até o final dos anos 90 (juntando as duas vertentes, a docência e a especialidade do ser pedagogo), perspectiva que foi mantida na Resolução supracitada. Independente dessas discussões a presente pesquisa tem como foco a docência tanto dos alunos iniciantes como dos concluintes dos cursos de Pedagogia.

Nesse estudo pretende-se discutir esses aspectos e a análise se dará tendo em vista as concepções e a identidade que esses estudantes possuem acerca da função docente e do futuro exercício profissional. Portanto, a definição de identidade está centrada nas funções e atribuições próprias do ser professor, que podem ser construídas no dia a dia da sala de aula, mas também no decorrer da formação inicial dos acadêmicos.

Nesse aspecto, esclarece-se que nos cursos de formação de professores todas as suas disciplinas devem colaborar para essa formação contribuindo com conhecimentos e métodos para fazer educação (PIMENTA, 2011).

Nóvoa (2009) ressalta a importância de captar o sentido de uma profissão e, portanto, o cerne da identidade profissional docente. Esse cerne está ou deve estar ligado à aprendizagem e aponta a importância de vislumbrarmos uma educação, uma escola que tenha uma organização centrada na aprendizagem. Além disso, apresenta a necessidade de se construir um conhecimento pessoal "no interior do conhecimento profissional”, algo que não esta apenas na matriz científica dos cursos de formação (NÓVOA, 2009, p. 14).

É possível olhar para o desenvolvimento profissional do professor também tendo como foco a teoria de Jean Piaget. O estudo de Chakur (2001) investigou três aspectos da profissionalidade docente, a identidade, a autonomia e a prática pedagógica. Tal pesquisa demonstrou que a identidade do professor não é questão de tudo ou nada, mas obedece a uma sequência de níveis de desenvolvimento. 
Igualmente, os resultados de Paganini-da-Silva (2006; 2015) indicaram níveis de tomada de consciência piagetiana para a identidade do professor. A autora (PAGANINI-DA-SILVA, 2006) teve como objetivo desvendar os aspectos relacionados à identidade e a crise de identidade docente de professores do segundo ciclo do Ensino Fundamental, sob o ponto de vista da teoria piagetiana, encontrando diferentes níveis de consciência acerca de sua identidade apontando para uma crise de identidade com relação à função docente.

Em outro estudo (PAGANINI-DA-SILVA, 2015), a autora investigou as concepções pedagógicas como parte constituinte da identidade docente e se os professores da Educação Básica tomavam consciência acerca desse aspecto do ser professor. A pesquisa ocorreu em duas escolas pedagogicamente distintas, uma escola denominada sócio construtivista e uma escola piagetiana. Os resultados indicaram que uma parte significativa dos participantes da escola piagetiana tomavam consciência do aspecto pedagógico como parte fundante da profissionalidade docente.

Jean Piaget (1886-1980) realizou pesquisas direcionadas ao conhecimento físico, lógico-matemático e ao conhecimento social. É bem verdade que o próprio Piaget não se aprofundou neste último campo de estudo, mas alguns teóricos, em continuidade às contribuições piagetianas, dedicaram־se a esta vertente.

Enesco et al. (1995) afirmam que o conhecimento social tem por objetivo explicar aquilo que é produzido em um contexto social e que, por isso, adquire sentido nas relações com os outros. Esse objeto de conhecimento pode se caracterizar por diferentes dimensões, sendo elas: o conhecimento do eu e dos outros (conhecimento psicológico ou pessoal), as relações interpessoais, os papéis sociais, as normas que regulam as condutas dentro do grupo social, bem como o funcionamento e a organização da sociedade.

Nesse sentido, a identidade profissional docente insere-se como uma temática inerente à construção social do conhecimento, porque conforme já 
afirmado, sua constituição e consolidação dá-se em processos de origem individual, mas que são fortemente influenciados pelas informações e vivências sociais.

Compreender esse fenômeno de natureza social, não é fácil. Quando trata-se do conhecimento social depara-se com um objeto de conhecimento muito complexo, com questões multifacetadas e ambíguas, uma vez que não é simplesmente absorver informações acerca de uma realidade social, mas, a partir de tais informações, interpretá-las e organizá-las na atribuição de significados próprios e pessoais.

Diante de tais particularidades, Delval (2002, 2013) empregando inúmeras investigações, em diferentes países e acerca de distintos conteúdos da realidade social apresentou que os indivíduos se adequam a essa natureza do conhecimento percorrendo três níveis de compreensão.

No primeiro nível, que ocorre até por volta dos 10-11 anos, os sujeitos baseiam suas ideias sempre por meio dos aspectos mais visíveis das situações em questão, desconsiderando processos ocultos e subjetivos, comuns às questões sociais.

As considerações sobre os conteúdos da realidade social são visões estereotipadas e simplistas. Além disso, não existe a coordenação de diferentes perspectivas e, desta forma, os conflitos decorrentes desta visão incompleta não são concebidos.

No que diz respeito ao segundo nível, que ocorre por volta dos 10-11 anos até os 13-14 anos, os sujeitos começam a levar em conta aspectos não visíveis das questões inicia-se a consideração de processos que precisam ser inferidos, mas a coordenação de diferentes pontos de vista ainda é algo difícil de ocorrer.

No terceiro nível, que se inicia aos 13-14 anos, apresenta explicações que revelam o conhecimento e a consideração de processos ocultos e mais, as diferentes perspectivas presentes em distintas situações passam a ser consideradas. Nesse momento, existe criticidade em relação à ordem e aos fenômenos sociais. 


\section{Metodologia}

O estudo caracteriza-se por ser de abordagem qualitativa. Assim, foram participantes 65 estudantes do curso de Pedagogia de uma Universidade Estadual paranaense, sendo 33 acadêmicos do primeiro ano e 32 pertencentes ao quarto e último ano dessa licenciatura. Entre os participantes, 6 acadêmicos são do sexo masculino e 59 do sexo feminino.

Ressalta-se a opção de tal recorte evolutivo, acadêmicos do primeiro e do quarto ano, em razão da busca pela existência de uma evolução de ideias entre os ingressantes e concluintes.

Para a coleta de dados, empreendeu-se a aplicação de um questionário, adaptado do instrumento já validado por Paganini-da-Silva (2015). As questões que o compuseram foram: 1) Qualquer pessoa pode ser professor?;2) Em sua opinião, como seria um bom professor? Defina com exemplos.; 3) Que tipo de dificuldade os professores enfrentam para exercer sua profissão?; 4) Você acha que tem ou não alguma diferença na função do professor se ele lida com a Educação Infantil, com o Ensino Fundamental I ( $1^{\circ}$ ao $5^{\circ}$ ano $)$ ou Ensino Fundamental II ( $6^{\circ}$ ao $9^{\circ}$ ano)? Por quê?;5) Você se sente realizado em sua escolha profissional? Por que escolheu o curso de Pedagogia?;6) Que imagem você mesmo tem de si mesmo como futuro professor?; 7) O que é ser professor para você?

Observa-se que todas as questões foram de caráter aberto, possibilitando aos participantes apresentar, livremente, suas ideias.

No decurso da realização da pesquisa, primeiramente, uma das pesquisadoras foi às salas de aula do $1^{\circ}$ e do $4^{\circ}$ ano de Pedagogia e informou os alunos sobre os objetivos da pesquisa. Neste mesmo momento, tais discentes foram convidados a participar da investigação e, logo após o devido consentimento, os questionários foram distribuídos para serem respondidos, de maneira individual. A pesquisadora acompanhou o preenchimento das respostas, tendo esta etapa duração média de 25 minutos. 
As respostas às questões foram analisadas à luz dos níveis de compreensão do conhecimento social (DELVAL, 2002; 2013) e, em específico, de acordo com os níveis construídos para a noção investigada, a identidade profissional docente, em consonância com Dubar (1997), Pimenta (1997), Arroyo (2000), Brzezinski (2002), Nóvoa (1991), dentre outros.

Cabe esclarecer que a escolha metodológica, de enquadrar as respostas dos participantes em níveis de compreensão do conhecimento social, ocorreu porque a perspectiva de desenvolvimento de Piaget não se limita a compreensão do pensamento das crianças, sobretudo, se nos debruçarmos a compreensão de mecanismos adjacentes ao estádio operatório formal, em tese, intrínsecos a um entendimento mais objetivo do conhecimento. Ademais, coerente com o presente estudo e corroborando Chakur (2001), essa perspectiva teórica pode alicerçar a compreensão da constituição e atuação de diferentes profissões, por tratar-se de uma parcela do mundo social que deve ser mais bem compreendida.

Ressalta-se que o próprio Piaget (1977), quando investiga os processos de tomada de consciência realiza-os em adultos e crianças ${ }^{3}$. A tomada de consciência, bem como a abstração reflexionante, são fundamentais para compreender o desenvolvimento, seja ele relacionado ao conhecimento físico, lógico matemático ou social.

Para o presente estudo serão apresentados os resultados das questões: Qualquer pessoa pode ser professor? Que imagem você tem de si mesmo como futuro professor? e O que é ser professor para você? A escolha destas deu-se pelo fato delas permitirem que sejam conhecidas as concepções mais ligadas a identidade docente propriamente dita.

\footnotetext{
${ }^{3}$ Na prova de andar de gatinhas, Piaget e seu colaborador, em 1970, submeteram à situação, convidados de um simpósio, todos adultos e foram constatadas respostas do nível I B (correspondente ao equilíbrio do estádio préoperatório).
} 


\section{Resultados e discussões}

As respostas dos participantes puderam ser enquadradas nos três níveis de compreensão da realidade social para a identidade docente. A fim de conhecer de forma mais analítica os tipos de respostas, optou-se por enquadrar as respostas de cada questionamento nos níveis de compreensão da realidade social. Assim tem־se:

\section{Questionamento “Qualquer pessoa pode ser professor?”}

As respostas que se aproximam ao nível 1 apresentam uma imagem docente que pauta-se apenas nos aspectos simplistas da profissão, por exemplo, na vocação ou dom e no amor em ensinar. Acompanha-se:

Não [...], pois nem todo mundo tem "vocação" e paciência para estar em uma sala de aula (Acadêmico do $1^{\circ}$ ano).

Não, porque é um dom ensinar e nem todos o tem (Acadêmico do $1^{o}$ ano).

Qualquer pessoa que esteja disposta a realizar um trabalho pautado no amor [...] (Acadêmico do $4^{o}$ ano).

O conjunto de respostas apresentado revela que esses futuros professores entendem a necessidade de aspectos afetivos para o exercício da atividade docente. São concepções que propagam ideias muito presentes no senso comum, isto é, no âmbito coletivo, de que existe um "dom", algo inato, que determina a aproximação do sujeito com determinada profissão. Desse modo, não demonstram ideias que compreendem o trabalho do professor como uma profissão, por isso, aspectos técnicos, tal como a necessidade de uma formação específica, não são considerados. 
As ideias apresentadas vão ao encontro das características do primeiro nível descritas na pesquisa de Guimarães (2007). Nesse estudo que investigou as concepções de escola, embora realizado com estudantes do fundamental I, com idades entre 7 e 8 anos foram reveladas respostas semelhantes às encontradas na presente pesquisa, tal qual o desejo pessoal como determinante para ser professor.

A partir do nível 2 de compreensão da realidade social, passa-se a considerar o aspecto formativo como algo importante. No entanto, questões de afetividade, afinidade e vocação são, ainda, determinantes, conforme se pode acompanhar nos excertos:

Não é simplesmente ter formação, tem que gostar de criança ou de estar em contato com pessoas. (Acadêmico do $1^{\circ}$ ano).

Não, como qualquer profissão além da capacitação é necessária vocação. (Acadêmico do $4^{o}$ ano).

Somente em presença do nível 3 de compreensão dessas questões, o ser professor, desvincula-se das questões afetivas e independem de dom ou vocação. Considera-se a exigência de uma formação específica e da compreensão dos processos de ensino e de aprendizagem. Em acréscimo, são concepções que reconhecem o papel social da profissão na formação de pessoas críticas e atuantes na sociedade. Tem-se como exemplo:

Sim, tem que estudar. Ser professor não é um dom é responsabilidade com o mundo e com seu futuro. (Acadêmico do $4^{o}$ ano).

[...]. Não é qualquer pessoa, precisa de estudo, qualificação, especialização, precisa entender como as pessoas aprendem. (Acadêmico do $4^{\circ}$ ano). 
As concepções que se entendem como mais apropriadas ao terceiro nível de compreensão da realidade social, deixam claro uma preocupação a mais dos acadêmicos, algo que está no âmago da profissão docente, e reflete sobre a importância dos processos relacionados ao ensino e aprendizagem.

Por meio das respostas que surgiram a esse primeiro questionamento é possível perceber que faz parte do ideário dos futuros docentes uma concepção de que o dom e a vocação são essenciais, ou melhor, são eles que marcam um profissional da educação. É fato que essa imagem acaba por definir de certa forma a identidade dos professores. Como afirma Arroyo (2000) "a ideia de vocação pode estar incrustada na ideia de profissão [...] por mais que tentemos apagar esse traço vocacional" esse se encontra junto à ideia de amor e dedicação como parte do "imaginário social e pessoal sobre o ser professor, educador, docente". (ARROYO, 2000, p. 33).

De modo semelhante, Nóvoa (1991) e Brzezinski (2002) também indicam tais características como constituintes da profissão docente. Para Brzezinski (2002) o próprio Ministério da Educação (MEC) reforça a ideia de que qualquer um pode ser professor, afirmando que pesquisas sobre avaliação institucional corroboram que não existe diferença entre os alunos formados por professores licenciados ou não.

Os resultados da frequência de respostas para cada um dos níveis de compreensão da noção social investigada podem ser acompanhados no gráfico 1 , a seguir. 
Gráfico 1: Frequência de respostas para a questão "Qualquer pessoa pode ser professor?"

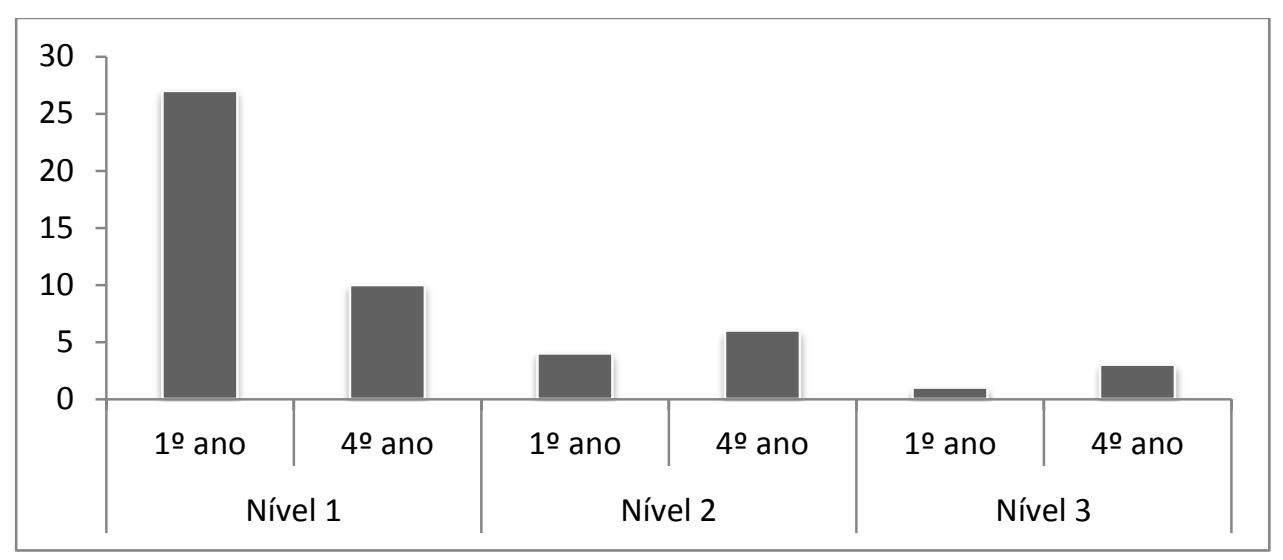

Fonte: Dados da pesquisa organizados pelas autoras.

Pode-se constatar que a maioria de respostas para essa questão enquadrou-se no primeiro nível, sobretudo, no que se refere aos acadêmicos do primeiro ano. Os concluintes dividiram-se, em grande maioria, em compreensões do primeiro e segundo ano. Apenas uma pequena parcela de sujeitos, e já acadêmicos do $4^{\circ}$ ano apresentaram uma concepção mais completa, presente no terceiro nível.

Esses são resultados importantes, pois mesmo tendo os acadêmicos iniciado e até mesmo vivenciado uma formação acadêmica específica para uma profissão, esta não é entendida como essencial para a formação profissional do professor. Em especial e relacionado aos participantes concluintes do curso de Pedagogia, questiona-se sobre o papel das disciplinas cursadas para a constituição de sua identidade docente, uma vez que em poucos casos, somente em respostas de segundo e terceiro nível, houve a preocupação com os processos de ensino e aprendizagem.

Tais apontamentos colaboram para refletir acerca do próximo questionamento, no qual solicitou-se aos participantes que indicassem a imagem que possuem deles, atuando como futuros professores. 


\section{Questionamento "Que imagem você tem de si mesmo como futuro professor?"}

Em resposta a essa questão, no primeiro nível estão as concepções que indicam a imagem de um futuro professor feliz, realizado e sem problemas. Por tratar-se de uma compreensão quase anedótica dos conteúdos sociais (DELVAL, 2002) surgem, mais uma vez, ideias de um professor atuante que ensina por amor e é sempre compreensível com seus alunos. Apresenta-se alguns excertos, em sequência.

Alguém que vai fazer o possível para ajudar as crianças, ensiná-las com todo carinho. (Acadêmico do $1^{\circ}$ ano).

[...] profissionalmente competente e realizado. (Acadêmico do $1^{o}$ ano).

Quero responder ao chamado, tentar compreender meu aluno [...] (Acadêmico do $4^{\circ}$ ano).

Os depoimentos apresentados sugerem uma ligação entre o instinto amoroso e maternal e a imagem de professor dedicado, assim como ressaltado anteriormente. Esta é, sem dúvida, uma das imagens recorrentes no senso comum, entre os leigos especialmente.

As respostas desse primeiro nível se assemelham muito às indicadas por Paganini-da-Silva (2006) quando investigou professores de $6^{\circ}$ ano $9^{\circ}$ anos. As imagens que surgiram em sua pesquisa foi a de "professor amigo; professor dedicado; professor competente; professor menteaberta/consciência; professor modelo" (p. 139).

Por ocasião do nível 2 de compreensão da realidade social, as ideias utópicas de um profissional realizado e capaz de resolver todos os problemas da educação ainda se mantem mas, passa-se a considerar que existem processos de ensino e aprendizagem que devem ser considerados e pondera- 
se sobre a necessidade de inovação na maneira de ensinar. Pensa-se sobre a necessidade de permanecer em formação contínua. Vejamos os depoimentos:

[...] pretendo ser dedicada ao objetivo de ensinar, fazendo atividades diferenciadas que facilitem a aprendizagem de meus alunos. (Acadêmico do $1^{\circ}$ ano).

Uma professora calma, atenciosa e preocupada com o desenvolvimento mental, moral e intelectual de cada aluno. (Acadêmico do $4^{\circ}$ ano).

Diante dos exemplos de respostas que ilustram o segundo nível, inferese que existe um avanço ao pensar na imagem profissional futura em comparação ao primeiro nível. Entretanto, como característico desse modo de compreensão, mais elementos são incorporados, mas ainda não permitem uma visão global e crítica da profissão.

Nas respostas que puderam ser reservadas ao nível 3 tem-se que os elementos relacionados à vontade desaparecem e considera-se a futura imagem profissional como uma construção, um aprendizado constante. Existe a clareza da necessidade de relações de diálogo com os alunos, isto é, busca-se ser um profissional que contextualiza o ensino, bem como apresenta uma atuação docente que almeja a diversificação de estratégias didáticas.

Ainda não tenho imagem, pois penso que a cada dia vou construir a minha identidade como professor. (Acadêmico do $1^{\circ}$ ano).

[...] dialogando, fazendo atividades diferenciadas. (Acadêmico do $4^{o}$ ano).

Uma professora aberta a questionamentos novos e estudos que irão ampliar minha área de atuação. (Acadêmico do $4^{o}$ ano). 
Surpreende a resposta de um acadêmico ingressante, presente no primeiro excerto apresentado, o entrevistado afirma que a imagem profissional não é algo pronto e acabado, mas que se constrói no dia-a-dia.

De maneira geral, as concepções encontradas para o segundo questionamento remetem as considerações de Dubar (1997) sobre a identidade social que é constituída tendo em vista uma identidade para si que depende do olhar do outro, pois é este que reflete nossa própria imagem. Cabe ressaltar que a experiência do outro nunca é diretamente vivida por si, e, por conta disso, acaba-se por forjar uma identidade para nós próprios.

Complementa-se com Gauthieret al. (1998) ao indicarem como um saber docente, uma das imagens que aparecem nas respostas dos acadêmicos que é o professor-competente. De acordo com essa crença para ser um bom professor é necessário apenas conhecer e dominar o conteúdo. No entanto, para os autores os saberes docentes não podem ser reduzidos à pura transmissão de conhecimento, pois ser professor é muito mais que isso, de modo que envolve e requer uma série de habilidades e competências.

Vale retomar que as imagens docentes sofrem alterações no decorrer da história e estas deixam resquícios na imagem atual dessa categoria. As imagens públicas dos professores são construídas nas disputas que se estabelecem no campo educacional, inclusive com relação aos currículos, como assegura Arroyo (2014), nas relações de grupo e movimentos que procuram um maior reconhecimento de seu trabalho diante de outras categorias profissionais.

É interessante ressaltar uma situação específica e pontual desse trabalho. Em 4 questionários dos alunos do $4^{\circ}$ ano não foi possível determinar o nível de compreensão da realidade social para esse questionamento, pois os alunos afirmaram não conseguir fazer uma imagem profissional futura, seja pela incerteza em atuar na educação, seja pela demonstração de desânimo com a futura profissão. 
As frequências de respostas desse segundo questionamento podem ser acompanhadas por meio do gráfico 2 , em sequência.

Gráfico 2 : Frequência de respostas para a questão "Que imagem você tem de si mesmo como futuro professor?"

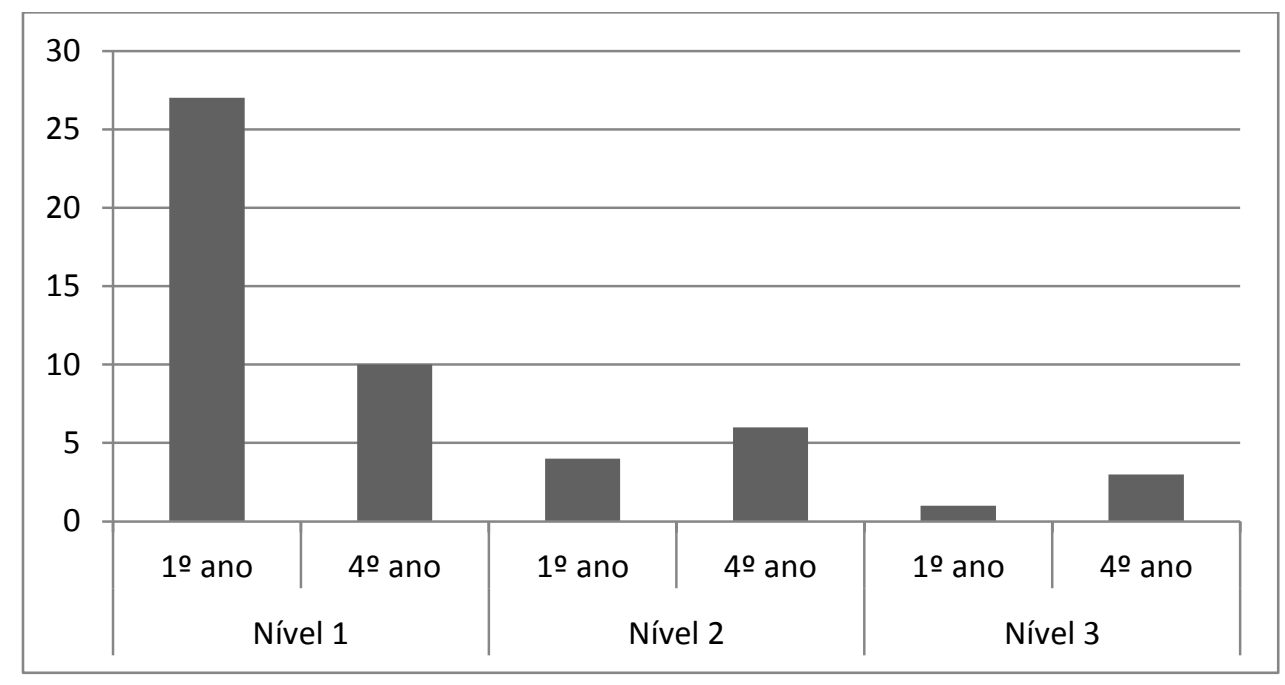

Fonte: Dados da pesquisa organizados pelas autoras.

As frequências apresentadas mostram que os participantes, em sua maioria, apresentam respostas cujo conteúdo aproxima-se a compressão do primeiro nível, mesmo em acadêmicos do quarto ano. Diante disso, ressaltase o quanto concepções presentes na sociedade, por exemplo, a ideia de quem tem uma profissão é bem sucedido e realizado, são enraizadas não permitindo que outros elementos sejam incorporados à reflexão e constituição da imagem profissional docente. 


\section{Questionamento "O que é ser professor para você?"}

Objetivou-se nessa questão conhecer, de fato, a concepção que permeia o imaginário de nossos participantes acerca da atuação docente. Sendo assim, no nível 1, encontrou-se ideias ligadas apenas a transmissão de conhecimentos, a qual caracterizaria o "ser professor". Também aparecem pensamentos ligados à função de cuidado e zelo pelas crianças, conforme podemos acompanhar, a seguir.

Passar para os alunos os conhecimentos que adquiriu na sua vida. (Acadêmico do $1^{\circ}$ ano).

Ser mediador do conhecimento [...]. (Acadêmico do $4^{o}$ ano).

Cuidar, ensinar e amar [...]. (Acadêmico do $4^{\circ}$ ano).

No nível 2, passa-se a perceber que o ensinar não é somente a transmissão de conteúdos e concebe-se que as pessoas aprendem de maneiras diferentes, por isso a função está mais próxima aos saberes de uma profissão específica. É o caso das afirmações, em sequência.

Ser professor é transmitir o saber, o conhecimento para aquele que quer aprender, é incentivar a aprendizagem. (Acadêmico do $1^{o}$ ano).

[...] transmitir conhecimento com comprometimento [...] utilizando diversos recursos para que o aprendizado aconteça. (Acadêmico do $4^{\circ}$ ano).

Somente no terceiro nível de compreensão da realidade socialos sujeitos compreendem que é importante e necessário escolher a melhor didática para que a aprendizagem ocorra, ou seja, a preocupação é com a aprendizagem e 
não apenas com a transmissão de conhecimentos. Nesse momento existe uma posição mais reflexiva com relação a função docente sendo representado por um olhar sob diferentes perspectivas para o exercício da profissão, por exemplo, o professor tem consciência de que ele precisa encaminhar seu aluno ao "aprender a aprender". Pode-se acompanhar tal compreensão nos excertos que afirmam:

Transformar pessoas em seres melhores, trazendo novas chances e oportunidades para seu futuro. (Acadêmico do $1^{\circ}$ ano).

$A$ função de ensinar é mediar, tornar o aluno autônomo $e$ independente, o professor precisa tornar seu aluno questionador, crítico, fazendo com que busque conhecimento, e sinta vontade de aprender, não por obrigação e sim por "descobertas", o professor deve mostrar ao aluno caminhos além do que ele está vendo. (Acadêmico do $4^{o}$ ano).

No gráfico 3, a seguir, apresenta-se a frequência de respostas encontradas em cada nos anos pesquisados.

Gráfico 3: Frequência de respostas para a questão "O que é ser professor para você?"

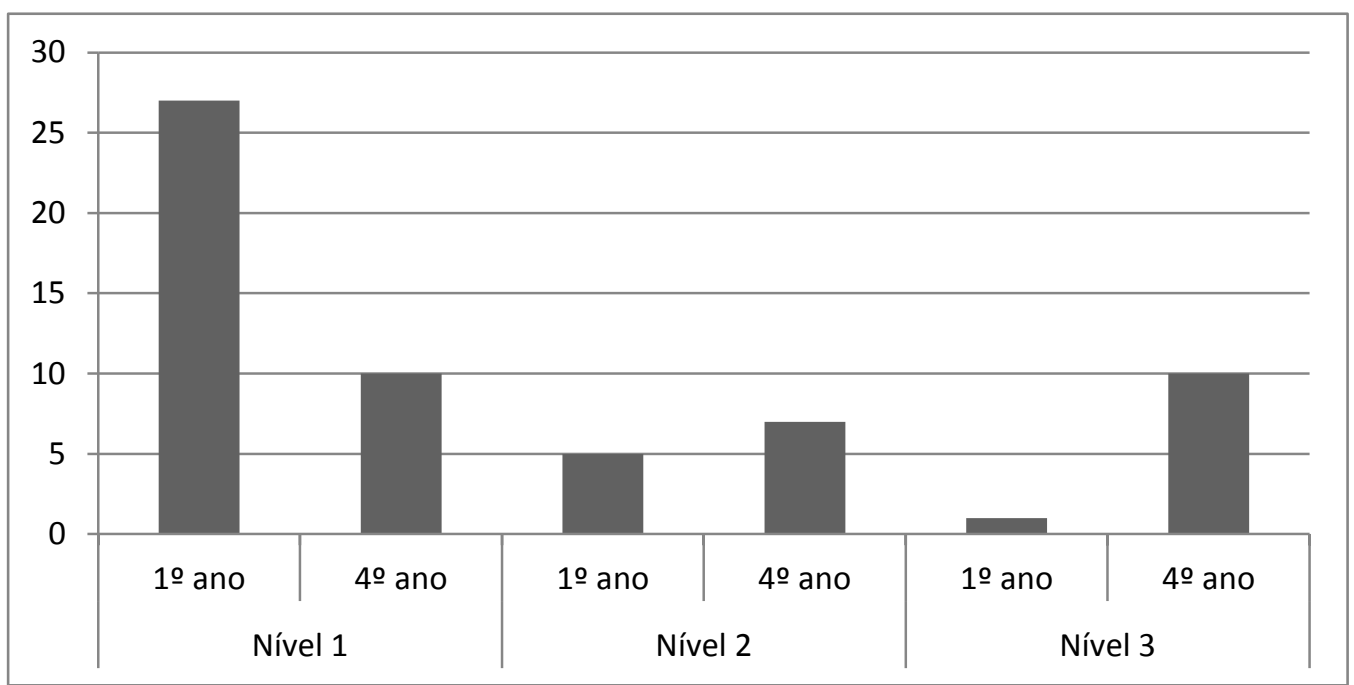


Fonte: Dados da pesquisa organizados pelas autoras.

No que tange aos resultados desse questionamento, é possível acompanhar que os acadêmicos ingressantes concentram suas ideias na compreensão de que a atuação do professor relaciona-se apenas da transmissão de conhecimentos, sem levar em conta demais aspectos presentes no processo educativo. Essa constatação aproxima-se do observado em Paganini-da-Silva (2006) com relação aos professores já em serviço.

Nesse particular, chama atenção as respostas dos acadêmicos concluintes, uma vez que puderam ser enquadradas em compreensões de nível 2 e 3 , o que revela um maior conhecimento do papel profissional do professor. Acredita-se que esse resultado é decorrente do fato dos acadêmicos quartanistas já terem tido maior contato com a profissão, sobretudo, por meio dos estágios obrigatórios, ao longo do curso.

De certo modo, tais momentos e os demais presentes em sua formação permitiram, para a maior parte dos discentes, reflexões sobre a consciência de seu papel, isto é, afere-seque a formação inicial é extremamente importante, mas, além disso, há a necessidade de ela possuir qualidade e uma fundamentação pedagógica que ultrapasse os requisitos técnicos.

No entanto é preciso considerar que:

A dificuldade de definição das atribuições do professor acaba por levar à incorporação de uma multiplicidade de tarefas que, muitas vezes, ultrapassam a função docente, fugindo de seu alcance e caracterizando atividades de profissões ou ocupações distintas das do magistério. Sabemos que a identidade profissional docente diz respeito ao modo como os professores se veem e como são vistos pelos outros; diz respeito ao próprio trabalho, ao valor social que possuem ou não, a seus saberes e à sua competência para ensinar. (PAGANINI-DA-SILVA, 2006, p. 210). 
Esta questão trazia de forma mais direta o tema da presente pesquisa impulsionando os acadêmicos a pensar a respeito da função e identidade docente. Para Gimeno Sacristán (1991) a função docente encontra-se em permanente elaboração e depende diretamente das relações e dos contextos sociais nos quais a comunidade docente se encontra.

Tendo isso em mente, ressalta-se que os sujeitos investigados são acadêmicos do curso de Pedagogia e, por isso, sua identidade não poderia e nem deveria estar formada por completo. Entretanto, considerando a participação de acadêmicos do último ano de curso esperava-se que a construção da identidade, a qual deveria ser promovida pela formação inicial apresentasse mais elementos próximos ao nível 3 de compreensão da realidade social, isto é, de uma forma mais elaborada de pensar os conteúdos dessa natureza.

\section{Conclusões}

A pesquisa apresentada teve por objetivo conhecer as concepções de estudantes ingressantes e concluintes do curso de Pedagogia a respeito da identidade docente, isto é, do papel do professor. Para tanto apresentou-se os resultados obtidos a três questionamentos realizados que investigaram se os estudantes concebiam que qualquer pessoa poderia ser professor, como eles se imaginavam no futuro ao atuar na profissão escolhida e, por fim, qual seria o papel do professor.

A hipótese que permeou o presente estudo é a que esse é um tema de natureza social, construído por meio das relações que se estabelecem com esse objeto de conhecimento específico, por isso, haveria uma evolução de respostas. Desse modo, acreditou-se que os participantes matriculados no primeiro ano apresentariam respostas mais elementares e características do primeiro nível de compreensão da realidade social, já os participantes concluintes do curso revelariam ideias mais elaboradas, que poderiam ser enquadradas no terceiro nível. 
Ao longo da análise qualitativa apresentada observa-se que a hipótese revelada foi, sutilmente, confirmada, haja vista que somente em um dos questionamentos a evolução das ideias, entre primeiranistas e quartanistas, pôde ser melhor observada.

Assim, a concepção mais presente para a indagação se qualquer pessoa poderia ser professor, foi a do nível 1, isto revela que é muito presente entre os acadêmicos pesquisados, ideias mais simplistas, por meio das quais entende-se que a atuação docente depende muito mais de aspectos afetivos, tais como gostar de crianças e ter o dom de ensinar, do que a aspectos técnicos e adjacentes à profissão.

De modo semelhante, no que se refere à imagem profissional, encontrou-se a maioria das respostas enquadradas no primeiro nível de compreensão, revelando que ao conceberem sua atuação enquanto profissionais da educação, os futuros professores, imaginam-se bemsucedidos, felizes e capazes de resolver os problemas que surgirão. De maneira alguma, defende-se que a atuação profissional não pode apresentar essas características, mas entende-se que é preciso pensar em todos os aspectos que, de maneira intrínseca, passam pela atuação docente, por exemplo, questões ligadas às políticas públicas, ao currículo, às condições de trabalho docente, entre outras.

Destarte, quanto às respostas encontradas para o questionamento sobre o ser professor foram encontrados resultados mais positivos e que corroboram a hipótese inicial. Assim, os alunos de primeiro ano mostram-se presos a aspectos mais visíveis e estereotipados da profissão, típico do primeiro nível, já os de quarto ano, apresentaram, ainda, essa concepção, mas a maior parte das respostas dividiu-se entre o segundo e o terceiro nível, indicando que aspectos mais subjetivos e que precisam ser levados em conta para a construção da identidade docente, passaram a ser considerados.

Novamente é preciso deixar claro que para nenhuma das questões desconsidera-se a importância de um professor gostar do que faz ou ser dedicado à sua profissão, apenas não é possível entender como concepção 
mais "evoluída" respostas que centraram-se apenas em um único aspecto da docência e de sua constituição identitária, deixando de perceber sua totalidade.

Os professores deveriam se expor mais à sociedade sendo importante essa comunicação e se aproximando mais dos problemas e da realidade escolar trocando experiências com seus pares, atuando mais como pesquisadores e menos como meros executores. Nesse sentido, pensando no desenvolvimento profissional dos professores sob a ótica piagetiana, é possível afirmar a relevância dessas trocas na expectativa de promover reflexão acerca dos problemas e, ainda, causar desequilíbrios e equilíbrios posteriores em relação à sua prática.

Essa pesquisa não esgota a temática, mas fornece subsídios para a reflexão acerca desse conhecimento social, sobretudo, no que se refere a formação inicial docente, uma vez que essa é essencial para a construção do ser professor. Ressalta-se a necessidade de voltar-se a atenção aos cursos de licenciatura, com sua qualidade, promovendo contextualizações sobre a profissão docente, algo que nem sempre é considerado nessa etapa de formação.

\section{Referências}

ARROYO, M. G. Ofício de mestre: imagens e auto-imagens. 3. ed. Petrópolis: Vozes, 2000 .

Currículo, território em disputa. Petrópolis: Vozes, 2014.

BERGER, P. L.; LUCKMANN, T.A construção social da realidade: tratado de sociologia do conhecimento. Petrópolis: Vozes, 1985.

BRZEZINSKI, I. (Org.). Profissão professor: identidade e profissionalização docente. Brasília: Editora Plano, 2002.

CHAKUR, C. R. S. L. Desenvolvimento profissional docente: contribuições de uma leitura piagetiana. Araraquara: JM Editora, 2001.

DELVAL, J. Introdução à prática do método clínico: descobrindo o pensamento da criança. Tradução de Fátima Murad. Porto Alegre: Artmed, 2002. 
DUBAR, C. A socialização: construção das identidades sociais e profissionais. Porto: Porto Editora, 1997.

ENESCO, I. et al. La comprensión de la organización social en niños y adolescentes. Madrid: CIDE, 1995.

LIBÂNEO, J. C.; PIMENTA, S. G. Formação dos profissionais da educação: visão crítica e perspectivas de mudança. Educação \& Sociedade, Campinas, ano XX, n. 68, 1999.

GAUTHIER, C. et al. Por uma teoria da pedagogia: pesquisas contemporâneas sobre o saber docente. Ijuí: Unijuí, 1998.

GIMENO SACRISTÁN, J. Consciência e acção sobre a prática como libertação profissional dos professores. In: NÓVOA, A. Profissão Professor. Porto: Porto Editora, 1991, p.61-92.

GIDDENS, A. Modernidade e Identidade. Rio de Janeiro: Zahar, 2002.

GUIMARÃES, T. As ideias infantis a respeito da escola e do professor: um estudo comparativo acerca da construção do conhecimento social em ambiente sócio-morais construtivistas e ambientes tradicionais. $120 \mathrm{f}$. Trabalho de conclusão de curso (Graduação em Pedagogia) - Faculdade de Filosofia e Ciências, Universidade Estadual Paulista "Júlio de Mesquita Filho", Marília, 2007.

NÓVOA, A. Para o estudo sócio histórico da gênese e desenvolvimento da profissão docente. Teoria \& Educação, Porto Alegre, n. 4, p. 109-139, 1991.

em:

Professores: imagens do futuro presente. Educa. Lisboa, 2009. Disponível

http://www.etepb.com.br/arq_news/2012texto_professores imagens do futuro pres ente.pdf. Acesso em: 25 out. 2012.

PIMENTA, S. G. Formação de Professores - Saberes da docência e identidade do professor. Nuances, Presidente Prudente, v. 3, p. 5-14, 1997.

De professores, pesquisa e didática. Papirus: Campinas, 2002.

ROGERS, C. Tornar-se pessoa. São Paulo: Martins Fontes, 1972.

PAGANINI-DA-SILVA, E. A profissionalização docente: identidade e crise. 2006. 221f. Dissertação (Mestrado em Educação Escolar) - Universidade Estadual Paulista "Júlio de Mesquita Filho", Araraquara, 2006.

Ser professor e a relação ensino-aprendizagem: uma contribuição piagetiana. $253 \mathrm{f}$. Tese (Doutorado em Educação) - Universidade Estadual Paulista "Júlio de Mesquita Filho", Marília, 2015.

VIANNA, C. Os nós do "nós": crise e perspectiva da ação coletiva docente em São 
Paulo. São Paulo: Xamã, 1999.

Recebido em 27 de setembro de 2017. Aprovado em 12 de janeiro de 2018. 


\title{
Entrevista $^{1}$
}

\author{
Orly Zucatto Mantovani de Assis
}

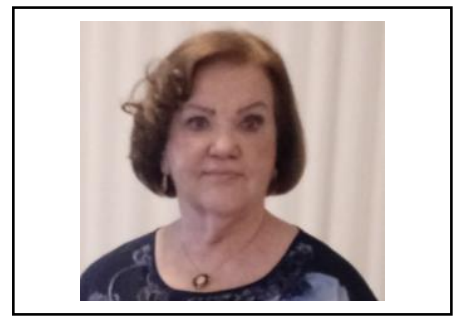

Orly Zucatto Mantovani de Assis é pedagoga e iniciou sua carreira como professora do ensino fundamental no município de Amparo-SP. Durante esse período, interessou-se em compreender o que ocorria com os alunos quando estes demonstravam não reter aquilo que lhes era transmitido, no que se refere à matemática elementar. Passou então a se dedicar ao estudo e aprofundamento sobre o desenvolvimento e a aprendizagem, numa perspectiva piagetiana, tendo concluído seu doutoramento em 1976, pela UNICAMP. Sua investigação provou que um processo, denominado pela pesquisadora de Processo de Solicitação do Meio e caracterizado por mudanças no ambiente físico da sala, na estrutura diária das atividades, na conduta do professor, na maneira como as relações interpessoais se processam e no tipo de atividade e material oferecido ao aluno, favorece o desenvolvimento da criança em seus aspectos cognitivo, afetivo, social e psicomotor. Esse processo denominado de PROEPRE- Programa de Educação Pré-Escolar-inicialmente, e depois Programa de Educação Infantil e Ensino Fundamental, embasado na teoria piagetiana foi implantado em mais de vinte Secretarias Estaduais de Educação e Secretarias de Educação Municipais de inúmeras cidades do Distrito Federal, São Paulo, Minas Gerais, Pará, Mato Grosso do Sul, Mato Grosso, Piauí. De 1992 em diante, os cursos para formação de professores do PROEPRE passaram a ser oferecidos anualmente pela Escola de Extensão da UNICAMP, com mais de 140 turmas até a atualidade. Desde 1983, a professora Orly coordena o Laboratório de Psicologia Genética da Faculdade de Educação da UNICAMP e grupo de pesquisa do $\mathrm{CNPq}$, tendo orientado mais de 130 trabalhos entre teses, dissertações, trabalhos de conclusão de curso e de iniciação científica. Foi em 1994, por ocasião do III Simpósio Internacional de Epistemologia Genética, realizado em Águas de Lindóia-SP e organizado pela professora Orly, que Juan Delval esteve no Brasil pela primeira vez, trazendo, naquele momento, dados inusitados sobre suas pesquisas a respeito do conhecimento social. A professora Orly está, atualmente, atuando como docente do Programa de Pós-Graduação em Educação da UNICAMP e permanece coordenando o LPG e os cursos de formação de professores do PROEPRE.

\footnotetext{
${ }^{1}$ Entrevista concedida a Érica de Cassia Gonçalves na cidade de Campinas-SP. 
E: Os estudos que a senhora orientou que tiveram como tema o conhecimento social foram pioneiros em nosso país? Como foi esse início de pesquisas? Qual foi a motivação para estudar esse campo de conhecimento? Orly: Penso que sim. Se eu me lembro bem, quando o Prof, Delval esteve pela primeira vez no Brasil e realizou alguns seminários aqui, no LPG (Laboratório de Psicologia Genética/FE/UNICAMP), algumas pósgraduandas que faziam parte de nosso grupo de pesquisa se interessaram por esse tema, dentre elas, a Eliane, a Roberta, a Valéria, a Larissa ${ }^{2}$.

\section{E: Então, Orly, o início da pesquisa foi depois que Juan Delval esteve aqui no Brasil?}

Orly: Sim, depois que Delval esteve pela primeira vez entre nós, participando do III Simpósio Internacional de Epistemologia Genética e dos Encontros do PROEPRE de Águas de Lindóia/SP e ministrando palestras e seminários, promovidos pelo LPG, aqui na Faculdade de Educação. A motivação foram os trabalhos que nós tomamos conhecimento que o Delval e a Ileana Enesco nos trouxeram. Eles não só trouxeram pesquisas como também várias publicações sobre o Conhecimento Social que passaram a compor o acervo do LPG e serviram como referências iniciais para nossos orientandos formularem seus problemas de pesquisa.

\section{E: Como a senhora vê a evolução das pesquisas sobre o Conhecimento Social aqui no Brasil?}

Orly: Olha, eu tenho ideia dessas pesquisas realizadas no LPG e mais ou menos as da Eliane Saravali, lá na UNESP. Então, a minha hipótese vai abranger apenas Campinas-SP e Marília-SP. Então, eu acho o seguinte: considerando o tempo em que essas pesquisas foram realizadas e também a

\footnotetext{
${ }^{2} \mathrm{~A}$ esse respeito, vale dizer que as pesquisas do Laboratório de Psicologia Genética, orientadas pela professora Orly, foram precursoras dos trabalhos sobre o conhecimento social no Brasil. Grande parte destes trabalhos estão referenciados ao final desta entrevista.
} 
época que a teoria piagetiana começou a ser estudada no Brasil, eu acho que até houve uma evolução significativa. Porque, juntando os trabalhos que a Eliane tem orientado na UNESP de Marília com estes 21 concluídos sob minha orientação, considerando ainda as dificuldades de realização das pesquisas que utilizam o método clínico crítico piagetiano, eu acho que é um número relativamente bom. Eu acho que houve uma expansão grande, considerando o tempo também (de 94/96 para cá).

$E$ : Muitos temas pertinentes ao conhecimento social foram alvo de estudos. A senhora acredita que ainda há espaço para novas pesquisas? $O$ que ainda necessitaria ser explorado?

Orly: Realmente há!

\section{E: A política, seria um conhecimento social?}

Orly: Sim, a ideia que se faz da política brasileira, da democracia. Não podemos esquecer dos trabalhos da Marianela Denegri, sobre as ideias de consumo e educação econômica. Um outro tema que está sendo pesquisado agora, por Eliane Cleonice Alves Precoma, em seu pós doc, supervisionado por mim, trata das Representações de Resiliência e de Redes de Proteção.

E: Orly, a questão da diversidade de gêneros que tem sido muito discutida, poderia ser abordada na perspectiva da construção do conhecimento social?

Orly: Sim, social... diversidade de gênero, mas isso pra mim é também uma questão de inclusão, cuja problemática faz parte do conhecimento social.

\section{E: E este seria um campo a ser explorado também ou não?}

Orly: Sim, também. Resiliência, por exemplo. É um tema importante para ser estudado dentro do campo do conhecimento social. Outra coisa, a violência. Outra questão importante também é a graduação em Educação Social, e estes educadores sociais estão sendo requisitados em obras sociais. Então, por exemplo, aqui na Casa Santana (Centro de Convivência e 
Inclusão Social para a Cidadania de Campinas) eles têm o programa Jovem Aprendiz e, para este programa, foram contratados educadores sociais.

\section{E: Como a senhora avalia as práticas pedagógicas que ocorrem em nossas escolas e que envolvem a construção do conhecimento social?}

Orly: Eu acho que as práticas pedagógicas que têm em vista a construção do conhecimento social, em geral, são práticas que utilizam apenas a transmissão social. Não há, no meu modo de ver, o entendimento de que o conhecimento social é também construído, isto até daria uma boa pesquisa para se fazer, para provar isso, é uma hipótese. Vamos encontrar, na maioria das escolas, um trabalho que não considera o que o aluno pensa sobre o conhecimento social. Existe um livro que se chama "Piaget: o diálogo com a criança e o desenvolvimento do raciocínio" de Maria da Glória Seber. Ela fez uma pesquisa sobre como a criança entende a história do Brasil, por exemplo. Os resultados encontrados por ela mostram a não compreensão dos fatos históricos, devido à maneira como eles são ensinados. Outra coisa que não se leva em consideração ao trabalhar o conhecimento social é o nível de desenvolvimento da criança. Segundo a pesquisa de Seber, ao falar sobre o que sabe a respeito da história do Brasil, crianças do $4^{\circ}$ e $5^{\circ}$ ano misturam acontecimentos, causas e consequências revelando uma total incompreensão, como por exemplo: que D. Pedro I descobriu o Brasil, e Cabral gritou "Independência ou Morte" semelhante ao chamado "Samba do Crioulo Doido". É um samba em que a história do Brasil é toda contada erradamente, incoerentemente, invertida de modo a se fazer rimas. O que as crianças, na verdade, fazem com os conteúdos de história que elas

aprendem? É um verdadeiro samba do crioulo doido! Por exemplo, na letra do samba se diz que a princesa Leopoldina virou estação de trem, isso é compreendido por elas ao pé da letra. Já ouvi uma criança dizer que o Brasil tinha uma coberta em cima e veio Cabral e "descobriu” o Brasil (risos).

E: O Proepre, programa que a senhora criou, propõe ações específicas para o 


\section{trabalho com o conhecimento social. Quais são essas ações?}

Orly: Eu prefiro mencionar os princípios que essas ações devem respeitar. O primeiro é que o conhecimento social é construído. E, inicialmente, quando se trata de trabalhar o conhecimento social, é preciso fazer um levantamento prévio sobre o que a criança já conhece daquilo que a gente quer tratar. Quando a Eliane Saravali, por exemplo, em sua pesquisa sobre os direitos das crianças, perguntou o que é direito, as crianças respondiam: "Direito é assim" (apontando com a mão o lado direito). Eles têm uma ideia e se você não levar em consideração esse conhecimento prévio da criança corre o risco de tudo ser mal compreendido, aí vem aquela história, que a professora perguntou qual era a maior bacia do Brasil, e aí criança respondeu: "A bacia que minha professora toma banho." Porque ele não sabia a que bacia ela estava se referindo, podia até falar que era fluvial, mas ele não sabia o que era fluvial e não sabia o que era bacia. Então, esses mal-entendidos de fato pesam na compreensão. Quanto mais for possível que a criança realize ações sobre os objetos, porque é a partir da ação que o conhecimento social também se constrói e da interação social, é que ela vai ver, por exemplo, se o que ela pensa pode não ser o que o outro pensa, isso poderá levá-la a ideia de uma contradição. Então, os passos seriam realmente os mesmos que são utilizados na construção do conhecimento lógico-matemático e na descoberta do conhecimento físico e invenção do conhecimento lógico matemático. Então é por isso que, quanto mais estes temas corresponderem ao interesse da criança, mais chance têm de ser compreendidos por ela. Por exemplo, existem temas do conhecimento social que satisfaziam mais as crianças, por exemplo: as grandes invenções. Há um texto que se chama "Interesse e Liberdade" de Maria Dolors Busquets que aborda bem essa questão.

Veja, o princípio da ação, Piaget diz que o conhecimento é adquirido por meio da ação sobre o objeto e da interação social, certo? Então, se você respeitar isso, sem esquecer de levar em conta os conhecimentos prévios que a criança tem, porque aí entra o problema da linguagem, você precisa acertar o seu vocabulário com o vocabulário da criança e saber o que ela está 
pensando sobre este tema, porque muitas vezes ela faz a pergunta corretamente, mas ela não sabe nem o que ela está perguntando. Certa vez uma criança pequena perguntou-me, quando estava sentada ao meu lado num carro... estava ventando fiz com que o vidro de sua janela subisse ao acionar um botão, sem que ela percebesse: “- É automático?”, aí eu perguntei o que era automático e ela não sabia o que era. Eles usam a expressão certa, na pergunta certa, mas sem ter uma compreensão do significado daquilo. Então, como o significado do conhecimento social, depende muito da linguagem, é preciso que isto seja considerado, o conhecimento que a criança tem.

A criança terá oportunidades de construir o conhecimento social quando faz inferências, a partir de determinadas informações que poderão ser confirmadas ou não quando interage com adultos ou consulta livros ou mesmo o computador. Em situações como essas a criança adquire o conhecimento a respeito do que está interessada, aprende a pesquisar, a comparar suas ideias com a dos outros pares ou adultos, põe em atividade suas estruturas de pensamento. Enfim, se desenvolve...

\section{Referências}

ARAÚJO, R. M. B. O desenvolvimento do pensamento econômico em crianças: avaliação e intervenção em classes de $3^{\mathrm{a}}$ e $4^{\mathrm{a}}$ série do Ensino Fundamental. 2007. Tese (Doutorado em Educação) - Faculdade de Educação, Universidade Estadual de Campinas, Campinas, 2007.

BAPTISTELLA, E. C. F. A compreensão de um conteúdo de um comercial televisivo na infância. 2001. Dissertação (Mestrado em Educação) - Faculdade de Educação Universidade Estadual de Campinas, Campinas, 2001.

BARROSO, L. M. S. As ideias das crianças e adolescentes sobre seus direitos: um estudo evolutivo à luz da teoria piagetiana. 2000. 327f. Dissertação (Mestrado em Educação) - Faculdade de Educação, Universidade Estadual de Campinas, Campinas, 2000.

BORGES, R. R. A construção da noção de família em crianças pré-escolares. 2001. Dissertação (Mestrado em Educação) Faculdade de Educação, Universidade Estadual de Campinas, Campinas, 2001. 
BRAGA, A. A influência do projeto "A formação do professor e a educação ambiental" no conhecimento, valores, atitudes e crenças nos alunos do ensino fundamental. 2003. Dissertação (Mestrado em Educação) - Faculdade de Educação, Universidade Estadual de Campinas, Campinas, 2003.

CANTELLI, V. C. B. Um estudo psicogenético sobre as representações de escola em crianças e adolescentes. 2000. Dissertação (Mestrado em Educação) - Faculdade de Educação, Universidade Estadual de Campinas, Campinas, 2000.

CANTELLI, V.C.B. Procedimentos utilizados pelas famílias na educação econômica de seus filhos. 2009, Tese (Doutorado em Educação) - Faculdade de Educação, Universidade Estadual de Campinas, Campinas, 2009.

GODOY, E. A representação étnica por crianças pré-escolares: Um estudo de caso à luz da teoria piagetiana. Dissertação (Mestrado em Educação). Universidade Estadual de Campinas, Faculdade de Educação, 1996, 245 f.

PIRES, L.; ASSIS, O. Z. M. As representações das crianças sobre a noção de lucro: a construção do conhecimento social numa perspectiva construtivista. In: ASSIS, Mucio e MANTOVANI DE ASSIS, Orly. Anais do XXII Encontro Nacional de Professores do PROEPRE: Educação e Cidadania. Campinas: UNICAMP/FE/LPG, p. $471,2005$.

SARAVALI, E. G. As idéias das crianças sobre seus direitos: a construção do conhecimento social numa perspectiva piagetiana. Dissertação (mestrado em educação) - Faculdade de Educação, Universidade Estadual de Campinas, Campinas, 1999.

TORTELLA, J. C. B. Amizade no contexto escolar. Dissertação (Mestrado em Educação) - Faculdade de Educação, Universidade Estadual de Campinas, Campinas, 1996.

TORTELLA, J. C. B. A representação de amizade em díades de amigos e não amigos. Tese (Doutorado em Educação) - Faculdade de Educação, Universidade Estadual de Campinas, Campinas, 2001. 


\title{
A formação escolar e o componente curricular: a Educação Física em tempos de capitalismo mundial integrado ${ }^{1}$
}

\author{
Rogério Rodrigues ${ }^{2}$
}

\begin{abstract}
RESUMO
O referido ensaio tem como objetivo analisar criticamente a proposição e a implementação do documento preliminar da Base Nacional Comum Curricular da Educação Básica - BNC (BRASIL, 2015). Justifica-se esse ensaio ao considerar que, em relação a qualquer proposta para o ensino da Educação Física na Educação Básica, dever-se-ia partir do pressuposto de que esta disciplina se encontra limitada pelo aspecto da redução do espaço destinado para suas aulas no ambiente escolar e, principalmente, pela formação do profissional da Educação Física pautada, hegemonicamente, na concepção dos conteúdos escolares relativos a esta área do saber direcionados para aspectos esportivos e competitivos. Conclui-se que a peça-chave para a democratização do ensino no campo da cultura corporal e esportiva seria a formação de profissionais de Educação Física como intelectuais da cultura e, portanto, sujeitos capazes de absorver criticamente a implementação de qualquer proposta de ensino.
\end{abstract}

PALAVRAS-CHAVE: Fundamentos da Educação; Educação Básica; Currículo; Educação Física Escolar.

\section{A formation school and curriculum component: Physical} Education in times of capitalism wordl integrated

\begin{abstract}
Such an assay aims to critically analyze the proposition and implementation of the draft document of the Common National Base
\end{abstract}

\footnotetext{
${ }^{1}$ Agradecimentos aos colegas da primeira turma do curso de Educação Física da UNESP de Rio Claro (1984-1987); a Universidade Federal de Itajubá (UNIFEI) e a Faculdade de Educação da Universidade de São Paulo (USP) na supervisão do Pós-doutorado pelo Prof. Dr. Leandro de Lajonquière.

${ }^{2}$ Doutor em Educação (UNICAMP). Docente da Universidade Federal de Itajubá Av. BPS, 1303, Bairro Pinheirinho, Itajubá - MG Caixa Postal 50 CEP: 37500 903. e-mail: rogerio@unifei.edu.br.
} 
Curriculum of Basic Education - BNC (BRASIL, 2015). It justified this test when considering that, in relation to any proposal for the teaching of Physical Education in Basic Education, duty would be to assume that this discipline is limited by the aspect of reducing the space devoted to their classes in school environment, and especially the formation of the professional of Physical Education guided hegemonically in the design of educational content relating to this area of knowledge directed to sporting and competitive aspects. It is concluded that a key to the democratization of education in the field of physical and sports culture would be the formation of Physical Education professionals as culture intellectuals and therefore subject able to critically absorb the implementation of any educational proposal.

KEY-WORDS: Foundations of Education; Basic Education; Curriculum;

School Physical Education.

\section{Introdução: o papel do ensino da Educação Física na educação básica}

Tornou-se senso comum pedagógico a compreensão de que o aparelho escolar deve possuir a função principal de formar o cidadão crítico e participativo. Para tanto, a unidade escolar incorpora como tarefa de fundamental importância a transmissão dos diversos elementos da cultura através do currículo escolar.

Todos aqueles que trabalham no campo educacional compreendem que, no caso específico da unidade de ensino, os diversos saberes difusos na sociedade encontram-se em interface direta e indiretamente com a cultura escolar. Essa relação entre escola e cultura promove a organização e transmissão desses saberes que se encontram elaborados no transcorrer da existência do homem.

Nesse caso, parte-se da hipótese de que a função democrática da escola seria formar o cidadão crítico e participativo ao dar acesso a diversos elementos da cultura e, principalmente, permitir a ele interpretar os diversos saberes presentes na sociedade. 
Portanto, a cidadania é também elemento constituído na formação cultural do sujeito e o aparelho escolar pode desempenhar um papel fundamental no processo de escolarização do sujeito referente ao domínio da cultura letrada.

O letramento da cultura escolar encontra-se presente em diversas disciplinas curriculares e, portanto, a transmissão dos elementos da cultura elaborada na unidade escolar apresenta-se com algum consenso, como, por exemplo, no caso da comunicação e expressão no ensino da língua portuguesa, pode-se encontrar a exigência estabelecida no Plano Nacional da Educação que determina como meta que todos os alunos até oito anos de idade devem se encontrar alfabetizados e isso corresponde ao final da terceira série do ensino fundamental (BRASIL, 2016).

Compreende-se que o processo de alfabetizar é uma linha de corte para o ingresso no campo da cultura escolar. Entretanto, a passagem para a condição de sujeito alfabetizado seria algo para além do fato de ler, pois é preciso que ele possa também interpretar a linguagem escrita, falada e corporal.

Pode-se fazer um paralelo entre esse paradigma de alfabetizar em diversos campos dos saberes com diversas situações, o que pode ser também vivenciado no campo da comunicação e expressão ou em outras áreas do conhecimento. A partir dessa referência, torna-se possível perguntar: o que seria, em termos de educação básica, encontrar-se "alfabetizado" no campo da Educação Física?

Responde-se em parte a essa questão ao afirmar que, no caso do ensino da Educação Física escolar, essa tarefa de alfabetizar realiza-se ao transmitir a cultura e, principalmente, ao permitir a incorporação nos sujeitos de elementos pertencentes à cultura corporal e esportiva. Torna-se evidente compreender o papel do ensino dessa disciplina na educação básica brasileira no sentido de formar o cidadão questionador e participativo como aquele que interpreta criticamente o uso do corpo na modernidade. 
Entretanto, outra parte dessa resposta sobre como formar o cidadão já se encontra dada por outras duas condições fundamentais que instauram os verdadeiros contornos, mais propriamente os determinantes no ensino da Educação Física escolar, como um elemento estruturante que permita ao sujeito compreender criticamente a vida em cidade, mais propriamente interpretar o mundo em que se encontra inserido como sujeito.

De um aspecto prático, os determinantes apresentam-se na formação do profissional da Educação Física e na própria realidade das escolas instauram, no cotidiano escolar, as possibilidades de realizar o ensino dessa disciplina. Em grande parte, os profissionais que atuam nessa área são formados numa concepção de educação do corpo pautada exclusivamente no sujeito biológico e que venha atender à demanda de "aptidão natural" na eficácia do desempenho esportivo. Essa concepção de ensino de Educação Física reduz as possibilidades de sua transmissão, pois grande parte da população brasileira escolar não atende ao estereótipo do sujeito esportivo.

Já em relação às unidades escolares, podem-se encontrar determinadas formas reduzidas nas possibilidades de realizar a Educação Física, em decorrência da arquitetura dos prédios, que diminui cada vez mais os espaços destinados para a atividade física. Em contrapartida, a redução dos espaços destinados para as aulas de Educação Física poderia ser contornada pela criatividade do professor na tarefa de transmitir os conteúdos escolares pertinentes à cultura corporal e esportiva. Entretanto, o processo de precarização do espaço associado à formação esportiva quanto a aspectos competitivos no ensino da Educação Física é algo que destitui a possibilidade de realizar o ensino dessa disciplina na escola.

Compreende-se que a crise no ensino da Educação Física é algo mais amplo que a própria restrição do espaço que atinge a unidade escolar como um todo e, portanto, a unidade escolar apresenta-se como lugar em que os diversos elementos da cultura transparecem-se na precariedade e indica a falta de criatividade e coerência que se constitui na nossa concepção como pressupostos para a formação do pensamento crítico. A repetição destituída 
de sentido e a incoerência no tratamento do conteúdo escolar resultam na ampliação do estado de regressão na transmissão da cultura corporal e esportiva.

O resultado dessa situação no campo escolar é um indicativo de que se reduz o acesso à cultura geral e esse elemento pode ser identificado nas avaliações que ocorrem no âmbito da educação, apontando a precária situação em que ela se encontra de modo geral. No denominado Programme for International Student Assessment - PISA (Programa para Avaliação Internacional de Estudantes), realizado pela Organização para a Cooperação e Desenvolvimento Econômico (OCDE) e implementado no Brasil em 2000, avalia-se o conhecimento em Ciências, Leitura e Matemática dos alunos na idade de 15 anos que estão concluindo o Ensino Fundamental ou cursando o Ensino Médio. Nos exames desse programa, o desempenho dos alunos brasileiros no ensino de Ciências encontra-se nas últimas posições do ranking internacional, ou seja, comparado a diversos países participantes do programa, o Brasil está quase na última colocação, ficando na frente apenas de países como Colômbia, Tunísia, Azerbaijão, Qatar e Quirguistão. Na área específica de Ciências, é possível identificar sérios problemas educacionais, pois

Em ciências, o Brasil obteve o $59^{\circ}$ lugar do ranking com 65 países. Apesar de ter mantido a pontuação (405), o país perdeu seis postos desde o $53^{\circ}$ lugar em 2009. Nessa disciplina, a média dos países da OCDE foi de 501 pontos. [...] No exame de ciências, 55,3\% dos alunos brasileiros alcança apenas o nível 1 de conhecimento, ou seja, são capazes de aplicar o que sabem apenas a poucas situações de seu cotidiano e dar explicações científicas que são explícitas em relação às evidências (SEM AUTOR, 2016).

Nesse caso, a formação escolar da Educação Física pautada na ciência do esporte competitivo constitui-se também em elemento de precarização do profissional dessa disciplina, pois se trata de imitar a aparência sem 
compreender radicalmente os diversos componentes que se encontram presentes na manifestação do esporte de competição. A imitação precária associada à redução dos espaços nas construções destinadas para a atividade física na unidade escolar pela própria estrutura arquitetônica que a escola condiciona reduz a prática da Educação Física na utilização da "quadra poliesportiva" como um espaço alheio ao ambiente escolar. Esse fato manifesta-se por diversas ações governamentais, que a todo o momento vêm reduzindo a oferta dessa disciplina na grade curricular.

Já se convencionou que a "quadra poliesportiva" é o espaço único destinado e permitido para a realização da Educação Física. O grande prejuízo é que nesse espaço reduzido do "poliesportivo" o que prevalece é o elemento contrário, pois o que se manifesta é o monoesportivo na prática do jogo do futebol. Diga-se de passagem: em grande maioria, reduz-se o ensino do futebol a um verdadeiro "rachão", a uma "pelada", a um "arranca toco", enfim, a uma negação por completo da presença do intelectual da Educação Física na quadra como espaço de reflexão sobre a cultura corporal. Nesse ponto, constitui-se a seguinte questão: se não trata de formar o sujeito no campo da cultura corporal, o que de fato estaria sendo a função social dessa transmissão de saber na unidade escolar?

Para responder a esse questionamento, levou-se em consideração que o aspecto teórico no ensino da Educação Física justifica-se como uma tentativa de estabelecer diversas proposições para a qualidade desta no campo escolar e no caso específico o documento preliminar da Base Nacional Comum Curricular da Educação Básica - BNC (BRASIL, 2015), que define um conjunto de ações para serem realizadas na unidade escolar, em se tratando da reflexão sobre o ensino da Educação Física.

Sobre essa proposição teórica sobre a transmissão do saber no campo da Educação Física, de modo geral, pode-se compreender que a proposta do BNC atende à demanda dos processos de escolarização no sentido de preencher uma lacuna no campo da cultura corporal e esportiva. Entretanto, o que deve ser avaliado é qual o direcionamento na formação do sujeito no 
campo da cultura em interface com a Educação Física. Portanto, trata-se de analisar o quanto e, principalmente, como o ensino da Educação Física encontra-se atrelado ou distanciado da lógica imperativa do Capitalismo Mundial Integrado - CMI (GUATTARI, 1990), no sentido de formar um tipo de sujeito apto para o consumo alienado na prática do esporte.

A lógica do capital constitui-se em ampliar o consumo de coisas e, portanto, em aumentar a produção numa sociedade não planejada em que a finalidade central seria a obtenção do lucro. O resultado dessa lógica seria a concentração de renda daqueles que possuem os meios de produção e, principalmente, a péssima distribuição da riqueza produzida. O uso do corpo na lógica do capital ao atender a essa demanda não planejada seria condicionar o sujeito ao consumo de coisas e inclusive do espetáculo esportivo como objeto de consumo como elemento impróprio ao pensamento no campo da cultura.

Trata-se de destacar a crítica ao CMI (GUATTARI, 1990) de que nos posicionamos na concepção de mundo que entende que formar o cidadão questionador e participativo seja um mecanismo de resistência a algo que gire em torno de somente formar o sujeito dócil no sentido de atender às exigências do mercado de ser produtor e consumidor.

Compreende-se a interface do sujeito no campo da cultura e em outras esferas e isso se apresenta na contraposição sobre como o campo escolar absorve a concepção de cultura como algo profundamente reacionário, pois ela seria

[...] uma maneira de separar atividades semióticas (atividades de orientação no mundo social e cósmico) em esferas, às quais os homens são remetidos. Isoladas, tais atividades são padronizadas, instituídas potencial ou realmente capitalizadas para o modo de semiotização dominante - ou seja, elas são cortadas de suas realidades políticas (GUATTARI \& ROLNIK, 2005, 21). 
A proposição do ensino dos elementos da cultura estruturado no currículo escolar é uma abstração do real no sentido de interpretá-los na lógica da hegemonia dominante. Nesse aspecto, a cultura se (re)apresenta como elemento da reificação e o que prevalece são os pressupostos dominantes. Pergunta-se no caso específico da proposta do BNC: ela possibilita alguma ruptura com a hegemonia do capital?

$\mathrm{O}$ que se pode constatar na referida proposta é que ainda prevalece a compreensão pautada na premissa do educar na base do pronunciamento do “mestre explicador" (RANCIÈRE, 2002).

Apesar de todo esforço na proposta da BNC de serem usados verbos como: "experimentar", "desfrutar", "formular", "realizar", "reconhecer", "compreender", "identificar", "refletir", "construir" e "contribuir" (BRASIL, 2015), ela ainda compreende o sujeito como alguém passivo, no sentido de que seja depositado nele um conjunto de informações que devem ser memorizadas e representadas para atender à demanda de que o sujeito aprendeu. Em outras palavras, ainda concebe-se o espaço escolar como lugar reservado e único para a transmissão de conjunto de saber, pois a própria estrutura organizacional opera como elemento para instaurar outros elementos e modelos e que impõe como verdade o que seria o ensino da Educação Física no período da Educação Básica. Portanto, a pergunta central seria: como identificar na Educação Física escolar, quanto ao uso do corpo, elementos de resistência à hegemonia do capital e, principalmente, à ruptura com os modos de consumo de coisas no campo do fenômeno esportivo?

O que se constata é que cada vez que retorno em quadra de aula o meu encontro são com alunos com suas vestimentas, modos de falar, corte de cabelo, técnicas de corpo que se modelam como elementos amplamente imitativos do fenômeno esportivo. Isso me leva a concluir que a ruptura com o CMI (GUATTARI, 1990) é uma luta de cada dia e talvez isso seja um dos grandes motivos pelos quais os alunos devam ir todos os dias à escola como longo processo temporal de inserir o sujeito no campo da cultura. 


\section{Discussão: o componente curricular em Educação Física - desafios e resistência para a democratização da cultura corporal e esportiva na unidade escolar}

Pensar na democratização do acesso à escola é também analisar como os conteúdos escolares são transmitidos. Aqueles que têm pouco trânsito no ambiente escolar e são pouco conhecedores sobre o cotidiano do ensino da Educação Física escolar podem compreender que ocorre uma redução do ensino sobre a prática corporal a elementos cada vez mais rudimentares e até podem observar a completa ausência do ensino da Educação Física.

Por diversos anos trabalhando como educador no campo da Educação Física, pude presenciar uma total falta de critério na transmissão da cultura corporal e esportiva. Inclusive, é possível encontrar alunos no ensino superior - ou seja, que passaram pelas aulas de Educação Física durante os quatorzes anos da Educação Básica (Educação Infantil, Ensino Fundamental e Ensino Médio) - que se apresentam como verdadeiros analfabetos sobre os elementos da cultura corporal e esportiva.

Nesse caso, pode-se pontuar o mérito da proposta BNC de buscar sistematizar e organizar os elementos que devem ser trabalhados na Educação Básica em se tratando do ensino da Educação Física escolar. Contudo, torna-se necessário compreender os diversos elementos que se apresentam no cotidiano escolar que fazem a cultura corporal e esportiva, quando ela ocorre, algo que se representa como pequeno esboço mal feito sobre os cuidados do corpo ou da prática do esporte. Portanto, é preciso compreender que, na realidade, ocorre, no campo escolar, um fenômeno paradoxal, qual seja: pouco se busca compreender a cultura corporal e esportiva em termos do saber crítico. Simultaneamente, de um lado, ocorre uma hipervalorização dos "cuidados com o corpo" e uma aclamação exacerbada no ufanismo na prática do esporte. Por outro lado, ocorre um completo abandono nos aspectos de transmissão dos conteúdos referentes à Educação Física escolar. Parte-se do pressuposto de que compreender esse 
contraditório pode ser um passo decisivo para implementação da proposta da BNC na Educação Física escolar.

Para se compreender esse paradoxo no campo do ensino da Educação Física escolar, deve-se afirmar que, quanto à cultura corporal e esportiva, a grande parte da população escolar apresenta-se "analfabeta", no sentido de não compreender o significado cultural e científico de fazer as coisas com o corpo. Essa condição produz um tipo de sujeito que se torna pouco resistente ao consumo de certos estigmas corporais, produtos e eventos esportivos.

Compreende-se que, no limite, a referida proposta do BNC deveria tocar diretamente nesta "ferida", ao propor uma crítica contundente sobre os modos de fazer as coisas com o corpo. Não basta ser uma proposta que se apresenta como mais uma nova orientação institucional geral e que tende a somente ficar no papel. Para a referida proposta concretizar-se, é de fundamental importância que ela deva ser constituída com a criticidade de compreender que há unidade entre teoria e prática - práxis (VÁZQUEZ, 1977) e que o uso do corpo está diretamente relacionado como uma concepção de mundo e, portanto, as "técnicas de corpo" trazem em suas marcas as sociedades que as produzem (MAUSS, 1974).

Avalia-se que se a proposta para o ensino da Educação Física não atacar diretamente o ponto que impede a democratização do ensino da cultura corporal e esportiva no campo escolar, qualquer tipo de proposição trata-se de mera ilustração para agrupar-se nas estantes das unidades escolares.

Parte-se do pressuposto de que a compreensão dos processos de escolarização deveria se estabelecer como elemento de ruptura com o senso comum pedagógico que invade o campo escolar, e isso seria, de certo modo, romper com o modelo de paradigma educacional do sujeito cognitivo, como algo que também se encontra nas diversas interfaces do campo de ensino da Educação Física. Torna-se possível identificar, nesse campo de ensino, uma exigência de normalização do sujeito, bem como o fato de que esse possa atender à lógica do mercado na hegemonia do CMI (GUATTARI, 1990). Isso 
circunscreve o sujeito como objeto e, portanto, condiciona todas as demais relações em que o educar é informar, o trabalho é produzir e a saúde é comércio.

\begin{abstract}
Não existe, a meu ver, cultura popular e cultura erudita. Há uma cultura capitalista que permeia todos os campos de expressão semiótica. É isso que tento dizer ao evocar os três núcleos semânticos do termo cultura. Não há coisa mais horripilante do que fazer a apologia da cultura popular, ou da cultura proletária, ou sabe-se lá o que do gênero. Há processos de singularização em práticas determinadas e há procedimentos de reapropriação, de recuperação, operados pelos diferentes sistemas capitalísticos. (GUATTARI \& ROLNIK, 2005, 30).
\end{abstract}

O ponto central desse estudo seria compreender se é possível, no fazer pedagógico, que a unidade entre a teoria e a prática produza mecanismos de resistência no campo escolar para além das inscrições oficiais instauradas pela cultura capitalista.

No fazer pedagógico, é preciso construir algo que possa romper com essa lógica de mercado do sujeito informado para o esporte, consumidor de esporte, e que possa pensá-lo numa nova recomposição de força em que prevaleça sua humanidade, em que educar seja troca de experiência humana, o trabalho corporal seja a expressão do intelecto do sujeito e a saúde seja uma tênue recomposição de equilíbrio entre os processos degenerativos e a ampliação da qualidade de vida no campo do social.

Neste caso, pode-se identificar o foco central desse ensaio, que seria reanalisar a proposição, estabelecida em grande parte dos planos de ensino, de formar o sujeito crítico e participativo, que, no caso da $\mathrm{BNC}$, fica pronunciado como estratégia de "[...] possibilitar às novas gerações a preservação e a reconstrução da herança científica e cultural acumulada pela humanidade sob forma de conhecimentos sistematizados" (BRASIL, 2015, p. 95). 
O paradigma de análise para compreender a educação do corpo na modernidade está pautado na compreensão de que, em seu uso, transparece no sujeito a materialidade do seu modo de existir e, portanto, no uso do corpo, encontram-se presentes as interações entre diversas formas de existência do sujeito. Entretanto, os elementos que compõem essa transmissão ocorrem em duas esferas, que seriam as formas conscientes e inconscientes. Essa compreensão sobre a educação do corpo aprofunda-se a partir do conceito de Michel Foucault (1979), que identifica no corpo um lugar em que se trata da realização de uma "[...] estratégia bio-política" (FOUCAULT, 1979, p. 80). Assim, no modo de existir do sujeito no corpo, pode-se compreender que:

O controle da sociedade sobre os indivíduos não se opera simplesmente pela consciência ou pela ideologia, mas começa no corpo, com o corpo. Foi no biológico, no somático, no corporal que, antes de tudo, investiu a sociedade capitalista. O corpo é uma realidade bio-política (FOUCAULT, 1979, p. 80).

Nesse caso, o sujeito tomado pelo uso do corpo encontra-se inscrito com elementos sociais que também produzem no sujeito a singularização do ser sujeito em formas abstratas que engendram as circunstâncias determinadas em que as técnicas do corpo são produzidas (MAUSS, 1974). Dentro desse quadro, fica novamente a seguinte questão: seria possível nas aulas de Educação Física romper ou fazer fissuras com a hegemonia do CMI (GUATTARI, 1990) e instituir outras formas no controle corporal?

Compreende-se que, em parte, esse papel de contra-hegemonia seria o eixo norteador a ser desempenhado pela educação escolar na constituição do sujeito crítico e participativo. Para compreender essa proposta no campo da cultura corporal e esportiva da Educação Física escolar, seria necessário que a referida proposição da BNC estivesse associada à presença do intelectual dessa disciplina, no sentido de instaurar novas formas de pensar à 
concepção de sujeito e, portanto, uma reinterpretação de uso do corpo que ressurja como contraposição "bio-política", que possa estabelecer outra lógica de compreender o sujeito e que realinhe novas possibilidades de inscrição no eixo da Educação Física escolar.

\section{Conclusões: Para um ensino democrático da Educação Física escolar}

No final da década de 1980, mais precisamente no ano de 1986, tive a grande oportunidade de iniciar participação no grupo de estudo do Professor Paulo Ghiraldelli Júnior, ${ }^{3}$ no qual se constituiu uma discussão sobre o papel da Educação Física no campo escolar como elemento para democratizar o acesso à cultura corporal e esportiva. O resultado dessa discussão encontrase, em parte, no livro publicado em 1988 e intitulado "Educação Física Progressista: a pedagogia crítico-social dos conteúdos e a educação física brasileira" (GHIRALDELLI, 1988). Nesse livro, ficou estabelecida a perspectiva teórica do professor de Educação Física no campo escolar:

Particularmente, o profissional da área da Educação Física desenvolve a tarefa de "agente cultural" no âmbito da mais decisiva intimidade, pois atua no sentido de implantar no próprio movimento humano os ditames da cultura. Assim, a denominação do professor de Educação Física como "educador do movimento" assume certa veracidade e, em inúmeros casos, certa tragicidade! Afinal, cabe ao "educador do movimento" a tarefa de engravidar o movimento humano de cultura e, mais precisamente, de uma determinada cultura. Ao professor de Educação Física coube, então, o destino, talvez pouco confortável, de transportar a hegemonia para o conjunto complexo da individualidade humana (GHIRALDELLI, 1988, p. 53).

\footnotetext{
${ }^{3}$ Grande parte da minha formação acadêmica se deve a esse professor, que, no interior da primeira turma do curso de Educação Física da UNESP de Rio Claro, que se encontrava, principalmente, pautado numa concepção de uso do corpo pelos conceitos do reducionismo biológico, tornou-se possível indicar outras formas de leitura sobre a questão do corpo no campo das ciências humanas.
} 
Esse elemento pertinente ao ensino da Educação Física na “[...] tarefa de engravidar o movimento humano de cultura e, mais precisamente, de uma determinada cultura" (GHIRALDELLI, 1988, p. 53) é que torna possível compreender a constituição da subjetividade do sujeito em elementos próprios da formação escolar. Portanto, compreende-se que a função principal das orientações estabelecidas no documento preliminar da Base Nacional Comum Curricular da Educação Básica - BNC (BRASIL, 2015) seria a de estabelecer uma direção na constituição dos processos de subjetivação do sujeito no campo do ensino da Educação Física. Nesse aspecto, a presença do profissional da Educação Física no papel de intelectual seria algo que se consegue interpretar no campo da cultura corporal e esportiva que, tendo como base a produção de subjetividade, compreenda:

[...] o essencial da subjetividade é de ela só se conhecer por fora, em sua própria invenção, e nunca por dentro. Se ela se conhecer por dentro, está morta; se ela for decifrada por fora, então está plena, torna-se, com efeito, objeto; mas ela é objeto em seus resultados, o que nos remete a uma subjetividade que, por sua vez, não é realmente objetivável (SARTRE, 2015, p. 54).

Essa análise sobre a produção da subjetividade é que torna o trabalho de educar o corpo fisicamente algo para além da repetição do movimento corporal. A compreensão de que a subjetividade resulta de produção social amplia o olhar para o documento preliminar da Base Nacional Comum Curricular da Educação Básica - BNC (BRASIL, 2015), e tal compreensão poderia assumir outros contornos, entendendo-se que não se trata mais de avaliar ou validar a competência técnica do referido documento.

O ponto central é saber qual o direcionamento, em termos de concepção de mundo, que se busca ao efetivar a referida proposta no ensino 
de Educação Física escolar. Tendo essa questão da produção da subjetividade como base, há a necessidade de ampliar dois elementos primordiais na junção dessa proposta do BNC, à qual já se fez referência anteriormente neste ensaio, quais sejam: investir em espaços condizentes com a prática da Educação Física escolar e, principalmente, aprimorar a formação dos licenciados em Educação Física escolar. Sem essas contrapartidas, que, em certos termos, beiram o senso comum em termos de política pública, qualquer proposta se tornará vã e não produzirá os seus efeitos pedagógicos no campo escolar.

Essa perspectiva no ensino da educação física centra-se na ideia que o movimento corporal humano está contido por certa historicidade e cabe ao intelectual da Educação Física retratar isso em sua prática educativa, ou seja, falar em "Educação Física" é também fazer uma prática educativa que seja progressista no sentido de estabelecer a criticidade na formação cultural do sujeito. Nesse caso, o trabalho do intelectual da Educação Física é a análise crítica do movimento corporal humano inserido na história das práticas culturais. Portanto,

Um professor de Educação Física, ao planejar suas aulas, deve se perguntar: que conteúdos e habilidades podem ajudar a ser um cidadão participativo? Em que as condições materiais de vida, experiências, conhecimentos, valores afetam o desenvolvimento das aulas? Como a educação do corpo, do movimento e os esportes podem contribuir para o exercício de uma prática social consciente e menos alienada? Por que a Educação Física higienista, militarista, pedagogista ou competitivista não são suficientes ou impróprias para um bom programa de Educação Física e esportes? (LIBÂNEO, 1988. p. 11).

Todos esses anos de trabalho com aquilo que se denomina Educação Física Escolar levaram-me a constatar que a materialização de uma prática educativa progressista está na dependência direta de uma sociedade que 
possua em suas raízes uma vertente democrática. Em muitas vezes, obtivemos pequenos pontos de avanço efetivo para a compreensão do que seja a realização de um trabalho pautado na realização de uma práxis educativa. Penso que este seja o momento de tornar atual esse debate anterior, ou seja, a possibilidade de realizarmos uma análise do sentido da nossa própria formação cultural no campo da Educação Física/Educação do Corpo.

O que se tem hoje é que no interior da escola estreita-se cada vez mais o caminho para a plena burocratização da prática educativa a ponto de impedir a livre circulação do pensamento crítico. O lugar da plena realização do desejo em aprender acaba se constituindo por instituições alternativas que cumprem o papel de inclusão de sujeitos que não encontram na escola o pleno reconhecimento de sua condição de vida e, principalmente, de sujeito.

Discutir esses pontos é apontar para a questão crucial referente ao nosso papel de educador numa sociedade que possui em seu interior as contradições das classes sociais. Portanto, apontar para a questão do papel que a Educação Física vem assumindo neste processo de escolarização, mais propriamente, seria questionar as condições necessárias para a realização de uma efetiva Educação Física Progressista inserida numa sociedade contraditória em si. A pergunta central para retomar o ensino da educação física no campo escolar é: qual o caminho a seguir para a plena realização de uma prática educativa progressista que possa favorecer a produção do sujeito saudável para além dos determinantes do biológico?

Temos um corpo determinado pelo uso como instrumento, ou seja, vive-se uma inversão, o instrumento passa a ter vida e o corpo passa a ser morto. Em muitos casos, utilizamos desse recurso quando precisamos submeter o corpo a práticas exaustivas, nas quais o que mais treinamos é a anulação do corpo e a sua plena subordinação à palavra, ou seja, uma ordem é uma ordem e deve ser cumprida e não questionada. Sentimos isso na pele quando é exigida do corpo uma ação não correspondida, o que se apresenta nas situações de combate e até nas práticas esportivas competitivas. O corpo 
passa a ser treinado nem tanto para o condicionamento físico e sim para o condicionamento psicológico, ou seja, um corpo que atua cegamente para atingir determinado objetivo. Isso seria um abandono da teoria cartesiana para o qual a relação entre corpo e alma colocaria a razão no comando (DESCARTES, 1974). Para tanto, é preciso que se tenham condições de estudo e elaboração de uso do corpo, isto é, que a Educação Física seja exercida de modo sistemático e não como algo casual, quando não se tem nada para fazer para passar o tempo. Esse modo de compreender a Educação Física é um ponto de destaque para o lugar que ela deve ocupar nas instituições de ensino e isso é, de certo modo, a nossa defesa do seu ensino e, principalmente, a democratização da cultura corporal em nossa sociedade e na produção do sujeito saudável no campo da cultura.

Penso que em grande parte a oportunidade de estar aqui e escrever algo sobre o movimento corporal humano pautado na teoria crítica acaba por despertar o sentimento de que temos ainda a possibilidade de nos opormos à hegemonia de uma ciência estritamente racionalista, que insiste em tratar o sujeito como coisa e, principalmente, a esperança que se possa consolidar na educação brasileira o ensino da Educação Física que esteja para além dos determinantes do capital.

\section{Referencias Bibliográficas}

BRASIL. Base Nacional Comum Curricular (BNC). Ministério da Educação. 2015. BRASIL. Plano Nacional de Educação - 2011 a 2020 - Metas e Estratégias. Disponível em: http://fne.mec.gov.br/images/pdf/notas tecnicas_pne_2011_2020.pdf $>$, acessado em 23 de março de 2016.

DESCARTES, René. Meditações. Trad. J. Guinsburg e Bento Prado Júnior. São Paulo: Abril Cultural. 1974.

FOUCAULT, Michel. Microfísica do Porder. Trad. Roberto Machado. Rio de Janeiro: Grall, 1979. 
GHIRALDELLI, Paulo. Educação Física Progressista: a pedagogia crítico-social dos conteúdos e a educação física brasileira.São Paulo: Edições Loyola, 1988.

GUATTARI, Félix. As três ecologias. Trad. Maria Cristina F. Bittencourt. Campinas: Papirus, 1990.

GUATTARI, Félix \& ROLNIK, Suely. Micropolítica: cartografias do desejo. $7^{\mathrm{a}}$ Edição. Petrópolis: Vozes, 2005.

LIBÂNEO, José Carlos. Prefácio. In: GHIRALDELLI Jr, Paulo. Educação Física Progressista: a pedagogia crítico-social dos conteúdos e a educação física brasileira. São Paulo: Edições Loyola, 1988.

MAUSS, Marcel. As técnicas corporais. In: Sociologia e antropologia. Trad. Mauro W. B. de Almeida. São Paulo: EPU/EDUSP, 1974. 2 v.

RANCIÈRE, Jacques. $O$ mestre ignorante: cinco lições sobre a emancipação intelectual. Trad. Lílian do Valle. Belo Horizonte: Autêntica, 2002.

SEM AUTOR, Pisa: desempenho do Brasil piora em leitura e 'empaca' em ciências. Disponível em: < https://educacao.uol.com.br/noticias/2013/12/03/pisa-desempenhodo-brasil-piora-em-leitura-e-empaca-em-ciencias.htm >. Acesso emः 13 abr. 2016. SARTRE, Jean-Paul. O que é subjetividade? Trad. Estela dos Santos Abreu. Rio de Janeiro: Nova Fronteira, 2015.

VÁZQUEZ, Adolfo Sánchez. Filosofia da Praxis. Trad.Luiz Fernando Cardoso. Rio de Janeiro: Paz e Terra, 1977. 


\title{
Da teoria à prática: problematização e metodologias diferenciadas no Cálculo Numérico
}

\author{
Carmem Lucia Graboski Gama ${ }^{1}$ \\ Mateus das Neves Gomes ${ }^{2}$ \\ Liceia Alves Pires ${ }^{3}$
}

\section{RESUMO}

Esse trabalho apresenta um estudo de caso que aborda a disciplina de Cálculo Numérico, em um curso de Licenciatura em Matemática em uma Universidade Estadual do Paraná,com metodologias diferenciadas, empregando a resolução de problemas, a modelagem matemática e as novas tecnologias como forma de minimizar os problemas de aprendizagem. Para isso, foi realizada com a referida turma uma atividade prática, em que os alunos deveriam encontrar resposta a um problema real, usando as metodologias empregadas no decorrer do curso e também os conceitos vistos em Cálculo Numérico. Após essa atividade os alunos fizeram uma avaliação que buscou identificar se a forma de trabalho os axiliou na aprendizagem. Pelas respostas percebeu-se que a grande maioria das respostas foram positivas, ou seja, os alunos aprenderam de forma diferenciada. Quando questionados se o dia que atuarem como professor, lecionariam usando as metodologias vivenciadas, todos responderam que sim. Com o trabalho, pode-se perceber que é possível e interessante que as aulas de Cálculo Numérico não fiquem somente restritas aos métodos tradicionais, mas que estas possam estar articulados com outras metodologias mais ativas.

PALAVRAS-CHAVE: Cálculo Numérico. Metodologias diferenciadas. Licenciatura em Matemática

From theory to practice: problematization and differentiated methodologies in Numerical Calculus

\footnotetext{
${ }^{1}$ Doutora em Métodos Numéricos em Engenharia. Instituto Federal do Paraná - Campus Paranaguá, Paranaguá, Brasil. E-mail: carmem.gama@ifpr.edu.br

${ }^{2}$ Doutor em Engenharia Mecânica. Instituto Federal do Paraná - Campus Paranaguá, Paranaguá, Brasil. E-mail: mateus.gomes@ifpr.edu.br

${ }^{3}$ Doutoranda do Programa de Pós-Graduação em Educação da PUC-PR. E-mail: liceia.pires@unespar.edu.br
} 


\begin{abstract}
This paper presents a case study performed with Numerical Calculus class, in the Mathematical undergraduate of University State Paraná. Differentiated methodologies were employed through problem solving, mathematical modeling and new technologies. The goal was to minimize learning problems. For this, a practical activity was carried out with the said class, in which the students had to find an answer to a real problem, using the methodologies used during the course and also the concepts seen in Numerical Calculus. After this activity, it was necessary to maked an evaluation that sought to identified a form of worked in the school.From the answers it was noticed that a great majority of the answers were positive, that is, the students learned in a different way. When asked if the day they act as teacher, would teach using the methodologies experienced, everyone answered yes. With this work, one can see that it is possible and interesting that Numerical Calculus classes are not only restricted to traditional methods, but that these can be articulated with other methodologies that are more active
\end{abstract}

KEYWORDS: Numerical Calculus. Differente methodologies. Degreen in mathematics.

$$
* * *
$$

\title{
Introdução
}

Muitas vezes ao lecionar a disciplina de cálculo numérico, nos cursos de graduação, o professor percebe que os acadêmicos não conseguem entender a sua aplicabilidade em situações reais e, dessa forma, muitas vezes se sentem desmotivados.

Um fator que pode contribuir para essa situação é a metodologia empregada na disciplina, o que muitas vezes se caracteriza apenas como tradicional, e entende-se, nesse estudo, como método tradicional aquele que o professor apresenta a teoria, exemplos e os alunos resolvem exercícios e realizam avaliações (provas individuais), como forma de verificação da aprendizagem. 
Buscando uma perspectiva metodológica diferenciada para o ensino do cálculo numérico, este trabalho apresenta, em forma de um estudo de caso, como é possível desenvolver algumas atividades diferenciadas, que tragam problemas reais a serem resolvidos nas aulas.

Essas metodologias: Resolução de Problemas, Modelagem Matemática e Novas Tecnologias, que trazem o problema real para a sala de aula, a ser resolvido com diferentes métodos, foram aplicadas em um curso de Licenciatura em Matemática no Município de Paranaguá no Estado do Paraná, numa Universidade Estadual, com alunos formandos de matemática, no ano de 2015 e 2016.

\section{A modelagem matemática}

A modelagem matemática pode ser vista como um conjunto de procedimentos que buscam fazer uma descrição matemática de um determinado fenômeno que está presente no mundo real. Ao longo dos anos o homem sempre utilizou modelos para resolver situações problema com as quais se deparava. Nesse sentido,

A Modelagem Matemática é um processo dinâmico utilizado para a obtenção e validação de modelos matemáticos. É uma forma de abstração e generalização com a finalidade de previsão de tendências. A modelagem consiste, essencialmente, na arte de transformar situações da realidade em problemas matemáticos cujas soluções devem ser interpretadas na linguagem usual. (BASSANEZI, 2002, p. 24)

Por meio da modelagem matemática, alguns problemas de diferentes áreas do conhecimento podem ser resolvidos, problemas estes que podem envolver o estudo de fenômenos ligados à saúde, ao meio ambiente, à administração, à teoria de decisão, dentre outros. 
$\mathrm{Na}$ educação, nos últimos anos, a modelagem matemática também está presente. Para Almeida (2013, p.12) “(...) a “origem” da Modelagem Matemática não se deu no âmbito da Educação Matemática. Pelo contrário o habitat natural da Modelagem Matemática é a área que se convencionou chamar de Matemática Aplicada.”, pois foi nesse meio, de aplicação da matemática, que surgiram os primeiros conceitos de modelagem e, posteriormente, a aplicação dos mesmos na Educação Matemática sob diferentes abordagens.

Atualmente, a modelagem matemática pode ser estudada como uma metodologia de ensino na educação básica ou até mesmo como uma disciplina no curso de matemática com o objetivo de auxiliar os alunos na aprendizagem da matemática.

\section{Resolução de problemas como metodologia de ensino}

Como metodologia de ensino, a resolução de problemas é uma das maneiras de levar o aluno a ter a oportunidade de aplicar conhecimentos matemáticos que aprendeu em sala de aula para resolver problemas novos, com novas abordagens e assim torna-lo mais habilitado para trabalhar com a matemática, seus conceitos e aplicações. Dante (1989,p.15), alerta os educadores que:

(...) é necessário formar cidadãos matematicamente alfabetizados, que saibam como resolver, de modo inteligente, seus problemas de comércio, economia, administração, engenharia, medicina e previsão do tempo e de outros da vida diária. (DANTE, 1989, p.15)

Ensinar a resolver problemas, da forma como é feita hoje, teve inicio com Polya em 1960, nos Estados Unidos, para Colombo (2005, p.16) "Entretanto, há referências de outro pesquisador e outras datas tais como Dewey (1896 e 1904) e Polya (1945) que já haviam realizados algumas 
experiências significativas (...)", tais experiências ainda não se configuravam com uma metodologia de ensino.

É importante lembrar que ensinar por meio de problemas ajuda os alunos a perceberem a importância da disciplina que está cursando, pois ajuda a visualizar onde a mesma pode ser inserida, quando se busca solucionar problemas que aparecem no dia a dia.

Para explanar sobre alguns tipos de problemas e suas etapas de resolução, que podem ser aplicados em sala de aula, neste trabalho foi utilizado como autor base Polya (2006, p.04-15). O autor apresenta que um problema pode ser resolvido mediante o emprego de quatro fases: a primeira é a compreensão do problema; a segunda se refere ao estabelecimento de um plano; a terceira onde ocorre a execução do plano e a última, onde é realizado o retrospecto.

\section{Tecnologias na educação}

Por mais que exista resistência por parte de professores e educadores em trazer as novas tecnologias para dentro da sala de aula, é algo que já estão sendo considerada como uma metodologia de ensino.

No entanto, é preciso estar atento que utilizar as novas tecnologias em sala de aula não é apenas levar os alunos a um laboratório faz-se necessário criar um ambiente “(..) onde cada grupo utilize os equipamentos necessários, de acordo com as suas necessidades. O problema não é saber ou não utilizar os computadores, é a informação." (OLIVEIRA, MARIM, 2010, p. 180). Essa ideia é complementada por Brasil (2008, p. 89) que apresenta "No uso de tecnologias para o aprendizado da Matemática, a escolha de um programa torna-se um fator que determina a qualidade do aprendizado".

Um recurso tecnológico de grande importância na matemática é o software GeoGebra, “(..) que reúne geometria, álgebra e cálculo." (Hohenwarter, 2007), o qual foi desenvolvido por Markus Hohenwarter para a educação matemática nas escolas. 
$\mathrm{Na}$ área de Cálculo Numérico pode-se utilizar o Visual Cálculo Numérico (VCN) que é software educacional criado pelos professores da PUC de Minas, para auxiliar os alunos do ensino superior na área de ciências exatas, especialmente para a disciplina de Cálculo Numérico e também auxilia na resolução de problemas do Cálculo Diferencial de Integral.

Por meio do VCN, o aluno pode obter solução para problemas que envolvam raízes de funções ou zero de equações, erros e representações numéricas, interpolação e extrapolação numérica, sistemas lineares e não lineares, ajuste de curvas, otimização, dentre outras.

\section{Cálculo Numérico}

Como disciplina, o cálculo numérico pode estar inserido nos cursos de graduação de Licenciatura e Bacharelado em matemática, nas engenharias e nos cursos de economia, isso porque, as ferramentas do cálculo numérico buscam a solução de problemas que o cálculo analítico, muitas vezes, não consegue solucionar ou que são de difícil resolução.

Para Amaral et al (2013,p.1), "Entre os objetivos do estudo do Cálculo Numérico, podemos destacar o estudo dos métodos numéricos para resolução de problemas em geral tais como de engenharia, economia, ambientais, biológicos entre outros.”, ou seja, por meio do cálculo numérico encontram-se soluções aproximadas de problemas complexos.

Para Sperandio (2003, p. 2), "o cálculo numérico tem sua importância centrada no fato de que, mesmo quando a solução analítica é difícil de ser obtida, as técnicas numéricas podem ser empregadas sem maiores dificuldades", enquanto ciência, surge a partir do Século XVIII, não desvinculado do cálculo analítico.

Não existe uma precisão de datas, separando os trabalhos de cálculo analítico do cálculo numérico. Até essa época problemas eram resolvidos sem que se pensasse na possibilidade de soluções numéricas de forma 
isolada. Foi com Newton (1642-1727), Lagrange (1736-1813), Gauss (17771855), Raphson (1648-1715) entre outros, que o cálculo numérico ganha destaque.

Segundo Eves (2004, p.450), "Newton descobriu um método para aproximar os valores das raízes reais de uma equação numérica, aplicável tanto para equações algébricas como para equações transcendentes”.

Já para encontrar solução de sistemas de equação, é importante destacar os métodos iterativos de Gauss Seidel ou de Gauss Jacobi, que buscam solução para um sistema de equações lineares.

Nessa época, as soluções de equações, de sistemas de equação, interpolações entre outros temas eram estudados apenas com o objetivo de estudar a matemática ou aplicá-la a problemas da física e da astronomia. Entre o século XVIII e XIX, surgem muitos trabalhos na área que vem a dar um destaque especial ao cálculo numérico.

Como disciplina, ele surge no Brasil a partir de escolas de engenharia em São Paulo e Rio de Janeiro. Para Noguti (2005, p.6):

O Cálculo Numérico aparece como disciplina nos cursos de engenharia e, em meados da década de 50, os professores da disciplina eram, em sua grande maioria, engenheiros. Nas décadas posteriores, com o advento dos computadores e a divisão da matemática em pura e aplicada, criaram-se novos departamentos de matemática aplicada e, com eles, as disciplinas de cálculo numérico para os cursos de matemática.

Como existem na literatura poucos trabalhos que tratem do ensino e aprendizagem do cálculo numérico é que, nesse trabalho, se busca apresentar como o professor pode usar nas aulas algumas metodologias alternativas tais como: modelagem, resolução de problemas e tecnologias, como forma diferenciada de lecionar a disciplina. 


\section{O contexto do trabalho com as diferentes metodologias}

Esse trabalho foi realizado em um quarto ano de um curso de Licenciatura em Matemática, de uma Universidade Estadual do Estado do Paraná, no terceiro bimestre, que devido a greve estadual, ficou situado entre os meses de novembro e dezembro de 2015 e teve continuidade em fevereiro de 2016.

A referida turma é composta de 9 alunos, oriundos de um ensino médio da rede pública estadual, trabalhadores, que atuam na rede privada, na área de saúde, administração, portuária e como professores contratados.

Durante o primeiro e segundo bimestre de 2015, os alunos tiveram as aulas de cálculo de forma tradicional, ou seja, eram apresentadas as teorias e os alunos tentavam resolver os exercícios e atividades propostas. No início do terceiro bimestre foi proposto o trabalho de forma diferenciada, usando a resolução de problemas, a modelagem e as novas tecnologias como metodologias de ensino para a disciplina.

No primeiro encontro, foi apresentado um problema, onde deveriam encontrar a área territorial de uma determinada Ilha no Estado do Paraná. A turma foi dividida em três grupos A, B e C com três alunos cada. O problema proposto era encontrar a área territorial da Ilha do Mel, na Cidade de Paranaguá, Estado do Paraná, tendo como base a (Fig. 1) abaixo:

FIGURA 1: Mapa da Ilha do Mel

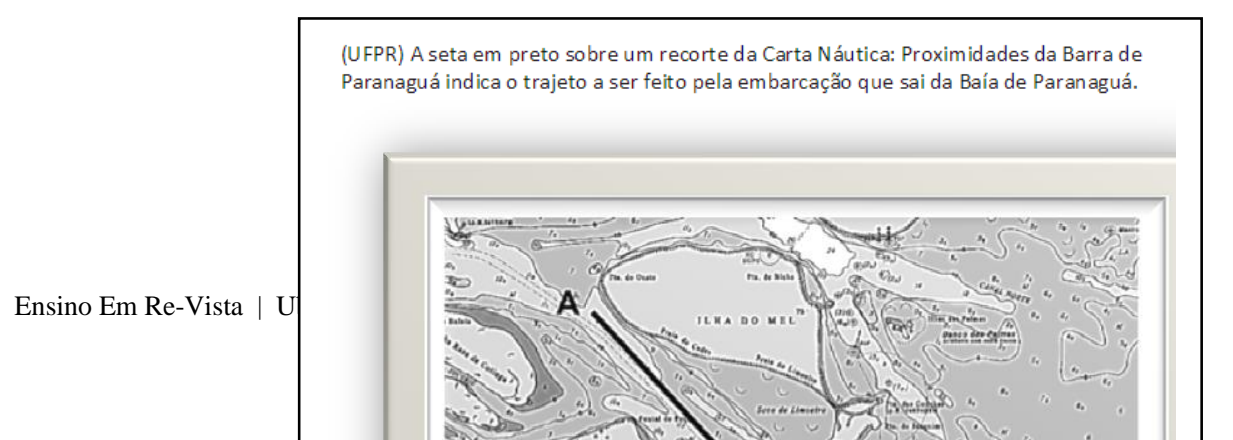


A Ilha do Mel, segundo dados da Prefeitura Municipal de Paranaguá (2016), está situada no Município de Paranaguá, estado do Paraná e conta com aproximadamente $95 \%$ de sua área territorial composta por ecossistemas de restinga e Floresta Atlântica. Tem 2.700 ha, sendo destes apenas 200 ha com permissão para uso.

Após esse primeiro contato com o problema, foram disponibilizadas 4 horas aula para que os alunos em grupo A, B e C buscassem resolver o problema ou criassem estratégias de como iniciar a sua solução. Somente um grupo conseguiu esboçar um rascunho para a solução do problema, que primeiro foi feito em um papel e depois os dados foram transpostos para $o$ geogebra.

O trabalho consistiu em tentar encontrar as áreas de pequenos triângulos usando o software, porém pelas respostas encontradas perceberam que esse não poderia ser o caminho. Conforme a (Fig 2.) abaixo.

FIGURA 2: Esboço da solução inicial pela equipe B 
A ideia inicial do grupo B era traçar triângulos na figura que formava a área territorial da Ilha do Mel e tentar encontrar uma área aproximada, usando uma regra de três e buscando um polinômio linear que descrevesse pequenos contornos da figura. Após algumas discussões e questionamentos perceberam que essa não era uma boa saída para o problema e ficaram de pensar em algo melhor. Os grupos A e C não apresentaram nenhum esboço de solução, estavam confusos e não sabiam por onde começar.

Nas aulas que seguiram, mais 4 horas aula, como os grupos ainda estavam com muitas dúvidas, um aluno da equipe $\mathrm{C}$ se propôs a ir ao quadro e tentar junto com os demais buscar uma pré-solução para o problema. O aluno M. apresentou no quadro, que uma das formas de fazer o trabalho, era fazer uma subdivisão da área maior e tentar encontrar por meio de interpolação polinomial, conteúdo estudado em cálculo numérico, polinômios que descrevessem o contorno da ilha e assim pudessem por meio de integral, encontrar pequenas áreas, que depois seriam somadas. E foi o que eles fizeram, como apresenta a (Fig 3.) abaixo:

FIGURA 3: Aluno da equipe C apresentando solução do problema

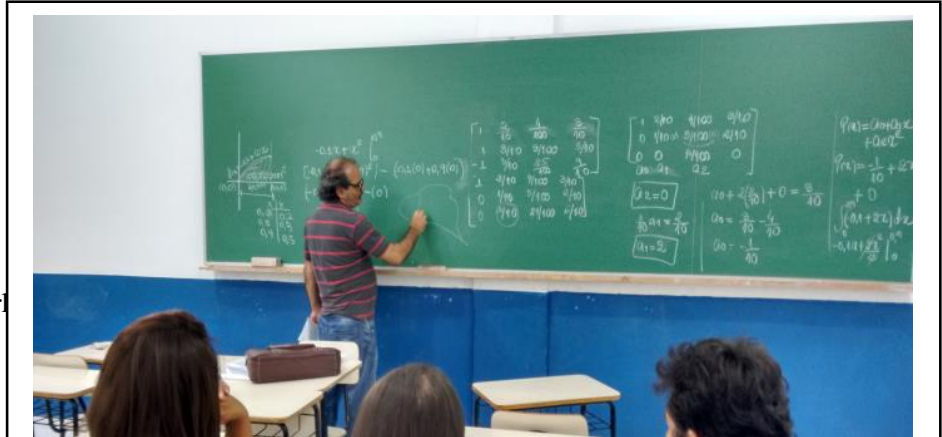


Esse encontro foi produtivo, pois os alunos conseguiram levantar algumas informações que foram relevantes para dar continuidade ao trabalho.

Para Polya (2006, p.5):

O estudante deve considerar as partes principais do problema, atenta e repetidamente, sob vários pontos de vista. Se houver uma figura relacionada ao problema, deverá traçar uma figura e nela indicar a incógnita e os dados. (POLYA, 2006, p.5)

Percebe-se que foram levantadas as partes principais do problema, usando aspectos da geometria e da álgebra. Traçaram a figura e criaram estratégias de solução.

Depois dessa aula, os alunos iriam apresentar como estavam realizando o trabalho, no entanto devido a problemas, a faculdade teve suas atividades paralisadas e o ano foi encerrado. A partir da paralisação, as comunicações foram feitas através de e-mails e mensagens via telefone.

\section{Resultados e discussões}


Os alunos deveriam resolver a proposição usando os passos da resolução de problemas propostos por Polya (2006), que são : compreensão do problema, estabelecimento de um plano, execução do plano e retrospecto. Para isso deveriam fazer um relatório escrito, contendo todos os quatro passos e como eles foram realizados.

Com relação a primeira etapa, que era a compreensão do problema, percebeu-se pelos relatos dos três grupos que conseguiram entender o solicitado. Por isso é importante que o professor apresente um problema que seja significativo para o aluno.

Os conteúdos devem ser significativos para os estudantes, isto é, precisam estar relacionados às experiências pessoais dos estudantes. Há professores que selecionam conteúdos retirados de textos elaborados em realidades muito diferentes das que são vivenciadas pelo grupo (...) (GIL, 2015, P.129)

Quando se pensa em ensino de terceiro grau, imagina-se que os alunos estão preparados para entender e assimilar quaisquer conteúdos ou conhecimentos, no entanto isso não é real.

Com relação ao segundo passo, que era a elaboração de um plano, abaixo é apresentado o relato de um dos grupos.

Quadro 1: Relato do grupo A na etapa II

ETAPA II - ELABORAÇÃO DE UM PLANO

Nunca haviamos resolvido um problema parecido com esse antes, sabíamos que havia uma escala proporcional ao tamanho real de algo, nos mapas, mas nunca 
Já o grupo C apresentou, além da primeira forma de resolução, em que utilizou o software geogebra, também utilizou uma segunda forma de resolução do problema.

Quadro 2: Relato do grupo C na etapa II

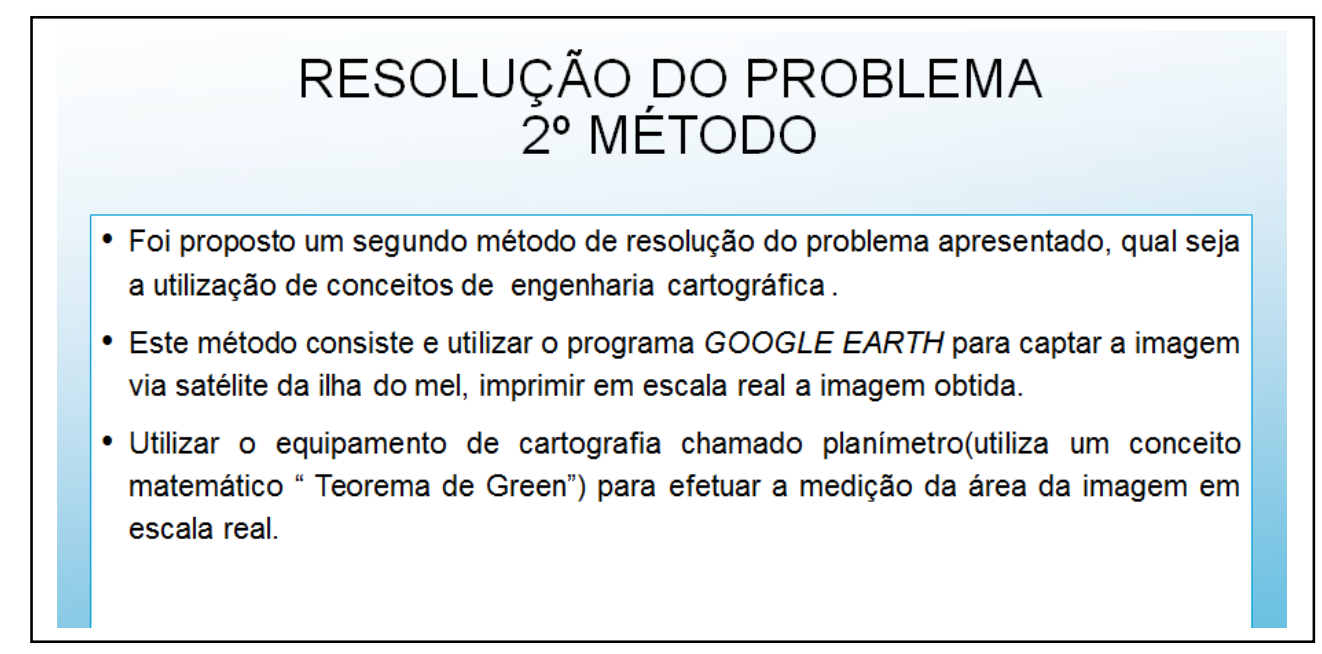

Fonte: Trabalho dos alunos (2016)

Nessa etapa o grupo C, buscou outros recursos computacionais que não foram apenas o programa Visual Cálculo Numérico, que já havia sido 
utilizado em outras aulas. Foram usados aqui, recursos da internet e o equipamento de cartografia.

$\mathrm{Na}$ terceira etapa, que consistia a execução do plano, a equipe A, apresentou que:

Quadro 3: Relato do grupo A na etapa III

\section{ETAPA III - EXECUÇĀOO DO PLANO}

Utilizaremos todos os conceitos cilados acima, inclusive o sottware.

Primeiro verificamos a fonte do mapa com escala, o cutro nào foi utilizado, para a partir do mapa criginal, poder tirar as medidas corretas em centimetros (no Paint, programa de computador). fazendo algo parecido com um gríco cartesiano. utilizando apenas a parte da Estạ̧äo Ecológiea como na figura ababxo:

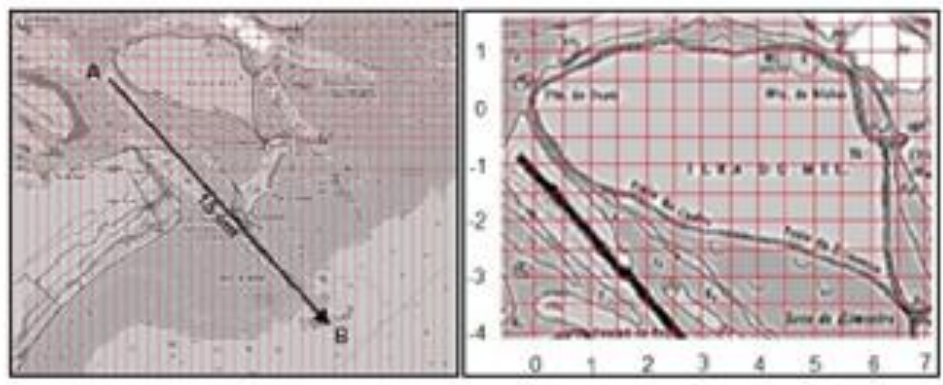

Em seguida, dividimos o mapa em 3 partes encontrando as coordenadas de cada ponto que forma cada uma das curvas. Para verificar qual o tipo de funçăo que mais se ajustaria a combinapia de pontos encontrados utizamos o item Ajuste de Curvas $\rightarrow$ Q.3 Ajuste Polinomial do software VCN, fazendo uma subdivis5o do mapa.

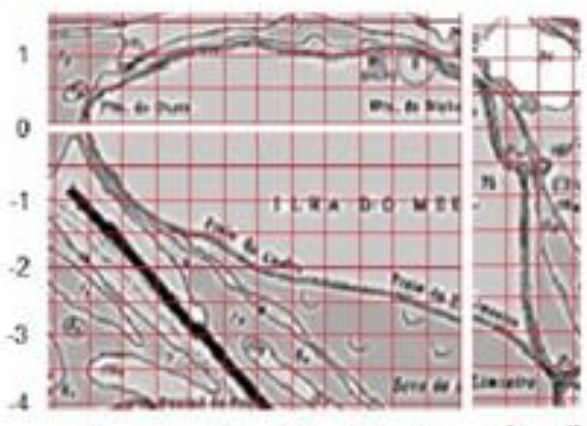

Fonte: Trabalho dos alunos alunos (2016)

\section{Quadro 4: Relato do grupo A na etapa III - Cálculos}

$1^{2}$ Subdivisão.
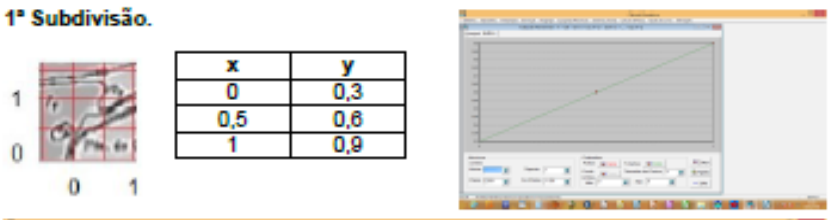
Nessa etapa, o grupo apresentou não somente a resposta, mas o erro, que nesse caso não é oriundo do levantamento de dados e nem dos cálculos, mas sim um erro do próprio equipamento que já vem especificado com o produto.

É interessante que esse tipo de erro não é tratado nas referências do Cálculo Numérico, que muitas vezes tratam apenas dos erros na fase de modelagem e de resolução que compreenderam a conversão de base, arredondamento e truncamento. Na quarta etapa, que foi o retrospecto ou verificação, foi apresentado:

Quadro 6: Relato do grupo A na etapa IV

$$
\text { ETAPA IV - RETROSPECTO OU VERIFICAÇÄO }
$$

Como a escala está em 1:100000 cm, logo, percebemos através de uma regra de très simples que $1 \mathrm{~cm}$ no mapa, equivale a $1 \mathrm{~km}$ real, pois $100000 \mathrm{~cm}=1 \mathrm{~km}$. Portanto a área é de $\frac{17901}{960} \mathrm{~km}^{2}$ que equivale a $1864,6875 \mathrm{ha}$, pois $1 \mathrm{~km}^{2}=100 \mathrm{ha}$. 
Nessa etapa, o grupo A tratou do erro absoluto e relativo, comparando a solução encontrada com a solução apresentada do problema nos guias turísticos que apresentam dados sobre a Ilha do Mel. Entre estes dados é possível encontrar os números relativos com relação à área territorial da Ilha.

Quadro 5: Relato do grupo C na etapa IV

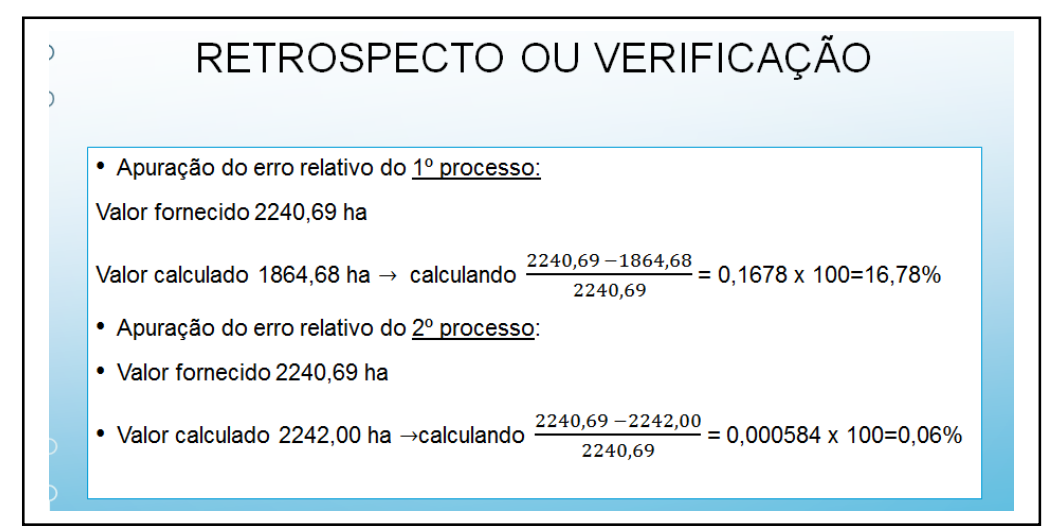

Fonte: Trabalho dos alunos (2016)

Nessa quarta etapa, pode-se perceber que os alunos utilizaram os dados reais do problema e os compararam com os valores encontrados, dessa forma, também trabalharama com o erro, que foi um dos primeiro tópicos apresentado na disciplina de cálculo numérico, ou seja, os grupos mobilizaram conhecimentos do primeiro bimestre.

Quadro 6: Relato do grupo C sobre os erros

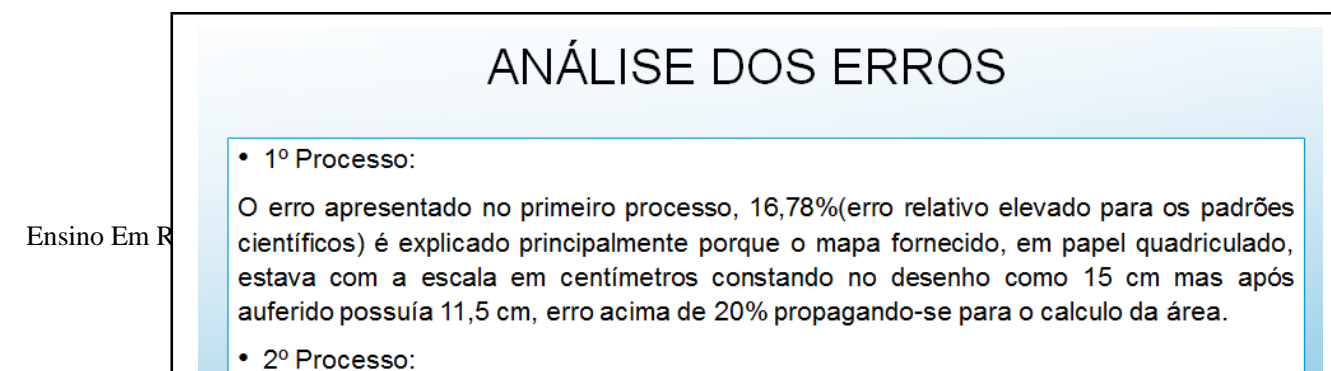


O grupo $\mathrm{C}$ fez nessa etapa um comparativo entre os dois valores encontrados por métodos diferentes, o que foi interessante, porque na apresentação foi comentado que a diferença entre os erros de $20 \%$ e de 0,06\% não foi devido aos cálculos matemáticos, mas sim à precisão do material inicial que serviu de base para inícios do trabalhos.

\section{A percepção dos alunos com relação ao trabalho}

Para que houvesse uma avaliação com relação a percepção dos alunos com relação as metodologias diferenciadas que foram desenvolvidas durante o terceiro bimestre, foi elaborado e aplicado um questionário para verificar qual a percepção deles da disciplina, as aulas teóricas e a prática realizada.

Abaixo são apresentadas as respostas dadas pelos alunos ao questionário realizado na última semanda de fevereiro de 2016. Os envolvidos responderam ao questionário impresso que depois foi transpassado para o docs do google.

Os alunos foram questionados sobre a comparação entre os trabalhos do primeiro e do segundo bimestres, comparados com o terceiro. Nas respostas $87,5 \%$ apresentaram que comparando as aulas tradicionais com a as aulas que envolveram as diferentes metodologias, eles aprenderam de 
forma diferenciada. Somente $12,5 \%$ respondeu que aprendeu mais no terceiro bimestre.

O questionário também era composto de questões abertas, que solicitavam que fossem citados pontos positivos, com relação ao trabalho com metodologias diferenciadas. As respostas foram: "Aprendizagem diferenciada", "Interação com o grupo, relação da matéria com a prática e encontros para a solução e desenvolvimento", "Estimula o raciocínio", "Consegui entender o conteúdo, mas não aplicar na prática", "Por ter sido em grupo o que facilitou a resolução de problemas" e “ 1)Resolução de problemas como método de ensino e aprendizagem de matemática, em qualquer nível. 2) Enfoque multidisciplinar na resolução de problemas".

Pelas respostas é possível perceber que os alunos se sentiram confortáveis em trabalhar em grupo, o que para eles se tornou um ponto positivo na hora de resolver problemas, além do enfoque multidisciplinar.

$\mathrm{Na}$ questão que pedia sobre as maiores dificuldades encontradas no trabalho realizado no terceiro bimestre, as respostas foram: "Encontrar a função", "Travei na função", "Encontrar a função ou polinômio interpolador e encontrar o erro", "Dificuldade em entender o que pedia", "Concentração", "Encontrar o modelo matemática para resolver o trabalho" "Entender num primeiro momento o que o trabalho estava propondo", "foi o tempo disponível para execução do trabalho, pois para quem estuda à noite é importante que a atividade seja inteiramente executada em sala de aula, nem sempre isso foi possível”.

Pelas respostas dos alunos, percebe-se que alguns conseguiram sair da fase inicial, que era entender o problema, porém não conseguiam identificar ou modelar a função.

Para outro aluno, o problema foi o tempo, como já citado anteriormente, todas as atividades estavam programadas para serem realizadas nas aulas, mas devido a paralisação, isso não foi possível e muitos tiverem que trabalhar sozinhos. 
Quanto aos pontos negativos, apenas quatro alunos responderam, e foram os seguintes comentários: "Muito pouca hora", "Aplicação prática, desenvolvimento pessoal, superar limites, interações", "os cálculos" e "não houve". Pelas respostas os pontos negativos foram variados, mas se referem ao limitado tempo para a realização da atividade, cálculos e interação entre o grupo.

A última questão tinha como objetivo identificar, entre as metodologias vivenciadas ou não pelos alunos, a qual eles adotariam quando fossem professores. Dessa forma, foi perguntado se eles fossem professores na disciplina de Cálculo Numérico, como iria trabalhar.

As respostas foram unânimes, ou seja, 100\% dos alunos apresentaram que iriam intercalar as metodologias diferenciadas com a tradicional.

Ao final do trabalho, pode-se perceber que é possível nas aulas do curso de Licenciatura em Matemática trabalhar utilizando diferentes metodologias. Alguns alunos apresentaram na pesquisa que a metodologia tradicional é onde a aprendizagem ocorre realmente, no entanto pode-se perceber pelo padrão de respostas que eles também acharam interessante as metodologias diferenciadas.

\section{Considerações finais}

Muitas vezes, ao lecionar no ensino superior, o professor pode ficar preso a metodologias tradicionais de ensino, acreditando que os alunos por estarem em um grau mais avançado de ensino não necessitem vivenciar formas de aprendizado diferentes.

No entanto, acredita-se que isso não é o ideal, sobretudo para os alunos das Licenciaturas, pois esses, provavelmente após concluírem o curso, irão lecionar na educação básica onde é necessário muitas vezes inovar. No entanto, eles não terão como trabalhar de forma diferenciada se nunca vivenciaram essa experiência. 
É necessário que as aulas dos cursos de Licenciatura, e aqui em especial do Curso de Licenciatura em Matemática, leve o aluno a ter oportunidade de pensar, de criar estratégias e novas ações, que possam servir de modelo para quando estes atuarem em sala de aula.

Nesse contexto, é que se propôs este estudo objetivando mostrar como é possível trabalhar construtivamente na disciplina de Cálculo Numérico, com metodologias diferenciadas que empregam a resolução de problemas, a modelagem matemática e novas tecnologias como forma de ajudar a minimizar os problemas de aprendizagem.

Ao ser proposto um problema para a turma onde o trabalho foi aplicado, foi possível perceber que os alunos corresponderam muito bem ao que estava sendo esperado deles, ou seja, conseguiram entender o que era proposto no problema, levantar dados, encontrar uma resposta satisfatória.

Alguns pontos positivos foram identificados no decorrer do processo, entre os quais o fato, dos alunos por exemplo, trabalharem com a questão do erro. Esse foi um tema abordado no primeiro bimestre, não esperava que fossem mobilizados tais conhecimentos, afinal a questão era para apenas encontrar a área de uma determinada região territorial.

O que ficou marcante no decorrer do trabalho, foi a busca por conceitos de outras disciplinas, como do Cálculo Diferencial Integral, da Álgebra, da Geometria e da Engenharia Cartográfica.

Por tais motivos, acredita-se que o objetivo tenha sido cumprido, pois além de vivenciar a experiência de utilizar diferentes métodos na resolução de problemas, pode-se perceber, nas respostas dadas, que se fossem professores da disciplina também iriam alternar diferentes métodos de ensino, ou seja, eles acreditam que tal procedimento pode facilitar a aprendizagem do aluno.

\section{Referências}

ALMEIDA, L.W de. Modelagem Matemática na educação básica. São Paulo: Contexto, 2013. 
ALMEIDA, L. M. W. de.; VERTUAN, R. E. Discussões sobre "como fazer" modelagem matemática em sala de aula. In: ALMEIDA, L. M. W. (Org.). Práticas de modelagem matemática: relatos de experiências e propostas pedagógicas. Londrina: Eduel, 2011.

AMARAL, T. R, et al. O ensino de cálculo numérico utilizando o scilab. Rio Grande do Sul, 2013. 9 f. Trabalho apresentado no VI Congresso Internacional de Ensino da Matemática. Ulbra, 2013.

BASSANEZI, R. C. Ensino-aprendizagem com modelagem matemática: uma nova estratégia. São Paulo: Contexto, 2002.

BRASIL. Orientações Curriculares para o ensino médio: Ciências da Natureza, Matemática e suas Tecnologias. Ministério da Educação, Secretaria de Educação Basica, 135p., 2008.

COLOMBO, J. A.; LAGOs, M. B(Org.). Problemas, Quem não tem?. Pato Branco, Imprepel, 2005.

DANTE, L.R. Didática da resolução de problemas. São Paulo: Ática, 1989.

EVES, H. Introdução a história da matemática. Campinas, SP: Editora da UNICAMP, 2004.

GIL, A. C. Didática do ensino superior. São Paulo: Atlas, 2015

HOHENWARTER, M. (2014). $O$ que é GeoGebra. 2007. Disponível em: http://www.nre.seed.pr.gov.br/cascavel/arquivos/File/CRTE/geogebra/apostila curso .pdf Acesso em: 21 de out. 2015.

NOGUTI, F. C. H. (2005). O livro “THÉORIE DES APPROXIMATIONS NUMÉRIQUES ET DU CALCUL ABRÉGÉ” de Agliberto Xavier. Dissertação (Mestrado em Educação Matemática) - Universidade Estadual Paulista, Rio Claro, 2005.

OLIVEIRA, C.C; MARIM, V. (Org.). Educação matemática: contextos e práticas docentes. Campinas, SP: Editora Alínea, 2010.

PARANAGUÁ. Guia Turístico da Ilha do Mel. Disponível em: http://www.paranagua.pr.gov.br/conteudo/guia-turistico/ilha-do-mel. Acesso $21 \mathrm{de}$ ago. 2016.

POLYA, G. A arte de resolver problemas. Rio de Janeiro: Interciência, 2006.

SPERANDIO, D. Cálculo numérico: características matemáticas e computacionais dos métodos numéricos. São Paulo: Prentice Hall, 2003. 
DOI http://dx.doi.org/10.14393ER-v25n1a2018-11

Recebido em dezembro de 2016.

Aprovado em outubro de 2017. 


\title{
Curiosidades e desafios matemáticos nas aritméticas da série Concórdia
}

\author{
Malcus Cassiano Kuhn ${ }^{1}$
}

Arno Bayer ${ }^{2}$

\begin{abstract}
RESUMO
$\mathrm{O}$ artigo tem por objetivo discutir curiosidades e desafios matemáticos encontrados nas aritméticas da série Concórdia, editadas pela Igreja Luterana, na década de 1940, para suas escolas paroquiais, no Rio Grande do Sul. Baseando-se na pesquisa histórica, analisaram-se as edições da Primeira, Segunda e Terceira Aritmética, identificando-se curiosidades e desafios envolvendo: construção do significado de número até 10, quadrados mágicos, meses do ano, provas reais para as quatro operações elementares com números naturais, a prova dos 9 fora, exercícios de raciocínio lógico, contas curiosas e tabuada com frações. Embora algumas destas curiosidades e desafios estejam alicerçados no método de ensino intuitivo, os mesmos refletem a tradição pedagógica da memorização, destacando-se algoritmos e procedimentos de cálculos escritos e mentais, considerados fundamentais para que os futuros colonos fizessem a correta administração do orçamento familiar e o gerenciamento da sua propriedade rural.
\end{abstract}

PALAVRAS-CHAVE: Curiosidades. Desafios Matemáticos. Série Concórdia. Ensino da Matemática. Escolas Paroquiais Luteranas Gaúchas.

Curiosities and mathematical challenges in the arithmetic of the Concordia series

\begin{abstract}
The article aims to discuss curiosities and mathematical challenges found in the arithmetic of the Concordia series, edited by the Lutheran Church, in the 1940s, for their parochial schools in Rio Grande do Sul.
\end{abstract}

\footnotetext{
${ }^{1}$ Pós-doutorando do Programa de Pós-Graduação em Ensino de Ciências e Matemática da Universidade Luterana do Brasil, Canoas, Rio Grande do Sul, Brasil. Professor do Instituto Federal de Educação, Ciência e Tecnologia Sul-riograndense - IFSul, Câmpus Lajeado, Rio Grande do Sul, Brasil.E-mail: malcusck@ yahoo.com.br.

${ }^{2}$ Doutor em Ciências da Educação pela Universidade Pontifícia de Salamanca, Espanha. Professor e pesquisador do Programa de Pós-Graduação em Ensino de Ciências e Matemática da Universidade Luterana do Brasil, Canoas, Rio Grande do Sul, Brasil.E-mail: bayer@ulbra.br
} 
Basing on historical research, analyzed the editions of the First, Second and Third Arithmetic, identifying curiosities and challenges involving: construction of the meaning of number until 10, magic squares, months of the year, real proofs for the four elementary operations with natural numbers, the proof of 9 out, logical reasoning exercises, curious counts and multiplication tables with fractions. Although some of these curiosities and challenges are grounded in the intuitive teaching method, they reflect the pedagogical tradition of the memorization, highlighting algorithms and procedures of written and mental calculations, considered fundamental for that future colonists would did the correct administration of the family budget and the management of his rural property.

KEYWORDS: Curiosities. Mathematical Challenges. Concordia Series. Mathematics Teaching. Gaucho Lutheran Parochial Schools.

$$
* * *
$$

\section{Introdução}

O presente artigo tem por objetivo discutir curiosidades e desafios matemáticos encontrados nas edições da Primeira, Segunda e Terceira Aritmética, integrantes da série Concórdia, editadas pela Igreja Luterana na década de 1940, para suas escolas no Rio Grande do Sul - RS. Trata-se de um recorte de tese, complementado por pesquisas realizadas durante o estágio Pós-doutoral em um Programa de Pós-Graduação.

$\mathrm{O}$ movimento migratório no RS tem sido objeto de investigações. No âmbito da História da Educação no RS, os trabalhos de Kreutz (1991, 1994), Rambo (1994), Lemke (2001) e Weiduschadt (2007) são destaques. Na História da Educação Matemática no estado gaúcho, destacam-se as pesquisas de Mauro (2005), Wanderer (2007) e Kuhn (2015).

Conforme Prost (2008), os fatos históricos são constituídos a partir de traços deixados no presente pelo passado. Assim, a tarefa do historiador consiste em efetuar um trabalho sobre esses traços para construir os fatos. Como a temática investigada se insere na História da Educação Matemática 
no RS, busca-se na pesquisa histórica o suporte para discussão. Certeau (1982) define o fazer história, no sentido de pensar a história como uma produção. Para o autor, a história, como uma produção escrita, tem a tripla tarefa de convocar o passado que já não está em um discurso presente, mostrar as competências do historiador (dono das fontes) e convencer o leitor. O trabalho do historiador, de acordo com Certeau (1982), é fazer um diálogo constante do presente com o passado, e o produto desse diálogo consiste na transformação de objetos naturais em cultura.

Chervel (1990) considera importante o estudo histórico da cultura escolar para a compreensão dos elementos que participam da produção/elaboração/constituição dos saberes escolares e, em particular, da matemática escolar e sua história. Julia (2001) define a cultura escolar como um conjunto de normas que estabelecem conhecimentos a ensinar e condutas a inspirar, e um conjunto de práticas que permitem a transmissão desses conhecimentos e a incorporação desses comportamentos. De acordo com Valente (2007), pensar os saberes escolares como elementos da cultura escolar, realizar o estudo histórico da matemática escolar, exige que se devam considerar os produtos dessa cultura no ensino de matemática, que deixaram traços que permitem o seu estudo, como as aritméticas da série Concórdia, principais fontes documentais desta investigação.

Precedendo a discussão das curiosidades e dos desafios matemáticos encontrados nas aritméticas da série Concórdia, apresenta-se uma breve caracterização das escolas paroquiais luteranas gaúchas do século passado.

\section{As escolas paroquiais luteranas gaúchas do século $\mathrm{XX}$}

No Brasil, os princípios cristãos de Lutero, se fizeram presentes, a partir de 1824, com a vinda das ideias luteranas através dos primeiros imigrantes alemães. Lutero traçou princípios gerais sobre a educação, os quais se fundamentaram na Bíblia. "A premissa fundamental é de que a 
Bíblia ensina que Deus criou o universo e mantém, governa e sustenta toda a criação, sendo o homem a obra máxima da criação" (LEMKE, 2001, p. 34).

Nesta perspectiva luterana, o Sínodo Evangélico Luterano Alemão de Missouri $^{3}$, hoje Igreja Evangélica Luterana do Brasil - IELB, iniciou missão nas colônias alemãs do RS, em 1900, fundando congregações religiosas e escolas paroquiais. Para o Sínodo de Missouri era necessário consolidar um campo religioso e fortalecê-lo investindo na escola, influenciando o campo familiar dos seus possíveis fiéis. Por isso, os egressos das escolas paroquiais luteranas gaúchas tinham amplo conhecimento da Bíblia e uma formação consistente de crenças e valores cristãos tradicionais que enfatizavam a importância do relacionamento com Deus e com outras pessoas.

De acordo com Kuhn (2015), as escolas paroquiais luteranas estavam inseridas num projeto missionário e comunitário que buscava ensinar a língua materna, matemática, valores culturais, sociais e, principalmente, religiosos. Tinham uma responsabilidade para com a comunidade no sentido de, junto e com ela, promover o crescimento e o desenvolvimento pessoal de todos que a compõe, focando a cidadania. Se a escola formasse o ser humano com postura ética e moral exemplar, este poderia promover transformações sólidas em seu contexto social e seria um verdadeiro colaborador na seara de Deus e para o governo do mundo. As escolas paroquiais luteranas gaúchas foram assim caracterizadas por Weiduschadt (2007):

As escolas eram organizadas de forma multisseriada. As turmas eram compostas de 20 a 40 alunos. Na maioria das vezes, o pastor da comunidade era, ao mesmo tempo, professor. A comunidade sustentava a estrutura física e mantinham o professor da escola. $\mathrm{O}$ prédio era muitas vezes o mesmo local do templo. O projeto escolar dentro da comunidade religiosa era marcante, a orientação e a obrigação de os pais enviarem os filhos à escola eram quase

\footnotetext{
${ }^{3}$ Em 1847, um grupo de imigrantes luteranos alemães da Saxônia fundou no estado de Missouri (EUA), o Sínodo Evangélico Luterano Alemão de Missouri, Ohio e Outros Estados, atualmente Igreja Luterana - Sínodo de Missouri.
} 
obrigatórias, com sanções econômicas e morais, caso não concordassem. (WEIDUSCHADT, 2007, p. 166-168).

O Sínodo de Missouri também tinha uma preocupação acentuada em relação aos recursos didáticos usados nas escolas paroquiais, pois este material era escasso e a dificuldade era grande em manter um ensino planificado e organizado. De acordo com Weiduschadt (2007, p. 41), "os livros usados nas escolas paroquiais e utilizados pelos alunos foram produzidos pelas instituições religiosas com objetivo de formar e moldar as condutas e as práticas ao fazer a escolarização das comunidades”. Assim, por meio dos livros didáticos, como as aritméticas da série Concórdia, as escolas paroquiais luteranas gaúchas conseguiram desenvolver uma educação integral cristã em todas as disciplinas.

\section{As aritméticas da série Concórdia}

Conforme Kuhn (2015), o ensino da matemática, nos primeiros anos de escolarização nas escolas paroquiais luteranas gaúchas do século passado, priorizava os números naturais, os sistemas de medidas, as frações e os números decimais, complementando-se com a matemática comercial e financeira e a geometria. O ensino da matemática deveria acontecer de forma prática e articulada com as necessidades dos futuros agricultores, observando-se a doutrina luterana. Esta aparece e é reforçada nas aritméticas da série Concórdia através de exercícios e de problemas associados com operações comerciais (cálculo correto do troco) e com as quatro operações elementares (provas reais). Com este tipo de atividades, os autores das aritméticas esperavam que os alunos das escolas paroquiais preservassem valores, como a verdade e a honestidade, visando uma atuação consciente e responsável para sua subsistência e procurando o bem do próximo e da sociedade de acordo com a vontade de Deus. 
Nas escolas paroquiais luteranas do RS se dava ênfase aos Kopfrechnungen (cálculos feitos mentalmente), já que na vida agrícola a pessoa teria que calcular, com frequência, sem ter o papel e lápis à mão. $\mathrm{O}$ próprio título de um dos manuais usados nesta disciplina, o Praktische Rechenschule (o ensino prático da matemática), de Otto Büchler ${ }^{4}$, reflete este entendimento. Até aproximadamente 1932, predominava o ensino tradicional no Brasil. De 1932 até 1960, os alunos sofreram influências do evolucionismo e do pragmatismo, período denominado de Escola Nova.

Os primeiros 30 anos de existência das escolas paroquiais luteranas no RS foram marcados pela carência de materiais didáticos e progressiva adoção dos quatro manuais de Büchler, tanto em alemão, quanto em português, para as aulas de matemática. No periódico Unsere Schule (ago. $^{2}$ 1933, p. 6, tradução nossa), afirma-se que "os livros de aritmética de Büchler (editora Rotermund) ${ }^{6}$ são usados na maioria das nossas escolas e que a mesma editora lançou recentemente um novo manual: meu livro de contas, por W. Nast e L. Tochtrop". Na mesma edição, aponta-se a necessidade de uma edição com princípios morais e educacionais missourianos, uso de princípios pedagógicos modernos e adaptada às condições nacionais, pois o processo de nacionalização do ensino ${ }^{7}$ estava em curso.

Por isso, o Sínodo de Missouri começou a produzir seus próprios livros de aritmética na década de 1930. A Casa Publicadora Concórdia ${ }^{8}$ de Porto Alegre editou e publicou o material didático específico para as escolas paroquiais luteranas. Para as aulas de matemática, foram publicadas duas séries: a série Ordem e Progresso, lançada na década de 1930, pela

\footnotetext{
${ }^{4}$ Otto Büchler foi autor de livros de aritmética utilizados nas escolas teuto-brasileiras do século XX.

${ }^{5} \mathrm{Na}$ década de 1930, a IELB começou a publicar um periódico pedagógico dirigido às escolas paroquiais, chamado Unsere Schule (Nossa Escola), predominando informações e artigos escritos em alemão.

${ }^{6}$ A editora Rotermund, de São Leopoldo, editava e publicava o material didático relacionado ao Sínodo RioGrandense (Igreja Evangélica de Confissão Luterana no Brasil - IECLB).

${ }^{7}$ Uma série de decretos dos governos estadual e federal, emitidos no final da década de 1930, disciplinaram a licença de professores e o material didático a ser usado nas escolas, tornaram o idioma nacional obrigatório (português) para a instrução e prescreveram a formação cívica brasileira.

${ }^{8}$ Fundada em 1923, publicava livros e periódicos relacionados à literatura religiosa e escolar da IELB. Foi a primeira e a única redatora da IELB, existente até os dias atuais. Antes de sua fundação, os livros e periódicos eram impressos pela Concordia Publishing House, nos Estados Unidos, e enviados ao Brasil.
} 
divulgação feita no periódico Unsere Schule, e a série Concórdia, lançada na década de 1940.

A série Ordem e Progresso e a série Concórdia contém três aritméticas voltadas para o ensino da matemática nos primeiros anos de escolarização. No Instituto Histórico da IELB, em Porto Alegre, localizaramse a Primeira e a Terceira Aritmética da série Ordem e Progresso, além de uma edição da Primeira Aritmética, duas edições da Segunda Aritmética e uma edição da Terceira Aritmética da série Concórdia.

Neste artigo se realiza a discussão de curiosidades e desafios matemáticos encontrados nas aritméticas da série Concórdia, apresentadas no Quadro 1, tendo como base teórico-metodológica a pesquisa histórica.

QUADRO 1: Aritméticas analisadas.

\begin{tabular}{|c|c|c|c|}
\hline Obra & Data & Autor & Páginas \\
\hline Primeira Aritmética & {$\left[194^{-}\right]$} & Otto A. Goerl ${ }^{9}$ & 68 \\
\hline Segunda Aritmética & {$[194-]$} & Otto A. Goerl & 84 \\
\hline Segunda Aritmética & 1948 & Sem autoria declarada & 96 \\
\hline Terceira Aritmética & 1949 & Sem autoria declarada & 143 \\
\hline
\end{tabular}

Fonte: Série Concórdia.

Observa-se, no Quadro 1, que duas aritméticas possuem autoria declarada, um professor paroquial, e sobre os autores das demais obras não se obteve informações. Verifica-se que o número de páginas de cada aritmética aumenta conforme o nível de escolarização primária. Não se pode informar a quantidade de exemplares publicados em cada edição, pois esta informação não foi encontrada. Ressalta-se que as aritméticas da série Concórdia foram editadas com base em princípios morais e educacionais idealizados pela IELB.

\footnotetext{
9 O gaúcho Otto Adolpho Goerl (1905-1998) se formou no Seminário Concórdia (Instituto pedagógicoteológico que atuou na formação de pastores e professores paroquiais para IELB), em 1925, e foi ordenado pastor em 1926. Além de pastor, foi professor paroquial, professor e diretor do Seminário Concórdia. Autor de livros para o ensino de aritmética e leitura nas escolas paroquiais luteranas.
} 


\section{Curiosidades e desafios matemáticos nas aritméticas analisadas}

A Primeira Aritmética da série Concórdia aborda os números até 100. Exploram-se as operações de adição, subtração, multiplicação e divisão, e a pequena tabuada. $\mathrm{O}$ autor dessa aritmética dá maior ênfase para o método intuitivo em suas propostas de ensino, mas também traz atividades que enfatizam a memorização. O estudo da numeração até 10 é proposto de forma intuitiva pelo autor, associando-se quantidades de animais, pessoas ou objetos à representação simbólica do número, seguida de cálculos que envolvem as operações de adição ou subtração até 10. A Figura 1 ilustra a proposta de estudo para o número 6:

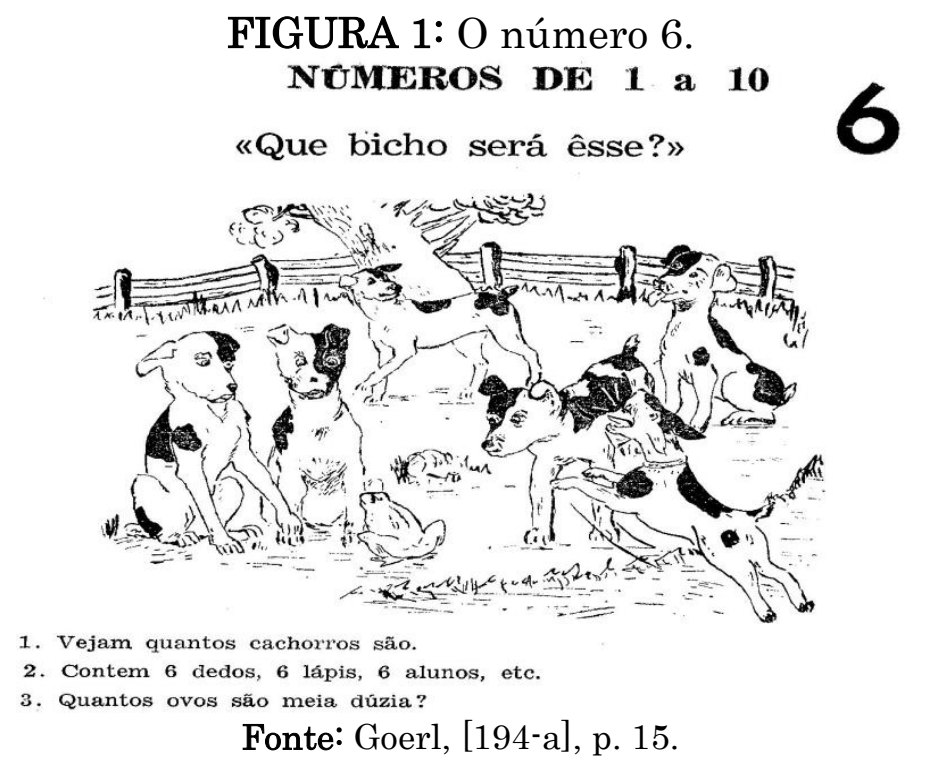

Observa-se que o autor emprega o método de ensino intuitivo para construção do conceito de número, associando o número 6 com a representação de 6 cachorros, propondo a contagem de 6 dedos, 6 lápis e 6 alunos, além de envolver a unidade de medida dúzia. Empregando o método de ensino intuitivo, o autor esperava que os alunos das escolas paroquiais luteranas gaúchas se apropriassem do significado de número.

A Segunda Aritmética de Goerl [194-b] está dividida em três seções: números de 1 a 100 (recapitulação); números de 1 a 1000; números até 10000. Mesmo que o autor desta aritmética proponha a resolução de 
problemas contextualizados com a realidade dos alunos das escolas paroquiais luteranas gaúchas, observam-se propostas de ensino para o desenvolvimento de habilidades para o cálculo mental e escrito, envolvendo as quatro operações elementares com números naturais.

$\mathrm{Na}$ análise realizada, verificou-se que essa aritmética traz atividades com quadrados mágicos, conforme descrito no Quadro 2:

QUADRO 2: Quadrados mágicos.

Num quadrado mágico a soma dos números em linha horizontal, vertical e diagonal é sempre igual.

\begin{tabular}{|l|l|l|}
\hline 4 & 9 & 2 \\
\hline 3 & 5 & 7 \\
\hline 8 & 1 & 6 \\
\hline
\end{tabular}

2.

\begin{tabular}{|l|l|l|}
\hline 8 & 3 & \\
\hline & 5 & \\
\hline & & \\
\hline
\end{tabular}

3.

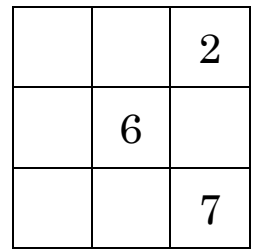

1. Somem, no quadrado mágico número 1, os números de cima para baixo, da esquerda para a direita e de um canto para o outro. Que resultado terão?

2. O resultado do número 2 também é 15 . Coloquem os números que faltam, começando com a linha horizontal, passando então para a vertical, e assim por diante.

3. Façam o mesmo com o quadrado número 3, cujo resultado é 18 . Depois da vertical somem a diagonal. Daí em diante será fácil.

4.

\begin{tabular}{|l|l|l|}
\hline & 8 & \\
\hline & 4 & \\
\hline & 0 & 5 \\
\hline
\end{tabular}

5 .

\begin{tabular}{|c|c|c|}
\hline 6 & & \\
\hline 11 & 7 & \\
\hline 4 & & \\
\hline
\end{tabular}

6. 7

\begin{tabular}{|l|l|l|l|}
\hline 7 & & 1 & 14 \\
\hline & 13 & 8 & \\
\hline 16 & 3 & & \\
\hline & & & 4 \\
\hline
\end{tabular}

4. Descobrir a soma de cada linha. Coloquem os números que faltam.

5. Façam o mesmo com o número 5. Não esqueçam a diagonal.

6. O quadrado número 6 tem por soma 34. Coloquem os números que faltam começando com a diagonal.

\section{Fonte: Goerl, [194-b], p. 40.}

Observa-se que, após uma breve sistematização sobre os quadrados mágicos, o autor propõe atividades com seis quadrados mágicos, sendo cinco deles $3 \times 3$ e um deles $4 \times 4$. Também não se explora a origem dos quadrados 
mágicos ${ }^{10}$, mas se tratam de atividades desafiadoras para os alunos e uma estratégia que pode incentivar a curiosidade e o gosto pela matemática. A Segunda Aritmética de 1948 também apresenta exercícios envolvendo quadrados mágicos, sendo dois deles 4 x 4 e um deles 5 x 5 .

O recorte da Segunda Aritmética de Goerl, apresentado na Figura 2, apresenta informações sobre a quantidade de dias dos meses do ano:

FIGURA 2: Número de dias dos meses do ano.

\begin{abstract}
Notem bem: Na aritmética o més conta 30 dias. Seguindo, porém, o calenđário veremos que alguns meses têm 31 dias e o fevereiro apenas 28 dlas. Vejam como ê fácil saber os dias de cada mệs.
\end{abstract}

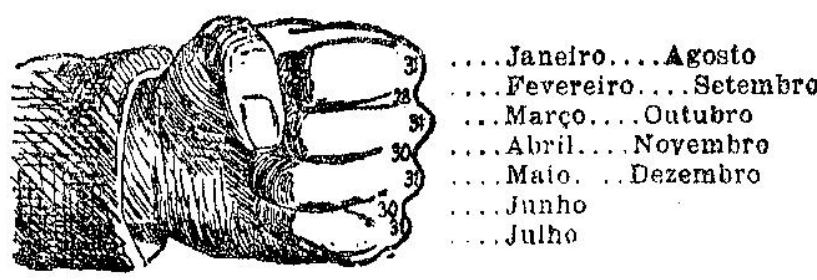

Fonte: Goerl, [194-b], p. 60.

O fragmento do livro, observado na Figura 2, mostra quantos dias tem um mês utilizando os nós superiores dos dedos e os seus intervalos. A cada nó, intercalado com o intervalo com o próximo nó, é atribuído sequencialmente um mês, começando pelo mês de janeiro. O número de dias é dado da seguinte forma: se o mês está num nó do dedo, terá 31 dias; se o mês está num intervalo, então terá 30 dias, à exceção de fevereiro, que poderá ter 29 ou 28 dias, consoante seja ano bissexto ou não, respectivamente. Aponta-se que o livro traz uma informação incompleta, pois não faz referência ao mês de fevereiro com 29 dias em anos bissextos. Ressalta-se que esta associação e a informação incompleta sobre o número de dias do mês de fevereiro, também foram observadas na edição da Segunda Aritmética de 1948. A associação proposta pelo autor pode auxiliar o aluno na memorização da quantidade de dias em cada mês do ano, utilizando-se de partes do corpo humano no ensino da matemática.

\footnotetext{
10 "Um dos primeiros registros de um quadrado mágico apareceu na China. Conta a lenda que o quadrado foi trazido aos homens por uma tartaruga, através do Rio Lo, há mais de 4000 anos" (CARVALHO, 1997, p. 58).
} 
$\mathrm{Na}$ antepenúltima página dessa aritmética, Goerl [194-b] propõe 15 perguntas divertidas para os alunos, conforme os exemplos no Quadro 3:

QUADRO 3: Perguntas divertidas.

\begin{tabular}{|c|c|}
\hline $\begin{array}{l}\text { Pensem bem antes de responder! } \\
\text { 1) Tenho } 2 \text { irmãos e } 2 \text { irmãs. Quantos filhos tên } \\
\text { 2) Uma choca tinha } 12 \text { pintos; } 2 \text { morreram e os } \\
\text { uantos pintos a choca tem ainda? } \\
\text { 3) Um ovo leva } 4 \text { minutos para cozinhar. Qu } \\
\text { vos? } \\
\text { 4) Um homem leva } 3 \text { horas para ir a pé da sua } \\
\text { oras levam } 4 \text { homens? } \\
\text { 5) Um homem ia a São Leopoldo. Vêm ao se } \\
\text { ada uma leva } 3 \text { gatos, e cada gato } 3 \text { gatinhos. } \\
\text { ão a São Leopoldo? } \\
\text { 6) João tinha } 3 \text { bolas. Disse ele a Pedro: Se eu } \\
\text { dobro do que você tem. Quantas bolas tem Pedro } \\
\text { Respostas elaboradas pelos autores do artigo: } \\
\text { 1) } 5 \text { filhos. } \\
\text { 2) Nenhum pinto. } \\
\text { 3) } 4 \text { minutos se todos forem cozinhados juntos. }\end{array}$ & $\begin{array}{l}\text { ros ficaram grandes. } \\
\text { até à vila. Quantas } \\
\text { contro } 3 \text { mulheres. } \\
\text { tos são ao todo que }\end{array}$ \\
\hline
\end{tabular}

Fonte: Goerl, [194-b], p. 82.

Estas perguntas divertidas são desafios que exigem a atenção dos alunos - pensem bem antes de responder! - e incentivam o raciocínio lógico. A Segunda Aritmética de 1948 também traz desafios de raciocínio lógico, intitulados como charadas. Acredita-se que propostas de ensino envolvendo uma matemática mais lúdica tenham sido uma estratégia dos autores para aguçar a curiosidade dos alunos e incentivar o seu gosto pela matemática.

A edição da Segunda Aritmética, editada em 1948, traz como principais unidades de estudo: numeração 1 - 1000; os números até 10000; números além de 10000. Nesta aritmética, focam-se as quatro operações elementares com números naturais para o desenvolvimento de habilidades para o cálculo mental e escrito.

Nessa aritmética se encontrou o seguinte exercício: "Somar a 97 tantas vezes 129 até se alcançar 1000” (SÉRIE CONCÓRDIA, 1948, p. 32). Uma versão semelhante deste exercício é citada por Gans (2013, apud KUHN, 2015), que estudou na escola paroquial de Linha Brasil, Nova 
Petrópolis/RS, no período de 1936 a 1941, ao falar sobre as aulas de matemática:

[...] Os conteúdos da $2^{\mathrm{a}}$ série eram somas e subtrações mais complexas e contas tripas ${ }^{11}$, além dos números até 1000. [...] As contas tripas eram, por exemplo, somar 7 ao número 23 até chegar ao número 233, ou subtrair 7 do número 210 até chegar a zero:

\begin{tabular}{lc}
23 & 210 \\
+7 & -7 \\
30 & 203 \\
+7 \\
37 & -7 \\
+7 \\
44 & -79 \\
+7 & 189 \\
51 etc. & -7 \\
\hline
\end{tabular}

Enquanto fazíamos essas contas, o professor atendia outra série ${ }^{12}$ [...]. (GANS, 2013, apud KUHN, 2015, p. 253).

Verifica-se que o exercício encontrado na Segunda Aritmética é uma conta tripa, pois é necessário somar 7 vezes a parcela 129 ao 97 para se obter 1000. Acredita-se que este tipo de exercício, bem como os demais exercícios de cálculo, geralmente em grande quantidade nas aritméticas analisadas, ajudavam a manter os alunos de uma série ocupados enquanto o professor atendia outra série, nas escolas paroquiais luteranas gaúchas com turmas multisseriadas.

No Quadro 4 são descritas as provas reais da adição e subtração, localizadas na Segunda Aritmética de 1948:

\footnotetext{
${ }^{11}$ Eram contas compridas de adição ou subtração com algoritmo na vertical. Partia-se de uma quantia e através de somas ou subtrações constantes e sucessivas se chegava a outra quantia determinada.

${ }^{12}$ Essa escola era multisseriada, ou seja, um único professor atendia mais de uma série na mesma sala de aula e no mesmo turno.
} 
QUADRO 4: Provas reais da adição e subtração.

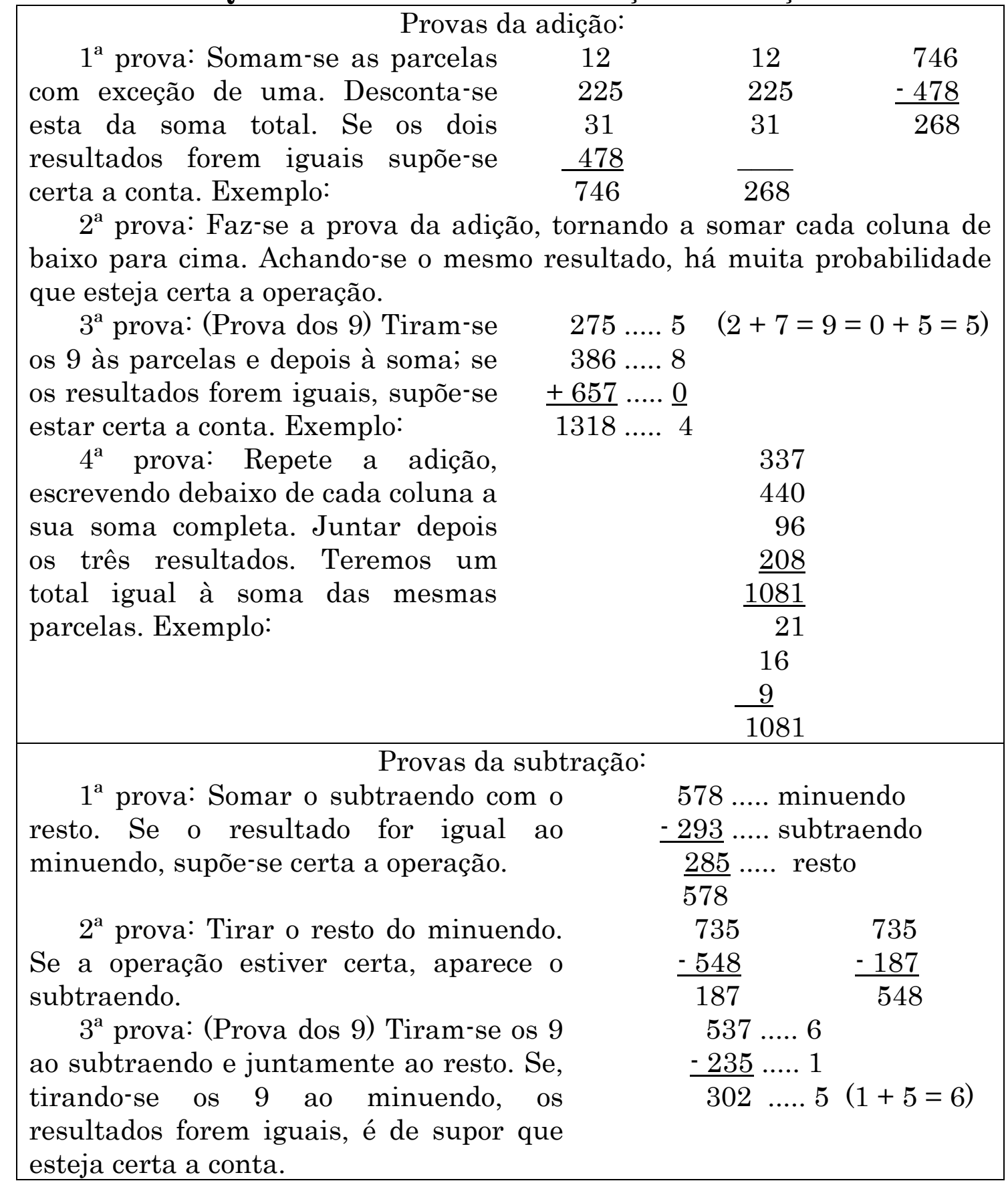

Fonte: Série Concórdia, 1948, p. 56-57.

O Quadro 4 apresenta quatro modos de fazer a prova real nos cálculos de adição e três maneiras de realizar a prova real nos cálculos de subtração, inclusive a prova dos 9 . Observa-se que a $1^{\text {a }}$ prova da adição e as duas primeiras provas da subtração exploram a ideia da adição e subtração como operações inversas para fazer a verificação dos cálculos escritos. A $2^{\mathrm{a}}$ prova da adição propõe a realização das somas em ordem inversa, verificando-se o 
resultado quando a soma de cima para baixo for igual à soma de baixo para cima das parcelas. A $4^{\mathrm{a}}$ prova da adição explora o sistema decimal com a composição de centenas, dezenas e unidades e de forma subentendida, o uso do quadro valor lugar (QVL) para verificar a operação de adição.

A $3^{\mathrm{a}}$ prova da adição e subtração é a prova dos 9. De acordo com Lavaca e Costa (2016, p. 58), "tirar os 9 fora de um número natural qualquer n, significa subtrair deste número o maior múltiplo de 9 nele contido, o que é equivalente a encontrar o resto da divisão deste número n por 9”. De forma prática, pode-se somar os algarismos deste dado número que se deseja obter os 9 fora, obtendo outro valor. A partir deste novo valor, somam-se novamente os algarismos e assim por diante até restar um número de um algarismo.

No caso da adição, tiram-se os 9 das parcelas e das somas, se os resultados forem iguais, supõe-se que a soma esteja verificada.

Exemplo da prova dos 9 para a adição:

$$
\begin{aligned}
& 275 \ldots . .2+7=9-9=0+5=5 \\
& 386 \ldots . .3+8=11-9=2+6=8 \\
& 5+8+0=13-9=4 \\
& +657 \ldots .6+5=11-9=2+7=9-9= \\
& 1318 \ldots . .1+3+1+8=13-9=4
\end{aligned}
$$

$\mathrm{Na}$ subtração, tiram-se os 9 do minuendo, do subtraendo e do resto. Então, se a soma do subtraendo com o resto foi igual ao minuendo, acreditase que o cálculo esteja correto.

Exemplo da prova dos 9 para a subtração:

$$
\left.\begin{array}{rl}
537 \ldots . .5+3+7 & =15-9=6 \\
-235 \ldots . .2+3+5 & =10-9=1 \\
302 \ldots . .3+0+2 & =5
\end{array}\right] 1+5=6
$$

Como $6=6$, acredita-se que a subtração esteja correta.

Ressalta-se que esta proposta de ensino do livro está centrada nos procedimentos e algoritmos para verificação da prova real de cada operação matemática. Essas atividades evidenciam uma proposta pedagógica que 
desenvolve habilidades para cálculos escritos com precisão nas escolas paroquiais luteranas, pois as aritméticas da série Concórdia desenvolvem, gradativamente, as operações de adição, subtração, multiplicação e divisão, culminando seu estudo com as provas reais destas operações. No Quadro 5 se apresentam as provas reais para a operação de multiplicação:

QUADRO 5: Provas reais para multiplicação.

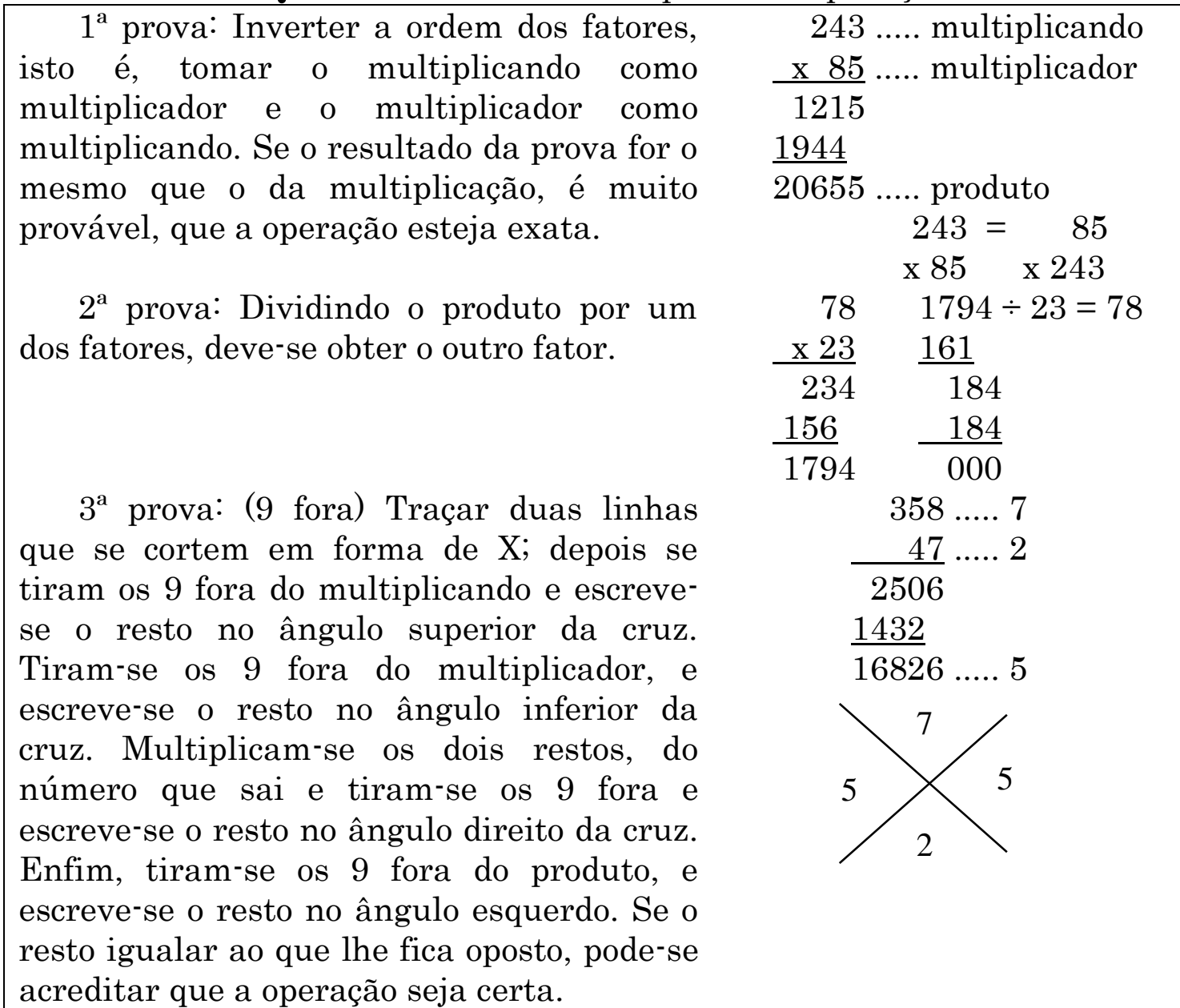

Fonte: Série Concórdia, 1948, p. 90.

O livro aborda três provas reais para a operação de multiplicação, apresentando-se os algoritmos e os procedimentos para realização da prova real em multiplicações. A $1^{\mathrm{a}}$ prova consiste em inverter a ordem dos fatores para verificar o produto. A $2^{\mathrm{a}}$ prova envolve a divisão como operação inversa da multiplicação e a $3^{\text {a }}$ prova é a dos 9 fora, conforme descrito no Quadro 5.

A Segunda Aritmética de 1948 ainda traz as provas reais para a operação de divisão, conforme apresentado no Quadro 6: 
QUADRO 6: Provas reais para divisão.

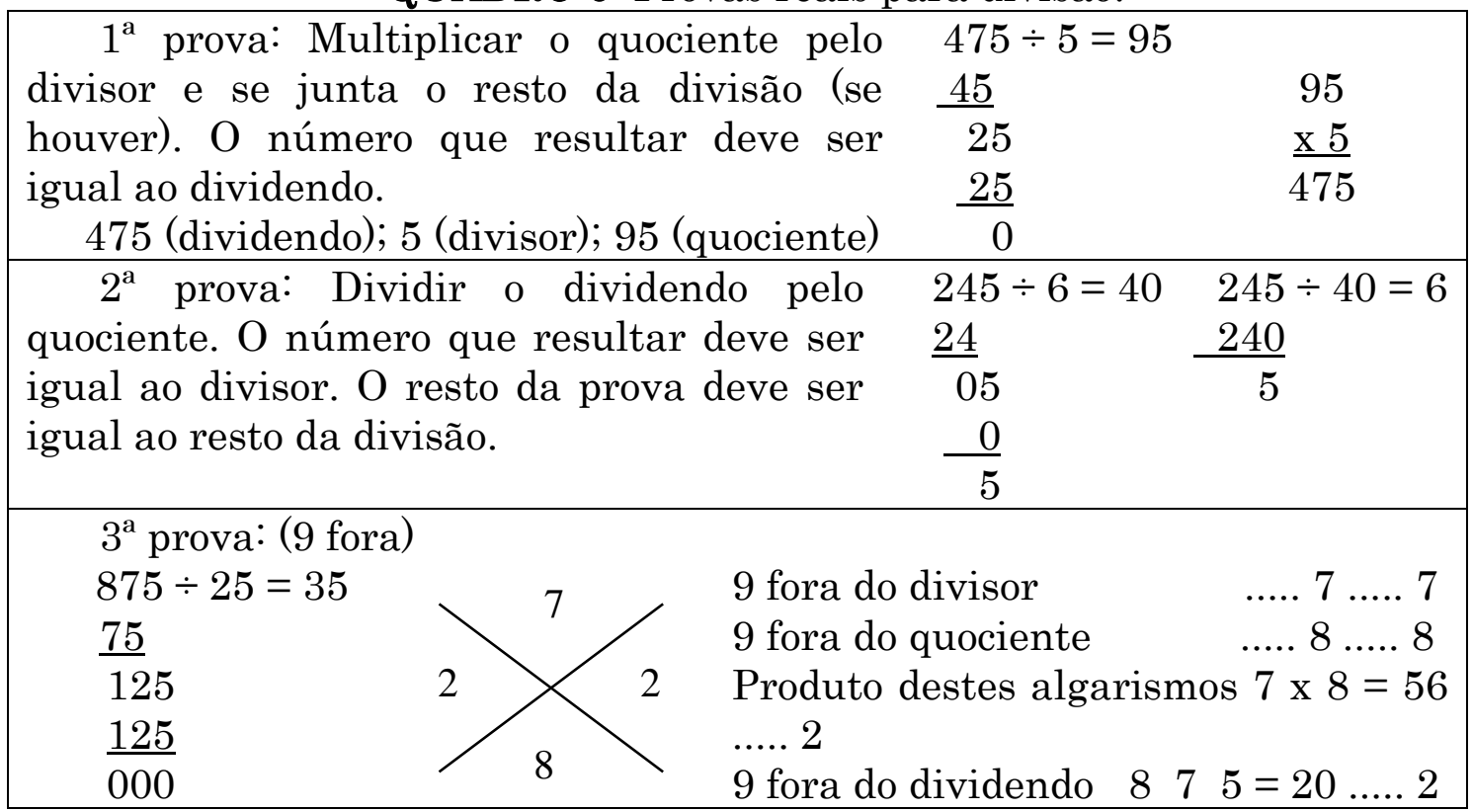

Fonte: Série Concórdia, 1948, p. 91.

O Quadro 6 mostra como o livro aborda as três provas reais para a operação de divisão, apresentando-se os algoritmos e os procedimentos para realização da prova real em divisões. A $1^{\mathrm{a}}$ prova envolve a multiplicação como operação inversa da divisão. A $2^{a}$ prova consiste em dividir o dividendo pelo quociente obtido, devendo-se obter um resultado igual ao divisor e os restos da prova e da divisão devem ser iguais. A $3^{\mathrm{a}}$ prova é dos 9 fora, conforme descrito no excerto acima.

A partir das três provas de multiplicação e divisão apresentadas, ressalta-se que a proposta da Segunda Aritmética de 1948 enfatiza os algoritmos e os procedimentos para verificação da prova real de cada operação matemática, na intenção de desenvolver habilidades nos alunos para o cálculo escrito e mental, refletindo-se a tradição pedagógica da memorização (VALENTE; PINHEIRO, 2015).

A Segunda Aritmética de 1948 apresenta uma conta curiosa, conforme descrito no Quadro 7: 
QUADRO 7: Conta curiosa.

$$
\begin{aligned}
& 9 \times 1+1=10 \\
& 9 \times 12+2=110 \\
& 9 \times 123+3= \\
& 9 \times 1234+4= \\
& 9 \times 12345+5= \\
& 9 \times 123456+6= \\
& 9 \times 1234567+7= \\
& 9 \times 12345678+8= \\
& 9 \times 123456789+9=
\end{aligned}
$$

Fonte: Série Concórdia, 1948, p. 93.

Esta conta curiosa, encontrada no livro, envolve as operações de multiplicação por 9 e de adição dos números naturais de 1 a 9 . Verifica-se que os resultados de cada cálculo possuem a quantidade de algarismos 1 correspondente a parcela somada, acrescidos do algarismo 0. Por exemplo, 9 x $123456+6=1111110$ ( 6 vezes o algarismo 1 acrescido do 0 ). Novamente se observa a instrumentalização dos alunos para o cálculo, porém, isto é feito de maneira curiosa com o emprego de regularidades.

As principais unidades de estudo da edição da Terceira Aritmética são: frações decimais e sistema métrico; frações ordinárias; regra de três; porcentagem; porcentagem comercial; juros; razão e proporção; geometria prática. Essa aritmética é caracterizada por apresentar propostas de estudo mais sistematizadas dos conhecimentos matemáticos.

Nessa edição se observaram registros relacionados à tabuada com frações, conforme mostrado no Quadro 8:

QUADRO 8: Tabuada com frações.

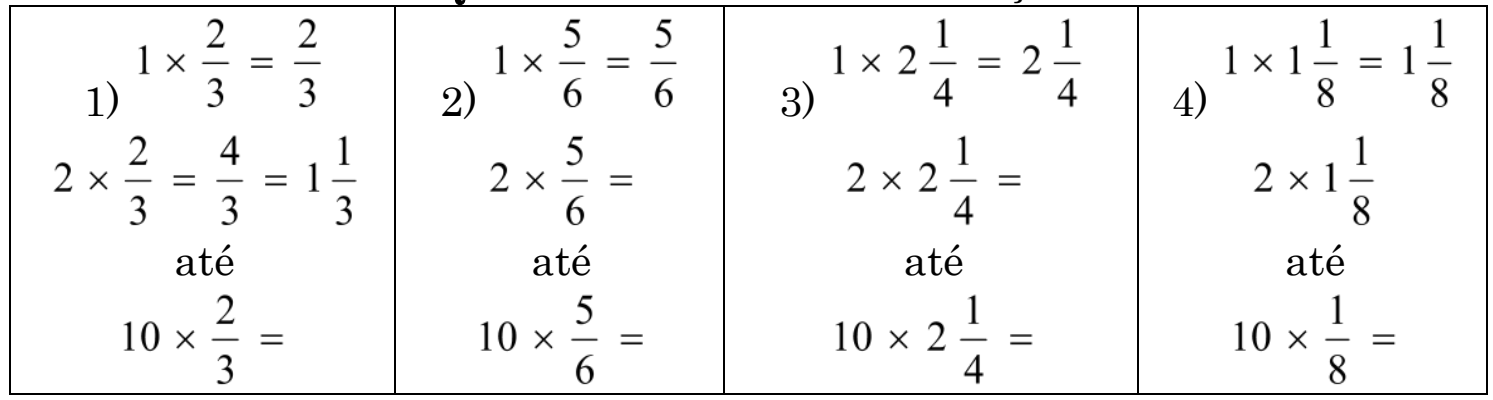

Fonte: Série Concórdia, 1949, p. 51. 
O Quadro 8 apresenta uma proposta com quatro exercícios de tabuada com as frações ordinárias $\frac{2}{3}, \frac{5}{6}, 2 \frac{1}{4}$ e $1 \frac{1}{8}$. Ressalta-se que as atividades também envolvem números mistos com a representação de frações impróprias como números mistos e vice versa. Este tipo de exercício reforça a ideia de que no ensino da matemática nas escolas paroquiais luteranas gaúchas havia uma preocupação com o desenvolvimento de habilidades para o cálculo mental e escrito.

A análise das aritméticas da série Concórdia, direcionadas para as escolas paroquiais luteranas gaúchas, no século passado, permitiu um adentramento na cultura escolar num lugar e num tempo determinados, identificando-se curiosidades e desafios matemáticos nesse contexto.

\section{Considerações finais}

Partindo da base teórico-metodológica da pesquisa histórica se investigaram curiosidades e desafios matemáticos encontrados em quatro aritméticas da série Concórdia, editadas pela IELB, através da Casa Publicadora Concórdia, na década de 1940, para suas escolas paroquiais no RS. Neste contexto missionário e de formação geral, a Igreja Luterana editou livros didáticos de acordo com seus princípios morais e educacionais, adaptando-se ao processo de nacionalização do ensino.

Na análise da Primeira Aritmética se identificou que o autor propôs a construção do significado de número pelo método de ensino intuitivo, evidenciando-se a estratégia de associar cada número até $10 \mathrm{com}$ animais ou objetos do cotidiano dos alunos. Na edição da Segunda Aritmética, Goerl propõe a resolução de quadrados mágicos, curiosidades sobre o número de dias dos meses do ano e exercícios de raciocínio lógico. $\mathrm{Na}$ Segunda Aritmética de 1948 se observaram quadrados mágicos, charadas para o desenvolvimento do raciocínio lógico, contas compridas de adição ou subtração com algoritmo na vertical, provas reais para as operações de 
adição, subtração, multiplicação e divisão com números naturais - inclusive a prova dos 9 fora, além de contas curiosas. Na edição da Terceira Aritmética chamou atenção a tabuada com frações. As curiosidades e os desafios nestas três aritméticas são marcados por cálculos escritos e mentais, destacando-se os algoritmos e os procedimentos das provas reais para as quatro operações elementares.

Mesmo que as aritméticas da série Concórdia tenham sido editadas num período marcado pelo movimento da Escola Nova no Brasil e que, algumas curiosidades e desafios matemáticos estejam alicerçadas no método de ensino intuitivo, as mesmas ainda refletem a tradição pedagógica da memorização. Isto está associado ao fato de que o ensino da matemática nas escolas paroquiais luteranas gaúchas do século passado foi caracterizado pelo desenvolvimento de habilidades para o cálculo mental e escrito, de forma prática e contextualizada, para que os futuros colonos fizessem a correta administração do orçamento familiar e o gerenciamento da sua propriedade rural. Ressalta-se que algumas dessas tarefas desafiadoras (curiosidades e desafios matemáticos), localizadas nas aritméticas da série Concórdia, ainda estão presentes em livros de matemática atuais e em obras como as de Malba Tahan.

\section{Referências}

CARVALHO, M. C. C. S. Padrões numéricos e sequências. São Paulo: Moderna, 1997.

CERTEAU, M. A escrita da História. Tradução Maria de Lourdes Menezes. Rio de Janeiro: Forense Universitária, 1982.

CHERVEL, A. História das disciplinas escolares - reflexões sobre um campo de pesquisa. Teoria \& Educação, Porto Alegre, n. 2, p. 177-229, 1990.

GOERL, O. A. Série Concórdia: Primeira Aritmética. Porto Alegre: Casa Publicadora Concórdia, [194-a].

- Série Concórdia: Segunda Aritmética. Porto Alegre: Casa Publicadora Concórdia, [194-b]. 
JULIA, D. A cultura escolar como objeto histórico. Revista Brasileira de História da Educação, Campinas, n. 1, p. 9-43, jan./jun. 2001.

KREUTZ, L. O professor paroquial: magistério e imigração alemã. Porto Alegre: Ed. da UFRGS; Caxias do Sul: EDUCS, 1991.

. Material didático e currículo na escola teuto-brasileira. São Leopoldo: Ed. UNISINOS, 1994.

KUHN, M. C. O ensino da matemática nas escolas evangélicas luteranas do Rio Grande do Sul durante a primeira metade do século XX. 2015. 466 f. Tese (Doutorado em Ensino de Ciências e Matemática) - Universidade Luterana do Brasil, Canoas.

LAVACA, A. G.; COSTA, D. A. A prova dos nove e o caso da "Arithmetica Primaria" de Cezar Pinheiro. REVEMAT, Florianópolis, v. 11, n. 1, p. 54-73, 2016.

LEMKE, M. D. Os princípios da educação cristã luterana e a gestão de escolas confessionárias no contexto das ideias pedagógicas no sul do Brasil (1824 - 1997). Canoas: Ed. ULBRA, 2001.

MAURO, S. Uma história da matemática escolar desenvolvida por comunidades de origem alemã no Rio Grande do Sul no final do século XIX e início do século XX. 2005. 257 f. Tese (Doutorado em Educação Matemática) - Universidade Estadual Paulista, Rio Claro.

PROST, A. Doze lições sobre a História. Belo Horizonte, Autêntica, 2008.

RAMBO, A. B. A escola comunitária teuto-brasileira católica. São Leopoldo: Ed. UNISINOS, 1994.

SÉRIE Concórdia: Segunda Aritmética. Porto Alegre: Casa Publicadora Concórdia, 1948.

SÉRIE Concórdia: Terceira Aritmética. Porto Alegre: Casa Publicadora Concórdia, 1949.

UNSERE SCHULE. Porto Alegre: Casa Publicadora Concórdia, 1933-1935.

VALENTE, W. R. História da Educação Matemática: interrogações metodológicas. REVEMAT - Revista Eletrônica de Educação Matemática, UFSC, v. 2.2, p. 28-49, 2007.

; PINHEIRO, N. V. L. Chega de decorar a tabuada! - As cartas de Parker e a árvore do cálculo na ruptura de uma tradição. Educação Matemática em Revista $R S$, Canoas, v. 1, n. 16, p. 22-37, 2015.

WANDERER, F. Escola e Matemática Escolar: mecanismos de regulação sobre sujeitos escolares de uma localidade rural de colonização alemã no Rio Grande do 
Sul. 2007. 228 f. Tese (Doutorado em Educação) - Universidade do Vale do Rio dos Sinos, São Leopoldo.

WEIDUSCHADT, P. O Sínodo de Missouri e a educação pomerana em Pelotas e São Lourenço do Sul nas primeiras décadas do século XX: identidade e cultura escolar. 2007. 255 f. Dissertação (Mestrado em Educação) - Universidade Federal de Pelotas, Pelotas.

Recebido em dezembro de 2016.

Aprovado em janeiro de 2018. 


\section{Normas para publicação}

1. A redação deve primar pela clareza, brevidade e concisão. O material deve vir devidamente revisado pelo autor, sendo que os textos, assinados, são de inteira responsabilidade deste.

2. A revista se permite fazer alterações formais no texto visando à editoração final.

3. Eventuais modificações de estrutura ou de conteúdo sugeridas pelos pareceristas ou pela comissão editorial só serão incorporadas mediante concordância dos autores.

4. O trabalho pode ser recusado por não se coadunar com a linha editorial e temática da revista.

5. A apresentação dos artigos deverá seguir a NBR 6022 de agosto de 1994 da ABNT (apresentação de artigos em publicação periódica).

6. Os artigos devem ter entre 15 e 20 páginas e as resenhas entre 5 e 7 páginas. Artigos e resenhas devem apresentar nome(s) completo(s) do(s) autor(es), vínculo acadêmico e profissional e endereço (físico e eletrônico) completo. Título, resumo (entre 100 e 150 palavras) e palavras-chave (máximo cinco) devem estar na língua de origem do texto e em inglês. Trabalhos que exijam publicação de gráficos, quadros e tabelas ou qualquer tipo de ilustração devem apresentar as respectivas legendas, citando fonte completa e sua posição no texto. Os arquivos devem ser encaminhados no corpo do texto, onde se deseja que seja editado.

7. O texto deve ser digitado em software compatível com o ambiente (Word for Windows). A fonte usada para o texto deve ser Times New Roman, tamanho 12, com espaçamento 1,5. Notas de rodapé, de caráter explicativo, deverão ser evitadas e utilizadas apenas quando estritamente necessárias para a compreensão do texto.

8. A revista recebe textos escritos em português, inglês, espanhol, italiano, alemão ou francês, escritos em qualquer época do ano.

9. As citações bibliográficas deverão estar de acordo com a NBR 10520 (jul/2001) da ABNT.

\section{Exemplos:}

• citação direta: “...” (FREITAS, 2002, p. 61) 
- citação indireta: Romanelli (1996, p. 27) considera...

- citação de citação: Ausubel (1977, apud SILVEIRA et al, 2002, p. 139) afirma...

- havendo mais de uma referência do mesmo autor no mesmo ano, usar a, b, c imediatamente após a data (FREIRE, 1996b; 132)

- havendo mais de dois autores, mencionar o primeiro seguido da expressão "et alli"

10. As referências deverão ser de acordo com a NBR 6023 (ago/2000) da ABNT.

Exemplos:

- LIVRO:

CICILLINI, G. A.; NOGUEIRA, S. V. (Org.). Educação escolar: políticas, saberes e práticas escolares. Uberlândia: Edufu, 2002.

\section{- ARTIGO:}

BOLDRIN, L. C. F. Cultura, Sociedade e Currículo - dimensões sócioculturais do currículo.

Ensino em Re-Vista, Uberlândia, v. 8, n. 1, p. 7-25, jul. 1999/jun. 2000.

\section{- TESE/DISSERTAÇÃO:}

MARQUES, Mara Rúbia A. Um fino tecido de muitos fios... mudança social e reforma educacional em Minas Gerais. 2000. 247 f. Tese (Doutorado em Políticas Públicas e Gestão da Educação) - Universidade Metodista de Piracicaba, Piracicaba, 2000.

11. O material para submissão deverá ser enviado para: ensinoemrevista@gmail.com ou então ser postado via homepage da Ensino em Re-Vista em: http://www.seer.ufu.br/index.php/emrevista 


\section{General information to employees}

1. Education in Re-View is a journal aimed at researchers, teachers and students in the field of Education. Publishes articles that deal with research findings and original essays, book reviews (two years) and translations. Annually publishes a thematic dossier, organized by researchers in theme, bringing articles by invited experts - Brazilians and foreign - and covering topics of current interest and discussion in various fields of education.

2.The texts will be judged by members of the Editorial Board for an opinion as to the publication, entitled to the remittance of the original and without a royalty payment.

3. The process to process the articles occurs with blind assessment of the Editorial Board. For each text are issued two opinions, and in case of divergence in opinions, a third reviewer is consulted.

4. In texts of collective authorship, authors must appear in descending order of titration. The magazine is not responsible for conflicts of interest among authors, funders, sponsors and others possibly involved and / or quoted in the text.

5. The magazine will inform the author (s) on the publishing of your articles, and the originals will not be returned.

6. The author who have their papers accepted for publication will receive a document by email, which must print, sign and send by mail to the Teaching Re-View. In this paper, the authors show that it is an original text, which was not previously published in any other medium, and authorizing the transfer of copyright rights in the Education Re - View . No texts will be published of those who do not submit such a document.

Guidelines for publication

1. The writing must strive for clarity, brevity and conciseness. The material should come duly reviewed by the author. The text, signed, are the sole responsibility of the author.

2. The magazine is allowed to make formal changes to the text, in order to final editing.

3. Any modifications to the structure or content as suggested by the editorial committee or are only incorporated into by agreement of the authors. 
4. The work may be refused by not conform to the editorial line and theme of the magazine.

5. The submission of articles should follow the NBR 6022 August 1994 from ABNT (submission of periodical articles).

6. Articles should be between 15 and 20 pages and reviews between 5 and 7 pages. Articles and reviews must provide name ( $\mathrm{s}$ ) complete ( $\mathrm{s}$ ) (s) of author (s ), academic affiliation, professional and complete addresses ( physical and electronic) . Title, abstract (100 to 150 words) and keywords (maximum of five ) in the source language text and English . Work requiring publication of charts and tables or any type of graphic should submit their captions, citing one source and its position in the text. Files should be sent in the body of the text where you want to be edited.

7. The text should be typed into the environment (Word for Windows) software. The font used for the text should be Times New Roman, size 12 with 1.5 spacing. Footnotes, explanatory character, should be avoided and used only when strictly necessary for understanding the text.

8. The journal receives texts any time of the year written in English, Portuguese, Spanish, Italian, German or French.

9. The citations should be according to NBR 10520 (Jul/2001) ABNT .

\section{Examples:}

- Direct quote : “... “(Freitas , 2002, p. 61)

- Paraphrase : Romanelli ( . 1996: 27 ) consider ...

-Quote quotation: Ausubel (1977, apud Silveira et al , 2002, p 139 ) states ...

- There is more than one reference by the same author in the same year, use a, b, c, immediately following the date (Freire, 1996b , 132).

- There are more than two authors, the first name followed by " et alli “

10. References should be according to NBR 6023 (Aug/2000) ABNT.

\section{Examples:}

- BOOK :

CICILLINI, G. A. ; WALNUT, S. V. ( Eds.). Education: policies, knowledge and school practices. Uberlandia: Organizing agency, 2002. 


\section{Normas para publicación}

1. La redacción debe primar por la claridad, brevedad y concisión. El material debe venir debidamente revisado por el autor. Los textos, firmados, son de entera responsabilidad del autor.

2. La revista se permite hacer alteraciones formales en el texto, procurando la edición final.

3. Eventuales modificaciones de estructura o de contenido, sugeridas por los pareceristas o por la comisión editorial, sólo serán incorporadas mediante autorización de los autores.

4. El trabajo puede ser reprobado por no corresponderse con la línea editorial y temática de la revista.

5. La presentación de los artículos deberá seguir la NBR 6022 de agosto de 1994 de la ABNT (presentación de artículos en publicación periódica).

6. Los artículos deben tener entre 15 y 20 páginas y las reseñas entre 5 y 7 páginas. Artículos y reseñas deben presentar nombre(s) completo(s) del (los) autor(es), vínculo académico y profesional y dirección (física y electrónica) completos. Título, resumen (entre 100 y 150 palabras) y palabras clave (máximo de cinco) en la lengua original del texto y en inglés. Trabajos que exijan publicación de gráficas, cuadros y tablas o cualquier tipo de ilustración deben presentar las respectivas leyendas, citando la fuente completa y su posición en el texto. Los archivos deben ser encaminados en el cuerpo del texto, donde se desea que sea editado.

7. El texto debe ser digitado en software compatible con el ambiente (Word for Windows). La fuente usada para el texto debe ser Time New Roman, tamaño 12, con espacios 1,5. Notas de pie de página, de carácter explicativo, deberán ser evitadas y utilizadas apenas cuando estrictamente necesarias para la comprensión del texto.

8. La revista recibe textos en cualquier época del año escritos en portugués, inglés, español, italiano, alemán o francés.

9. Las citaciones bibliográficas deberán ser de acuerdo con la NBR 10520 (jul/2001) de la ABNT.

\section{Ejemplos:}

- Citación directa: “...” (FREITAS, 2002, p. 61) 
- Citación indirecta: Romanelli (1996, p. 27) consideran..

- Citación de citación: Ausubel (1977, apud SILVEIRA et al, 2002, p. 139) afirma...

- Existiendo más de una referencia del mismo autor en el mismo año, usar a, b, c, inmediatamente después de la fecha (FREIRE, 1996b; 132).

- Existiendo más de dos autores, mencionar el primero seguido de la expresión "et alli"

10. Las referencias deberán ser de acuerdo con la NBR 6023 (ago/2000) da ABNT.

Ejemplos:

- LIBRO:

CICILliNI, G. A.; NOGUEIRA, S. V. (Org.). Educação escolar: políticas, saberes e práticas escolares. Uberlândia: Edufu, 2002.

\section{ARTÍCULO:}

BOLDRIN, L. C. F. Cultura, Sociedade e Currículo - dimensões sócioculturais do currículo. Ensino em Re-Vista, Uberlândia, v. 8, n. 1, p. 7-25, jul. 1999/jun. 2000 .

\section{- TESIS/DISERTACIÓN:}

MARQUES, Mara Rúbia A. Um fino tecido de muitos fios... mudança social e reforma educacional em Minas Gerais. 2000. 247 f. Tese (Doutorado em Políticas Públicas e Gestão da Educação) - Universidade Metodista de Piracicaba, Piracicaba, 2000.

11.El material para sumisión deberá ser enviado para: ensinoemrevista@gmail.com ou

entonces ser postado vía homepage de la Ensino em Re-Vista em: http://www.seer.ufu.br/index.php/emrevista 